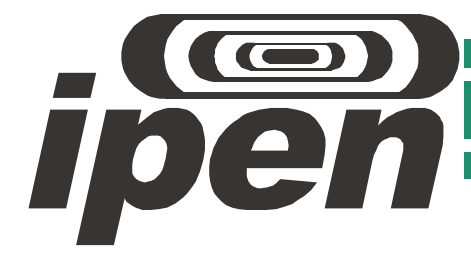

AUTARQUIA ASSOCIADA À UNIVERSIDADE DE SÃO PAULO

\title{
SÍNTESE DE NANOMARCADORES LUMINESCENTES CONTENDO ÍONS TERRAS RARAS PARA APLICAÇÃO EM TESTES DE DIAGNÓSTICO PARA A DOENÇA DE CHAGAS
}

\section{KLAUSS ENGELMANN}

Dissertação apresentada como parte dos requisitos para obtenção do Grau de Mestre em Ciências na Área de Tecnologia Nuclear - Materiais

Orientadora:

Profa. Dra. Maria Cláudia França da Cunha Felinto 
INSTITUTO DE PESQUISAS ENERGÉTICAS E NUCLEARES

AUTARQUIA ASSOCIADA À UNIVERSIDADE DE SÃO PAULO

\title{
SÍNTESE DE NANOMARCADORES LUMINESCENTES CONTENDO ÍONS TERRAS RARAS PARA APLICAÇÃO EM TESTES DE DIAGNÓSTICO PARA A DOENÇA DE CHAGAS
}

\author{
KLAUSS ENGELMANN
}

Dissertação apresentada como parte dos Requisitos para obtenção do grau de Mestre em Ciências na Área de Tecnologia Nuclear Materiais

Orientadora:

Dra. Maria Cláudia França da Cunha Felinto

\section{Versão Corrigida}

Versão Original encontra-se disponível no IPEN

São Paulo 
Dedico esse trabalho a minha Mãe, por abrir mão de muitos dos seus sonhos para que eu e meus irmãos pudéssemos realizar os nossos. 


\section{AGRADECIMENTOS}

A minha orientadora, Dra Maria Cláudia França da Cunha Felinto pela atenção, orientação e ensinamentos.

A minha professora da graduação, Dra. Maria Encarnación Vásquez Suárez Iha, pela indicação para realização desse trabalho no IPEN.

A minha família, em especial minha mãe, Nirleni e minha irmã Haila.

Ao Paulo André, pelo apoio constante.

Aos amigos de longa data da Escola Técnica Walter Belian - ETWB, Universidade Presbiteriana Mackenzie, Instituto de Pesquisas do Estado de São Paulo - IPT, Lanxess e agregados.

Aos meus amigos da Universidade Federal de São Paulo - UNIFESP, Bruno Mattei e Alexandre Barros pela ajuda nas análises e discussões sempre tão esclarecedoras.

A Dra Karin do Amaral Riske e ao Dr. Antônio de Miranda da Universidade Federal de São Paulo - UNIFESP, pela autorização nas realizações de análises.

Aos amigos do IPEN, Liana, Débora, Paula, Heloísa, Ellen e pela ajuda e conversas.

A Dra Cláudia Akemi pelas precisas dicas.

Aos amigos do Instituto de Pesquisas do Estado de São Paulo - IPT, Wagner Aldeia e Kleber Lanigra pela disponibilidade de realização de testes.

Aos colegas da Universidade Estadual de Campinas - UNICAMP, Prof. Dr. Fernando Sigoli pela autorização para realização de análises e ao Ernesto Rezende pelo treinamento.

Aos colegas da Universidade de São Paulo - USP, Prof. Dr. Hermi Felinto de Brito pela autorização na realização de ensaios.

Aos meus alunos Henrique Pereira, Maressa Donato, Marcos Lourenço e Julio Vieira da ETEC Irmã Agostina, pela ajuda em experimentos e amostras.

Ao Conselho Nacional de Desenvolvimento Cientifico e Tecnológico CNPq, pela bolsa concedida. 


\title{
SÍNTESE DE NANOMARCADORES LUMINESCENTES CONTENDO ÍONS TERRAS RARAS PARA APLICAÇÃO EM TESTES DE DIAGNÓSTICO PARA A DOENÇA DE CHAGAS
}

\author{
KLAUSS ENGELMANN
}

\section{RESUMO}

Os íons terras raras apresentam propriedades espectroscópicas diferenciadas e números de coordenação entre 6 e 12 e seu estado de oxidação mais comum é o íon trivalente. Apesar de esses íons apresentarem uma baixa intensidade de luminescência, em função de sua baixa absortividade molar, esses são capazes de formar complexo onde o ligante absorva luz e transfira para o centro metálico essa energia, fenômeno conhecido como "efeito antena". Essas propriedades tornam os seus complexos alvos de estudos como marcadores em ensaios imunoluminescentes, aliado ao uso de nanopartículas poliméricas. Todos esses fatores podem ser utilizados para a montagem de uma metodologia para o diagnóstico da doença de Chagas, doença tropical negligenciada, que apesar de seus mais de 100 anos após descoberta, ainda possui diversas questões em aberto e sem estudo aprofundado. Dessa maneira, propomo-nos a sintetizar e caracterizar nanopartículas de PHB misturadas aos complexos de terras raras, especificamente, complexos $\beta$-dicetona - $\mathrm{Tb}^{3+}, \mathrm{Sm}^{3+}, \mathrm{Gd}^{3+}$, ou $\mathrm{Eu}^{3+}$. Pretende-se ligar essas nanopartículas a um espaçador como o glutaraldeído ou então diretamente a um anti-lgG humano e assim, num acoplamento antigeno-anticopo verificar sua emissão de luminescência para detecção de soro positivo para a doença. Dessa forma, obtém-se um biomarcador luminescente para diagnóstico da doença de Chagas. 


\title{
SYNTHESIS OF LUMINESCENTS BIOMARKERS CONTAINING RARE-EARTH IONS FOR APPLICATION FOR DIAGNOSTICS TESTS FOR DISEASE CHAGAS
}

\author{
KLAUSS ENGELMANN
}

\begin{abstract}
The rare-earth ions exhibit different spectroscopic properties, coordination numbers between 6 and 12 and trivalent is its most common oxidation state. Despite these ions present low luminescence, due to their low molar absorptivity, they are capable of forming complexes where the ligand absorbs light and transfers this energy to the metal center, a phenomenon known as "antenna effect". These properties make their complexes object of studies as markers in fluoroimmunoassay allied to the use of polymeric nanoparticles. All these factors can be used for the assembly of a methodology for diagnosis of Chagas' disease, a tropical overlooked disease, which despite its more than 100 years after discovering, still has several open issues and without thorough study. Thus, We propose to synthesize and characterize PHB nanoparticles labeled with the rare earth complexes, most specifically $\beta$-diketone complexes $-\mathrm{Tb}^{3+}, \mathrm{Sm}^{3+}$, $\mathrm{Gd}^{3+}$, or $\mathrm{Eu}^{3+}$ as marker for biological targets. It's intended to link these nanoparticles to a glutaraldehyde as a spacer or directly to an anti-human $\lg G$ and thus, in a coupling antibody-antigen, verify its luminescence-emission for detecting positive serum sickness. Therefore, we have a luminescent biomarker for diagnosis of Chagas' disease.
\end{abstract}




\section{SUMÁRIO}

1 INTRODUÇÃO__ _ 2

REFERÊNCIAS BIBLIOGRÁFICAS___ 5

2 OBJETIVO

3 REVISÃO BIBLIOGRÁFICA _ 10

3.1 Elementos Terras Raras __ 10

3.2 Espectro de emissão na região do visível ___ 13

3.2.1 Luminescência de íons Terras Raras __ 13

3.2.2 O efeito antena _ 15

3.3 As $\beta$-dicetonas — 17

3.3.1 As $\beta$-dicetonatos de Terras Raras ___ 20

3.4 Nanoparticulas poliméricas ___ 20

3.4.1 Métodos de preparo de nanopartículas poliméricas __ 21

3.4.2 Secagem por liofilização __ 24

3.4.3 Funcionalização___ 25

3.5 Polimero PHB (poli-3-hidroxibutirato) __ 26

3.6 Biomarcadores luminescentes __ 27

3.7 Doença de Chagas ___ 29

3.7.1 Métodos laboratoriais de diagnóstico da doença de Chagas____ 29

3.7.2 Antigenos Recombinantes __ 30

REFERÊNCIAS BIBLIOGRÁFICAS___ 31

4 MATERIAIS E MÉTODOS___ 38

4.1 Reagentes e Solventes __ 38

4.2 Síntese dos complexos de $\beta$-dicetonatos de terras raras __ 40

4.2.1 Síntese dos complexos [TR(tta) $\left.)_{3}\left(\mathrm{H}_{2} \mathrm{O}\right)_{2}\right] \_40$

4.2.2 Síntese dos complexos $\left[\operatorname{TR}(\mathrm{acac})_{3}\left(\mathrm{H}_{2} \mathrm{O}\right)_{3}\right]$ 
4.2.3 Síntese das nanopartículas do compósito PHB+ complexos $\beta$ dicetonatos de terras raras hidratados 43

4.2.4 Funcionalização das Nanopartículas de PHB e Complexos de $\mathrm{TR}^{3+}$ 45

4.3 Análise elementar de carbono, hidrogênio e nitrogênio $(\mathrm{CHN})$ 45

4.4 Volumetria de complexação usando EDTA para determinação de íons terras raras. 45

4.5 Espectroscopia de absorção molecular na região do infravermelho. 46

4.6 Curvas Termogravimétricas 46

4.7 Difração de raios $X$ 46

4.8 Microscopia eletrônica de varredura 46

4.9 Citotoxicidade 47

4.10 Testes de Hemocompatibilidade 47

4.11 Espectroscopia de Correlação de Fotóns e Potencial Zeta 47

4.12 Espectroscopia de luminescência 48

4.12.1 Espectros eletrônicos de excitação e emissão dos complexos precursores. 48

4.12.2 Medidas do tempo de vida do nível excitado 48

4.13 Espectros de absorção na região do ultravioleta-visível 48 REFERÊNCIAS BIBLIOGRÁFICAS 49

5 RESULTADOS E DISCUSSÕES 52

5.1 Características estequiométricas e quantitativas dos complexos precursores e as nanopartículas. 52

5.1.1 Análise elementar de carbono, hidrogênio e nitrogênio $(\mathrm{CHN})$ e porcentagem de lantanídeos. 54

5.1.2 Espectroscopia de absorção molecular no Infravermelho 54

5.1.2.1 Espectros de infravermelho dos complexos com ligante acac e nanopartículas de PHB + Complexos. 
5.1.3 Análises térmicas 61

5.1.3.1 Decomposição térmica dos complexos precursores 62

5.1.3.2 Decomposição térmica das nanopartículas 65

5.2 Difração de Raios X 69

5.3 Microscopia eletrônica de varredura (MEV) das nanopartículas 73

5.4 Testes de Citotoxicidade e Hemocompatibilidade 75

5.5 Espectroscopia de correlação de fotóns 78

5.6 Análise de Potencial Zeta das nanopartículas 82

5.7 Espectroscopia de luminescência 85

5.7.1 Fotoluminescência dos sistemas contendo íon $\mathrm{Gd}^{3+}$. 85

5.7.1.1 Complexo precursor $\left[\mathrm{Gd}(\mathrm{tta})_{3}\left(\mathrm{H}_{2} \mathrm{O}\right)_{2}\right]$ 86

5.7.1.2 Complexo precursor $\left[\mathrm{Gd}(\mathrm{acac})_{3}\left(\mathrm{H}_{2} \mathrm{O}\right)_{2}\right]$ 88

5.7.2 Fotoluminescência dos sistemas contendo íon $\mathrm{Eu}^{3+}$. 89

5.7.2.1 Complexo precursor $\left.\mathrm{Eu}(\mathrm{tta})_{3}\left(\mathrm{H}_{2} \mathrm{O}\right)_{2}\right]$ 91

5.7.2.2 Nanopartículas de PHB com o complexo $\left[\mathrm{Eu}(\mathrm{tta})_{3}\left(\mathrm{H}_{2} \mathrm{O}\right)_{2}\right]$ 94

5.7.2.3 Complexo precursor $\left.\mathrm{Eu}(\mathrm{acac})_{3}\left(\mathrm{H}_{2} \mathrm{O}\right)_{3}\right]$ 99

5.7.2.4 Nanopartículas de PHB com o complexo $\left[\mathrm{Eu}(\mathrm{acac})_{3}\left(\mathrm{H}_{2} \mathrm{O}\right)_{3}\right]$. 101

5.7.3 Fotoluminescência dos sistemas contendo íon $\mathrm{Tb}^{3+}$. 103

5.7.3.1 Complexo precursor $\left[\mathrm{Tb}(\mathrm{acac})_{3}\left(\mathrm{H}_{2} \mathrm{O}\right)_{3}\right]$ 103

5.7.3.2 Nanopartículas de PHB com o complexo $\left[\mathrm{Tb}(\mathrm{acac})_{3}\left(\mathrm{H}_{2} \mathrm{O}\right)_{3}\right]$ 105

5.7.4 Fotoluminescência dos sistemas contendo íon $\mathrm{Sm}^{3+}$. 108

5.7.4.1 Complexo precursor $\left[\mathrm{Sm}(\mathrm{tta})_{3}\left(\mathrm{H}_{2} \mathrm{O}\right)_{2}\right]$ 109

5.7.4.2 Nanopartículas de PHB com o complexo [Sm(tta) $\left.)_{3}\left(\mathrm{H}_{2} \mathrm{O}\right)_{2}\right]$ 111

5.7.4.3 Complexo precursor $\left.\mathrm{Sm}(\operatorname{acac})_{3}\left(\mathrm{H}_{2} \mathrm{O}\right)_{3}\right]$ 113

5.7.4.4 Nanopartículas de PHB com o complexo $\left[\mathrm{Sm}(\mathrm{acac})_{3}\left(\mathrm{H}_{2} \mathrm{O}\right)_{2}\right]$ 115

5.8 Tempo de vida do nível excitado 118

5.9 Nanopartículas funcionalizadas 123

5.9.1 Comportamento das nanopartículas funcionalizadas e conjugadas em função do tamanho das partículas 
5.9.2 Comportamento das nanopartículas funcionalizadas e conjugadas em função do Potencial Zeta

5.9.3 Comportamento das nanopartículas funcionalizadas e conjugadas em função do Espectro de Absorção no UV-Vísivel 130 REFERÊNCIAS BIBLIOGRÁFICAS 132

6 CONCLUSÕES E PERSPECTIVAS FUTURAS 138

6.1 Conclusões 138

6.2 Perspectivas Futuras 140 


\section{LISTA DE TABELAS}

TAB 4.1: Reagentes e solventes utilizados nos experimentos. 38

TAB 5.1: Resultados de CHN e do teor de terras raras nos complexos. 54

TAB 5.2:Principais frequências vibracionais $\left(\mathrm{cm}^{-1}\right)$ do Hacac e $\left[\mathrm{Tb}(\mathrm{acac})_{3}\left(\mathrm{H}_{2} \mathrm{O}\right)_{3}\right]$ 56

$T A B$ 5.3: Principais frequências vibracionais $\left(\mathrm{cm}^{-1}\right)$ do $P H B$, das nanopartículas de PHB dopado e $\left[\mathrm{Tb}(\mathrm{acac})_{3}\left(\mathrm{H}_{2} \mathrm{O}\right)_{3}\right]_{\text {. }}$ 58

TAB 5.4: Principais frequências vibracionais $\left(\mathrm{cm}^{-1}\right)$ do $\mathrm{Htta}$ e $\left[\mathrm{Eu}(\mathrm{tta})_{3}\left(\mathrm{H}_{2} \mathrm{O}\right)_{2}\right] \_60$

$T A B$ 5.5: Principais frequências vibracionais $\left(\mathrm{cm}^{-1}\right)$ do $\mathrm{PHB}$, das nanopartículas de PHB com complexo e $\left[\mathrm{Eu}(\mathrm{tta})_{3}\left(\mathrm{H}_{2} \mathrm{O}\right)_{2}\right]$

TAB 5.6: Dados de decomposição térmica dos complexos precursores derivados do ligante tta.

TAB 5.7: Dados de decomposição térmica dos complexos precursores derivados do ligante acac.

$T A B$ 5.8: Dados de decomposição térmica das nanopartículas de PHB dopadas com complexos precursores derivados do ligante tta.

TAB 5.9: Dados de decomposição térmica das nanopartículas de PHB dopadas com complexos precursores derivados do ligante acac.

TAB 5.10: Resultados de potencial zeta das nanopartículas de PHB dopadas com complexos de terras raras e valores de $\mathrm{pH}$ das soluções.

TAB 5.11: Parâmetros de intensidade $\eta_{\mathrm{sm}}$ experimentais dos compostos de $\mathrm{Sm}^{3+}$ e $\eta_{\mathrm{sm}}$ dos complexos de $\mathrm{Eu}^{3+}$.

TAB 5.12: Tempos de vida dos níveis emissores do $\mathrm{Eu}^{3+}, \mathrm{Tb}^{3+}$ e do estado tripleto dos ligantes tta e acac nos complexos de $\mathrm{Gd}^{3+}$. 121

TAB 5.13: Tempos de vida dos níveis emissores do $\mathrm{Eu}^{3+}, \mathrm{Tb}^{3+}$ e $\mathrm{Sm}^{3+}$. 122 


\section{LISTA DE FIGURAS}

FIG. 3.1: Diagrama de energia dos íons $\operatorname{TR}^{3+}$ obtidos a partir de cristais de $\mathrm{LaF}_{3}$. 12

FIG. 3.2: Fluorescência e Fosforescência de espécies orgânicas. 14

FIG. 3.3: Esquema simplificado do efeito antena. 15

FIG. 3.4: Representação da transferência de energia em complexos $\beta$ dicetonatos de $\mathrm{Eu}^{3+}$ onde $\mathrm{RV}=$ Relaxação Vibracional; CIS=Cruzamento Intersistema; TE=Transferência de Energia. 16

FIG. 3.5: Fórmula estrutural das $\beta$-dicetonas. 18

FIG. 3.6: Equilibrioceto-enólico das $\beta$-dicetonas 18

FIG. 3.7: Representação do anel quelato para os complexos de $\beta$-dicetonas. 19

FIG. 3.8: Estrutura do Hacac (a) e do Htta (b). 19

FIG. 3.9: Representação esquemática de nanopartículas (a) e nanoesferas

(b) poliméricas. 22

FIG. 3.10: Representação esquemática dos principais métodos de preparação de nanopartículas poliméricas. 22

FIG. 3.11: Esquema de uma nanopartícula polimérica funcionalizada 25

FIG. 3.12: Fórmula estrutural do polímero PHB 26

FIG. 3.13: Exemplo esquemático de um teste DELFIA. 28

FIG. 4.1:Fluxograma do processo de síntese dos complexos [TR(tta) $\left.)_{3}\left(\mathrm{H}_{2} \mathrm{O}\right)_{2}\right]$. _ 41

FIG. 4.2: Fluxograma do processo de síntese dos complexos $\left[\mathrm{TR}(\mathrm{acac})_{3}\left(\mathrm{H}_{2} \mathrm{O}\right)_{3}\right]$. 43

FIG. 4.3: Fluxograma do processo de síntese das nanopartículas poliméricas.

FIG. 5.1: Comportamento da emulsão ao longo do tempo de evaporação. 52

FIG. 5.2: Comportamento da emulsão com nanopartículas de PHB dopadas com complexo $\left[\mathrm{Eu}(\mathrm{tta})_{3}\left(\mathrm{H}_{2} \mathrm{O}\right)_{2}\right.$ ] em ambiente com luz UV. 53

FIG. 5.3: Comportamento das suspensões de nanopartículas mediante feixe de excitação. 
FIG. 5.4: Espectros de absorção no infravermelho registrados a temperatura ambiente no intervalo de 4000 a $400 \mathrm{~cm}^{-1}$ do Hacac e do complexo $\mathrm{Tb}(\mathrm{acac})_{3}\left(\mathrm{H}_{2} \mathrm{O}\right)_{3}$.

FIG. 5.5: Espectros de absorção no infravermelho registrados a temperatura ambiente no intervalo de 4000 a $400 \mathrm{~cm}^{-1}$ do complexo $\left[\mathrm{Tb}(\mathrm{acac})_{3}\left(\mathrm{H}_{2} \mathrm{O}\right)_{3}\right]$, PHB puro, e das nanopartículas de $\mathrm{PHB}+$ Complexo após liofilização.

FIG. 5.6: Espectros de absorção no infravermelho registrados a temperatura ambiente no intervalo de 4000 a $400 \mathrm{~cm}^{-1}$ do $\mathrm{Htta}$ e do complexo $\left[\mathrm{Eu}(\mathrm{tta})_{3}\left(\mathrm{H}_{2} \mathrm{O}\right)_{2}\right]$.

FIG. 5.7: Espectros de absorção na região do infravermelho registrados a

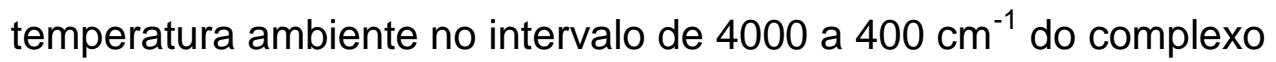
$\left[\mathrm{Eu}(\mathrm{tta})_{3}\left(\mathrm{H}_{2} \mathrm{O}\right)_{2}\right]$, PHB puro, e das nanopartículas de PHB + Complexo após liofilização. 60

FIG. 5.8: Curvas de TG e DTG do complexo $\left[\mathrm{Eu}(\mathrm{tta})_{3}\left(\mathrm{H}_{2} \mathrm{O}\right)_{2}\right]$. 63

FIG. 5.9: Curvas de TG e DTG do complexo $\left[\mathrm{Tb}(\mathrm{acac})_{3}\left(\mathrm{H}_{2} \mathrm{O}\right)_{3}\right]$. 64

FIG. 5.10: Curvas de TG e DTG das nanopartículas de PHB com complexo $\left[\mathrm{Eu}(\mathrm{tta})_{3}\left(\mathrm{H}_{2} \mathrm{O}\right)_{2}\right]$. 66

FIG. 5.11: Curvas de TG e DTG das nanopartículas de PHB com complexo $\left[\mathrm{Tb}(\mathrm{acac})_{3}\left(\mathrm{H}_{2} \mathrm{O}\right)_{2}\right]$. 68

FIG. 5.12: Difratogramas de Raios $X$ dos complexos de acac. 71

FIG. 5.13: Difratogramas de Raios $X$ dos complexos de tta. 71

FIG. 5.14: Difratogramas de Raios $X$ das nanopartículas de PHB + complexos com ligante tta.

FIG. 5.15: Difratogramas de Raios $X$ das nanopartículas de $\mathrm{PHB}+$ complexos com ligante acac.

FIG. 5.16: Micrografias dos papéis de filtro sem e com nanopartículas de PHB com complexos de terras raras. 74

FIG. 5.17: Gráfico de Citotoxicidade para as nanopartículas de PHB e PHB com $\left[\mathrm{Eu}(\mathrm{tta})_{3}\left(\mathrm{H}_{2} \mathrm{O}\right)_{2}\right]$. 
FIG. 5.18: Micrografias de filmes de PHB com e sem complexos de terras raras.

FIG. 5.19: Distribuição granulométrica obtida pela técnica de Espectroscopia de Correlação de Fótons (PCS) para as nanopartículas de PHB + complexos $\mathrm{TR}(\mathrm{tta})_{3}\left(\mathrm{H}_{2} \mathrm{O}\right)_{2}$.

FIG. 5.20: Distribuição granulométrica obtida pela técnica de Espectroscopia de Correlação de Fótons (PCS) para as nanopartículas de PHB + complexos $\mathrm{TR}(\mathrm{acac})_{3}\left(\mathrm{H}_{2} \mathrm{O}\right)_{3}$.

FIG. 5.21: Desenho esquemático do Potencial Zeta ${ }^{21}$. 83

FIG. 5.22: Espectro de fosforescência do complexo $\left[\mathrm{Gd}(\mathrm{tta})_{3}\left(\mathrm{H}_{2} \mathrm{O}\right)_{2}\right]$ no intervalo de 400 a 700 nm, monitorado a excitação em 365 nm a 77 $\mathrm{K}$.

FIG. 5.23: Espectro de fosforescencia do complexo $\left[\mathrm{Gd}(\mathrm{acac})_{3}\left(\mathrm{H}_{2} \mathrm{O}\right)_{3}\right]$ no intervalo de 400 a 700 nm, monitorado a emissão em 330 nm a 77 $\mathrm{K}$.

FIG. 5.24: Espectro de excitação do complexo $\left[\mathrm{Eu}(\mathrm{tta})_{3}\left(\mathrm{H}_{2} \mathrm{O}\right)_{2}\right]$ no intervalo de 250 a $590 \mathrm{~nm}$, monitorado a emissão em $611 \mathrm{~nm}$ a $298 \mathrm{~K}$. 92

FIG. 5.25: Espectro de emissão do complexo $\left[\mathrm{Eu}(\mathrm{tta})_{3}\left(\mathrm{H}_{2} \mathrm{O}\right)_{2}\right]$ no intervalo de 420 a 720 nm, monitorado a excitação em 394 nm a 298 K. A FIG. inserida apresenta o espectro de emissão a $77 \mathrm{~K}$. 93

FIG. 5.26: Espectro de excitação da suspensão de nanopartículas de PHB incorporando o complexo $\left[\mathrm{Eu}(\mathrm{tta})_{3}\left(\mathrm{H}_{2} \mathrm{O}\right)_{2}\right]$.

FIG. 5.27: Espectro de excitação da suspensão de nanopartículas de PHB incorporando o complexo $\left[\mathrm{Eu}(\mathrm{tta})_{3}\left(\mathrm{H}_{2} \mathrm{O}\right)_{2}\right]$. 96

FIG. 5.28: Espectro de emissão da suspensão de nanopartículas incorporando o complexo $\left[\mathrm{Eu}(\mathrm{tta})_{3}\left(\mathrm{H}_{2} \mathrm{O}\right)_{2}\right]$. Avaliação do efeito de tamanho de partícula.

FIG. 5.29: Espectro de emissão da suspensão de nanopartículas incorporando o complexo $\left[\mathrm{Eu}(\mathrm{tta})_{3}\left(\mathrm{H}_{2} \mathrm{O}\right)_{2}\right.$ Avaliação do efeito do agente de emulsão na intensidade do espectro. 
FIG. 5.30: Espectro de excitação do complexo $\left[\mathrm{Eu}(\mathrm{acac})_{3}\left(\mathrm{H}_{2} \mathrm{O}\right)_{3}\right]$ no intervalo de 250 a $590 \mathrm{~nm}$, monitorando a emissão em $611 \mathrm{~nm}$ a $298 \mathrm{~K}$

FIG. 5.31: Espectro de emissão do complexo $\left[\mathrm{Eu}(\mathrm{acac})_{3}\left(\mathrm{H}_{2} \mathrm{O}\right)_{3}\right]$ no intervalo de 570 a $720 \mathrm{~nm}$, monitorado a excitação em 465 nm a $298 \mathrm{~K}$. A figura inserida apresenta o espectro de emissão a $77 \mathrm{~K}$. 100

FIG. 5.32: Espectro de excitação da suspensão de nanopartículas contendo $\left[\mathrm{Eu}(\mathrm{acac})_{3}\left(\mathrm{H}_{2} \mathrm{O}\right)_{3}\right]$. Avaliação do efeito de tamanho de partícula. 101

FIG. 5.33: Espectro de emissão da suspensão de nanopartículas contendo $\left[\mathrm{Eu}(\mathrm{acac})_{3}\left(\mathrm{H}_{2} \mathrm{O}\right)_{3}\right]$. Avaliação do efeito de tamanho de partícula. 102

FIG. 5.34: Espectro de excitação do complexo $\left[\mathrm{Tb}(\mathrm{acac})_{3}\left(\mathrm{H}_{2} \mathrm{O}\right)_{3}\right]$ no intervalo de 250 a 590 nm, monitorado a emissão em 548 nm a $298 \mathrm{~K}$. 104

FIG. 5.35: Espectro de emissão do complexo $\left[\mathrm{Tb}(\mathrm{acac})_{3}\left(\mathrm{H}_{2} \mathrm{O}\right)_{3}\right]$ no intervalo de 470 a $700 \mathrm{~nm}$, monitorado a excitação em $338 \mathrm{~nm}$ a $298 \mathrm{~K}$. A FIG. inserida apresenta o espectro de emissão a $77 \mathrm{~K}$. 105

FIG. 5.36: Espectro de excitação da suspensão de nanopartículas contendo $\left[\mathrm{Tb}(\mathrm{acac})_{3}\left(\mathrm{H}_{2} \mathrm{O}\right)_{3}\right]$. Avaliação do efeito de tamanho de partícula. 106

FIG. 5.37: Espectro de emissão da suspensão de nanopartículas contendo $\left[\mathrm{Tb}(\mathrm{acac})_{3}\left(\mathrm{H}_{2} \mathrm{O}\right)_{3}\right]$. Avaliação do efeito de tamanho de partícula. 107

FIG. 5.38: Espectro de excitação do complexo [Sm(tta) $\left.)_{3}\left(\mathrm{H}_{2} \mathrm{O}\right)_{2}\right]$ no intervalo de 240 a $630 \mathrm{~nm}$, monitorado a emissão em $644 \mathrm{~nm}$ a $298 \mathrm{~K}$. A figura inserida apresenta o espectro de excitação a $77 \mathrm{~K}$

FIG. 5.39: Espectro de emissão do complexo [Sm(tta) $\left.)_{3}\left(\mathrm{H}_{2} \mathrm{O}\right)_{2}\right]$ no intervalo de 450 a 750 nm, monitorado a excitação em $390 \mathrm{~nm}$ a $298 \mathrm{~K}$. A figura inserida apresenta o espectro de emissão a $77 \mathrm{~K}$.

FIG. 5.40: Espectro de excitação da suspensão de nanopartículas contendo $\left[\mathrm{Sm}(\mathrm{tta})_{3}\left(\mathrm{H}_{2} \mathrm{O}\right)_{2}\right]$. Avaliação do efeito de tamanho de partícula.

FIG. 5.41: Espectro de emissão da suspensão de nanopartículas incorporando o [Sm(tta $\left.)_{3}\left(\mathrm{H}_{2} \mathrm{O}\right)_{2}\right]$. Avaliação do efeito de tamanho de partícula. 
FIG. 5.42: Espectro de excitação do complexo $\left[\mathrm{Sm}(\operatorname{acac})_{3}\left(\mathrm{H}_{2} \mathrm{O}\right)_{3}\right]$ no intervalo de 250 a $580 \mathrm{~nm}$, monitorado a excitação em $645 \mathrm{~nm}$ a 298 K. A figura inserida apresenta o espectro de excitação a $77 \mathrm{~K}$.

FIG. 5.43: Espectro de emissão do complexo $\left[\mathrm{Sm}(\mathrm{acac})_{3}\left(\mathrm{H}_{2} \mathrm{O}\right)_{3}\right]$ no intervalo de 450 a 700 nm, monitorado a excitação em 363 e 403 nm a 298 $\mathrm{K}$. A figura inserida apresenta os espectros de emissão a $77 \mathrm{~K}$.

FIG. 5.44: Espectro de excitação da suspensão de nanopartículas contendo $\left[\mathrm{Sm}(\mathrm{acac})_{3}\left(\mathrm{H}_{2} \mathrm{O}\right)_{3}\right]$. Avaliação do efeito de tamanho de partícula.

FIG. 5.45: Espectro de emissão da suspensão de nanopartículas contendo $\left[\mathrm{Sm}(\operatorname{acac})_{3}\left(\mathrm{H}_{2} \mathrm{O}\right)_{3}\right]$. Avaliação do efeito de tamanho de partícula.

FIG. 5.46: Curvas de decaimento dos complexos precursores 120

FIG. 5.47: Curvas de decaimento das suspensões de nanopartículas 121

FIG. 5.48: Distribuição granulométrica obtida pela técnica de Espectroscopia de Correlação de Fótons (PCS) para as nanopartículas de PHB + complexo Eu(tta) $)_{3}\left(\mathrm{H}_{2} \mathrm{O}\right)_{2}$ conjugadas com BSA.

FIG. 5.49: Distribuição granulométrica obtida pela técnica de Espectroscopia de Correlação de Fótons (PCS) para as nanopartículas de PHB + complexo $\mathrm{Eu}(\mathrm{tta})_{3}\left(\mathrm{H}_{2} \mathrm{O}\right)_{2}$ funcionalizadas com Glutaraldeído. 125

FIG. 5.50: Distribuição granulométrica obtida pela técnica de Espectroscopia de Correlação de Fótons (PCS) para as nanopartículas de PHB + complexo $\mathrm{Tb}(\mathrm{acac})_{3}\left(\mathrm{H}_{2} \mathrm{O}\right)_{3}$ conjugadas com BSA.

FIG. 5.51: Distribuição granulométrica obtida pela técnica de Espectroscopia de Correlação de Fótons (PCS) para as nanopartículas de PHB + complexo $\mathrm{Tb}(\mathrm{acac})_{3}\left(\mathrm{H}_{2} \mathrm{O}\right)_{3}$ funcionalizadas com Glutaraldeído.

FIG. 5.52: Comportamento de Potencial Zeta das Nanopartículas frente a variação de concentração de BSA.

FIG. 5.53: Comportamento de Potencial Zeta das Nanopartículas frente a variação de concentração de glutaraldeído.

FIG. 5.54: Espectro de absorção na região do UV-vis da BSA e das nanopartículas funcionalizadas com BSA. 
FIG. 5.55: Espectro de absorção na região do UV-vis da nanopartícula, do glutaraldeído e da nanopartícula funcionalizada com glutaraldeído. 131 
1

INTRODUÇÃO 


\section{INTRODUÇÃO}

A nanotecnologia tem possibilitado a associação das características ópticas, magnéticas e térmicas de moléculas às propriedades de sólidos numa escala ínfima. Essas características tem possibilitado o transporte de ativos químicos e a interação com diversos meios de forma direcionada e organizada $^{[1]}$. Um exemplo clássico dessa associação é o preparo de nanopartículas (NPs) poliméricas utilizadas como carreadores de fármacos com ação específica. Este tipo de sistema possui maior estabilidade quando aplicados em fluidos biológicos, principalmente quando se utiliza polímeros biodegradáveis como o poli-3-hidroxibutirato $(\mathrm{PHB})^{[2]}$.

O uso de nanopartículas como marcadores biológicos ou biomarcadores vem conquistando destaque nesta área. Um exemplo que merece destaque é o uso de nanopartículas como marcadores biológicos ou biomarcadores. Em especial, marcadores contendo íons terras raras que apresentam boa intensidade de luminescência com longo tempo de vida. O que de fato é extremamente vantajoso, pois no espaço de tempo da promoção da excitação até a emissão de luminescência, ocorrem os efeitos de espalhamento de luz e de fluorescência de fundo, que acabam dissipando semmaiores interferências na detecção ${ }^{[3,4]}$.

O estudo de complexos de terras raras trivalentes $\left(\mathrm{TR}^{3+}\right)$ tem crescido de forma acentuada nos últimos anos enfocando diversos tipos de aplicações, dentre as quais se destacam o uso de compostos de $\mathrm{Eu}^{3+} \mathrm{e} \mathrm{Tb}^{3+}$ como sondas luminescentes em imunofluoroensaios em razão da alta emissão na região do vermelho $(\lambda \sim 615 \mathrm{~nm})$ e no verde $(\lambda \sim 545 \mathrm{~nm})$ respectivamente. 
Outras aplicações importantes ocorrem no sequenciamento de DNA e na marcação biológica para microscopia ${ }^{[4]}$.

Para que uma partícula apresente boas característicascomo um biomarcador, é importante torná-la funcional, ou seja, modifica-la para que apresente especificidade no momento de sua aplicação. Dessa forma, torna-se relevante o processo de funcionalização da partícula, que consiste em colocar via processo de adsorção física ou interação química, um agente específico para a função requerida para aquela partícula. Um exemplo desse processo, é o uso de moléculas de anticorpo $(\mathrm{lgG})$ adsorvidas na superfície de partículas de óxido de gadolínio $\left(\mathrm{Gd}_{2} \mathrm{O}_{3}\right)$ dopadas com íons $\mathrm{Eu}^{3+}$, que vem sendo estudado para a marcação de anticorpos. No entanto, nem sempre é possível ligar por reação direta uma partícula com o agente de especificidade como é o caso da marcação de uma reação de conjugação do tipo antígeno-anticorpo. Desse modo, pode-se utilizar outras moléculas que são capazes de formar uma ponte entre a partícula aqui entendida como biomarcador e o agente de interesse biológico, e são chamados de espaçadores ${ }^{[5,6]}$.

A primeira característica para uma efetiva funcionalização é o tipo de superfície que a partícula terá, dentre as quais se destacam nanopartículas de sílica e poliméricas. Entre os polímeros, merece destaque o PHB, material biodegradável gerado por microrganismos através do consumo de sacarose da cana-de-açúcar e que possui uma alta taxa de biodegradação, o que torna o uso desse material interessante para fins biomédicos. O PHB pertence a família dos poli(3-hidroxialcanoatos) e ao contrário de outros biopolímeros, é um termoplástico com alto grau de cristalinidade ${ }^{[7]}$.Nos últimos anos, o uso de polímeros como o PHB no preparo de nanopartículas, nanocápsulas ou no recobrimento de esferas de diversas matrizes, como partícula de óxido de silício $\left(\mathrm{SiO}_{2}\right)$ tem atraído a atenção de diversos grupos de pesquisas, em função de suas propriedades e aplicações ${ }^{[8]}$.

O estudo de nanopartículas ou nanocápsulas poliméricas tem tido uma atenção especial pela indústria farmacêutica, para a liberação controlada de fármacos. Dela advém a extensão desses estudos para outras áreas, em um exemplo citado anteriormente, o uso como biomarcadores. Todas essas 
aplicações têm ajudado no desenvolvimento de métodos de preparo e caracterização dessas nanopartículas, com ênfase no controle de tamanho de partículas e na estrutura do sistema, como uma partícula ou esfera.

Dentre os processos utilizados para a obtenção destas nanopartículas, podem-se destacar dois métodos mais usuais, que são a síntese a partir de uma reação de polimerização e a preparação a partir de um polímero pré-formado. Dentre as técnicas utilizadas para a obtenção de partículas a partir de um polímero pré-formado, tem-se o método por evaporação de solvente, que consiste na dissolução do polímero e do principio ativo ou complexo em um solvente orgânico e a sua emulsificação em água destilada contendo um estabilizante. Através de aquecimento brando e baixa pressão, evapora-se o solvente, recristalizando-se o polímero e o complexo na forma de nanopartículas ${ }^{[9]}$.

Desta forma, o laboratório de química supramolecular e nanotecnologia do IPEN vem desenvolvendo pesquisa e dando sua contribuição no estudo de marcadores para área biológica, utilizando como detecção, a propriedade de luminescência dos íons terras raras. É importante enfatizar que 0 desenvolvimento desses biomateriais tem focado especialmente marcadores para doenças negligenciadas, como a doença de Chagas e a Leishmaniose, doenças presentes acentuadamente em países em desenvolvimento e que não tem recebido a devida atenção da indústria farmacêutica de diagnóstico. 


\section{REFERÊNCIAS BIBLIOGRÁFICAS}

[1] STARK, W. J. Nanoparticles in Biological Systems. Angewandte Chemie, p.1242-1258,2011.

[2] SCHAFFAZICK, S. R.; GUTERRES, S. S.; FREITAS, L. L.; POHLMANN, A. R. Caracterização e estabilidade físico-química de sistemas poliméricos nanoparticulados para administração de fármacos. Química Nova, v. 26 , n. 5 , p. $726-737,2003$

[3] SAMMES, P. G.; YAHIOGLU, G. Modern Bioassaysusing Metal Chelates as Luminescent Probes. Natural Product Reports, p. 1-28, 1996.

[4] JIANG, H.; HONGFEI; WANG, G.; ZHANG, W.; LIU, X.; YE, Z.; JIN, D.; YUAN, J.; LIU, Z. Preparation and Time-Resolved Luminescence Bioassay Application of Multicolor Luminescent Lanthanide Nanoparticles. Springer Science, p. 321-328, 2010.

[5] NICHKOVA, M.; GEE, S.; PERRON, R.; GEE, S. J.; HAMMOCK, B. D.; KENNEDY, I. M. Eu ${ }^{3+}$-doped $\mathrm{Gd}_{2} \mathrm{O}_{3}$ nanoparticles as reporters for optical detection and visualization of antibodies patterned by microcontact printing. Analytical Bioanalytical Chemistry, v. 384, p. 631-637, 2006.

[6] DOSEV, D. ; NICHKOVA, M.; LIU, M.; GUO, B.; LIU, G.; HAMMOCK, B. D.; KENNEDY, I. M.Application of luminescent Eu: $\mathrm{Gd}_{2} \mathrm{O}_{3}$ nanoparticles to the visualization of protein micropatterns. Journal of Biomedical Optics, v. 10, p. 1-7, 2005.

[7] KURUSU, R. S. Efeito do tempo e do recozimento nas propriedades mecânicas e de biodegradação de materiais baseados em Poli(3hidroxibutirato) (PHB). 2011.Dissertação (Mestrado) - Universidade de São Paulo, São Paulo.

[8] SHI, Z.; ZHOU, Y.; YAN, D. Preparation of poly(b-hydroxybutyrate) and poly(lactide) hollow spheres with controlled wall thickness. Polymer, v. 47, p. 8073-8079, 2006.

[9] NAKACHE, E.; POULAIN, N.; CANDAU, F.; ORECCHIONI, A. M.; IRACHE, J. M.Biopolymer and polymer nanoparticles and their biomedical applications. v. 5, 2000. Cap. 11, p. 577-635. Handbook of Nanostructured Materials and Nanotechnology. 


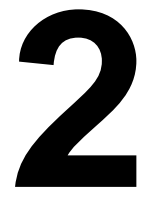

OBJETIVO 


\section{OBJETIVO}

O objetivo geral deste trabalho consiste no preparo de nanopartículas oriundas de uma mistura de complexos $\beta$ dicetonatosacetilacetona (Hacac) e a 2-tenoiltrifluoracetona ( $\mathrm{Htta}$ ) de terras raras $\left(\mathrm{Eu}^{3+}, \mathrm{Tb}^{3+}, \mathrm{Sm}^{3+}\right.$ e $\mathrm{Gd}^{3+}$ ) com o polímero biodegradável PHB (poli-3hidroxibutirato) e funcionalizadas para aplicação como biomarcadores luminescentes em imunoensaios, com ênfase para doenças negligenciadas, como a doença de Chagas.

Como objetivos específicos, pretende-se:

$\checkmark$ Sintetizar e caracterizar os complexos de $\beta$-dicetonas (tta e acac) de terras raras $\left(\mathrm{Eu}^{3+}, \mathrm{Tb}^{3+}, \mathrm{Sm}^{3+}\right.$ e $\left.\mathrm{Gd}^{3+}\right)$.

$\checkmark$ Avaliar as propriedades espectroscópicas desses complexos em estado sólido nas temperaturas de $298 \mathrm{~K}$ e $77 \mathrm{~K}$ com utilizando nitrogênio líquido.

$\checkmark$ Preparar as nanopartículas com a mistura de PHB e o complexo precursor pelo método de evaporação de solvente utilizando Tween 80 como dispersante.

$\checkmark$ Avaliar as propriedades espectroscópicas dessas nanopartículas em suspensão.

$\checkmark$ Efetuar testes para confirmação do processo de funcionalização da partícula com o glutaraldeído e a proteína albumina do soro bovino (BSA) como modelo.

$\checkmark$ Avaliar 0 tamanho de partícula e 0 potencial zeta das nanopartículas com e sem funcionalização. 
Logo, o presente trabalho visa contribuir para produção de métodos de diagnóstico sensíveis e específicos para diversas doenças, em específico, as doenças consideradas negligenciadas com ênfase na doença de Chagas. De forma ampla, este estudo visa o desenvolvimento social e o crescimento da tecnologia nacional. 


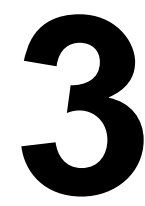

REVISÃO BIBLIOGRÁFICA 


\section{REVISÃO BIBLIOGRÁFICA}

\subsection{Elementos Terras Raras}

De acordo com a Comissão de Nomenclatura em Química Inorgânica da IUPAC (Intenational Union of Pure and Applied Chemistry) designa-se o termo "metais de terras raras" para os elementos lantânio (La, $Z=57$ ) ao lutécio ( $L u, Z=71$ ) dentre os quais se incluem o escândio ( $S c, Z=21$ ) e o ítrio ( $Y, Z=39$ ). O termo "terra" é um antigo modo de designar os metais obtidos na forma de óxido e "rara" é oriundo da dificuldade no processo de separação desses elementos e da sua origem.

No entanto, é relevante enfatizar que o termo "rara" não é adequado, uma vez que esses elementos são muito mais abundantes na natureza do que outros elementos. Um exemplo que pode ser levado em consideração com os elementos túlio $(0,5 \mathrm{ppm})$ e lutécio $(0,8 \mathrm{ppm})$ que são as terras raras menos abundantes na crosta terrestre, ainda assim, são mais abundantes do que elementos como prata $(0,07 \mathrm{ppm})$ e o bismuto $(0,008 \mathrm{ppm})^{[1]}$.

O termo "série do lantânio" refere-se aos elementos de números atômicos de 57 a 71 ( $\mathrm{La}$ a Lu) e a "série lantanídica" exclui o lantânio, considerando apenas os elementos de numero atômico de 58 a 71 . No caso da série lantanídica, sua principal característica refere-se ao preenchimento sucessivo e progressivo dos orbitais $4 \mathrm{f}$. Todos os átomos dessa série possuem em comum configuração eletrônica $6 s^{2}$. A configuração eletrônica desses elementos pode ser resumida em [Xe] $4 \mathrm{f}^{\mathrm{n}-1} 5 \mathrm{~d}^{1} 6 \mathrm{~s}^{2}$ ( La, Ce, Gd e Lu) e [Xe] $4 f^{n} 6 s^{2}$ para os demais elementos da série ${ }^{[2]}$.

Outra importante característica dos elementos da série lantanídica é o fenômeno de contração lantanídica, que ocorre em função de uma blindagem 
imperfeita do elétron da camada $4 f$ exerce sobre outro elétron da camada $4 f$. Consequentemente, há um aumento da carga nuclear efetiva, reduzindo o raio atômico com o aumento do número atômico ${ }^{[3-4]}$.

$\mathrm{Na}$ questão sobre o arranjo espacial, os íons terras raras são muito diferentes em relação a outros metais no estado trivalente. Os metais terras raras formam íons relativamente grandes, portanto, temos um aumento do número de coordenação, que varia de 6 a 12, independente de ser um meio sólido ou líquido. No entanto, os mais comum, são números de coordenação de 8 e $9^{[1]}$.

Para os diferentes estados de oxidação, o íon trivalente é o mais comum além de mais estável termodinamicamente, não dependente apenas da configuração eletrônica, mas também do ambiente químico. Nos compostos com terras raras no estado trivalente, os orbitais $4 f$ se encontram na parte interna da eletrosfera do átomo e são totalmente protegidos pelos orbitais preenchidos 5 s e $5 p$, sendo assim, sem participação em ligações, apenas um leve envolvimento com orbitais dos ligantes, dessa forma, é explicado porque íons lantanídeos geram complexos com alto caráter iônico ${ }^{[3]}$.

Os compostos com íons terras raras $\left(\mathrm{TR}^{3+}\right)$ apresentam propriedades ópticas de grande interesse, com estudos aprofundados onde é possível se fazer o design dos compostos para exibir as propriedades requeridas nos processos de aplicação já há bastante tempo. Essas propriedades são sensíveis ao ambiente químico no qual o íon $\mathrm{TR}^{3+}$ se encontra e ao tipo de ligante envolvido na formação do complexo. A teoria do campo ligante aplicado a esses compostos são extensivamente conhecidos e suas interpretações e aplicações são bastante desenvolvidas.

A teoria das intensidades espectrais $4 \mathrm{f}-4 \mathrm{f}$ que completam este ano 50 anos de sua publicação, também conhecida como Teoria Judd Ofeld ${ }^{[5-6]}$ tem se mostrado muito útil na descrição de propriedades ópticas, principalmente no envolvimento de complexos com ligantes orgânicos. Esses ligantes tem papel de destaque nos trabalhos publicados ao longo dos últimos anos em estudos envolvendo íons $\mathrm{TR}^{3+}$ dando destaque aos trabalhos dos grupos brasileiros dos professores O. L. Malta e H. F. Brito ${ }^{[7-18]}$. 
A baixa interferência do ligante sobre os elétrons $4 f$ dos íons $T R^{3+}$ implica em bandas de absorção e emissão bastante estreitas e são características dos seus níveis de energia, uma vez que as transições intraconfiguracionais $4 \mathrm{f}-4 \mathrm{f}$ possuem comportamento de raias ou linhas, somente observadas em espectros atômicos. Dessa forma, com os dados espectrais dos compostos dos íons $\mathrm{TR}^{3+}$ é possível quantificar as energias dos níveis fundamentais e excitados destes íons, conforme FIG 3.1.

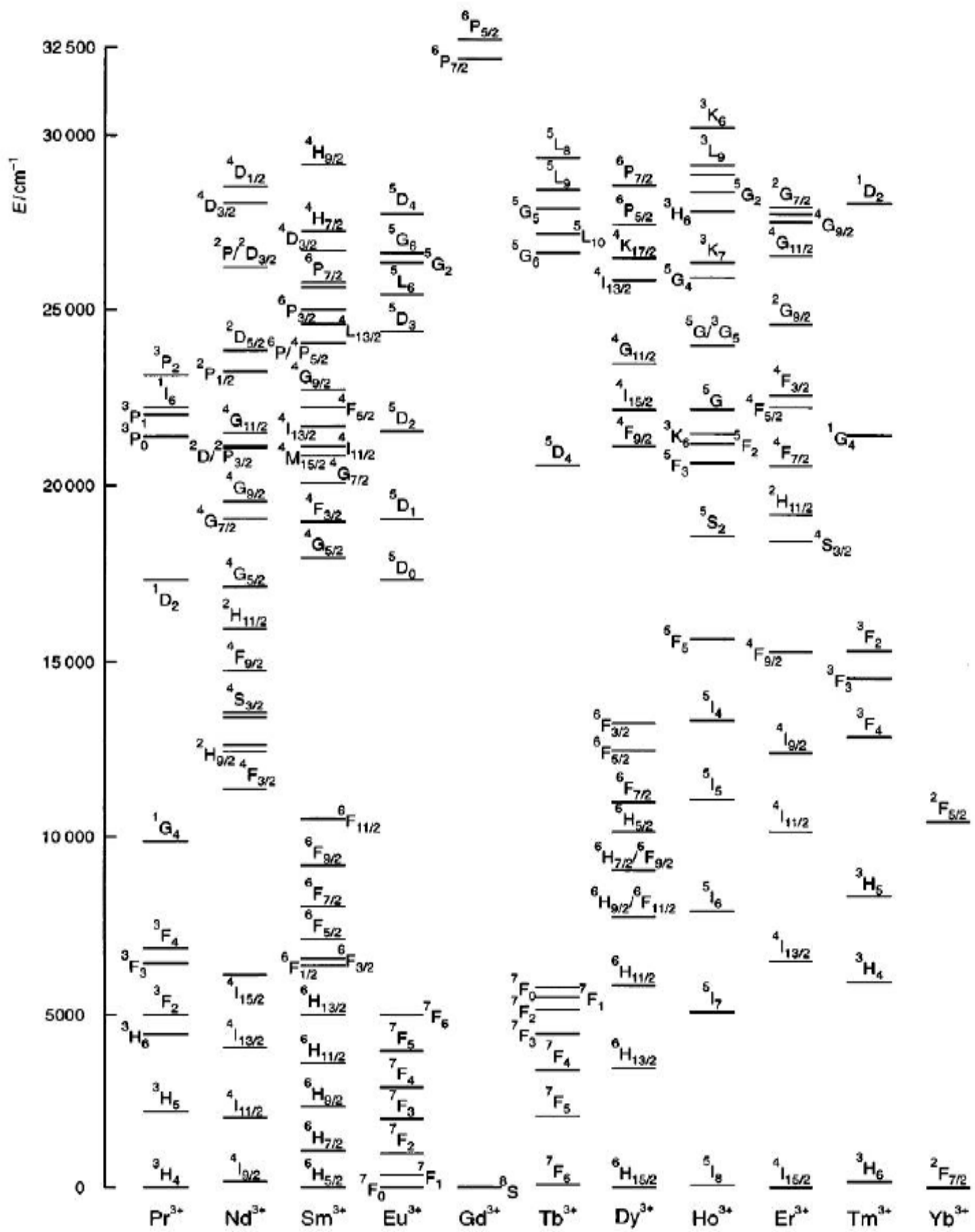

FIG.3.1: Diagrama de energia dos íons $\mathrm{TR}^{3+}$ obtidos a partir de cristais de $\mathrm{LaF}_{3}{ }^{[19]}$ 
Estes dados são suficientes para prever complexos com alta luminescência, considerando as energias dos níveis excitados dos íons $\operatorname{TR}^{3+} \mathrm{e}$ dos estados excitados do ligante ${ }^{[18]}$.

\subsection{Espectro de emissão na região do visível}

\subsubsection{Luminescência de íons Terras Raras}

De acordo com a IUPAC, luminescência é definida como a emissão espontânea de radiação por uma espécie que se encontra em estado excitado, seja ele eletrônico ou vibracional. Embora muitos trabalhos se refiram a emissão de radiação por esses íons como sendo fosforescência ou fluorescência, a recomendação recente é o uso do temo Luminescência para todos os fenômenos.

Para que se possa esclarecer as diferenças, define-se fluorescência como a perda de energia por emissão espontânea de radiação quando um luminóforo volta de um estado excitado, normalmente o estado fundamental, de mesma multiplicidade de spin $(\Delta S=0)$. Já no caso da fosforescência, ocorre o mesmo processo, no entanto com espécies com multiplicidades diferentes de spin $(\Delta S \neq 0)$. De forma mais clara, a fosforescência possui o estado excitado com maior tempo de vida em relação à fluorescência ${ }^{[20]}$.

Os termos fluorescência e fosforescência são normalmente usados para descrever emissões radiativas de espécies orgânicas que ocorrem entre estados singleto-singleto e tripleto-singleto de acordo com a FIG 3.2.

Os estados singleto e tripleto de ligantes orgânicos podem sofrer implicações oriundas de efeitos indutivos (tendência de doar ou retirar elétrons) de seus substituintes assim como os decorrentes do ambiente químico, o que explica as bandas largas de emissão na região do visível.

Já os efeitos de deslocamento de energias das emissões pouco interferem para os íons $\mathrm{TR}^{3+}$, até mesmo em diferentes ambientes químicos, colaborando com transições em comprimentos de onda bem definidos. Esse 
fato explica a geração de emissões monocromáticas para um determinado íon $\mathrm{TR}^{3+}$, os quais pode-se citar o $\mathrm{Eu}^{+3}$ emitindo na região do vermelho e o $\mathrm{Tb}^{+3}$ na região do verde, relacionadas às energias de transições intraconfiguracionais destes íons de acordo com o diagrama de energia na FIG 3.1 ${ }^{[18]}$.

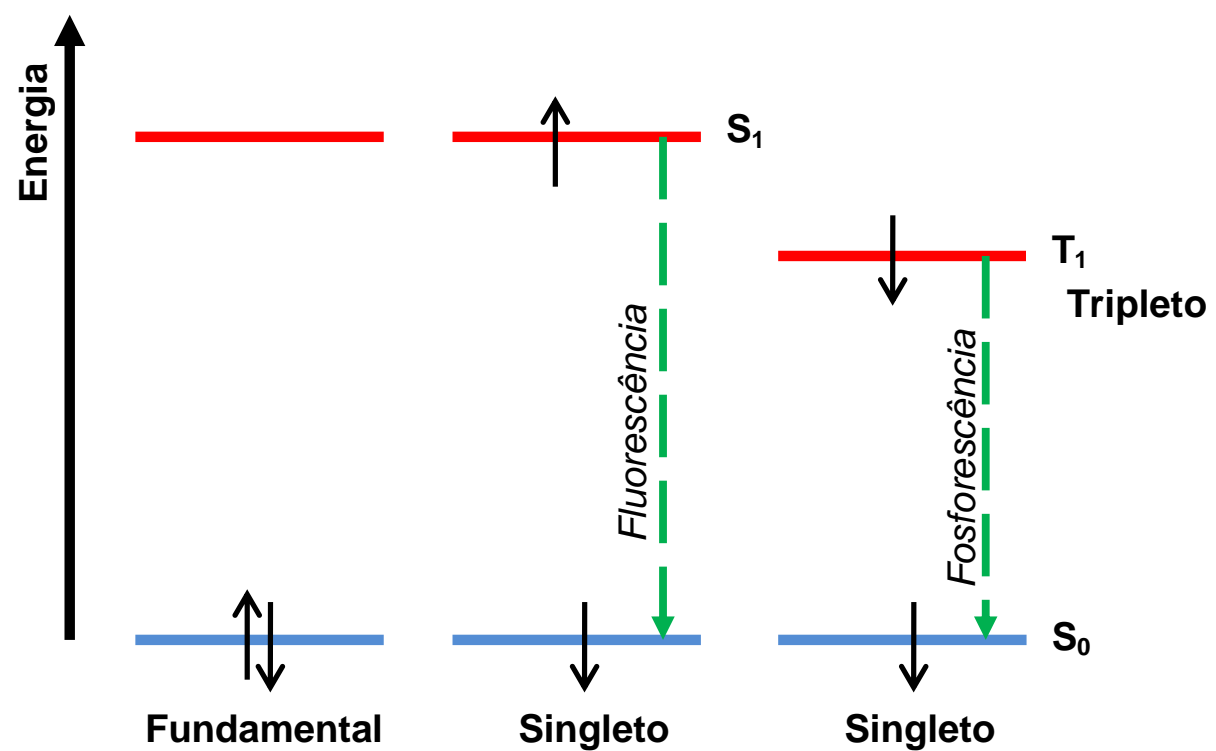

FIG.3.2: Fluorescência e Fosforescência de espécies orgânicas.

Pode-se dividir os íons terras raras em três grupos em razão das propriedades luminescentes ${ }^{[19]}$. São eles:

$\checkmark$ Íons que não possuem luminescência $\left(\mathrm{La}^{3+}\right.$ com orbital $4 \mathrm{f}^{0}$ e $\mathrm{Lu}^{3+}$ com orbital $4 f^{14}$ ) e íons com estados excitados de alta energia no qual o fenômeno de luminescência é extremamente fraco $\left(\mathrm{Gd}^{3+} \mathrm{com}\right.$ orbital $4 \mathrm{f}^{7}$ )

$\checkmark$ Íons com intensa luminescência, com grande diferença de energia entre os estados excitados e fundamentais, além de níveis de energia abaixo dos estados tripletos dos ligantes $\left(\mathrm{Sm}^{3+}, \mathrm{Eu}^{+3}, \mathrm{~Tb}^{+3} \mathrm{e}\right.$ $\left.\mathrm{Dy}^{+3}\right)$.

$\checkmark$ Íons cuja intensidade de luminescência é muito fraca em razão da contribuição de processos não radiativos oriundas da pequena diferença entre as energias dos estados $\left(\mathrm{Pr}^{3+}, \mathrm{Nd}^{3+}, \mathrm{Ho}^{3+}, \mathrm{Er}^{3+}, \mathrm{Tm}^{3+}\right.$ $\left.e \mathrm{Yb}^{3+}\right)^{[19]}$. 
Grande parte dos estudos relacionados aos íons $\mathrm{TR}^{3+}$ atualmente, se concentram na tentativa de intensificar sua luminescência seja no visível para íons como $\mathrm{Sm}^{3+}, \mathrm{Eu}^{+3}, \mathrm{~Tb}^{+3}$ como para o infravermelho próximo para os íons $\mathrm{Nd}^{3+} \mathrm{e} \mathrm{Yb}^{3+}$, com o objetivo de obter materiais com maior intensidade de luminescência em diversos ambientes químicos.

\subsubsection{O efeito antena}

Em 1942, observou-se que o íon $\mathrm{Eu}^{3+}$ quando ligado a compostos orgânicos, apresentava uma intensidade de emissão maior quando o sistema é excitado na transição do ligante. Para esses sistemas, se observou que a energia absorvida pelo ligante é transferida eficientemente para o íon $\mathrm{Eu}^{3+}$, resultando em uma emissão característica das transições $4 \mathrm{f}-4 \mathrm{f}$ desse íon. A intensidade da emissão se justifica de duas maneiras ${ }^{[23]}$ :

$\checkmark$ Regras de transição são bem mais relaxadas nesses tipos de sistemas, em função do aumento de diversas contribuições, como o acoplamento dinâmico.

$\checkmark$ Como o ligante é mais eficientemente excitado do que o íon $\mathrm{TR}^{3+}$ nota-se que os níveis emissores ${ }^{5} \mathrm{D}_{\mathrm{J}}$ do íon $\mathrm{Eu}^{3+}$ são melhores preenchidos por transferência de energia dos níveis do ligante do que por irradiação direta ${ }^{[23]}$.

De forma simplificada, pode-se representar 0 processo de transferência de energia de acordo com a FIG 3.3.

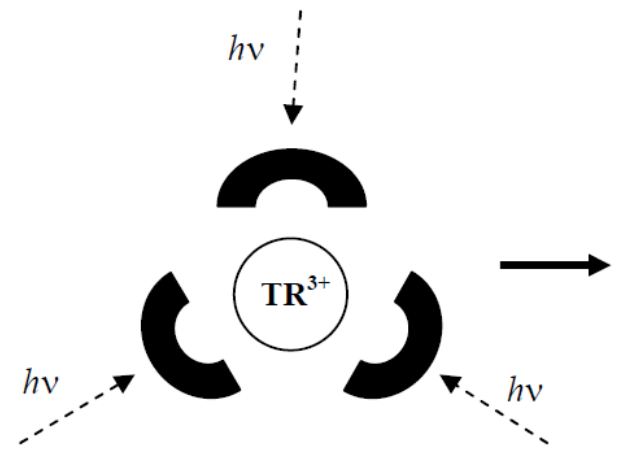

Absorção Eficiente

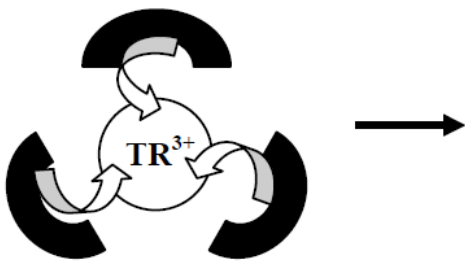

Transferência de Energia eficiente

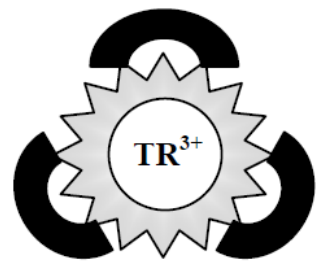

Emissão eficiente

FIG.3.3: Esquema simplificado do efeito antena ${ }^{[24]}$. 
Os íons terras raras possuem baixa absortividade molar em função das transições proibidas de $4 f-4 f$ de acordo com a regra de Laporte $(\Delta \ell= \pm 1)$, portanto o íon trivalente por si só não apresenta eficiência por excitação direta deste íon ${ }^{[1]}$.

Atualmente, pode-se representar o mecanismo de transferência de energia do ligante orgânico para o íon $\mathrm{TR}^{3+}$ de acordo com a FIG 3.4 $4^{[19,25,26]}$.

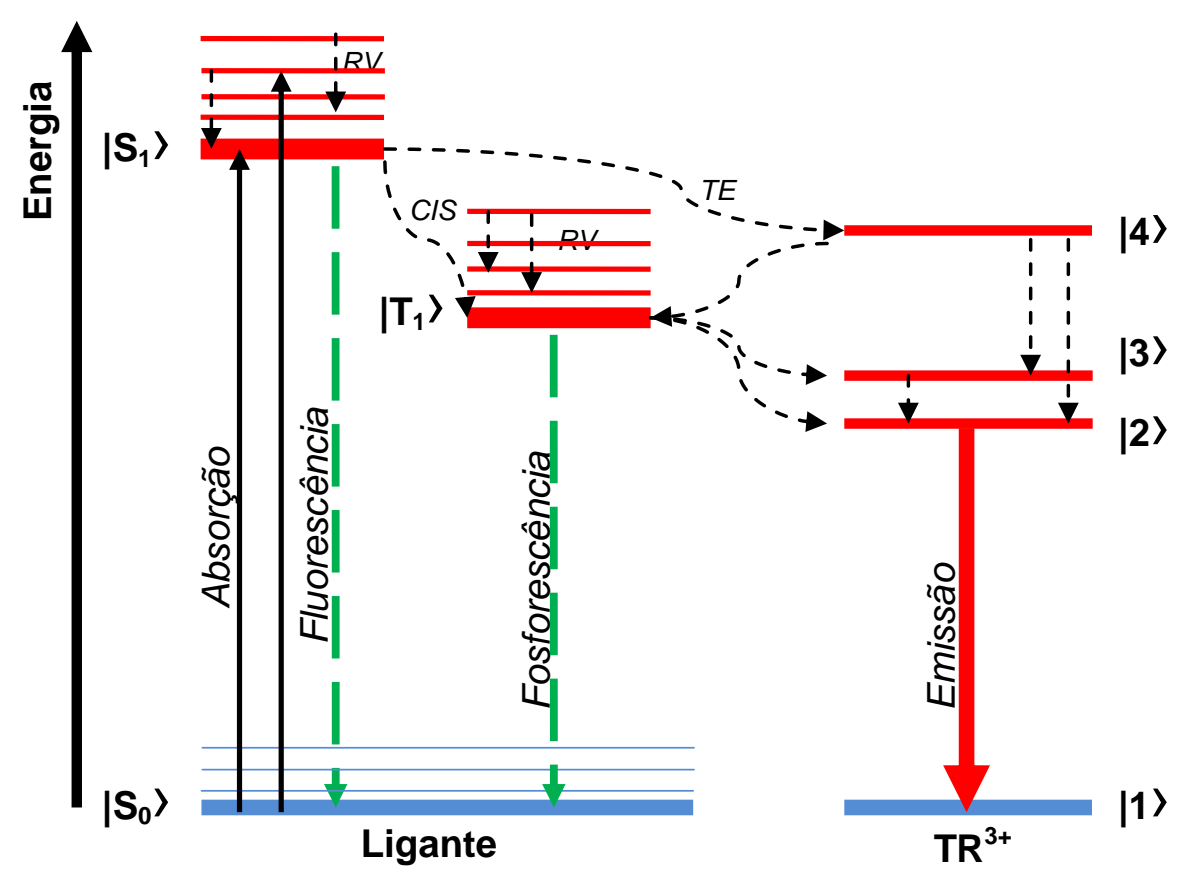

FIG.3.4: Representação da transferência de energia em complexos $\beta$ dicetonatos de $\mathrm{Eu}^{3+}$ onde $\mathrm{RV}=$ Relaxação Vibracional; $\mathrm{CIS}=$ Cruzamento Intersistema; TE=Transferência de Energia.

É possível interpretar o diagrama de energia da seguinte forma:

Primeiro, o estado fundamental $\left|S_{0}\right\rangle$ do ligante absorve energia na forma de radiação UV passando para o primeiro estado excitado $\left|S_{1}\right\rangle$. $O$ primeiro estado excitado pode apresentar conversão interna entre seus níveis de energia vibracionais. Nesta etapa, a partir do estado $\left|S_{1}\right\rangle$, três processos são possíveis:

$\checkmark 1^{\circ}-\left|\mathrm{S}_{1}\right\rangle$ transfere energia ao estado excitado $|4\rangle$ do íon $\mathrm{TR}^{3+}$, posteriormente decaindo não-radioativamente para 0 estado emissor $|2\rangle$. 
$\checkmark 2^{\circ}-|4\rangle$ do íon $\mathrm{TR}^{3+}$ devolve a energia ao estado $\left|\mathrm{T}_{1}\right\rangle$ do ligante, transferindo essa energia aos estados $|3\rangle$ a $|2\rangle$ do íon $\mathrm{TR}^{3+}$.

$\checkmark 3^{\circ}-\left|S_{1}\right\rangle$ decai de forma não-radiativa para o estado $\left|T_{1}\right\rangle$ (CIS) do ligante, que transfere essa energia aos estados $|3\rangle$ ou $|2\rangle$ do íon $\mathrm{TR}^{3+}$.

Experimentalmente se verifica que os íons $\mathrm{Eu}^{+3}$ e $\mathrm{Tb}^{+3}$ interagem com alguns ligantes orgânicos preferencialmentevia $3^{\circ}$ processo. Evidências teóricas também vão de acordo com essa tendência.

Nota-se que a eficiência de transferência de energia só será eficaz se o estado $T_{1}$ dos ligantes estiver localizado próximo, porém um pouco acima do nível $4 f$ da $T R^{3+}$. Nos casos em que o estado $T_{1}$ do ligante é muito próximo ou abaixo do nível emissor do íon $\mathrm{TR}^{3+}$, são favorecidos fenômenos pouco desejáveis como a fosforescência, fluorescênciade retardo ou ainda a perda da energia através de outros fenômenos (processos não radiativos) ${ }^{[27-28]}$.

Além destas possibilidades, a diminuição de eficiência da luminescência pode ocorrer através da supressão por ação de moléculas de água, onde os níveis vibrônicos da molécula de água estão energeticamente acoplados aos níveis ${ }^{7} F_{J}$ do íon $\mathrm{TR}^{3+}$, fenômeno também observado com outras moléculas além da água ${ }^{[29-30]}$. Uma das formas de evitar esse processo é através da síntese de complexos sem a presença de moléculas de água ou então com a substituição dessas moléculas por ligantes orgânicos, o que torna o processo de transferência de energia mais vantajoso com um sensibilizador a mais no processo de transferência de energia.

\subsection{As $\beta$-dicetonas}

As estruturas conhecidas como $\beta$-dicetonas são compostos orgânicos que apresentam dois grupos carbonilas separados por um átomo de carbono ligado a duas ramificações. A fórmula estrutural das $\beta$-dicetonas é apresentada na FIG 3.5. 


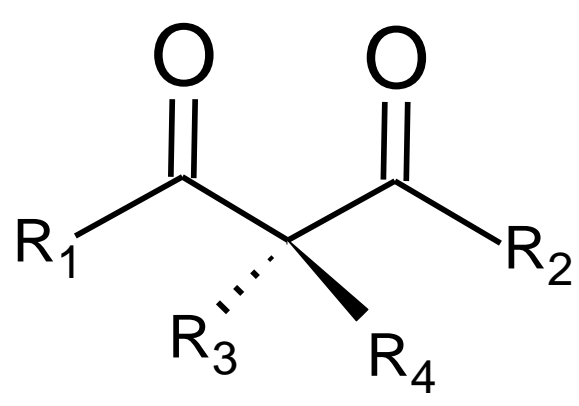

FIG.3.5: Fórmula estrutural das $\beta$-dicetonas.

Muitos são os compostos classificados como $\beta$-dicetonas, com diversos substituintes nas posições do grupo $R_{3}$ e $R_{4}$, ou seja, posições a.No entanto, no estudo dos complexos de $\beta$-dicetonas de $\mathrm{TR}^{3+}$ o enfoque dado tem sido em estruturas com átomos de hidrogênio na posição a. Para as posições $R_{1}$ e $R_{2}$ têm-se usado grupos alquil, fluoroalquil, aromáticos e heteroaromáticos ${ }^{[21]}$.

As estruturas de $\beta$-dicetonas possuem uma característica peculiar, que é o efeito ceto-enólico ou tautomerismo, representado na FIG 3.6.
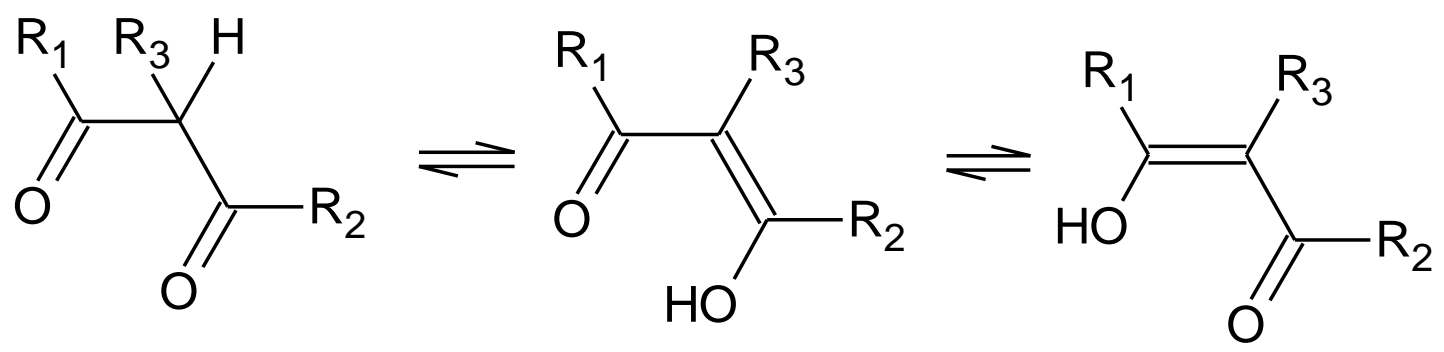

FIG.3.6: Equilibrioceto-enólico das $\beta$-dicetonas.

O tautomerismo ceto-enólico ocorre quando um ou dois substituintes na posição a $\left(R_{3}\right.$ e $\left.R_{4}\right)$ são um hidrogênio. No caso da forma enólica, tem-se tanto a forma trans como a forma cis, onde na forma cis-enólica ocorre à ligação de hidrogênio intramolecular entre o átomo de hidrogênio da função enol e o oxigênio da carbonila. A porcentagem relativa das formas cis e trans são diretamente influenciadas pelos grupos na posição $R_{1}$ e $R_{2}$, temperatura e o 
solvente do meio reacional. Em condições apropriadas, o átomo de hidrogênio participante da ligação de hidrogênio com o oxigênio da carbonila pode ser substituído por um cátion metálico, produzindo um anel de seis membros, favorecendo o deslocamento do equilíbrio ceto-enólico para a direita, o que favorece a conformação enólica, conforme mostrado na FIG 3.7.

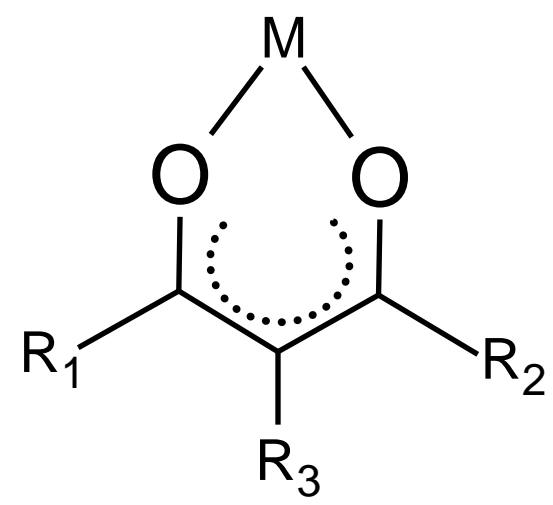

FIG.3.7: Representação do anel quelato para os complexos de $\beta$-dicetonas.

Muitos exemplos de $\beta$-dicetonas são citados na literatura ${ }^{[31-33]}$, no entanto, serão citados como exemplos apenas as duas $\beta$-dicetonas alvo deste trabalho: a acetilacetona (Hacac) e a 2-tenoiltrifluoracetona ( $\mathrm{Htta}$ ) apresentadas na FIG 3.8.

(a)
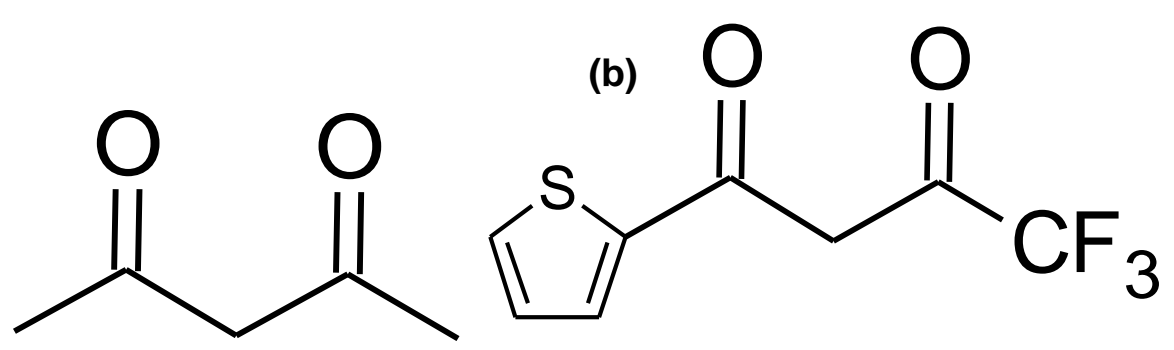

FIG.3.8: Estrutura do Hacac (a) e do Htta (b). 


\subsubsection{Os $\beta$-dicetonatos de Terras Raras}

Os ligantes $\beta$-dicetonas são excelentes quelatos para íons de transição $d$ e terras raras trivalentes, onde o grupo 1,3-dicarbonila apresenta um sítio de coordenação eficiente.

Os primeiros complexos de terras raras com $\beta$-dicetonas foram os acetilacetonatos, reportados por Urbain no final do século XIX ${ }^{[31]}$. Na década de 60 , vários estudos foram realizados sobre os $\beta$-dicetonatos de terras raras relatando os efeitos dos grupos substituintes e do tamanho do raio do íon metálico sobre as estabilidades desses complexos em solução. Estes estudos foram voltados para o desenvolvimento de técnicas de extração dos íons terras raras. De acordo com os valores de log $k$ para os derivados da acetilacetona, observou-se que estes valores aumentam com o tamanho do grupo alquila na presença de substituintes aromáticos.

A maioria dos complexos $\beta$-dicetonatos de terras raras são obtidos na forma de triscomplexos hidratados. No entanto, complexos anidros com fórmula $\operatorname{Sc}(\beta \text {-dicetonatos) })_{3}$ são geralmente sintetizados quando os grupos substituintes nos $\beta$-dicetonatos são relativamente grandes, como por exemplo o grupo t-butila. Os complexos tris(acetilacetonatos) podem também ser obtidos sob condições controladas, usando solventes anidros e ânion com baixa habilidade coordenante. A adição de um quarto ligante $\beta$-dicetonato na primeira esfera de coordenação formam os tetrakis-derivados ${ }^{[46]}$ e geralmente, envolvem ligantes com substituintes pequenos o suficiente para minimizar interações estéricas. Nestes casos, os complexos obtidos apresentam fórmulas $\mathrm{M}\left[\mathrm{TR}(\beta \text {-dicetonatos) })_{4}\right]$, onde $\mathrm{M}$ é geralmente um cátion $\mathrm{Li}^{+}, \mathrm{Na}^{+}, \mathrm{K}^{+}$ou um cátion orgânico.

\subsection{Nanopartículas poliméricas}

Nanotecnologia é a área que trabalha com materiais em escala nano, $\left(1 \mathrm{~nm}=10^{-9} \mathrm{~m}\right)$ situação em que as propriedades químicas, físicas e biológicas são diferenciadas tornando estes materiais de tamanho nanométrico, muito atrativo do ponto de vista de pesquisas, e, portanto com alta 
aplicabilidade em diversas áreas ${ }^{[34]}$. Normalmente classificam-se as nanopartículas como sólidos em um sistema coloidal com faixa de tamanho em torno de 100 a $1000 \mathrm{~nm}^{[35]}$.

O uso de nanopartículas poliméricas tem apresentado uma rápida expansão e se coloca com um papel importantíssimo em diversas áreas, como a eletrônica, meio ambiente, medicina, biotecnologia, entre outras. Este fato é facilmente percebido pelo crescente aumento de publicações sobre o assunto nos últimos anos ${ }^{[35]}$.

Uma das aplicações em prática de nanopartículas poliméricas se dá no processo de liberação de fármacos de forma controlada e com ação específica. Os polímeros biodegradáveis tem atraído a atenção para essa aplicação, uma vez que apresentam alta estabilidade em fluidos biológicos ${ }^{[36]}$. Essa interação com o meio biológico pode ser explicada pela capacidade da nanopartícula de possuir característica de sólido com alta superfície de contato e ao mesmo tempo, de molécula, em função da sua mobilidade ${ }^{[37]}$.

\subsubsection{Métodos de preparo de nanopartículas poliméricas}

A escolha de um polímero para síntese de nanopartículas leva em consideração a biodegradabilidade, ou seja, o processo natural na qual o polímero é convertido em moléculas mais simples no meio biológico; e a biocompatibilidade, que representa a interação efetiva do polímero com o meio biológico ${ }^{[38]}$. Pode-se citar os polímeros poli(ácido lático) (PLA), poli(cianoacrilato) (PCA) e poli(3-hidroxibutirato) (PHB), que já são estudados com aplicabilidade na síntese de nanopartículas ${ }^{[39]}$.

As nanopartículas podem apresentar dois tipos de estrutura: nanoesferas e nanocápsulas (FIG 3.9). Nanoesferas são estruturas onde o ativo (fármaco, complexo ou outros produtos) se encontra disperso de forma homogênea em toda partícula, inclusive em seu interior. As nanocápsulas apresentam o ativo envolto por uma capa, geralmente de material polimérico que mantém o isolamento do ativo em relação ao meio ${ }^{[40]}$. 

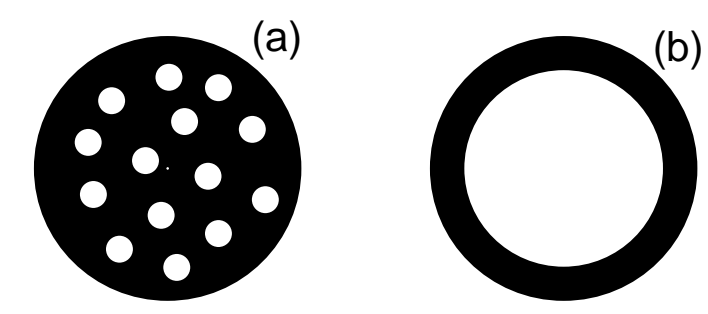

FIG.3.9: Representação esquemática de nanopartículas (a) e nanoesferas (b) poliméricas.

Classificam-se os métodos de preparação de nanopartículas ou nanocápsulaspoliméricas em dois grandes grupos, representados naFIG 3.10.
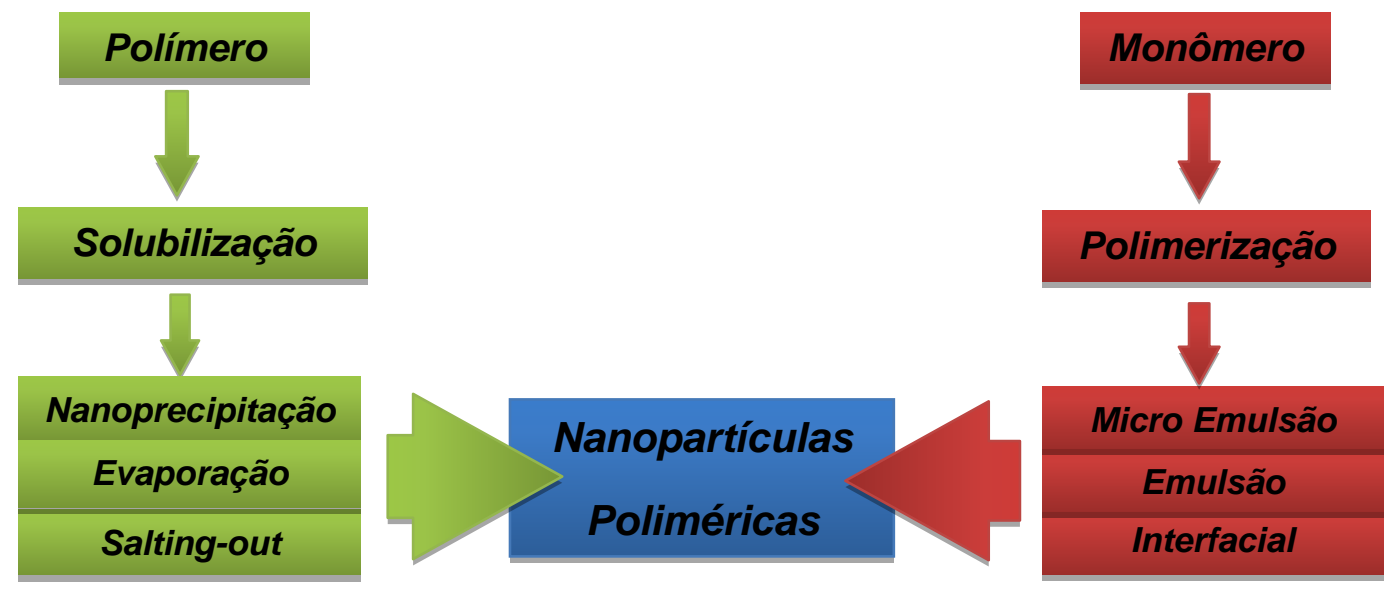

FIG.3.10: Representação esquemática dos principais métodos de preparação de nanopartículas poliméricas.

A técnica de evaporação de solvente foi um dos primeiros métodos utilizados para a síntese de nanopartículas poliméricas e embora tenha sido um método proposto por químicos, os farmacêuticos acabaram aprimorando a técnica, utilizando polímeros biodegradáveis para produção de medicamentos. Neste método, o polímero é solubilizado em um solvente orgânico, normalmente utiliza-se clorofórmio $\left(\mathrm{HCCl}_{3}\right)$, diclorometano $\left(\mathrm{H}_{2} \mathrm{CCl}_{2}\right)$ ou acetato de etila $\left(\mathrm{CH}_{3} \mathrm{COOCH}_{2} \mathrm{CH}_{3}\right)$. Cria-se uma emulsão de nanopartículas através de agitação vigorosa e elimina-se o solvente por evaporação. Com o auxílio de 
surfactantes, têm-se duas estratégias para a nanoemulsão: uma com a fase orgânica em água (emulsão $A / O$ ) utilizando um surfactante lipofílico; outra estratégia que pode ser adotada é a emulsão dupla $\mathrm{A} / \mathrm{O}$ em outra fase aquosa (emulsão A/O/A) com o auxílio de um surfactante hidrofílico ${ }^{[35]}$.

É possível ter um maior controle do tamanho de partícula através do controle de alguns parâmetros como viscosidade, velocidade de agitação e estabilizador da solução. A homogeneização do sistema é um parâmetro importante, uma vez que as gotículas formadas, após secagem, darão forma e tamanho à partícula polimérica, de modo que o auxílio de ultrassonicadores ou microfluidizadores tornam-se indispensável para obtenção de gotículas cada vez menores ${ }^{[41-42]}$.

Outro parâmetro importante para ser considerado com relação ao tamanho de partícula se refere à tensão interfacial na formação da nanopartícula de modo que quanto menor a tensão interfacial da fase orgânica, menor o tamanho da partícula ${ }^{[43]}$.

$\mathrm{Na}$ técnica de nanoprecipitação, tem-se uma fase interna constituída de um solvente orgânico polar, como a acetona, e o polímero dissolvido nesse solvente além de um agente tensoativo para inibir a coalescência de gotículas. Esse solvente orgânico se encontra disperso em uma fase externa e aquosa contendo outro tensoativo, como o PVA ou poloxâmer e com o auxílio de agitação magnética, cria-se uma emulsão. E, utilizando um sistema de pressão reduzida, remove-se o solvente orgânico, formando nanopartículas decorrente da difusão rápida do solvente através da fase aquosa ${ }^{[44]}$.

A técnica de salting-out é uma modificação do método de emulsificação com difusão de solvente. Nesta técnica a fase orgânica é emulsificada em uma pequena quantidade de água contendo um agente salting-out. Em seguida, um excesso de água é adicionado ao sistema para que ocorra a difusão do solvente, promovendo a deposição do polímero para formação das nanopartículas ${ }^{[4]}$.

O método de emulsão a partir da polimerização de um monômero é um dos processos mais rápidos para obtenção de nanopartículas poliméricas. 
O método pode ser dividido em duas categorias, de acordo com o uso de um solvente orgânico ou aquoso em fase contínua. No caso de uma fase orgânica, o monômero é disperso em uma emulsão ou uma micro-emulsão ou ainda em um material onde o monômero não é solúvel, sempre com o auxílio de um agente dispersante. No caso da fase aquosa contínua, o monômero é dissolvido em uma solução aquosa, sem necessidade de agentes emulsionantes. O processo de polimerização se inicia por ativação por catalisador ou através de alta energia (ultravioleta ou luz visível) ${ }^{[46]}$.

\subsubsection{Secagem por liofilização}

Como já comentado, a área farmacêutica possui um estudo aprofundado e diversificado sobre a síntese de nanopartículas poliméricas com função para carreadores de fármacos em meio biológico. A partir desse estudo, alguns problemas são relatados, principalmente no que se refere à estocagem por um longo período de tempo da suspensão de nanopartículas, onde são evidenciados problemas como a degradação do polímero e perda gradativa do ativo para o meio, provocando alterações em propriedades físico-químicas da suspensão ${ }^{[47-48]}$.

Uma alternativa interessante em relaçãoà manutenção da estrutura das nanopartículas poliméricas ao longo do tempo é o processo de liofilização, que consiste na sublimação da água pela redução da pressão do sistema. A amostra é congelada com auxílio de nitrogênio líquido e submetida a redução de pressão. Nestas condições, aágua passa do estado sólido para gás diretamente. No caso específico para nanopartículas, a secagem por congelamento acaba levando a um produto final com tamanho de partícula maior do que aquele encontrado quando o sistema estava em suspensão, ou seja, ocorre um processo de aglomeração ao longo da secagem. Desse modo, dados na literatura mostram o uso de crioprotetores, que são aditivos adicionados antes do congelamento e que inibem a aglomeração das partículas ao longo do processo de liofilização ${ }^{[47]}$. 
O grupo dos sacarídeos tem se apresentado como uma boa alternativa como agentes de crioproteção, gerando bons resultados. Esses aditivos, como sacarose e glicose, se apresentam como uma boa alternativa na criação de um espaçamento entre as matrizes poliméricas das nanopartículas, a fim de impedir uma possível agregação. Existe uma variedade grande de sacarídeos potenciais para essa aplicação, apresentando inclusive, bons resultados. No entanto, o mecanismo pelo qual se dá essa crioproteção ainda é incerta $^{[47]}$.

\subsubsection{Funcionalização}

Uma das características do uso de nanopartículas como marcador para imunoensaios associado a um polímero biodegradável consiste na sua facilidade de interação com o meio biológico. Esse fato pode ser melhorado ou especificado para um determinado sítio, através do uso do procedimento de funcionalização da superfície da partícula com ativos que facilitem o contato da partícula com o meio ou até mesmo, torne específica uma determinada ação, como por exemplo, uma marcação. Um exemplo clássico é o uso de polímeros hidrofílicos, tais como o polietileno glicol (PEG) ${ }^{[49]}$. Na FIG 3.11 é apresentado um esquema de funcionalização e aplicação de uma nanopartícula polimérica.
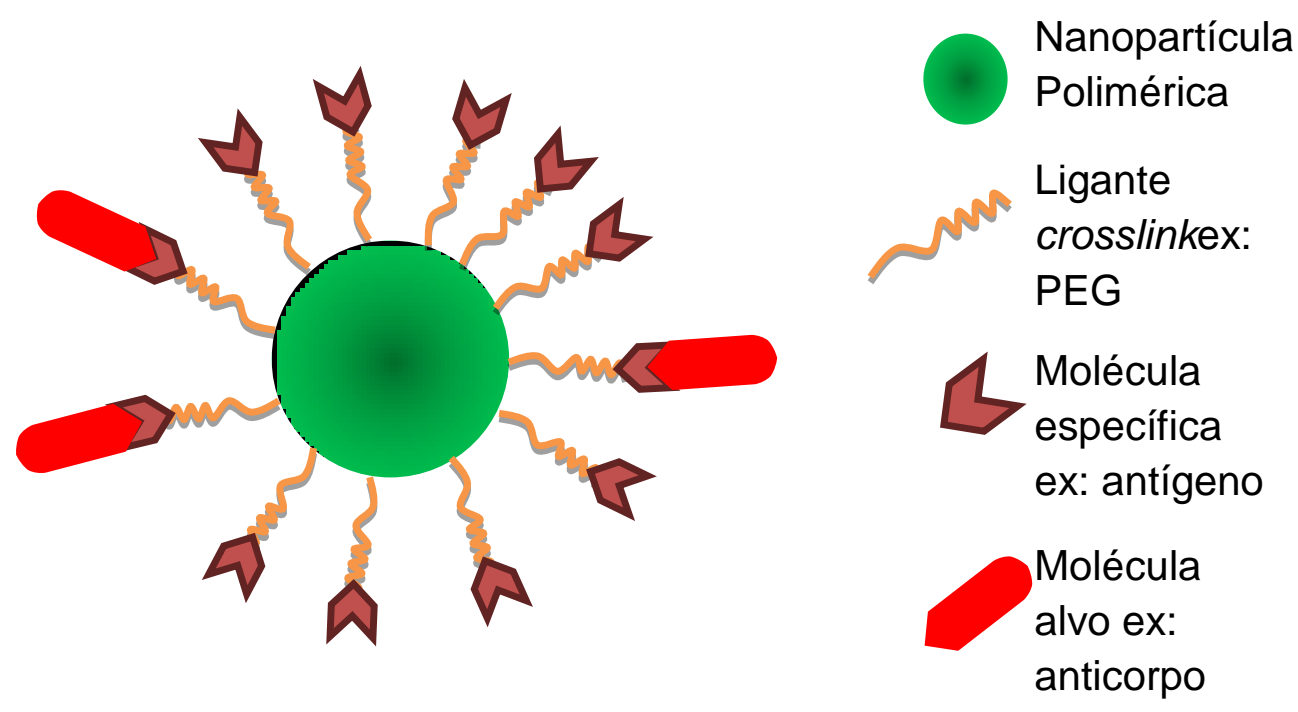

FIG.3.11: Esquema de uma nanopartícula polimérica funcionalizada. 
É relevante enfatizar o potencial das técnicas de funcionalização na aplicação em diversas áreas. Uma interessante ferramenta analítica ou bioanalítica consiste no ajuste de propriedades específicas de um material, aumentando sua biocompatibilidade. Em associação com variações ópticas, fazem surgir biomateriais com a função de marcadores, por exemplo, luminescentes. Esses dados trazem boa perspectiva no uso de nanopartículas funcionalizadas, para uma melhora significativa em exames de diagnóstico para câncer e outras doenças. $O$ estudo aprofundado dessas particularidades em meio biológico, tão complexo, irá inevitavelmente ter papel de destaque no futuro da nanotecnologia ${ }^{[50]}$.

\subsection{Polímero PHB (poli-3-hidroxibutirato)}

O (PHB) é um dos polímeros da família dos poli-hidroxialcanoatos (PHA) e sua estrutura é apresentada na FIG 3.12. Trata-se de um poliéster sintetizado a partir de micro-organismos com a função de reserva de carbono e energia, cuja cadeia linear se apresenta saturada e com apenas átomos de carbono, hidrogênio e oxigênio ${ }^{[24]}$.<smiles>CC(C)CC(=O)OC1CC1</smiles>

FIG.3.12: Fórmula estrutural do polímero PHB.

O PHB faz parte de uma classe de biopolímeros que apresenta grande diversidade, com mais de 100 monômeros identificados como constituintes dos PHA. Dentre esses diversos tipos de PHA que podem ser produzidos, destacam-se como os mais produzidos e estudados, o PHB e o poli-hidroxibutirato-co-hidroxivalerato (PHB-co-HV) ${ }^{[51]}$.

O PHB é produzido por uma bactéria, Alcaligeneseutrophorus, na forma de grânulos a partir da glicose e sacarose. O polímero é totalmente 
degradado, com geração de gás carbônico e convertido a biomassa por microorganismos $^{[52]}$.

Além de serem biodegradáveis, possuem outra importante característica, como a biocompatibilidade, tornando-o apto para aplicações na área médico-farmacêutica, através da fabricação de fios de sutura, próteses ósseas, suportes de culturas de tecidos para implantes e também para a encapsulação de fármacos para liberação controlada ${ }^{[53]}$.

O PHB é solúvel em solventes apolares como o clorofórmio e insolúvel em água. Possui limitações para uso como plástico comercial por ser um material semicristalino, dificultando seu processamento por ser quebradiço. Algumas das propriedades físico-químicas do PHB são a temperatura de fusão, em torno de $175^{\circ} \mathrm{C}$, massa molecular em torno de $5.10^{5} \mathrm{~g} \mathrm{moL}^{-1}$, temperatura de transição vítrea em torno de $4^{\circ} \mathrm{C}$ e densidade de $1,25 \mathrm{~kg} \mathrm{~m}^{-3[24]}$.

\subsection{Biomarcadores luminescentes}

A detecção de agentes químicos ou biológicos constitui um dos mais importantes alvos de estudo na área médica, forense, química e ambiental. Dessa forma, o desenvolvimento de biomarcadores tem tido um grande avanço na busca de técnicas mais sensíveis na detecção de doenças de forma a melhorar e antecipar terapias mais efetivas para cura ${ }^{[54]}$.

O sistema de detecção pelo uso de biomarcadores se baseia no sucesso de duas etapas fundamentais: a funcionalização do biomarcador de modo a torná-lo específico e após a especificidade, a forma como irá marcar o alvo ativo e transmitir o sinal dessa marcação. A eficiência dessas etapas está diretamente ligada a forma de resposta, o sinal emitido, sensibilidade e seletividade do método ${ }^{[54]}$.

Nanopartículas (NPs) possuem grande potencial no uso como biomarcadores, pois apresentam propriedades físico-químicas diferenciadas, tornando-as uma ferramenta inovadora nos métodos de detecção de ativos químicos e biológicos. Nos últimos anos, nanopartículas de metais nobres, 
quantum dots e nanopartículas magnéticas têm-se apresentado como uma alternativa na detecção de íons metálicos, pequenas moléculas e proteínas ${ }^{[54]}$. Além disso, nanopartículas poliméricas têm atraído a atenção em função da capacidade de funcionalização através da imobilização de biomoléculas para aplicações biomédicas como a liberação controlada de fármacos e a engenharia de tecidos ${ }^{[55]}$.

No que se refere ao uso dos complexos de terras raras como biomarcadores luminescentes para atuação em ensaios biomédicos, pode-se citar o uso de isótopos de $\mathrm{Sm}^{3+}$ em ressonância magnética, clivagem específica de DNA ou RNA e detecção de diversos analítos. Alguns complexos de $\mathrm{Eu}^{3+}$ foram utilizados como agentes neurotóxicos para monitoramento de bioterrorismo. No entanto, a aplicação dos complexos de $\mathrm{Eu}^{3+} \mathrm{e} \mathrm{Tb}^{3+}$ em ensaios bionalíticos de diagnóstico representam a maior demanda nessa área. Como exemplo pode-se citar o teste DELFIA (Dissociation-Enhanced Lanthanide Fluorescent Immunoassay) (FIG.3.13) cuja aplicação pode ser verificada em ensaios para diabetes, análise de sulfonamidas e proteínas ${ }^{[56]}$.

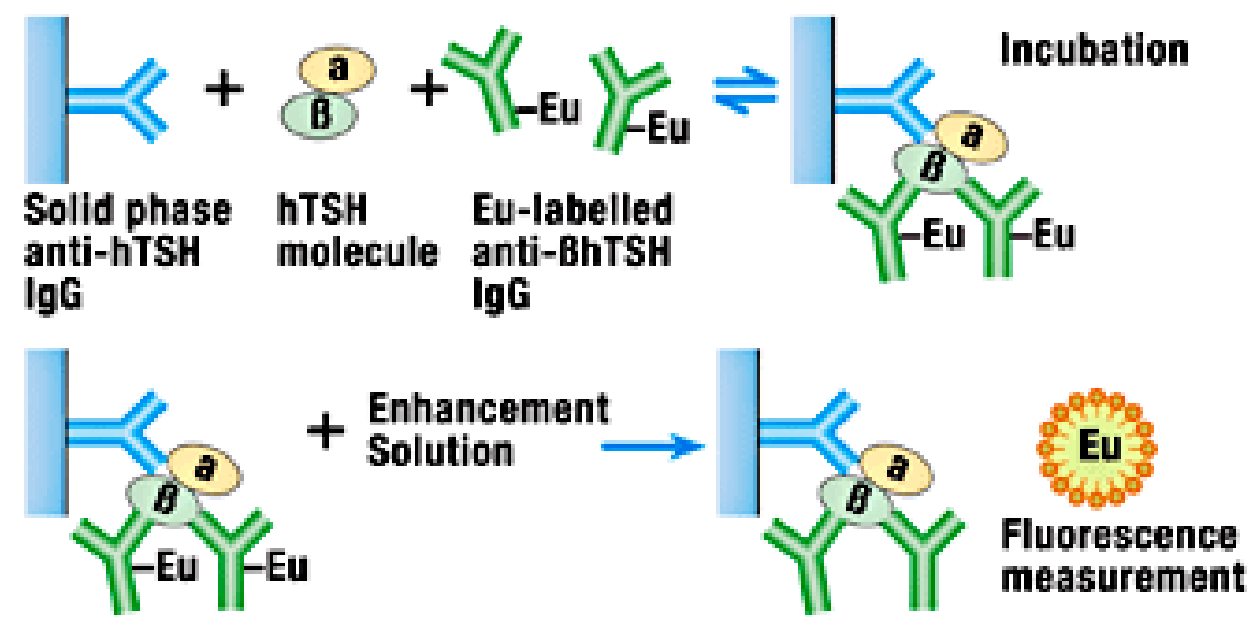

FIG.3.13: Exemplo esquemático de um teste DELFIA. Imagem Perkin Elmer 


\subsection{Doença de Chagas}

A doença de Chagas, provocada pela ação do agente etiológico Trypanosoma cruzi, 1909, é responsável pela infecção de cerca de 18 milhões de pessoas em 15 países endêmicos da América Latina. Além disso, estima-se que aproximadamente 120 milhões de pessoas estão sob risco de infecção ${ }^{[57]}$.

A doença é transmitida, principalmente, por insetos hematófagos, conhecidos como barbeiros. No entanto, existem outras formas de contaminação, tais como transfusão de sangue, congênita, via oral, transplante de órgãos contaminados e acidentes de laboratórios ${ }^{[58]}$.

A doença é dividida em duas fases: aguda e crônica. Na fase aguda, que costuma durar de um a três meses, ocorre uma intensa parasitemia. Tratase de uma fase sintomática ou assintomática. Na maioria dos casos, o infectado não apresenta nenhum sintoma característico nessa fase da doença. A fase crônica inicia-se cerca de dois a quatro meses após o término da fase aguda. Essa fase caracteriza-se pela ausência de parasitas e abundância de anticorpos ${ }^{[58]}$.A doença pode evoluir para a forma cardíaca, digestiva, mista (cardíaca + digestiva) e indeterminada ${ }^{[59]}$.

\subsubsection{Métodos laboratoriais de diagnóstico da doença de Chagas}

O diagnóstico da doença de Chagas leva em consideração o fator clínico do paciente e o diagnóstico laboratorial, onde o segundo tem grande relevância uma vez que apenas $5 \%$ dos infectados apresentam algum tipo de sintoma característico da doença ${ }^{[60]}$.

O diagnóstico laboratorial costuma ser realizado através de métodos parasitológicos diretos e/ou indiretos ou ainda através de métodos sorológicos, cada qual com especificidade e sensibilidade distintas em função da metodologia ou da fase da doença. O método sorológico é o mais utilizado, onde os principais são a ELISA (Enzyme Linked Immunossorbent Assay), Hemoaglutinação Indireta (HAI) e a Imunofluorêscencia Indireta (IFI) ${ }^{[59-60]}$.

O teste HAl tem como base a aglutinação entre as hemácias ligadas ao antígeno de Trypanosoma cruzi em meio ao soro contendo anticorpos 
contra esse parasita. Trata-se de uma técnica muito utilizada em função de baixo custo e simplicidade, porém, além de uma leitura subjetiva, ocorrem reações cruzadas com outras parasitoses, como com Leishmanioses ${ }^{[59]}$.

A interação entre o Trypanosoma cruzi e uma anti-imunoglobulina ligada ao isotiocianato de fluoresceína, onde a ligação entre antígenoanticorpo se dá por meio da fluorescência do parasita é a base para o teste de IFI. Nesse caso, a leitura é realizada através de um microscópio de fluorescência. Trata-se de um método sensível, análise em grande número de amostras e obtenção de reagentes padronizados. No entanto, possui baixa especificidade e ocorrência de reações cruzadas em baixas concentrações de anticorpo ${ }^{[59]}$.

No teste ELISA são utilizados anti-imunoglobulinas ligados a uma enzima, que na presença do anticorpo gerado pela presença do parasita, forma um complexo colorido que pode ser mensurado através da absorbância ou densidade óptica. O teste apresenta vantagens como elevada sensibilidade, necessidade de pouca amostra, muitas amostras podem ser analisadas em paralelo além da possibilidade de espectrofotômetros portáteis. No entanto, o método não possui especificidade quando se utilizam antígenos brutos ou semi-purificados ${ }^{[59]}$.

\subsubsection{Antigenos Recombinantes}

Através do método de DNA recombinantes é possível expressar e produzir em microrganismos adequados proteínas heterólogas. O método consiste em introduzir o DNA de um microorganismo em outro microorganismo de modo que o segundo seja "transformado" e passe a produzir esse DNA como se fosse seu ${ }^{[59]}$.

A resposta imune e o potencial diagnóstico desses antígenos foram estudados por diversos autores. Os mesmos propõem o uso de proteínas puras e quimicamente definidas para uso em diagnósticos uma vez que o mesmo é especifico ao parasita e, portanto, sua interação com o anticorpo é bem sucedida ${ }^{[59]}$. 


\section{REFERÊNCIAS BIBLIOGRÁFICAS}

[1] MARTINS, T. S.; ISOLANI, P. C. Terras Raras: Aplicações industriais e biológicas. Química Nova, v. 28, n. 1, p. 111-117, 2005.

[2] SANTOS, E. G. D. Desenvolvimento de nanomarcadores para serem utilizados na marcação de hemoglobina S (anemia falciforme). 2009. Dissertação (Mestrado) - Instituto de Pesquisas Energéticas e Nucleares - IPEN,São Paulo.

[3] LEE, J. D. Química Inorgânica não tão Consisa. São Paulo: Edgard Blücher Ltda, 1999.

[4] CHOPPIN, G. R.; PETERMAN, D. R. Applications of lanthanide luminescence spectroscopy to solution studies of coordination chemistry. Coordination Chemistry Reviews, n. 174, p. 283-299, 1998.

[5] JUDD,B. R. Optical Absorption Intensities of Rare-Earth lons.Physics Reviews, 127:750, 1962.

[6] G. S. Ofelt. Intensities of Crystal Spectra of Rare-Earth lons, Journal of Chemical Physics, 37:511-520, 1962.

[7] BRITO, H. F. ; MALTA, O. L. ;FELINTO, M. C. F.; TEOTONIO, E. E. S...Luminescence phenomena involving metal enolates. In: Jacob Zabicky. (Org.). The Chemistry of Metal Enolates, Part 1. Chichester: John Willey \& Sons Ltd., Publication, 2009, v. 01, p. 131-184.

[8] CARLOS, L. D. ; MALTA, O. L.Polarizabilidade da região de recobrimento da ligação química: uma escala de covalência para compostos de ions lantanídeos. Avanços nas ciências físicas: um volume em honra do professor António Luciano Leite Videira. Aveiro: Universidade de Aveiro Theoria poiesispraxis,v. , p. 33-41. 2008

[9] FERREIRA, RUTE A. S. ; NOLASCO, MARIELA ; ROMA, ANA C.; LONGO, RICARDO L.; MALTA, OSCAR L. ; CARLOS, LUIS D. . Dependence of the Lifetime upon the Excitation Energy and Intramolecular Energy Transfer Rates: The ${ }^{5} \mathrm{D}_{0} \mathrm{Eu}$ III Emission Case. Chemistry - A European Journal, 2012. 
[10] FAUSTINO, W. M. ;ROCHA, G. B.; MALTA, O. L. ;SÁ, G. F.; SIMAS, A. M.; SILVA, F. R. G. E. . Design of Ligands to Obtain Lanthanide Ion Complexes Displaying High Quantum Efficiencies of Luminescence Using the Sparkle Model. Journal of Molecular Structure.Theochem, Holanda, v. 527, p. 245-251, 2000.

[11] SÁ, G. F.; MALTA, O. L. ;DONEGÁ, C. M.; SIMAS, A. M. ; LONGO, R. L.; SANTA CRUZ, P. A.; SILVA JR, E. F.. Spectroscopic Properties and Design of Highly Luminescent Lanthanide Coodination Complexes. Coordination Chemistry Reviews, Holanda, v. 196, p. 165, 2000.

[12] M. A. GUEDES ; T. B. PAOLINI ; M. C. F. C. FELINTO ; J. KAI ;L. A. O. NUNES ;MALTA, O. L. ;BRITO, H. F.. Synthesis, characterization and spectroscopic investigation of new tetrakis (acetylacetonato) thulate(III) complexes containing alkaline metals as counter cations. Journal of Luminescence, v. 131, p. 99-103, 2011.

[13] KODAIRA, C. A. ; LOURENÇO, A. V. S.; M. C. F. C. FELINTO ; SANCHEZ, E.M.R.; RIOS, F.J.O. ; L. A. O. NUNES ; Gidlund, M. ; MALTA, O. L. ; BRITO, H. F.. Biolabeling with nanoparticles based on $\mathrm{Y}_{2} \mathrm{O}_{3}: \mathrm{Nd}^{3+}$ and luminescence detection in the near-infrared. Journal of Luminescence, v. 131, p. 727-731, 2011.

[14] J. KAI ; M. C. F. C. FELINTO ; L. A. O. NUNES ; MALTA, O. L. ; BRITO, H. F. . Intermolecular energy transfer and photostability of luminescencetuneable multicolour PMMA films doped with lanthanide $\beta$-diketonate complexes. Journal of Materials Chemistry (Print), v. 21, p. 3796-3802, 2011.

[15] Lourenço, A. V. S.; KODAIRA, C. A.; Souza, E. R. ; M. C. F. C. Felinto ; MALTA, O. L. ; BRITO, H. F.. Preparation and photoluminescence properties of functionalized silica materials incorporating europium complexes.Optical Materials (Amsterdam. Print), v. 33, p. 1548-1552, 2011.

[16] MALTA, O. L. . Mechanisms of non-radiative energy transfer involving lanthanide ions revisited. Journal of Non-Crystalline Solids, v. 354, p. 4770-4776, 2008.

[17] FELINTO, M. C. F. C.; TOMIYAMA, C. ; BRITO, H. F.; TEOTÔNIO, E. E. S.; MALTA, O. L. . Synthesis and Luminescent Properties of Supramolecules of B-diketonates of Eu(III) and Crown Ethers as Ligands. Journal of Solid State Chemistry, USA, v. 171, p. 189, 2003.

[18] TEOTONIO, E. E. S.; BRITO, H. F.; VIETLER, H. ; FAUSTINO, W. M. ; MALTA, O. L. ; SÁ, G. F. ; FELINTO, M. C. E. C. ; SANTOS, R. H. A. ; CREMONA, M.. Synthesis and luminescence properties of rare earth complexes with 2-acyl-1,3-indandionates and TPPO ligands: the first $X$ ray structure of a 2-acyl-1,3 indandionate rare earth complex. Polyhedron, Inglaterra, v. 25, n.00, p. 3488-3494, 2006. 
[19] CARNALL, W. T.; GOODMAN, G. L.; RAJNAK, K.; RANA, R. S. A systematic analysis of the spectra of the lanthanides doped into single cristals of $\mathrm{LaF}_{3}$. Journal of Chemical Physics.v.90(7), p.3443-3447, 1989.

[20] LATVA, M.; TAKALO, H.; MUKKALA, V. M.; MATACHESCUC, C.; RODRIGUEZ-UBISD, J. C.; KANKARE, J. Correlation between the lowest triplet state energy level of the ligand and lanthanide (III) luminescence quantum yield. Journal of Luminescence, V.75, p.149179, 1997.

[21] GUEDES, M. A. Comportamento fotoluminescente dos ânions complexos tetrakis(b-dicetonatos) de íons terras raras - $\mathrm{Eu}^{3+}, \mathrm{Gd}^{3+}, \mathrm{Tb}^{3+}$ e $\mathrm{Tm}^{3+}$. 2007. Tese (Doutorado) - Universidade de São Paulo, São Paulo

[22] BUNOCORE, G. E.; LI, H.; MARCINIAK, B. Quenching of excited states by lanthanide ion and chelates in solutions. Coordination Chemistry Reviews, v. 99, p. 55-57, 1990.

[23] WEISSMAN, S. I. Intramolecular Energy Transfer. The Fluorescence of Complexes of Europium. Journal of Chemical Physics., V.10, p.214217, 1942.

[24] KAl, J. Desenvolvimento de sistemas luminescentes à base de polímeros PHB e PMMA dopados com complexos terras raras. 2009 Tese (Doutorado) - Universidade de São Paulo, São Paulo.

[25] CROSBY, G.A.; ALIRE, R. M.; WHAN, R. E. Intramolecular energy transfer in rare earth chelates - role of tripletstate. Journal of Chemical Physics,v.34(3), p.743-748, 1961.

[26] SILVA F.; MALTA O. L. Calculation of the ligand-lanthanide ion energy transfer rate in coordination compounds: contributions of exchange interactions.Journal of Alloys and Compounds,v.250(1-2), p.427-430, 1997.

[27] FILIPESCU N.; SAGER, W. F.; SERAFIN, F.A. Substituent effects on intramolecular energy transfer. 2. Fluorescence spectra of Europium + Terbium Beta-Diketone chelates. Journal of Chemical Physics,v.68(11), p.3324-3346, 1964.

[28] SATO S.; WADA, M. Relations between intrmolecular energy transfer efficiencies and triplet state energies in rare earth beta-diketone chelates. Bulletin of the Chemical Society of Japan,v.43(7), p.1955-1962, 1970.

[29] FAUKNER T. R.; RICHARDSON, F. S. Vibronic coupling model for intensities of $f-f$ transitions in octahedral lanthanide (III) complexes. Molecular Physics.V.35(4), p.1141-1161, 1978. 
[30] SALAMA S.; RICHARDSON, F. S. Influence of ligand N-H oscillators vs $\mathrm{O}-\mathrm{H}$ oscillators on the luminescence decay constants of Terbium (III) complexes in aqueous-solution. Journal of Chemical Physics.V.84(5), p.512-517, 1980.

[31] TEOTONIO, E. E. S. Síntese e investigação das propriedades fotoluminescentes de dispositivos moleculares conversores de luz (DMCL) de complexos dicetonatos de terras raras com ligantes amidas.2004 - Tese (Doutorado) - Universidade de São Paulo, São Paulo.

[32] BINNEMANS, K. Rareearth beta-diketonates. Handbook on the Physics and Chemistry of Rare Earths.Elsevier, 2005.

[33] MEHROTRA, R. C.; BOHRA, R.; GAUR, D. P. Metal beta-diketonates and allied derivatives. London: Academic Press, 1978.

[34] KARAKOTI, A. S.; DAS, S.; THEVUTHASAN, S.; SEAL, S.PEGylated Inorganic Nanoparticles. Angewandte Chemie, p.1980 - 1994, 2011

[35] RAO, J. P.; GECKELER, K. E. Polymer nanoparticles: Preparation techniques and size-control parameters. Elsevier. p.887-913, 2011

[36] SCHAFFAZICK, S. R.; GUTERRES, S. S.; FREITAS, L. L.; POHLMANN, A. R. Caracterização e estabilidade físico-química de sistemas poliméricos nanoparticulados para administração de fármacos. Quimica Nova, v. 26, n.5,p.726-737. 2003.

[37] STARK, W. J. Nanoparticles in Biological Systems. Angewandte Chemie. 1242-1258, 2011.

[38] LINS, L. C. V. Obtenção e caracterização de micropartículas de PHB/Qt/Cetoprofeno. Relatório - UFSC. Florianópolis. 2010.

[39] SOPPIMATH, K. S.; AMINABHAVI, T. M.; KULKARNI, A. R.; RUDZINSKI, W. E. Biodegradable polymeric nanoparticles as drug delivery devices. Elsevier. p.1 - 20, 2001

[40] GASPARI, P. D. M.Preparação e caracterização de micro e nanopartículas poliméricas contendo estreptomicina.2006 - Dissertação (Mestrado) - Universidade Estadual de Campinas - UNICAMP, Campinas.

[41] SILVA, C.; RIBEIRO, A.; FERREIRA, D.; VEIGA, F. Administração oral de peptídeos e proteínas: II. Aplicação de métodos de microencapsulação. Revista Brasileira de Ciências Farmacêuticas, v. 39, n.1, p.1-20, 2003.

[42] POHLMANN, A. R.; POLETTO, F. S.; FIEL, L. A.; DONIDA, B.; RÉ, M. I.; GUTERRES, S. S. Controlling the size of poly(hydroxybutyrate-cohydroxyvalerate) nanoparticles prepared by emulsification-diffusion technique using ethanol as surface agent. Colloids and Surfaces A: Physicochemical and Engineering Aspects, v. 324, p.105-112, 2008. 
[43] LARA, V. C. D. Desenvolvimento de nanocapsulas contendo ácido retinóico para tratamento tópico de acne.2008 - Dissertação (Mestrado) - Universidade Federal de Minas Gerais, Belo Horizonte.

[44] SOUTO, E. ; SEVERINO, P.; SANTANA, M. H. A. Preparação de Nanopartículas Poliméricas a partir de Polímeros Pré-Formados - Parte II. Polimeros, São Carlos, v. 22, n.1, p.101-106, 2012.

[45] GOTO, P. L. Desenvolvimento de nanopartículas poliméricas por polimerização in situ a partir de nanoemulsões produzidas por inversão de fases.2011 - Dissertação (Mestrado) - Universidade Federal de Ouro Preto, Ouro Preto.

[46] NEUFELD, R. J.; REIS, C. P.; RIBEIRO, A. J.; VEIGA, F. Nanoencapsulation I. Methods for preparation of drug-loaded polymeric nanoparticles. Nanomedicine: Nanotechnology, Biology, and Medicine, v.2, p.8-21, 2005.

[47] MOLPECERES, J.; SAEZ, A.; GUZMÁN, M.; ABERTURAS, M. R. Freeze-drying of polycaprolactone and poly(d,I-lactic-glycolic) nanoparticles induce minor particle size changes affecting the oral pharmacokinetics of loaded drugs. European Journal of Pharmaceutics and Biopharmaceutics, v.50, p.379-387, 2000.

[48] QIAN, Y.; ZHANG, L.; LIU, L.; CHEN, Y. The effects of cryoprotectants on the freeze-drying of ibuprofen-loaded solid lipid microparticles (SLM).European Journal of Pharmaceutics and Biopharmaceutics, v. 69, p. 750-759, 2008.

[49] PANYAM, J.; PATIL, Y. B.; TOTI, U. S.; KHDAIR, A.; MA, L. Single-step surface functionalization of polymeric nanoparticles for targeted drug delivery. Biomaterials, v. 30, p.859-866, 2009.

[50] KNOPP, D.; TANG, D.; NIESSNER, R. Review: Bioanalytical applications of biomolecule-functionalized nanometer-sized doped silica particles. Analytica Chimica Acta, v. 647, p.14-30, 2009.

[51] MENDES, A. A. Seleção de suportes e protocolos de imobilização de lipases para a síntese enzimática de biodiesel. 2009 - Tese (Doutorado) - Universidade Federal de São Carlos.

[52] ROSA, D. D. S.; PENTEADO, D. F.; CALIL, M. R. Propriedades Térmicas e Biodegradabilidade de PCL e PHB em um Pool de Fungos. Revista de Ciência \& Tecnologia, v. 15, p.75-80, 2000.

[53] ARAGÃO, G. M. F. D.; SQUIO, C. R. Estratégias de cultivo para a produção dos plásticos biodegradáveis Poli(3-Hidroxibutirato) e Poli(3Hidroxibutirato-co-3-Hidroxivalerato) por bactérias. Quimica Nova. v. 27, n. 4, p. 615-622, 2004.

[54] AGASTI, S. S.; RANA, S.; PARK, M-H.; KIM, C. K.; YOU, C. C.; ROTELLO, V. M. Nanoparticles for detection and diagnosis. Advanced Drug Delivery Reviews, v. 62, p.316-328, 2010 
[55] TIAN, H.; TANG, Z.; ZHUANG, X.; CHEN, X.; JING, X.;. Biodegradable synthetic polymers: Preparation, functionalization and biomedical application. Progress in Polymer Science, v. 37, p. 237-280, 2012.

[56] HEMMILA, I.; LAITALA, V. Progress in Lanthanides as Luminescent Probes. Journal of Fluorescence, v. 15, p. 529-542, 2005.

[57] VERÇOSA, A.F.A. Caracterização do perfil isotípico das imunoglobulinas $G$ de indivíduos chagásicos frente aos antígenos recombinantes CRA e FRA de Trypanossoma Cruzi. 2006 - Dissertação (Mestrado) Fiocruz, Recife.

[58] LORENA, V.M.B. Avaliação da resposta imune celular de pacientes chagásicos após estímulo in vitro com os antígenos recombinantes CRA e FRA de Trypanosoma cruzi. 2006 - Dissertação (Mestrado) Fiocruz, Recife.

[59] GADELHA, A.A.M. Avaliação do Desempenho do "Kit" EIERecombinante-Chagas-Biomanguinhos Frente ao ELISA Convencional e ao Teste de Hemaglutinação Indireta. 2003 - Dissertação (Mestrado) Fiocruz, Recife.

[60] GIRARDI, F.P. Avaliação da imunoreatividade cruzada entre diferentes formas parasitárias de Trypanossoma Cruzi e Trypanossoma Rangeli. 2004 - Dissertação (Mestrado), Universidade Federal de Santa Catarina, Florianópolis. 
4

\section{MATERIAIS E MÉTODOS}




\section{MATERIAIS E MÉTODOS}

\subsection{Reagentes e Solventes}

Neste trabalho foram sintetizados os cloretos de terras raras $\left(\mathrm{TRCl}_{3} \cdot \mathrm{xH}_{2} \mathrm{O}\right.$ onde $\mathrm{TR}=\mathrm{Eu}^{3+}, \mathrm{Tb}^{3+}, \mathrm{Sm}^{3+}$ e $\left.\mathrm{Gd}^{3+}\right)$ a partir dos respectivos óxidos de terras raras. Desses cloretos, foram preparados os compostos de coordenação com os $\beta$-dicetonatos ( $\mathrm{acac}^{-}$e tta ${ }^{-}$). As nanopartículas foram preparadas utilizando o polímero PHB (poli-3-hidroxibutirato) misturado com os complexos precursores sintetizados. Todos os reagentes e solventes relacionados na TAB 4.1 foram usados nos processos citados sem tratamento prévio.

TAB4.1: Reagentes e solventes utilizados nos experimentos.

\begin{tabular}{lcc}
\hline \multicolumn{1}{c}{ Composto } & Fórmula & Procedência \\
\hline Óxido de európio 99,99\% & $\mathrm{Eu}_{2} \mathrm{O}_{3}$ & Merck \\
Óxido de gadolínio 99,99\% & $\mathrm{Gd}_{2} \mathrm{O}_{3}$ & Merck \\
Óxido de samário 99,99\% & $\mathrm{Sm}_{2} \mathrm{O}_{3}$ & Merck \\
Óxido de térbio 99,99\% & $\mathrm{Tb}_{4} \mathrm{O}_{7}$ & Merck \\
Ácido clorídrico 37\% & $\mathrm{HCl}$ & Synth \\
Ácido nítrico 63\% & $\mathrm{HNO}_{3}$ & Dinâmica \\
Ácido acético glacial & $\mathrm{H}_{3} \mathrm{CCOOH}$ & Dinâmica \\
Peróxido de hidrogênio 50\% & $\mathrm{H}_{2} \mathrm{O}_{2}$ & Synth \\
Hidróxido de amônio P.A. & $\mathrm{NH}_{4} \mathrm{OH}$ & Dinâmica \\
Hidróxido de sódio P.A. & $\mathrm{NaOH}$ & Quimbras \\
Acetato de Sódio & $\mathrm{H}_{3} \mathrm{CCOONa}$ & Synth
\end{tabular}


Continuação: TAB4.1: Reagentes e solventes utilizados nos experimentos.

\begin{tabular}{|c|c|c|}
\hline Composto & Fórmula & Procedência \\
\hline Etanol P.A. 99,8\% & $\mathrm{C}_{2} \mathrm{H}_{5} \mathrm{OH}$ & Merck \\
\hline Acetona P.A. $99,5 \%$ & $\mathrm{C}_{3} \mathrm{H}_{6} \mathrm{O}$ & Vetec \\
\hline Acetilacetona (Hacac) & $\mathrm{C}_{5} \mathrm{H}_{8} \mathrm{O}_{2}$ & Vetec \\
\hline Tenoiltrifluoroacetona $(\mathrm{Htta})$ & $\mathrm{C}_{8} \mathrm{H}_{5} \mathrm{~F}_{3} \mathrm{O}_{2} \mathrm{~S}$ & Sigma-Aldrich \\
\hline Metanol P.A. & $\mathrm{CH}_{3} \mathrm{OH}$ & Synth \\
\hline Clorofórmio P.A. & $\mathrm{CHCl}_{3}$ & Synth \\
\hline Alaranjado de xilenol & $\mathrm{C}_{31} \mathrm{H}_{28} \mathrm{~N}_{2} \mathrm{Na}_{4} \mathrm{O}_{13} \mathrm{~S}$ & Merck \\
\hline Poli-3-hidroxibutirato (PHB) & $\left(\mathrm{C}_{4} \mathrm{O}_{2} \mathrm{H}_{6}\right)_{\mathrm{n}}$ & Usina da Pedra \\
\hline Acído Etilenodiaminotetracético (EDTA) & $\mathrm{C}_{10} \mathrm{H}_{16} \mathrm{~N}_{2} \mathrm{O}_{8}$ & Merck \\
\hline Glutaraldeído $50 \%$ & $\mathrm{C}_{5} \mathrm{H}_{8} \mathrm{O}_{2}$ & Sigma-Aldrich \\
\hline Albumina do soro bovino (BSA) & - & Sigma-Aldrich \\
\hline Tween 80 & $\mathrm{C}_{64} \mathrm{H}_{124} \mathrm{O}_{26}$ & Merck \\
\hline Poli Alcool Vinílico (PVA) & $\left(\mathrm{C}_{2} \mathrm{OH}_{4}\right)_{\mathrm{n}}$ & Quimesp \\
\hline Monohidrogenofosfato de sódio & $\mathrm{Na}_{2} \mathrm{HPO}_{4}$ & Synth \\
\hline Dihidrogenofosfato de sódio & $\mathrm{NaH}_{2} \mathrm{PO}_{4}$ & Synth \\
\hline Cloreto de sódio & $\mathrm{NaCl}$ & Synth \\
\hline Sacarose & $\mathrm{C}_{12} \mathrm{H}_{22} \mathrm{O}_{11}$ & Inlab \\
\hline Piridina & $\mathrm{C}_{5} \mathrm{H}_{5} \mathrm{~N}$ & Vetec \\
\hline
\end{tabular}

Os procedimentos experimentais foram divididos em partes: preparação dos cloretos de terras raras, síntese dos complexos de $\beta$ dicetonatos de terras raras, caracterização e estudo de propriedades luminescentes dos complexos, síntese das nanopartículas poliméricas misturadas com os complexos de $\beta$-dicetonatos de terras raras, os nanocompósitos, sua caracterização e estudo de propriedades luminescentes das nanopartículas, funcionalização das nanopartículas com glutaraldeído ou Albumina do Soro Bovino (BSA). 


\subsection{Síntese dos complexos de $\beta$-dicetonatos de terras raras}

Os óxidos de terras raras possuem baixíssima solubilidade em água e em diversos outros tipos de solventes, de modo que, para a reação de síntese dos $\beta$-dicetonatos de terras raras hidratados $\left[T R(t t a)_{3}\left(\mathrm{H}_{2} \mathrm{O}\right)_{2}\right]$ e [TR $\left.(\mathrm{acac})_{3}\left(\mathrm{H}_{2} \mathrm{O}\right)_{3}\right]$ torna-se necessário o uso de outro reagente precursor, que nesse trabalho, foram os cloretos de terras raras hidratados $T R C_{3} \cdot 6 \mathrm{H}_{2} \mathrm{O}$, obtidos através da abertura dos respectivos óxidos de terras raras $\left(\mathrm{Eu}_{2} \mathrm{O}_{3}\right.$, $\mathrm{Gd}_{2} \mathrm{O}_{3}$, e $\mathrm{Sm}_{2} \mathrm{O}_{3}$ ) em suspensão aquosa e tratados com ácido clorídrico concentrado (reação 4.1). Especificamente para o óxido de térbio (Equação 4.2), foi necessário também adição de peróxido de hidrogênio adicionado simultaneamente ao ácido.

$$
\begin{gathered}
\mathrm{TR}_{2} \mathrm{O}_{3(\mathrm{~s})}+6 \mathrm{HCl}_{\text {(conc) }} \longrightarrow 2 \mathrm{TRCl}_{3}+3 \mathrm{H}_{2} \mathrm{O}(4.1) \\
\mathrm{Tb}_{4} \mathrm{O}_{7(\mathrm{~s})}+12 \mathrm{HCl}_{\text {(conc) }} \stackrel{\mathrm{H}_{2} \mathrm{O}_{2}}{\longrightarrow} 4 \mathrm{TbCl}_{3}+6 \mathrm{H}_{2} \mathrm{O}+1 / 2 \mathrm{O}_{2}(4.2)
\end{gathered}
$$

A reação foi perpetrada a $60^{\circ} \mathrm{C}$, com adição lenta de ácido e agitação magnética constante até que todo ou quase todo óxido fosse consumido. Nesse ponto, a solução foi filtrada e o filtrado foi levado a banho Maria para evaporação da água até formação dos cristais. Vale ressaltar nessa etapa, que deve haver um controle de pH, que deve ser mantido de 5,5 até 6,0. Após a secagem, o sólido cristalino foi mantido em um dessecador e submetido a pressão reduzida.

Os complexos de fórmula geral $\left[\mathrm{TR}(\mathrm{tta})_{3}\left(\mathrm{H}_{2} \mathrm{O}\right)_{2}\right]\left(\mathrm{TR}=\mathrm{Eu}^{3+}, \mathrm{Sm}^{3+} \mathrm{e}\right.$ $\left.\mathrm{Gd}^{3+}\right)$ e $\left[\mathrm{TR}(\mathrm{acac})_{3}\left(\mathrm{H}_{2} \mathrm{O}\right)_{3}\right]\left(\mathrm{TR}=\mathrm{Eu}^{3+}, \mathrm{Sm}^{3+}, \mathrm{Tb}^{3+}\right.$ e $\left.\mathrm{Gd}^{3+}\right)$ foram preparados de acordo com procedimentos já conhecidos ${ }^{[1-3]}$, com algumas modificações na metodologia.

\subsubsection{Síntese dos complexos [TR(tta $\left.)_{3}\left(\mathrm{H}_{2} \mathrm{O}\right)_{2}\right]$}

Para o preparo dos complexos de $\left[\mathrm{TR}(\mathrm{tta})_{3}\left(\mathrm{H}_{2} \mathrm{O}\right)_{2}\right]\left(\mathrm{TR}=\mathrm{Eu}^{3+}, \mathrm{Sm}^{3+} \mathrm{e}\right.$ $\mathrm{Gd}^{3+}$ ) duas soluções foram feitas. Para a solução de Natta (sódica), aproximadamente $6,7 \mathrm{~g}$ de Htta foi dissolvido em $30 \mathrm{~mL}$ de álcool etílico e após 
completa dissolução, adicionou-se $5 \mathrm{~mL}$ de uma solução $6,0 \mathrm{~mol} \mathrm{~L}^{-1}$ de $\mathrm{NaOH}$ para garantir a desprotonação do Htta e formação do Natta. Nesse processo, o controle de $\mathrm{pH}$ é importante, uma vez que em $\mathrm{pH}$ maior que 7 , ocorre a formação de hidróxidos de terras raras $\left[\mathrm{TR}(\mathrm{OH})_{3}\right]$ que são insolúveis.

A solução recém-preparada foi adicionada a uma solução contendo $0,01 \mathrm{~mol}$ de $\mathrm{TRCl}_{3} \cdot \mathrm{xH}_{2} \mathrm{O}\left(\mathrm{TR}=\mathrm{Eu}^{3+}, \mathrm{Sm}^{3+}\right.$ e $\left.\mathrm{Gd}^{3+}\right)$ contido em $30 \mathrm{~mL}$ de água, sob agitação magnética e aquecimento em torno de $50^{\circ} \mathrm{C}$. No início do processo, ocorrea formação do complexo de tenoiltrifluoroacetonato de terras raras de acordo com a reação 4.3 na forma de um óleo amarelo levemente avermelhado. Após 1 hora, adicionou-se $200 \mathrm{~mL}$ de água destilada com a agitação magnética e aquecimento a $50^{\circ} \mathrm{C}$ por mais 2 horas. Um fluxograma simplificado com o processo é descrito na FIG 4.1.

$$
\mathrm{TRCl}_{3} \cdot \mathrm{xH}_{2} \mathrm{O}_{(\text {aq. })}+3 \mathrm{Htta}_{(\text {sol. })} \stackrel{3 \mathrm{NaOH}}{\longrightarrow}\left[\mathrm{TR}(\mathrm{tta})_{3}\left(\mathrm{H}_{2} \mathrm{O}\right)_{2}\right]_{(\mathrm{s})}+3 \mathrm{NaCl}_{(\text {aq. })}(4.3)
$$
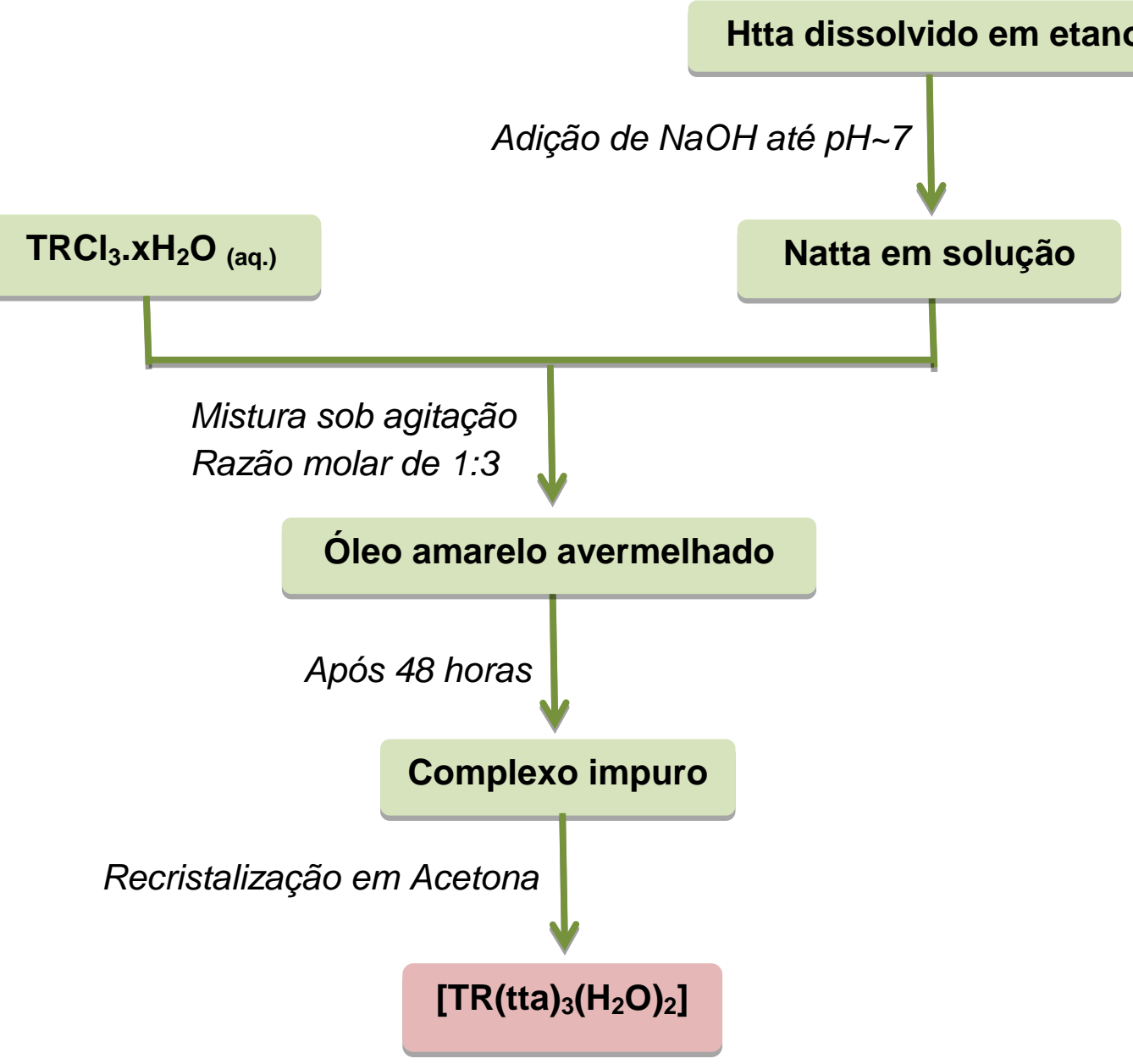

FIG.4.1:Fluxograma do processo de síntese dos complexos [TR(tta $\left.)_{3}\left(\mathrm{H}_{2} \mathrm{O}\right)_{2}\right]$. 
A mistura obtida foi mantida em repouso por 48 horas para que pudesse ocorrer a formação do complexo na forma de um pó fino amarelo alaranjado claro. Após essa etapa, o material foi filtrado, recristalizado em acetona, filtrado sob pressão reduzida e armazenado em um dessecador.

\subsubsection{Síntese dos complexos $\left[\mathrm{TR}(\mathrm{acac})_{3}\left(\mathrm{H}_{2} \mathrm{O}\right)_{3}\right]$}

Para o preparo dos complexos de $\left[\mathrm{TR}(\mathrm{acac})_{3}\left(\mathrm{H}_{2} \mathrm{O}\right)_{3}\right]\left(\mathrm{TR}=\mathrm{Eu}^{3+}\right.$, $\mathrm{Sm}^{3+}, \mathrm{Tb}^{3+}$ e $\mathrm{Gd}^{3+}$ ) duas soluções foram necessárias. A primeira solução foi preparada com a adição de aproximadamente $3,2 \mathrm{~mL}$ de Hacac em $200 \mathrm{~mL}$ de água destilada e $\mathrm{opH}$ ajustado até aproximadamente $7 \mathrm{com}$ a adição gota a gota de uma solução de $\mathrm{NaOH}$ de concentração de $6 \mathrm{~mol} \mathrm{~L}^{-1}$ sob agitação magnética constante.Nesse processo, assim como no preparo dos complexos tta, o controle de $\mathrm{pH}$ é importante, uma vez que em $\mathrm{pH}$ maior que 7 , ocorre a formação de hidróxidos de terras raras $\left[\mathrm{TR}(\mathrm{OH})_{3}\right]$ que são insolúveis.

A segunda solução foi preparada com a adição de aproximadamente $2,6 \mathrm{~g}$ do $\mathrm{TRCl}_{3}$ em $30 \mathrm{~mL}$ de água destilada. Após completa dissolução, esta solução foi vertida na primeira solução mantendo o sistema sob agitação magnética por aproximadamente 2 horas. $O$ produto final foi filtrado com auxílio de pressão reduzida e o resíduo foi separado e mantido em um dessecador por aproximadamente 24 horas. A reação 4.4 apresenta a síntese dos complexos e o processo é descrito de forma simplificada no diagrama da FIG.4.2.

$\mathrm{TRCl}_{3} . \mathrm{xH}_{2} \mathrm{O}_{(\text {aq. })}+3 \mathrm{Hacac}_{(\ell)} \stackrel{3 \mathrm{NaOH}}{\longrightarrow}\left[\mathrm{TR}(\mathrm{acac})_{3}\left(\mathrm{H}_{2} \mathrm{O}\right)_{3}\right]_{(\mathrm{s})}+3 \mathrm{NaCl}_{(\text {aq. })}(4.4)$ 


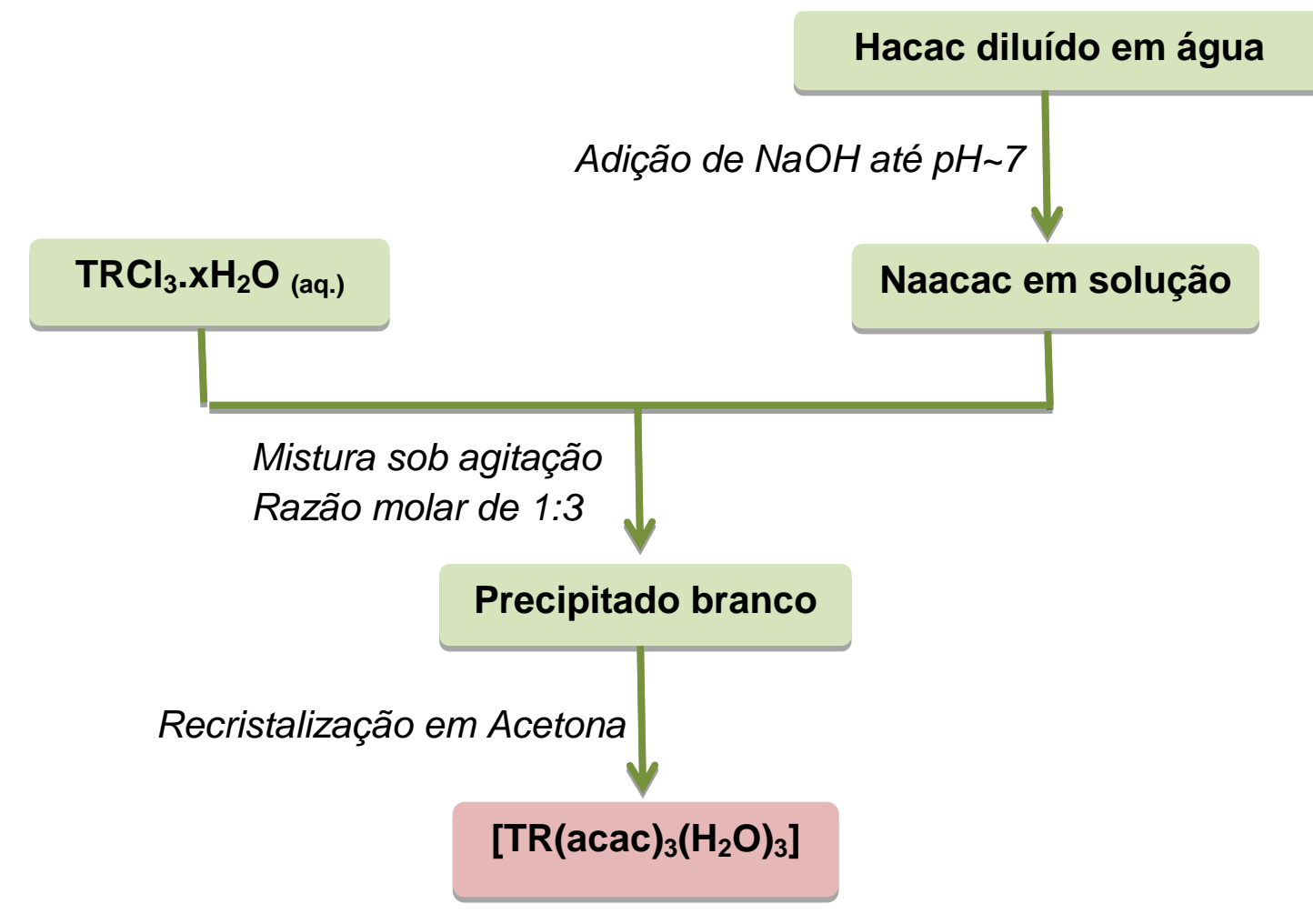

FIG.4.2: Fluxograma do processo de síntese dos complexos [TR(acac $\left.)_{3}\left(\mathrm{H}_{2} \mathrm{O}\right)_{3}\right]$.

\subsubsection{Síntese das nanopartículasdo compósito PHB+ complexos $\beta$ - dicetonatos de terras raras hidratados}

Para a obtenção das nanopartículas foram preparadas duas soluções, sendo uma orgânica e outra aquosa. A solução orgânica foi preparada pela dissolução de aproximadamente $10 \mathrm{mg}$ de PHB e a mesma massa do complexo de terra rara em $6 \mathrm{~mL}$ de clorofórmio, com aquecimento de até $60^{\circ} \mathrm{C}$ em um sistema de refluxo. Essa solução foi misturada com aproximadamente $74 \mathrm{~mL}$ de uma solução aquosa com 2,5\% do dispersante Tween 80. Por um período de 5 minutos, essa mistura foi agitada com o auxílio de um dispersor extrator, marca Químis, obtendo-se uma pré-emulsão, a qual foi vertida em $150 \mathrm{~mL}$ de solução aquosa com 2,5\% de dispersante Tween 80 .

O sistema foi mantido sob agitação magnética moderada, a $40^{\circ} \mathrm{C}$ e com pressão reduzida. Após 2 horas, desligou-se o aquecimento e o vácuo, e com agitação magnética baixa, o sistema foi mantido nessas condições por 24 
horas. Este método foi elaborado com base em trabalhos reportados na literatura ${ }^{[4-7]}$, com algumas modificações.

A solução final obtida foi então centrifugada por 30 minutos. Após esse período, o centrifugado, levemente turvo, foi separado e armazenado para análise. O resíduo obtido foi lavado com água destilada e centrifugado por três vezes. Após as lavagens, adicionou-se sacarose ${ }^{[8,9]} \mathrm{em}$ uma proporção de $10 \%$ em relação ao resíduo, sendo congelado com nitrogênio líquido e liofilizado até total secagem para obtenção dos aglomerados com nanopartículas. $O$ procedimento resumido é mostrado na forma de fluxograma na FIG 4.3.

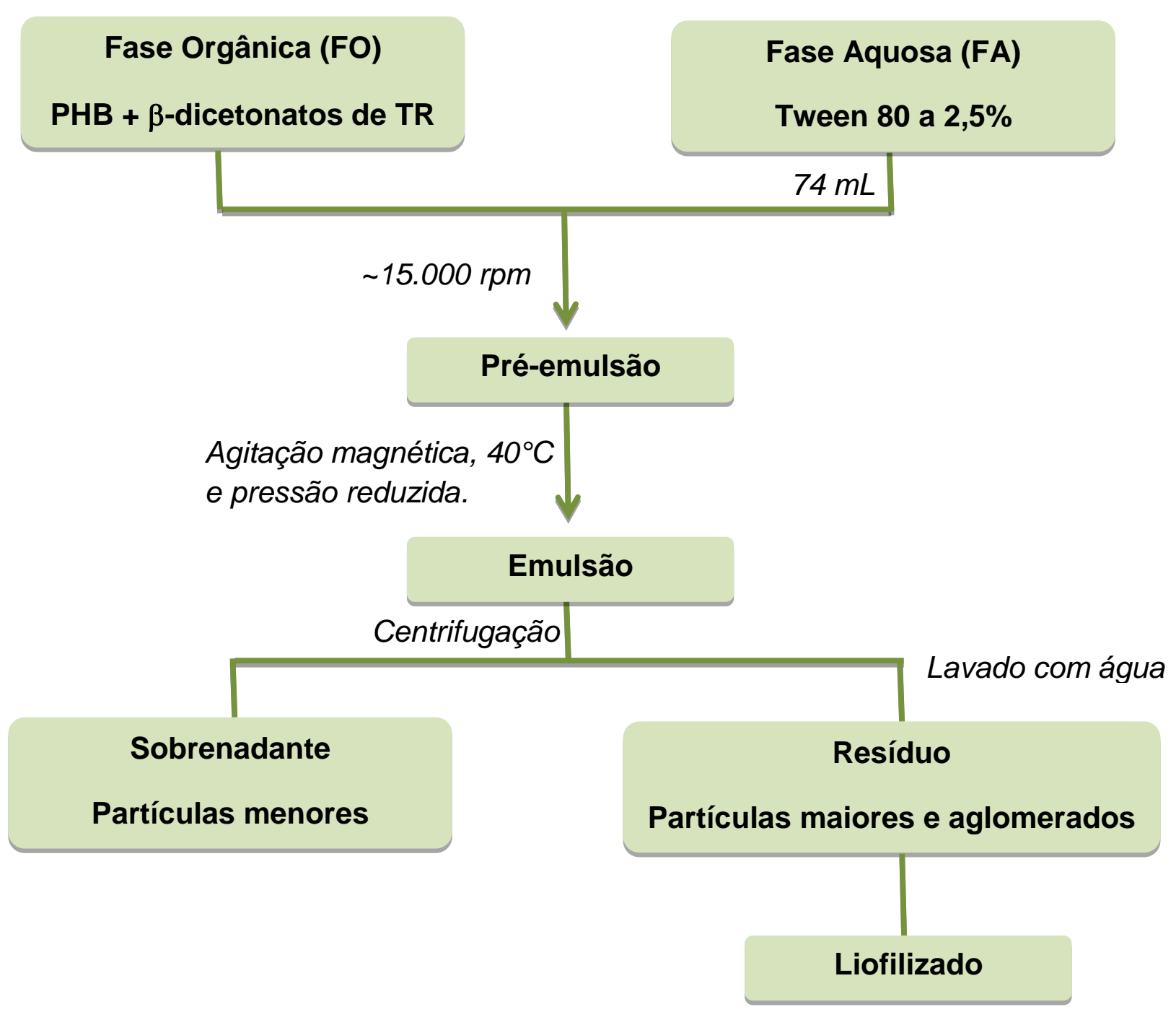

FIG.4.3: Fluxograma do processo de síntese das nanopartículas poliméricas. 


\subsubsection{Funcionalização das Nanopartículas de PHB e Complexos de $\mathrm{TR}^{3+}$}

Para a etapa de funcionalização, as suspensões preparadas foram filtradas com membranas filtrantes com porosidade de $450 \mathrm{~nm}$ e $1 \mathrm{~mL}$ do filtrado foi mantido em contato com a Albumina do Soro Bovino e Glutaraldeído separadamente em meio tamponado com PBS (Tampão Fosfato, pH 7,4) e um volume final de $2 \mathrm{~mL}$ para cada teste. Mantida a quantidade de partículas constante, variou-se a concentração dos ativos, com 0; 3,0 e 6,0 mg de Glutaraldeído e 0; 2,4 e 7,2 mg para a BSA. As amostras foram mantidas em temperatura ambiente e as leituras de tamanho de partícula e potencial zeta foram feitas 2 dias após o preparo.

\subsection{Análise elementar de carbono, hidrogênio e nitrogênio (CHN)}

Foram feitas as análises para determinação dos teores de carbono, hidrogênio e nitrogênio nos complexos de terras raras no laboratório de microanálise na Central Analítica do IQ-USP, por processos microanalíticos, utilizando o analisador de CHN da Perkin-Elmer, modelo 240.

\subsection{Volumetria de complexação usando EDTA para determinação de íons terras raras.}

O EDTA é um dos complexantes mais usados em volumetria e foi utilizado como agente quelante para determinação complexométrica de íons de $\mathrm{Eu}^{3+}, \mathrm{Sm}^{3+}, \mathrm{Tb}^{+3} \mathrm{e} \mathrm{Gd}^{3+}$. A solução a ser titulada foi preparada com a dissolução de cerca de $10 \mathrm{mg}$ de amostra em $\mathrm{HNO}_{3}$ e em seguida, submetida a aquecimento para eliminação do excesso de ácido. Após essa etapa, foram acrescentados $5 \mathrm{~mL}$ de solução tampão $\mathrm{pH} 4,5$ ácido acético/acetato, uma gota de piridina e aproximadamente $10 \mathrm{mg}$ de indicador alaranjado de xilenol. A solução final foi então titulada com uma solução de EDTA $10 \mathrm{mmol} \mathrm{L}^{-1} \mathrm{com}$ o auxílio de uma microbureta ${ }^{[10,11]}$. Os ensaios de volumetria de complexação foram realizados nos Laboratórios do Centro de Química e Meio Ambiente (CQMA)do IPEN-CNEN/SP. 


\subsection{Espectroscopia de absorção molecular na região do infravermelho.}

Os espectros de Infravermelho foram obtidos em um espectrômetro de absorção na região do infravermelho Thermo Scientific Nicolet $6700 \mathrm{Ft}-\mathrm{IR}$, Smart Orbit, Diamond 30,000 - $400 \mathrm{~cm}^{-1}$. Refletância Total Atenuada (ATR). As amostras foram processadas sem tratamento prévio.

\subsection{Curvas Termogravimétricas}

As curvas termogravimétricas (TG) foram obtidas em uma termobalança SDTA-822 (Mettler Toledo) utilizando amostras de aproximadamente $10 \mathrm{mg}$ em cadinho de alumina, sob atmosfera dinâmica de nitrogênio, com vazão de $50 \mathrm{mLmin}^{-1}$ e razão de aquecimento de $10{ }^{\circ} \mathrm{C} \mathrm{min}{ }^{-1}$. As curvas DTG foram obtidas a partir da derivatização do sinal eletrônico da curva TG.

\subsection{Difração de Raios $\mathrm{X}$}

Os difratogramas de RaioX foram obtidos em um equipamento Difratômetro de Raios X Rigaku modelo MiniFlex II onde utilizou-se fonte de radiação $\operatorname{CuK} \alpha(\lambda=1,54 \AA$ A)e filtro de $\mathrm{Ni}$. As amostras foram dispersas em lâminas de quartzo com varredura entre 5 e $80^{\circ}$ a $0,05^{\circ} \mathrm{s}^{-1}$.

\subsection{Microscopia eletrônica de varredura}

Para avaliação da morfologia e tamanho médio de partículas, utilizou-se um microscópio eletrônico de varredura da marca Philips XL-30, do Centro de Ciências e Tecnologia de Materiais (CCTM) do IPEN-CNEN/SP. As amostras foram filtradas, por pelo menos cinco passagens da mesma solução em um papel de filtração lenta, para que as partículas pudessem ficar aderidas ao papel. O papel de filtro foi mantido em um dessecador sob vácuo por 24 
horas. Um pedaço desse filtro foi recortado e colocado no porta-amostra e em seguida, a amostra foi recoberta com ouro através da técnica de sputtering.

\subsection{Citotoxicidade}

Para os testes de citotoxicidade, foram utilizados aglomerados de nanopartículas de PHB misturado com $\left[\mathrm{Eu}(\mathrm{tta})_{3}\left(\mathrm{H}_{2} \mathrm{O}\right)_{2}\right]$ obtida no processo de preparo de nanopartículas desse mesmo material. As amostras foram esterilizadas por radiação gama (25kGy) e sem seguida, foram feitas as diluições com 0,2 g de amostramL ${ }^{-1}$ em meio de cultura RPMI 1640 sem soro, mantendo a $37^{\circ} \mathrm{C}$ por 48 horas. A linhagem de células utilizada para o teste foi a CHO-k1 (Chinese Hamster Ovary) e a determinação quantitativa foi feita através do corante vital MTS (3-(4,5-dimetiltiazol-2-il)-5-(3-carboximetoxifenil)2-(4-sulfofenil)-2H-tetrazólio) em placas e com comprimento de onda de 490 nm no espectrofotômetro para leitura de placas ELISA (Enzyme-Linked Immunosorbent Assay).

\subsection{Testes de Hemocompatibilidade}

Para os testes de hemocompatibilidade, preparou-se filmes de PHB puro e PHB dopado com [ $\left.\mathrm{Eu}(\mathrm{tta})_{3}\left(\mathrm{H}_{2} \mathrm{O}\right)_{2}\right]$ e com $\left[\mathrm{Tb}(\mathrm{acac})_{3}\left(\mathrm{H}_{2} \mathrm{O}\right)_{3}\right]$. Todos estes filmes foram submetidos ao contato com sangue de acordo com a norma ISO $10.993^{[12]}$.

\subsection{Espectroscopia de Correlação de Fotóns e Potencial Zeta}

A determinação de tamanho de partículas e potencial zeta foram feitas em um equipamento Malvern Zetasizer Nano Series. O equipamento pertence ao Laboratório de Biomembranas da Unifesp - Universidade Federal de São Paulo 
As amostras utilizadas para a leitura foram obtidas após centrifugação e filtração através de uma membrana de $450 \mathrm{~nm}$ para eliminação de aglomerados e partículas maiores. As leituras foram feitas em temperatura ambiente, em cubeta de plástico com $1 \mathrm{~cm}$ de caminho óptico.

\subsection{Espectroscopia de luminescência}

\subsubsection{Espectros eletrônicos de excitação e emissão dos complexos precursores.}

Os espectros eletrônicos de excitação e emissão dos complexos precursores e nanopartículas em estado sólido e solução, a temperatura ambiente $(\sim 298 \mathrm{~K})$ e do nitrogênio líquido $(77 \mathrm{~K})$ foram registrados utilizandose um espectrofluorímetro Hitachi F-4500, Modular Fluorolog-3 com monocromadores duplos $0,22 \mathrm{~m}$ do tipo SPEX 1680 e lâmpada de xenônio de $450 \mathrm{~W}$ como fonte de radiação. Os espectros foram registrados na faixa espectral de 250 a $720 \mathrm{~nm}$. O aparato foi controlado por um sistema computacional DM3000F.

\subsubsection{Medidas do tempo de vida do nível excitado}

Para a obtenção das curvas de decaimento das emissões foi utilizada uma lâmpada pulsada de xenônio de $150 \mathrm{~W}$ até $11 \mathrm{~ms}$. Todos os dados espectrais foram coletados em um ângulo de $22,5^{\circ}$ (face frontal).

\subsection{Espectros de absorção na região do ultravioleta-visível}

Os espectros de absorção molecular dos conjugados foram obtidos utilizando-se um espectrofotômetro da Shimatzu modelo multispecs 1501 e utilizando-se cubetas de quartzo com caminho ótico de $1 \mathrm{~cm}$. 


\section{REFERÊNCIAS BIBLIOGRÁFICAS}

[1] MELBY, L.R.; ABRAMSON, E.; CARIS, J. C.; ROSE, N. J. Synthesis + Fluorescence of Some Trivalent Lanthanide Complexes. Journal American Chemical Society, v.86, p.5117-5125, 1964.

[2] BAUER, H.; BLANC, J.; ROSS, D. L. Octacoordinate Chelates of Lanthanides. 2 Series of Compounds.Journal American Chemical Society, v.86, p.5125-5131, 1964.

[3] BINNEMANS, K.; LANAERTS, P.; DRIESEN, K.; GORLLER-WALRAND, C. A. Luminescent tris(2-thenoyltrifluoroacetonato) europium (III) Complex Covalently Linked to a 1,10-phenanthroline-Functionalised SolGel Glass. Journal Material Chemistry, v.14, p.191-195, 2004.

[4] POHLMANN, A. R.; POLETTO, F. S.; FIEL, L. A.; DONIDA, B.; RÉ, M. I.; GUTERRES, S. S. Controlling the size of poly(hydroxybutyrate-cohydroxyvalerate) nanoparticles prepared by emulsification-diffusion technique using ethanol as surface agent. Colloids and Surfaces A: Physicochemical and Engineering Aspects, v. 324, p. 105-112, 2008.

[5] NEUfELD, R. J.; REIS, C. P.; RIBEIRO, A. J.; VEIGA, F. Nanoencapsulation I. Methods for preparation of drug-loaded polymeric nanoparticles. Nanomedicine: Nanotechnology, Biology, and Medicine, v. 2, p. 8-21, 2005.

[6] RAO, J. P.; GECKELER, K. E. Polymer nanoparticles: Preparation techniques and size-control parameters. Elsevier, 887-913. 2011

[7] SCHAFFAZICK, S. R.; GUTERRES, S. S.; FREITAS, L. L.; POHLMANN, A. R. Caracterização e estabilidade físico-química de sistemas poliméricos nanoparticulados para administração de fármacos. Quimica Nova, v.26, n.5. p.726-737, 2003

[8] MOLPECERES, J.; SAEZ, A.; GUZMÁN, M.; ABERTURAS, M. R. Freeze-drying of polycaprolactone and poly(d,I-lactic-glycolic) nanoparticles induce minor particle size changes affecting the oral pharmacokinetics of loaded drugs. European Journal of Pharmaceutics and Biopharmaceutics, v.50, p. 379-387, 2000.

[9] QIAN, Y.; ZHANG, L.; LIU, L.; CHEN, Y. The effects of cryoprotectants on the freeze-drying of ibuprofen-loaded solid lipid microparticles (SLM).European Journal of Pharmaceutics and Biopharmaceutics, v. 69, p. 750-759, 2008. 
[10] LYLE, S. J.; RAHMAN, M. M. Complexometric titration of ytrium and the lanthanons-I. Talanta, v. 10, p. 1177-1182, 1963.

[11] LYLE, S. J.; RAHMAN, M. M. Complexometric titration of ytrium and the lanthanons-II. Talanta, v. 10, p. 1183-1187, 1963.

[12] INTERNATIONAL ORGANIZATION FOR STANDARDIZATION. ISO 10993.Partes 1 a 20.Várias datas. 


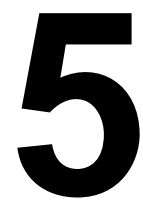

RESULTADOS E DISCUSSÕES 


\section{$5 \quad$ RESULTADOS E DISCUSSÕES}

\subsection{Características estequiométricas e quantitativas dos complexos precursores e as nanopartículas.}

Os complexos sintetizados apresentam-se na forma de pó fino, de coloração branca para os complexos com o ligante acac e ligeiramente amarelado para os complexos com o ligante tta. Ao contrário dos cloretos de terras raras, utilizados para a síntese desses complexos, os quelatos não apresentam comportamento higroscópico em condições ambientes $\left(\sim 25^{\circ} \mathrm{C}\right)$.

Com relação às emulsões obtidas com as nanopartículas poliméricas contendo os complexos de terras raras, a solução final apresentou leve turbidez e uma coloração da solução levemente amarelada para as sínteses utilizando os complexos com ligante tta. Na FIG 5.1 podemos observar que a emulsão contendo as nanopartículas, ao longo do tempo conforme 0 solvente evapora, a solução adquiriu um aspecto menos turvo do que no inicio do processo.
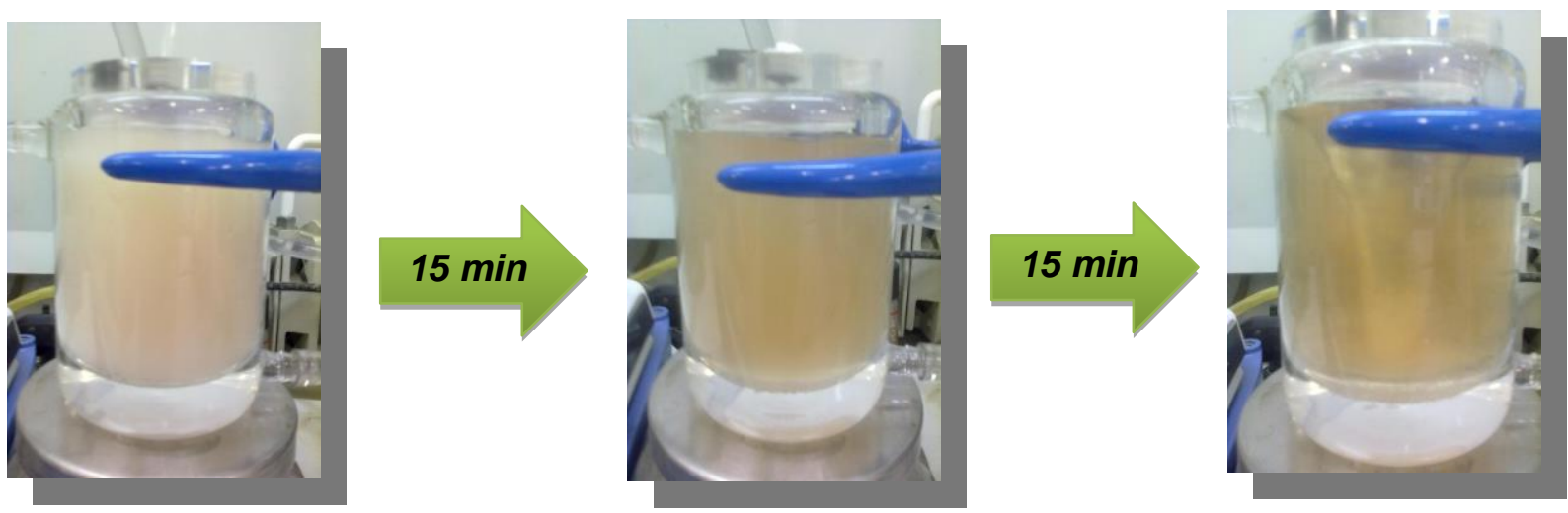

FIG.5.1: Comportamento da emulsão ao longo do tempo de evaporação. 
Apenas a emulsão com nanopartículas poliméricas dopadas com o complexo $\left[\mathrm{Eu}(\mathrm{tta})_{3}\left(\mathrm{H}_{2} \mathrm{O}\right)_{2}\right.$ ] apresentou luminescência quando irradiado com luz UV conforme ilustra a FIG 5.2, assim como o material obtido após liofilização.

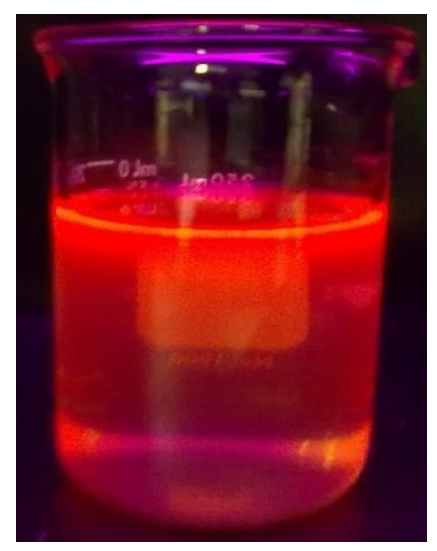

FIG.5.2: Comportamento da emulsão com nanopartículas de PHB contendo o complexo $\left[\mathrm{Eu}(\mathrm{tta})_{3}\left(\mathrm{H}_{2} \mathrm{O}\right)_{2}\right]$ irradiado com luz UV.

As suspensões filtradas em membrana filtrante de porosidade de $450 \mathrm{~nm}$ apresentaram tonalidades diferenciadas quando excitadas pelo feixe da lâmpada de xenônio do espectrofluorímetro nos comprimentos de onda de excitação de $340 \mathrm{~nm}$ para as emulsões com $\mathrm{Eu}^{3+}, 362 \mathrm{~nm}$ para a emulsão com [Sm(acac $\left.)_{3}\left(\mathrm{H}_{2} \mathrm{O}\right)_{3}\right], 390 \mathrm{~nm}$ para a emulsão contendo $\left[\mathrm{Sm}(\mathrm{tta})_{3}\left(\mathrm{H}_{2} \mathrm{O}\right)_{2}\right]$ e 338 para a emulsão contendo $\left[\mathrm{Tb}(\mathrm{acac})_{3}\left(\mathrm{H}_{2} \mathrm{O}\right)_{3}\right]$. Na FIG 5.3, são apresentadas as suspensões de nanopartículas: (a) $\mathrm{PHB}+\left[\mathrm{Eu}(\mathrm{tta})_{3}\left(\mathrm{H}_{2} \mathrm{O}\right)_{2}\right]$, (b) $\mathrm{PHB}+$ $\left[\mathrm{Eu}(\mathrm{acac})_{3}\left(\mathrm{H}_{2} \mathrm{O}\right)_{3}\right]$, (c) $\mathrm{PHB}+\left[\mathrm{Sm}(\mathrm{tta})_{3}\left(\mathrm{H}_{2} \mathrm{O}\right)_{2}\right],(\mathrm{d}) \mathrm{PHB}+\left[\mathrm{Sm}(\mathrm{acac})_{3}\left(\mathrm{H}_{2} \mathrm{O}\right)_{3}\right]$, (e) $\mathrm{PHB}+\left[\mathrm{Tb}(\mathrm{acac})_{3}\left(\mathrm{H}_{2} \mathrm{O}\right)_{3}\right],(\mathrm{f})\left[\mathrm{Eu}(\mathrm{tta})_{3}\left(\mathrm{H}_{2} \mathrm{O}\right)_{2}\right]$ e (g) $\mathrm{PHB}+\left[\mathrm{Eu}(\mathrm{tta})_{3}\left(\mathrm{H}_{2} \mathrm{O}\right)_{2}\right]+$ PVA.

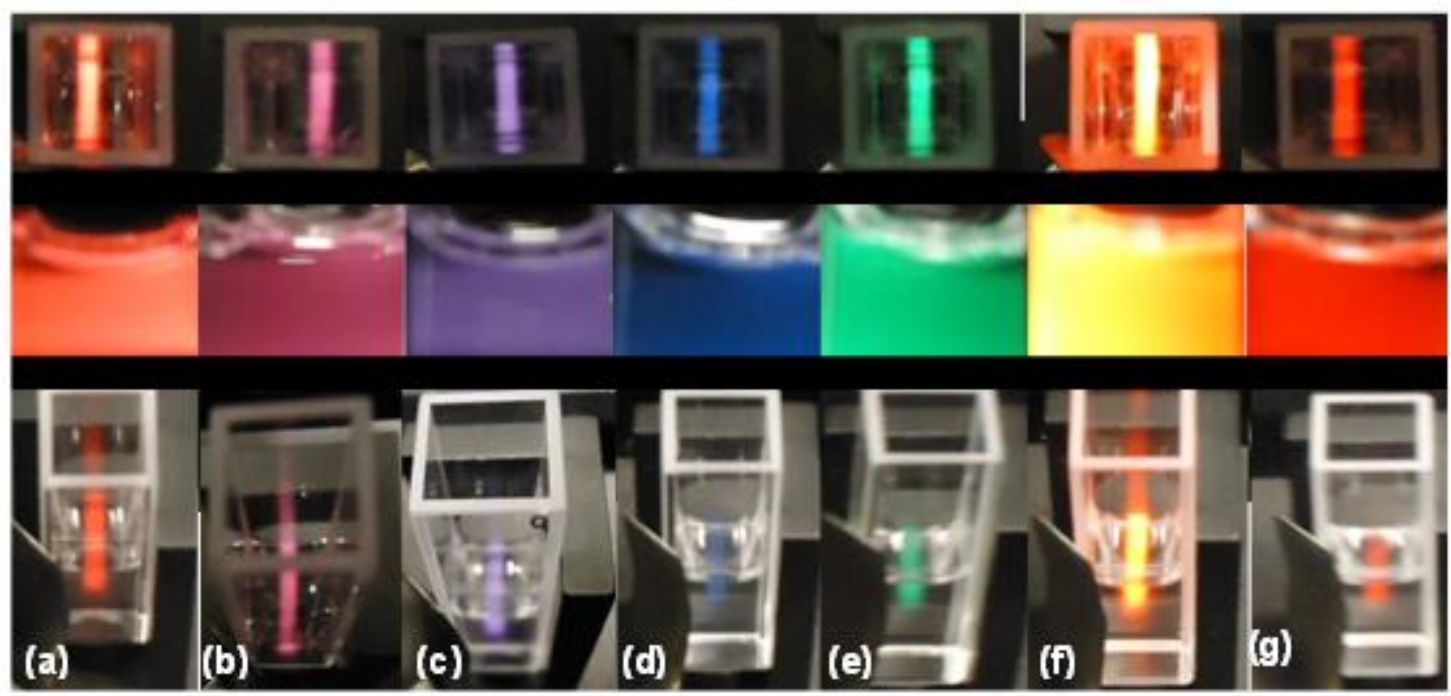

FIG.5.3: Comportamento das suspensões de nanopartículas mediante feixe de excitação. 


\subsubsection{Análise elementar de carbono, hidrogênio e nitrogênio (CHN) e porcentagem de lantanídeos.}

Os complexos precursores foram caracterizados por análise elementar de carbono, hidrogênio e nitrogênio e o teor de terras raras foi determinado pela técnica de volumetria de complexação, utilizando EDTA como titulante em um meio $\mathrm{pH} \mathrm{4,5.} \mathrm{Os} \mathrm{teores} \mathrm{de} \mathrm{C}, \mathrm{H}$ e $\mathrm{Ln}$ em porcentagem são apresentados na TAB 5.1 e visam demonstrar a coerência estequiométrica entre os valores teóricos e experimentais, confirmando a estrutura dos complexos precursores.

Com esses valores, pode-se propor as estequiometrias $\mathrm{TR}(\mathrm{tta})_{3}\left(\mathrm{H}_{2} \mathrm{O}\right)_{2} \mathrm{e}$ $\operatorname{TR}(\mathrm{acac})_{3}\left(\mathrm{H}_{2} \mathrm{O}\right)_{3}$ para os complexos utilizados nas sínteses das nanopartículas poliméricas. Variações entre os valores teóricos e experimentais podem ser associados à presença de umidade nos complexos precursores, no entanto, da mesma forma os valores apresentam a mesma ordem de grandeza, o que justifica as estruturas propostas. Estes dados também concordam com os dados da literatura.

TAB 5.1: Resultados de CHN e do teor de terras raras nos complexos.

\begin{tabular}{lcccccc}
\hline \multirow{2}{*}{\multicolumn{1}{c}{ Composto }} & \multicolumn{2}{c}{ \% Carbono } & \multicolumn{2}{c}{ \% Hidrogênio } & \multicolumn{2}{c}{ \% Terras Raras } \\
\cline { 2 - 7 } & Calc. & Exp. & Calc. & Exp. & Calc. & Exp. \\
\hline$\left[\mathrm{Eu}(\mathrm{tta})_{3}\left(\mathrm{H}_{2} \mathrm{O}\right)_{2}\right]$ & 33,70 & 34,16 & 2,22 & 1,79 & 17,90 & 18,41 \\
{$\left[\mathrm{Eu}(\mathrm{acac})_{3}\left(\mathrm{H}_{2} \mathrm{O}\right)_{3}\right]$} & 35,55 & 31,31 & 5,93 & 4,68 & 30,01 & 29,78 \\
{$\left[\mathrm{Sm}(\mathrm{tta})_{3}\left(\mathrm{H}_{2} \mathrm{O}\right)_{2}\right]$} & 33,77 & 34,18 & 2,23 & 1,84 & 17,63 & 17,47 \\
{$\left[\mathrm{Sm}(\mathrm{acac})_{3}\left(\mathrm{H}_{2} \mathrm{O}\right)_{3}\right]$} & 35,66 & 35,55 & 5,94 & 5,13 & 29,79 & 30,26 \\
{$\left[\mathrm{Gd}(\mathrm{tta})_{3}\left(\mathrm{H}_{2} \mathrm{O}\right)_{2}\right]$} & 35,07 & 35,05 & 5,84 & 5,20 & 18,29 & 19,33 \\
{$\left[\mathrm{Gd}(\mathrm{acac})_{3}\left(\mathrm{H}_{2} \mathrm{O}\right)_{3}\right]$} & 35,18 & 35,21 & 5,86 & 5,26 & 30,74 & 30,70 \\
{$\left[\mathrm{~Tb}(\mathrm{acac})_{3}\left(\mathrm{H}_{2} \mathrm{O}\right)_{3}\right]$} & 35,18 & 35,14 & 5,86 & 5,10 & 30,96 & 29,71 \\
\hline
\end{tabular}

\subsubsection{Espectroscopia de absorção molecular na região do Infravermelho}

Para que se possa verificar a formação ou quebra de ligações, assim como a interação entre espécies inorgânicas e orgânicas no que se refere a processos de complexação, foram feitas análises por espectroscopia de 
absorção na região do infravermelho, registrados na região de 4000 a $400 \mathrm{~cm}^{-1}$ a temperatura ambiente. A simbologia para as vibrações e rotações utilizadas são: $v$ (estiramento), $\delta$ (deformação angular), $s$ (simétrico) e as (assimétrico) e são relatados alguns pontos relevantes.

Neste trabalho foi realizado o estudo do comportamento dos complexos precursores de $\mathrm{TR}^{3+}\left(\mathrm{TR}^{3+}=\mathrm{Eu}^{3+}, \mathrm{Tb}^{3+}, \mathrm{Sm}^{3+}\right.$ e $\left.\mathrm{Gd}^{3+}\right)$ e dos aglomerados de nanopartículas poliméricas de PHB misturado com esses complexos frente à espectroscopia do infravermelho visando uma avaliação mais profunda sobre a interação do complexo na matriz polimérica. Uma vez que os resultados para cada ligante são muito semelhantes, serão apresentados apenas os resultados para o complexo $\mathrm{Tb}(\mathrm{acac})_{3}\left(\mathrm{H}_{2} \mathrm{O}\right)_{3}$ e $\mathrm{Eu}(\mathrm{tta})_{3}\left(\mathrm{H}_{2} \mathrm{O}\right)_{2}$, como exemplo.

\subsubsection{Espectros de infravermelho dos complexos com ligante acac e nanopartículas de PHB + Complexos.}

Uma das primeiras observações possíveis de se fazer ao observar os espectros de infravermelho do Hacac (FIG 5.4) é a presença de uma banda de intensidade média e desdobrada em torno de 1708 e $1728 \mathrm{~cm}^{-1}$ que são atribuídas ao estiramento simétrico $v_{s} \mathrm{C}=\mathrm{O}$ relacionadas as formas cis e trans da dicetona. e em torno de $1602 \mathrm{~cm}^{-1}$ verificamos a presença de uma banda larga referente ao estiramento assimétrico vas $\mathrm{C}=\mathrm{O}$ da forma enólica atribuída às ligações conjugadas $\mathrm{C}=\mathrm{C}$ e $\mathrm{C}=\mathrm{O}$ e que se sobrepõe a deformação angular $\delta \mathrm{O}-\mathrm{H}$ presente na estrutura planar do grupamento enol ${ }^{[1,2]}$.

No espectro do complexo $\left[\mathrm{Tb}(\mathrm{acac})_{3}\left(\mathrm{H}_{2} \mathrm{O}\right)_{3}\right]$ (FIG.5.4) a banda da forma enólica aparece desdobrada em 1588 e $1511 \mathrm{~cm}^{-1}$, e a banda referente ao estiramento simétrico ${ }_{v} \mathrm{C}=\mathrm{O}$ do grupamento carbonila da dicetona não aparece, o que indica a formação do anel quelato. Também foi possível observar a presença de uma banda larga na região entre 3500 e $3000 \mathrm{~cm}^{-1}$ que é atribuída ao estiramento $\mathrm{vO}-\mathrm{H}$ o que caracteriza a presença de moléculas de água nos complexos. 


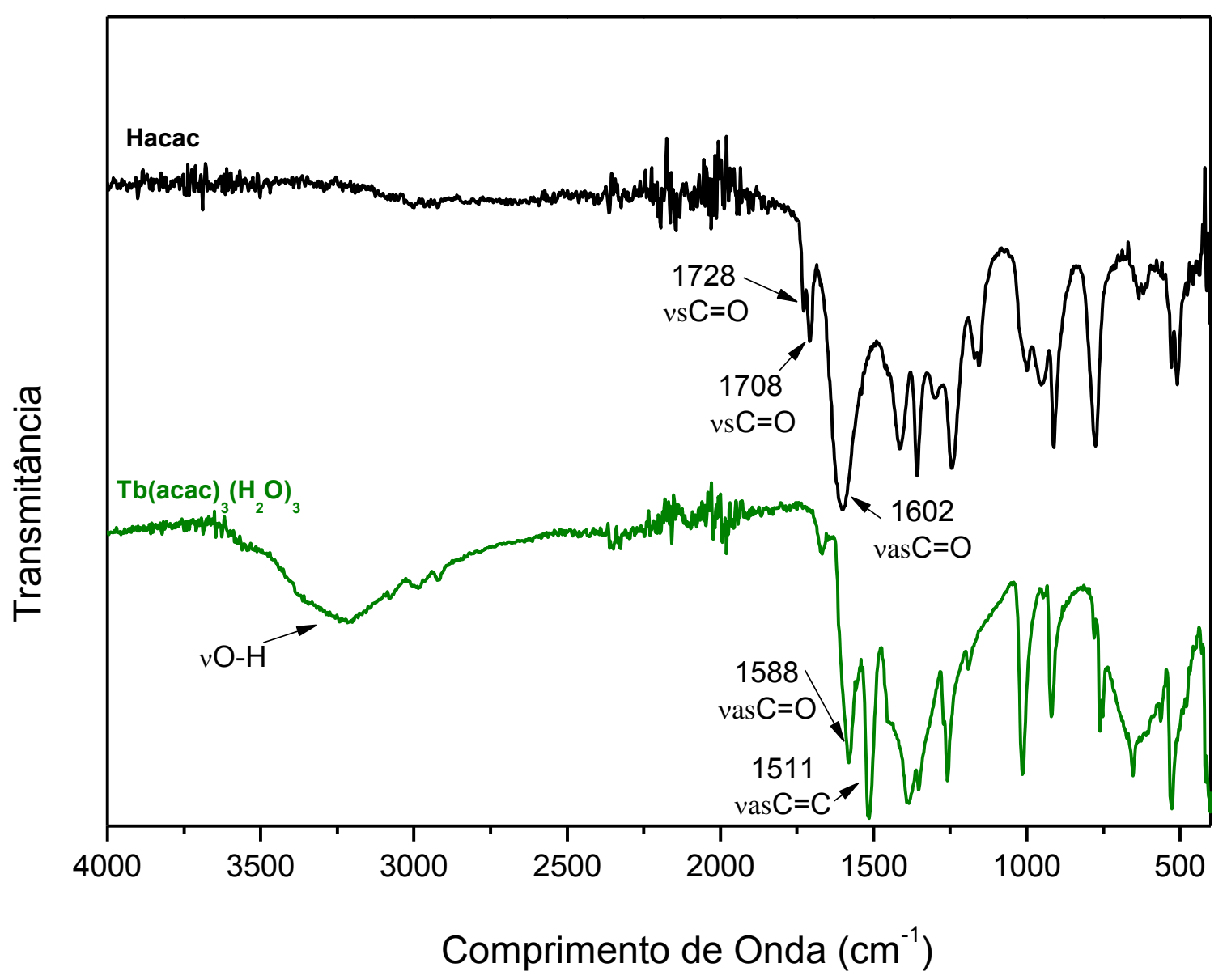

FIG.5.4: Espectros de absorção no infravermelho registrados a temperatura ambiente no intervalo de 4000 a $400 \mathrm{~cm}^{-1}$ do Hacac e do complexo $\mathrm{Tb}(\mathrm{acac})_{3}\left(\mathrm{H}_{2} \mathrm{O}\right)_{3}$.

Na TAB 5.2 apresentam-se as principais atribuições de bandas dos espectros de infravermelho, referentes às frequências vibracionais do Hacac $\mathrm{e}$ $\left[\mathrm{Tb}(\mathrm{acac})_{3}\left(\mathrm{H}_{2} \mathrm{O}\right)_{3}\right]$.

TAB 5.2: Principais frequências vibracionais $\left(\mathrm{cm}^{-1}\right)$ do Hacac e $\left[\mathrm{Tb}(\mathrm{acac})_{3}\left(\mathrm{H}_{2} \mathrm{O}\right)_{3}\right]$

\begin{tabular}{ccc}
\hline Atribuição & Hacac & {$\left[\mathrm{Tb}(\mathbf{a c a c})_{3}\left(\mathbf{H}_{2} \mathbf{O}\right)_{3}\right]$} \\
\hline$v s \mathrm{C}=\mathrm{O}$ & 1728 & - \\
$\nu \mathrm{C}=\mathrm{C}$ e vas $\mathrm{C}=\mathrm{O}$ & 1602 & 1588 \\
$\delta \mathrm{C}-\mathrm{H}_{\text {plano }}$ & 1156 & 1184 \\
$v \mathrm{O}-\mathrm{H}$ & - & 3350 \\
\hline
\end{tabular}


Os espectros de infravermelho do PHB puro e dos aglomerados de nanopartículas foram registrados para verificar as alterações devido a agregação dos complexos a matriz polimérica do PHB na formação das nanopartículas ou então a possibilidade de concentração do complexo ao centro da partícula com a formação de uma capa polimérica.

Verifica-se através dos espectros de infravermelho (FIG5.5) que o estiramento assimétrico vas $\mathrm{C}=\mathrm{C}$ em $1511 \mathrm{~cm}^{-1}$ presente no complexo de $\mathrm{Tb}^{3+}$, é ausente no polímero PHB e fracamente perceptível nos aglomerados de nanopartículas poliméricas agregadas com o complexo de $\mathrm{Tb}^{3+}$.

Além disso, a banda alargada presente no espectro de infravermelho do complexo, na região de 3500 a $3000 \mathrm{~cm}^{-1}$ atribuída ao estiramento $\mathrm{vO}-\mathrm{H}$ característica da presença de moléculas de água nos complexos se mantém no espectro das nanopartículas, possivelmente por uma contribuição das hidroxilas presentes na sacarose, utilizada como crioprotetor no processo de liofilização das mesmas.

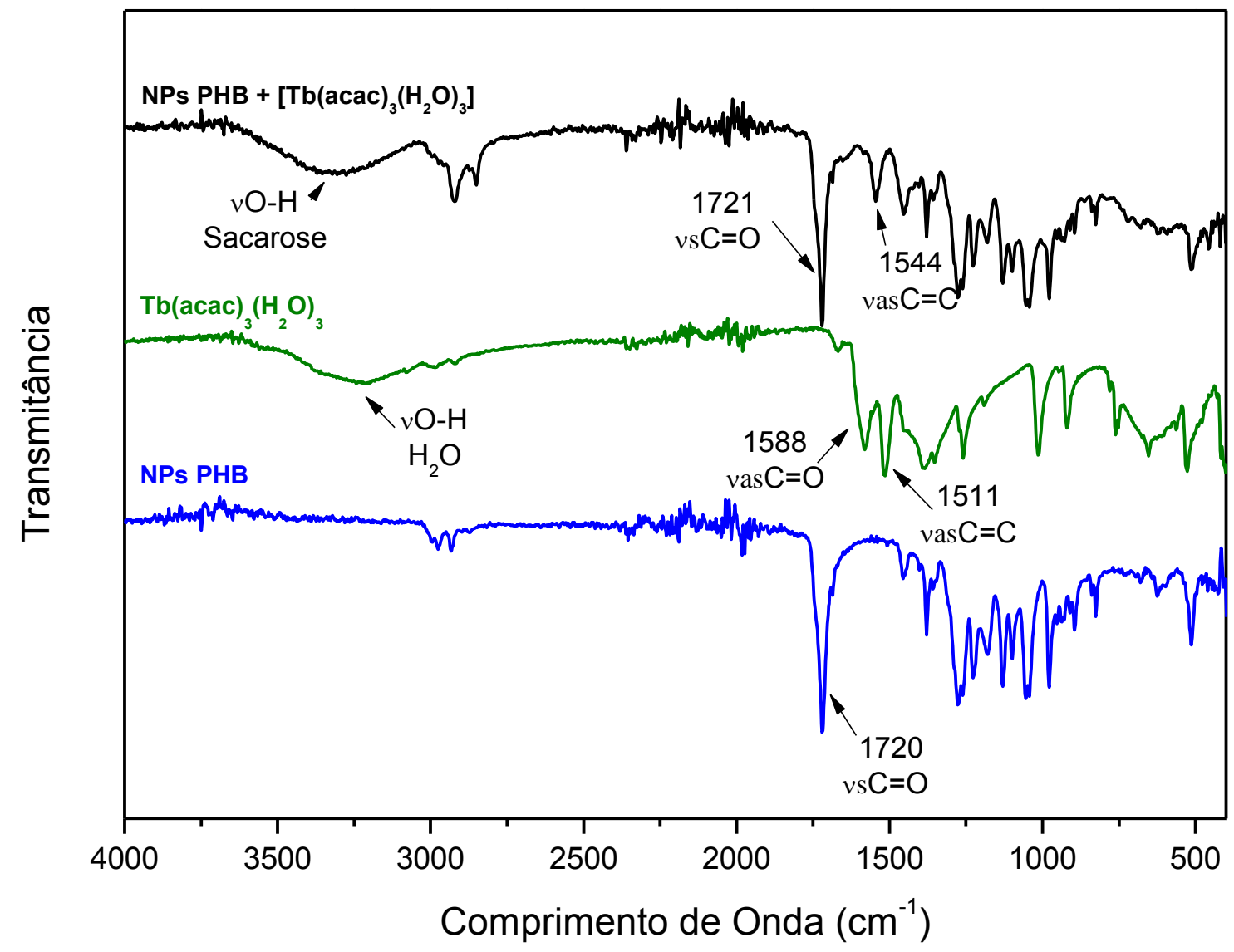

FIG.5.5: Espectros de absorção no infravermelho registrados a temperatura ambiente no intervalo de 4000 a $400 \mathrm{~cm}^{-1}$ do complexo $\left[\mathrm{Tb}(\mathrm{acac})_{3}\left(\mathrm{H}_{2} \mathrm{O}\right)_{3}\right]$, PHB puro, e das nanopartículas de PHB + complexo após liofilização. 
Apesar dessas informações, nota-se pouca diferença entre os espectros de infravermelho do PHB puro e do PHB agregado ao complexo, sugerindo que provavelmente a partícula obtida, não se apresenta homogênea, mas sim, uma estrutura com o complexo concentrado ao centro e envolto pela capa polimérica de PHB.

Pode-se levar isso em consideração pelo fato de que é possível uma diferença de solubilidade do complexo e do polímero no solvente usado no preparo das nanopartículas, de modo que a cristalização tenha ocorrido primeiro para o complexo, formando um centro com presença predominante desse e em seguida, a formação da capa do polímero, envolvendo o núcleo que no caso é o complexo.

Dessa forma, é possível dizer que, através da técnica de espectroscopia de absorção na região do infravermelho, não é possível confirmar que a partícula é homogênea com relação aos seus constituintes.

Na TAB 5.3 é possível visualizar os principais fenômenos obtidos nos espectros de infravermelho do $\mathrm{PHB}$, das nanopartículas de $\mathrm{PHB}+$ complexo e do complexo $\left[\mathrm{Tb}(\mathrm{acac})_{3}\left(\mathrm{H}_{2} \mathrm{O}\right)_{3}\right]$.

TAB 5.3: Principais frequências vibracionais $\left(\mathrm{cm}^{-1}\right)$ do $\mathrm{PHB}$, das nanopartículas de PHB dopado e $\left[\mathrm{Tb}(\mathrm{acac})_{3}\left(\mathrm{H}_{2} \mathrm{O}\right)_{3}\right]$

\begin{tabular}{cccc}
\hline Atribuição & PHB & PHB + Complexo & {$\left[\mathrm{Tb}(\mathbf{a c a c})_{3}\left(\mathbf{H}_{\mathbf{2}} \mathbf{O}\right)_{3}\right]$} \\
\hline$v s \mathrm{C}=\mathrm{O}$ & 1720 & 1721 & - \\
$v \mathrm{O}-\mathrm{H}$ & - & 3300 & 3300 \\
$\operatorname{vas} \mathrm{CH}_{3}$ & 2975 & 2920 & - \\
$\operatorname{vas} \mathrm{CH}_{2}$ & 2931 & 2850 & - \\
$v \mathrm{C}=\mathrm{C}$ e $\operatorname{vas} \mathrm{C}=\mathrm{O}$ & - & - & 1588 \\
\hline
\end{tabular}

Para os espectros do ligante Htta (FIG 5.6) observou-se a presença de duas bandas intensas em 1650 e $1632 \mathrm{~cm}^{-1}$ atribuídas ao estiramento simétrico vs $\mathrm{C}=\mathrm{O}$ e a mistura de estiramentos $v \mathrm{C}=\mathrm{C}$ e vas $\mathrm{C}=\mathrm{O}$, respectivamente. No entanto, no complexo [ $\left.\mathrm{Eu}(\mathrm{tta})_{3}\left(\mathrm{H}_{2} \mathrm{O}\right)_{2}\right]$, essas bandas são deslocadas para uma região de menor energia, 1600 e $1582 \mathrm{~cm}^{-1}$ indicando que o tta atua como 
um quelante, coordenando-se com o íon $\mathrm{TR}^{3+}$ através dos átomos de oxigênio presentes nos grupos carbonilas.

Observou-se também, bandas características relacionadas ao tiofeno, em 1518, 1403 e $1108 \mathrm{~cm}^{-1}$ tanto no ligante tta quanto nos complexos terras raras, além de bandas intensas presentes em $\beta$-dicetonatos com átomos de flúor, que no caso do Htta são observadas em uma região de 1400 a 900 $\mathrm{cm}^{-1}$, comumente atribuídas aos estiramentos simétricos e assimétricos $\mathrm{CF}$ e ao estiramento $\mathrm{CF}_{3}{ }^{[3]}$.

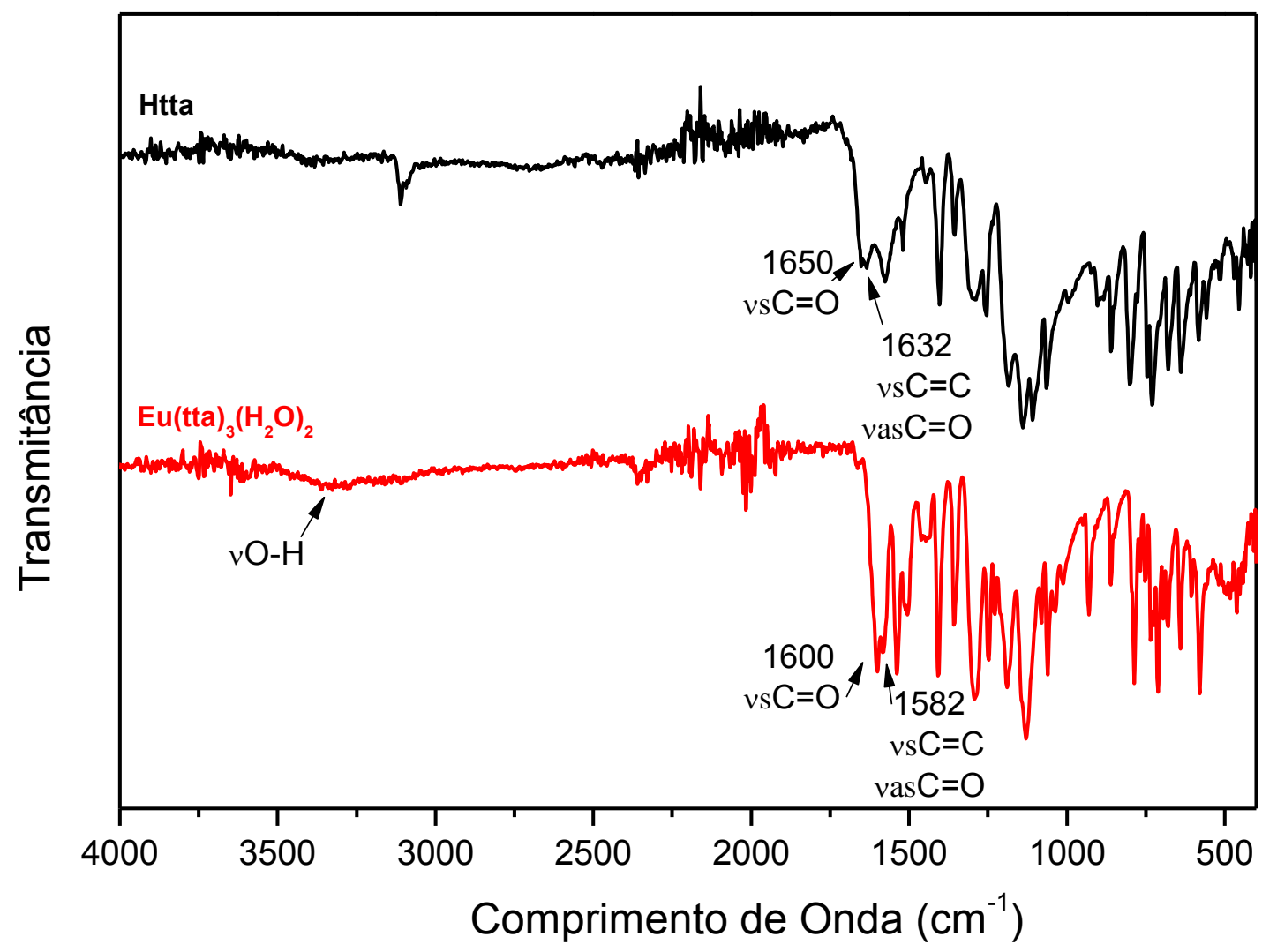

FIG.5.6: Espectros de absorção no infravermelho registrados a temperatura ambiente no intervalo de 4000 a $400 \mathrm{~cm}^{-1}$ do $\mathrm{Htta}$ e do complexo $\left[\mathrm{Eu}(\mathrm{tta})_{3}\left(\mathrm{H}_{2} \mathrm{O}\right)_{2}\right]$.

Na TAB 5.4 é possível visualizar os principais fenômenos obtidos nos espectros de infravermelho do $\mathrm{Htta}$ e $\left[\mathrm{Eu}(\mathrm{tta})_{3}\left(\mathrm{H}_{2} \mathrm{O}\right)_{2}\right]$. 
TAB 5.4: Principais frequências vibracionais $\left(\mathrm{cm}^{-1}\right)$ do $\mathrm{Htta}$ e $\left[\mathrm{Eu}(\mathrm{tta})_{3}\left(\mathrm{H}_{2} \mathrm{O}\right)_{2}\right]$

\begin{tabular}{ccc}
\hline Atribuição & Htta & {$\left[\mathrm{Eu}(\mathbf{t t a})_{3}\left(\mathbf{H}_{\mathbf{2}} \mathbf{O}\right)_{2}\right]$} \\
\hline$v s \mathrm{C}=\mathrm{O}$ & 1650 & 1600 \\
$v \mathrm{C}=\mathrm{C}$ e $v a s \mathrm{C}=\mathrm{O}$ & 1632 & 1582 \\
${ }_{s} \mathrm{CF}_{3}$ & 1291 & 1292 \\
$v \operatorname{vas} \mathrm{CF}_{3}$ & 1184 & 1189 \\
$v \mathrm{CF}$ & 1063 & 1061 \\
tiofeno & 1518 & 1510 \\
tiofeno & 1403 & 1407 \\
tiofeno & 1108 & 1080
\end{tabular}

No caso dos espectros de PHB e das nanopartículas de PHB com o complexo [ $\mathrm{Eu}(\mathrm{tta})_{3}\left(\mathrm{H}_{2} \mathrm{O}\right)_{2}$ ] (FIG 5.7) observa-se que o estiramento assimétrico vas $\mathrm{C}=\mathrm{C}$ em 1582 presente no complexo de $\mathrm{Eu}^{3+}$, é ausente no polímero $\mathrm{PHB}$ e fracamente perceptível nos aglomerados de nanopartículas poliméricas com 0 complexo de $\mathrm{Eu}^{3+}$.

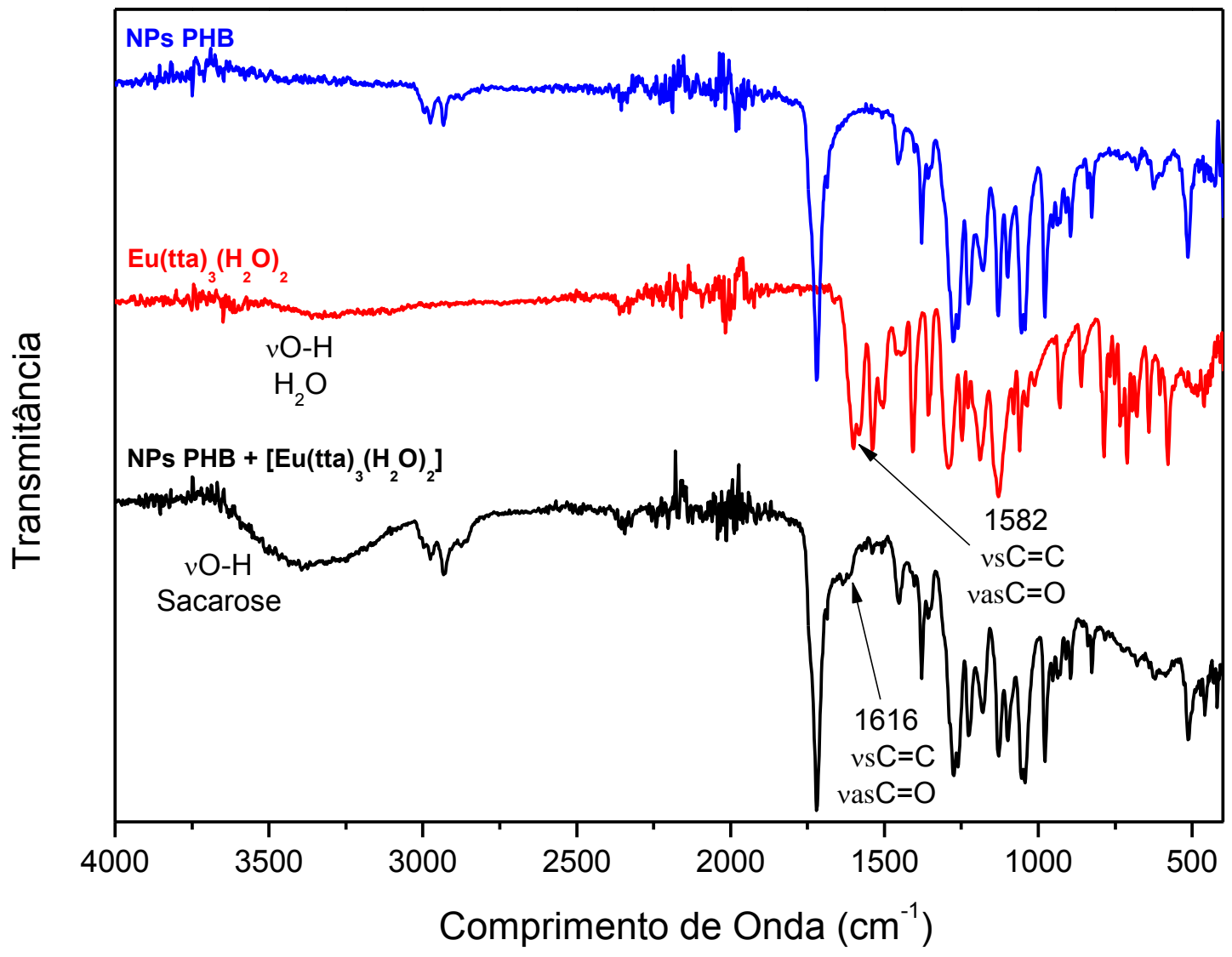

FIG.5.7: Espectros de absorção na região do infravermelho registrados a temperatura ambiente no intervalo de 4000 a $400 \mathrm{~cm}^{-1}$ do complexo [Eu(tta $\left.)_{3}\left(\mathrm{H}_{2} \mathrm{O}\right)_{2}\right]$, PHB puro, e das nanopartículas de PHB + complexo após liofilização. 
Além disso, a banda alargada presente no espectro de infravermelho do complexo, na região de 3500 a $3000 \mathrm{~cm}^{-1} \mathrm{e}$ atribuída ao estiramento $\mathrm{vO}-\mathrm{H}$ que é característica da presença de moléculas de água nos complexos, se mantém no espectro das nanopartículas, e possivelmente apresentam uma contribuição das hidroxilas presentes na sacarose utilizada como crioprotetor no processo de liofilização das mesmas, fato que também ocorreu com as nanopartículas liofilizadas contendo os complexos com ligantes acac.

$\mathrm{Na}$ TAB 5.5 é possível visualizar os principais modos vibracionais identificados nos espectros de infravermelho do PHB puro, PHB + complexo e do complexo.

TAB 5.5: Principais frequências vibracionais $\left(\mathrm{cm}^{-1}\right)$ do $\mathrm{PHB}$, das nanopartículas de PHB com complexo e $\left[\mathrm{Eu}(\mathrm{tta})_{3}\left(\mathrm{H}_{2} \mathrm{O}\right)_{2}\right]$

\begin{tabular}{cccc}
\hline Atribuição & PHB & PHB + complexo & {$\left[\mathrm{Eu}(\mathrm{tta})_{\mathbf{3}}\left(\mathbf{H}_{\mathbf{2}} \mathbf{O}\right)_{\mathbf{2}}\right]$} \\
\hline$v s \mathrm{C}=\mathrm{O}$ & 1720 & 1721 & 1600 \\
$v \mathrm{O}-\mathrm{H}$ & - & 3300 & 3300 \\
$v \operatorname{vas} \mathrm{CH}_{3}$ & 2975 & 2975 & - \\
$v \operatorname{vas} \mathrm{CH}_{2}$ & 2931 & 2930 & - \\
$v \mathrm{C}=\mathrm{C}$ e $\operatorname{vas} \mathrm{C}=\mathrm{O}$ & - & 1582 & 1582 \\
$v{ }_{s} \mathrm{CF}_{3}$ & - & - & 1292 \\
$v \operatorname{vas} \mathrm{CF}_{3}$ & - & - & 1189 \\
$v \mathrm{CF}$ & - & - & 1061 \\
tiofeno & - & 1508 & 1510 \\
tiofeno & - & 1402 & 1407 \\
tiofeno & - & 1098 & 1080 \\
\hline
\end{tabular}

\subsubsection{Análises térmicas}

A avaliação das propriedades térmicas é de suma importância quando se trata de materiais a base de polímeros, em função de uma gama de informações com relação a propriedades físicas e químicas do material. Dá-se o nome de análise térmica o grupo de técnicas onde uma determinada propriedade física é avaliada em função do tempo ou temperatura à medida 
que a substância sofre um aquecimento controlado ${ }^{[4,5]}$. Foram utilizadas para o desenvolvimento desse trabalho a termogravimetria/termogravimetria derivada (TG/DTG).

A termogravimetria é uma técnica que apresenta dados quantitativos de uma amostra, em relação à quantidade de um ligante orgânico, assim como a quantidade de cinzas (inorgânico) presentes na amostra. Nesta técnica, a amostra é submetida a um aquecimento controlado e a variação de massa é verificada em função do tempo e temperatura ${ }^{[6]}$. Os dados são obtidos pela curva TG ou então pela DTG que é a primeira derivada da variação da massa em função do tempo ou da temperatura e que normalmente apresenta uma forma mais clara e visualmente acessível dos dados obtidos ${ }^{[7]}$.

\subsubsection{Decomposição térmica dos complexos precursores}

Para que seja possível verificar a estabilidade térmica dos compostos utilizados no preparo das nanopartículas poliméricas, assim como questões relacionadas a presença de água e outras espécies na esfera de coordenação dos complexos de terras raras, se fez necessário o uso das técnicas de TG e DTG.

Para os compostos [TR $(\mathrm{tta})_{3}\left(\mathrm{H}_{2} \mathrm{O}\right)_{2}$ ] observam-se dois eventos relacionados a perda de água, seja residual do processo de secagem além das águas de coordenação do quelato. Essa perda de massa ocorre na faixa de 0 a $200^{\circ} \mathrm{C}$. Os demais eventos, entre 200 e $400^{\circ} \mathrm{C}$ se referem a decomposição térmica fracionada do ligante tta. Uma vez que todos os complexos com ligante tta apresentaram o mesmo comportamento termogravimétrico, na FIG 5.8 é apresentado a curva de TG e DTG do complexo $\left[\mathrm{Eu}(\mathrm{tta})_{3}\left(\mathrm{H}_{2} \mathrm{O}\right)_{2}\right]$ como exemplo e representativo dos demais.

A TAB 5.6 apresenta os principais eventos para todos os complexos de terras raras cujo ligante seja o tta onde se evidencia o comportamento semelhante entre eles. 


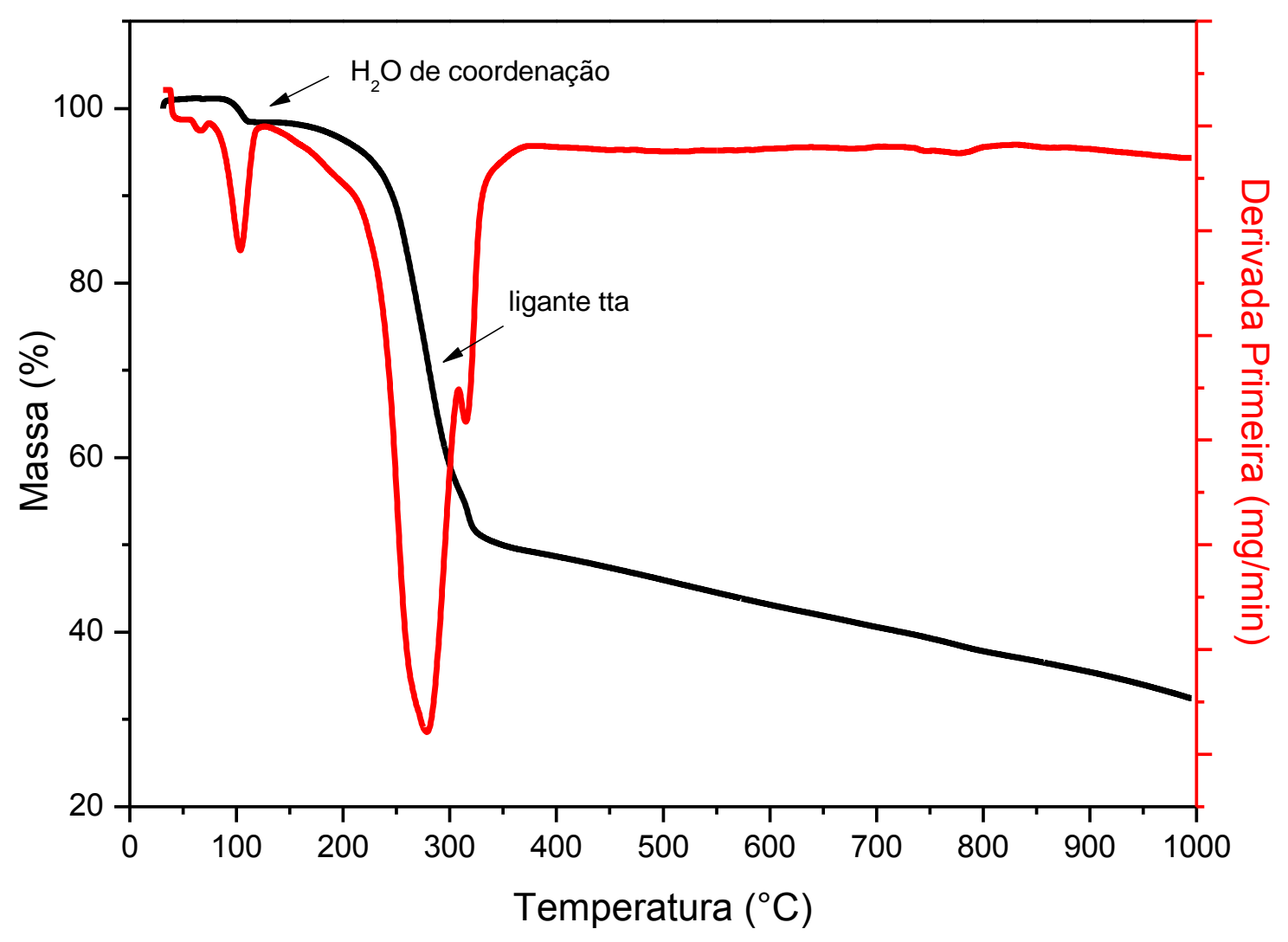

FIG.5.8: Curvas de TG e DTG do complexo $\left[\mathrm{Eu}(\mathrm{tta})_{3}\left(\mathrm{H}_{2} \mathrm{O}\right)_{2}\right]$.

TAB 5.6: Dados de decomposição térmica dos complexos precursores derivados do ligante tta.

\begin{tabular}{ccc}
\hline Complexos & Temperatura $\left({ }^{\circ} \mathbf{C}\right)$ & Massa perdida (\%) \\
\hline$\left[\mathrm{Eu}(\mathrm{tta})_{3}\left(\mathrm{H}_{2} \mathrm{O}\right)_{2}\right]$ & $31-132$ & 1,58 \\
& $130-410$ & 50,02 \\
& $409-995$ & 32,40 \\
& & \\
{$\left[\mathrm{Gd}(\mathrm{tta})_{3}\left(\mathrm{H}_{2} \mathrm{O}\right)_{2}\right]$} & $181-395$ & 2,42 \\
& $396-996$ & 49,68 \\
& & 31,83 \\
{$\left[\mathrm{Sm}(\mathrm{tta})_{3}\left(\mathrm{H}_{2} \mathrm{O}\right)_{2}\right]$} & $28-76$ & 6,34 \\
& $75-122$ & 1,42 \\
& $122-188$ & 2,70 \\
& $188-417$ & 45,88
\end{tabular}


Para os compostos $\left[\mathrm{TR}(\mathrm{acac})_{3}\left(\mathrm{H}_{2} \mathrm{O}\right)_{3}\right]$, novamente, nota-se o mesmo comportamento entre todos os complexos com esse ligante. Nos dois primeiros eventos, verificamos a perda de água, seja residual do processo de secagem como também das águas de coordenação do quelato. Essa perda de massa ocorre na faixa de 0 a $200^{\circ} \mathrm{C}$. Os demais eventos, entre 200 e $600^{\circ} \mathrm{C}$ referemse à decomposição térmica fracionada do ligante acac.

Em $600^{\circ} \mathrm{C}$ o pico largo é atribuído à formação de óxido de terra rara que apresenta um rearranjo na faixa entre 800 a $900^{\circ} \mathrm{C}$. Uma vez que todos os complexos com ligante acac apresentaram o mesmo comportamento termogravimétrico, na FIG5.9 é apresentado a curva de TG e DTG do complexo $\left[\mathrm{Tb}(\mathrm{acac})_{3}\left(\mathrm{H}_{2} \mathrm{O}\right)_{3}\right]$ como exemplo e representativo dos demais.

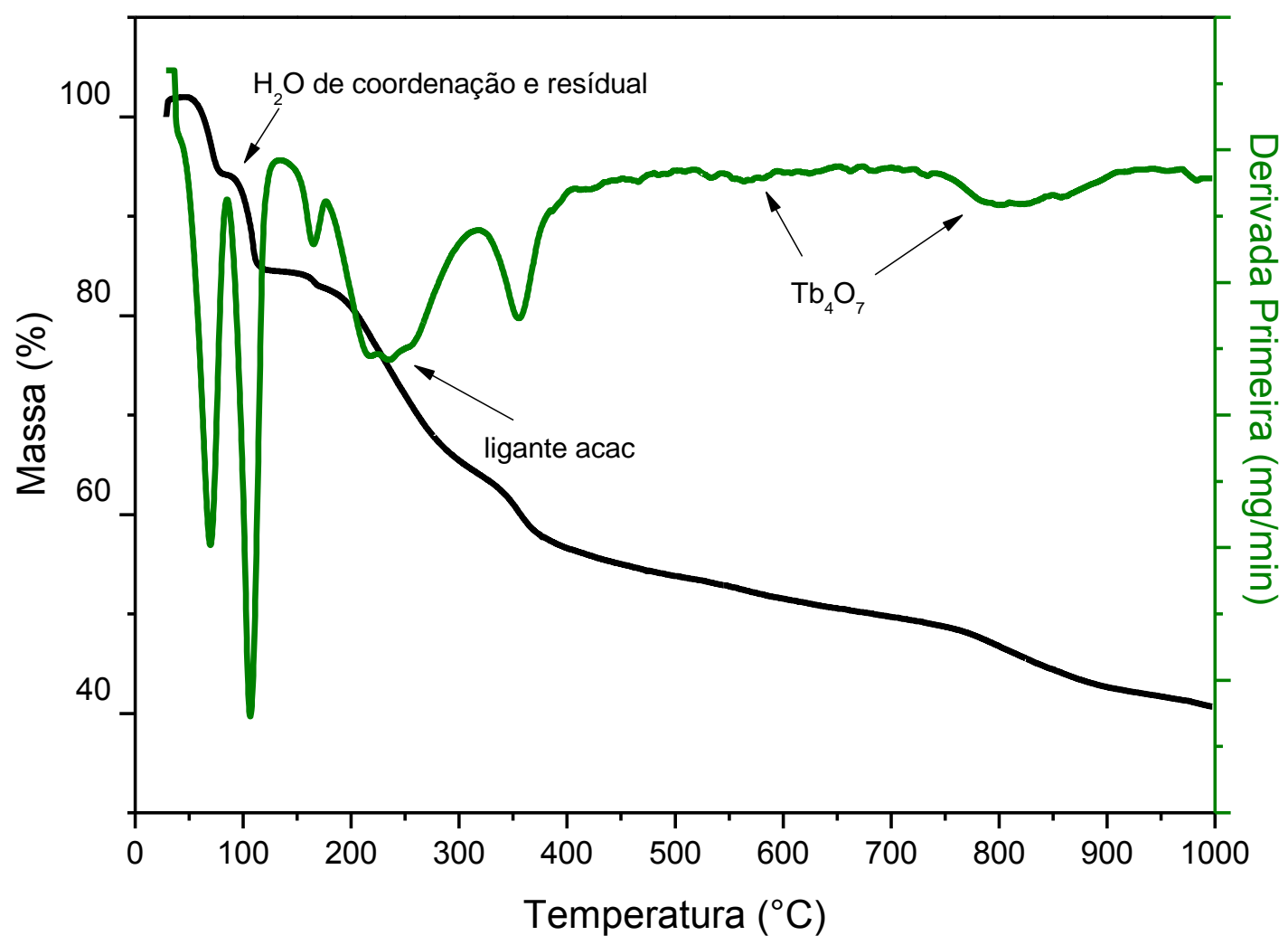

FIG.5.9: Curvas de TG e DTG do complexo $\left[\mathrm{Tb}(\mathrm{acac})_{3}\left(\mathrm{H}_{2} \mathrm{O}\right)_{3}\right]$.

A TAB 5.7 apresenta os principais eventos (5 eventos) para todos os complexos de terras raras cujo ligante seja $O$ acac onde se evidencia 0 comportamento semelhante entre eles. 
TAB 5.7: Dados de decomposição térmica dos complexos precursores derivados do ligante acac.

\begin{tabular}{ccc}
\hline Complexos & Temperatura $\left({ }^{\circ} \mathrm{C}\right)$ & Massa perdida (\%) \\
\hline & $29-81$ & 5,38 \\
{$\left[\mathrm{Eu}(\mathrm{acac})_{3}\left(\mathrm{H}_{2} \mathrm{O}\right)_{3}\right]$} & $81-125$ & 9,40 \\
& $125-180$ & 1,34 \\
& $181-307$ & 18,03 \\
& $307-431$ & 7,34 \\
{$\left[\mathrm{Gd}(\mathrm{acac})_{3}\left(\mathrm{H}_{2} \mathrm{O}\right)_{3}\right]$} & $29-85$ & 5,63 \\
& $85-134$ & 9,74 \\
& $134-181$ & 1,73 \\
& $182-315$ & 19,06 \\
& $316-472$ & 11,86 \\
& & \\
& $29-78$ & 4,69 \\
$\left.\mathrm{Sm}(\mathrm{acac})_{3}\left(\mathrm{H}_{2} \mathrm{O}\right)_{3}\right]$ & $78-128$ & 9,03 \\
& $128-307$ & 20,36 \\
& $307-435$ & 12,02 \\
& & \\
& $29-86$ & 5,86 \\
& $86-136$ & 9,70 \\
& $136-177$ & 1,72 \\
& $175-312$ & 18,26 \\
& $310-422$ & 8,77 \\
& &
\end{tabular}

\subsubsection{Decomposição térmica das nanopartículas}

Uma vez que todas as nanopartículas dos complexos com ligante tta apresentaram o mesmo comportamento termogravimétrico, na FIG 5.10 é apresentada as curvas de decomposição térmica, TG e DTG, das nanopartículas de PHB + complexo $\left[\mathrm{Eu}(\mathrm{tta})_{3}\left(\mathrm{H}_{2} \mathrm{O}\right)_{2}\right]$ como exemplo 
representativo das demais nanopartículas. Para as nanopartículas com $\left[\mathrm{Eu}(\mathrm{tta})_{3}\left(\mathrm{H}_{2} \mathrm{O}\right)_{2}\right]$, observam-se os mesmos eventos, sendo 0 primeiro relacionado a perda de água residual do processo de secagem além das águas de umidade da sacarose. Essa perda de massa ocorre na faixa de 0 a $110^{\circ} \mathrm{C}$. Os demais eventos, entre 110 e $240^{\circ} \mathrm{C}$ referem-se à decomposição térmica da sacarose $^{[8]}$. O evento principal que aparece entre 240 e $320^{\circ} \mathrm{C}$ refere-se à decomposição térmica do polímero $\mathrm{PHB}$ e provavelmente parte da decomposição fracionada do ligante tta.

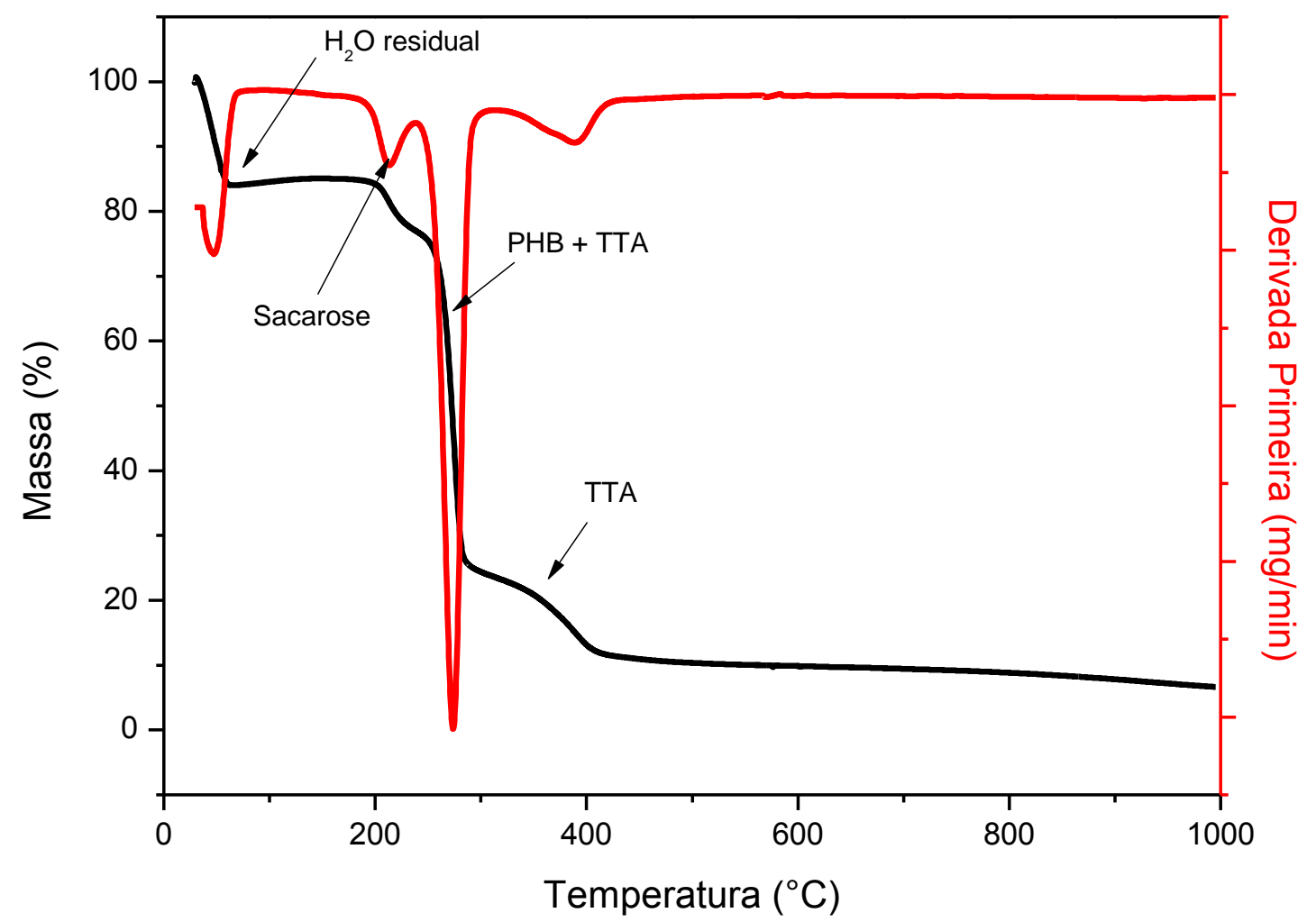

FIG.5.10: Curvas de TG e DTG das nanopartículas de PHB com complexo $\left[\mathrm{Eu}(\mathrm{tta})_{3}\left(\mathrm{H}_{2} \mathrm{O}\right)_{2}\right]$.

No caso do ligante tta, uma vez que esse trabalho propõe que a partícula formada apresenta o complexo interno envolto por uma capa polimérica, é possível que o evento entre 320 a $420^{\circ} \mathrm{C}$ se refira ao complexo do interior da partícula liberado após a decomposição do polímero.

A TAB 5.8 apresenta os principais eventos para todos os complexos de terras raras para o ligante tta onde se evidencia um comportamento semelhante entre eles. 
TAB 5.8: Dados de decomposição térmica das nanopartículas de PHB dopadas com complexos precursores derivados do ligante tta.

\begin{tabular}{ccc}
\hline Dopagem & Temperatura $\left({ }^{\circ} \mathbf{C}\right)$ & Massa perdida (\%) \\
\hline & $30-110$ & 15,28 \\
{$\left[\mathrm{Eu}(\mathrm{tta})_{3}\left(\mathrm{H}_{2} \mathrm{O}\right)_{2}\right]$} & $110-240$ & 7,71 \\
& $240-320$ & 53,90 \\
& $320-1000$ & 6,63 \\
& $32-236$ & 6,53 \\
{$\left[\mathrm{Gd}(\mathrm{tta})_{3}\left(\mathrm{H}_{2} \mathrm{O}\right)_{2}\right]$} & $242-308$ & 38,98 \\
& $312-1000$ & 9,30 \\
& & \\
{$\left[\mathrm{Sm}(\mathrm{tta})_{3}\left(\mathrm{H}_{2} \mathrm{O}\right)_{2}\right]$} & $32-240$ & 11,18 \\
& $242-308$ & 37,39 \\
& $312-1000$ & 14,99 \\
\hline
\end{tabular}

Novamente, para as nanopartículas dopadas com [ Tb(acac $\left.)_{3}\left(\mathrm{H}_{2} \mathrm{O}\right)_{3}\right]$ observam-se os mesmos eventos obtidos com as nanopartículas de PHB com os complexos de ligante tta. O primeiro refere-se a perda de água residual do processo de secagem além das águas de umidade da sacarose. Essa perda de massa ocorre na faixa de 0 a $170^{\circ} \mathrm{C}$. Os demais eventos, entre 170 e $240^{\circ} \mathrm{C}$ estão relacionados à decomposição térmica da sacarose ${ }^{[8]}$. $O$ evento principal que aparece entre 240 e $320^{\circ} \mathrm{C}$ foi atribuído à decomposição térmica do polímero PHB e provavelmente parte da decomposição fracionada do ligante acac.

Uma vez que todas as nanopartículas com complexos com ligante acac apresentaram o mesmo comportamento termogravimétrico, na FIG5.11é mostrada a curva de TG e DTG das nanopartículas de PHB com complexo $\left[\mathrm{Tb}(\mathrm{acac})_{3}\left(\mathrm{H}_{2} \mathrm{O}\right)_{3}\right]$ como exemplo dos demais materiais misturado com os complexos de acac. 


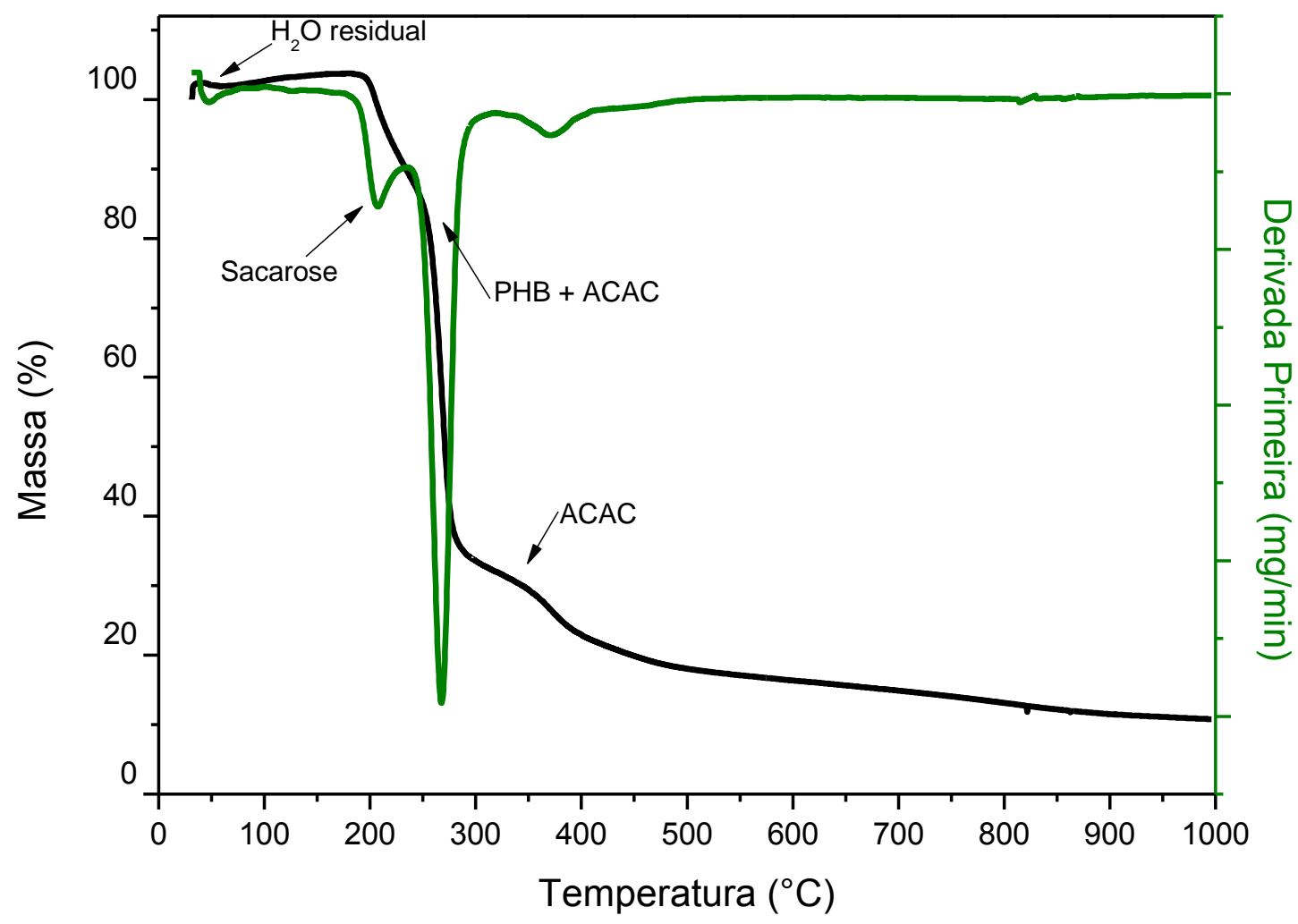

FIG.5.11: Curvas de TG e DTG das nanopartículas de PHB com complexo $\left[\mathrm{Tb}(\mathrm{acac})_{3}\left(\mathrm{H}_{2} \mathrm{O}\right)_{2}\right]$.

No caso do ligante acac, assim como descrito no caso do uso de complexo com ligante tta, é possível que o evento entre 320 a $420^{\circ} \mathrm{C}$ se refira ao complexo do interior da partícula liberado após a decomposição do polímero.

A TAB 5.9 apresenta os principais eventos para todos os complexos de terras raras cujo ligante seja o acac onde se evidencia o comportamento semelhante entre eles. 
TAB 5.9: Dados de decomposição térmica das nanopartículas de PHB dopadas com complexos precursores derivados do ligante acac.

\begin{tabular}{|c|c|c|}
\hline Dopagem & Temperatura $\left({ }^{\circ} \mathrm{C}\right)$ & Massa perdida (\%) \\
\hline \multirow{4}{*}[\mathrm{Eu}(\mathrm{acac})_{3}(\mathrm{H}_{2}\mathrm{O})_{3}]{} & $30-158$ & 0,83 \\
\hline & $158-230$ & 9,00 \\
\hline & $230-303$ & 52,70 \\
\hline & $302-1000$ & 14,28 \\
\hline \multirow{4}{*}[\mathrm{Gd}(\mathrm{acac})_{3}(\mathrm{H}_{2}\mathrm{O})_{3}]{} & $30-170$ & 2,35 \\
\hline & $170-230$ & 12,53 \\
\hline & $230-302$ & 59,81 \\
\hline & $302-1000$ & 8,01 \\
\hline \multirow{4}{*}[\mathrm{Sm}(\mathrm{acac})_{3}(\mathrm{H}_{2}\mathrm{O})_{3}]{} & $30-180$ & 4,50 \\
\hline & $180-230$ & 11,52 \\
\hline & $230-302$ & 62,39 \\
\hline & $302-1000$ & 8,72 \\
\hline \multirow{4}{*}[\mathrm{Tb}(\mathrm{acac})_{3}(\mathrm{H}_{2}\mathrm{O})_{3}]{} & $30-170$ & 3,70 \\
\hline & $170-240$ & 14,52 \\
\hline & $240-320$ & 57,30 \\
\hline & $320-1000$ & 10,78 \\
\hline
\end{tabular}

Tanto para os complexos com ligante acac quanto os complexos com ligante tta e materiais derivados, os comportamentos são semelhantes aos encontrados por Teotonio ${ }^{[9]}$ e Kai $^{[10]}$.

\subsection{Difração de RaiosX}

A técnica de Difração de Raios $X$ tem como base a emissão de radiações eletromagnéticas de Raios $X$ produzidos a partir do bombardeio do anôdo por elétrons acelerados do catodo, obtidos por alta voltagem. Essas 
radiações possuem alta energia com comprimento de onda $(\lambda)$ entre 0,02 e 100 Å. Essa faixa de comprimento de onda é comparável às dimensões atômicas, portanto, é possível ocorrer difração no estado sólido ${ }^{[11]}$.

Os Raios X são gerados através do bombardeio de uma placa metálica (geralmente de ferro ou cobre) com um feixe de elétrons ( 35 keV) que retiram os elétrons da camada mais interna do metal, a camada K. Para estabilização do sistema, um elétron da camada $L$ preenche o espaço na camada $K$, liberando energia na forma de Raios $X^{[12]}$.

Trata-se de uma das técnicas mais eficientes no que se refere à elucidação estrutural ${ }^{[13]}$ e tem sido largamente usada na análise de polímeros para atribuição de isomorfismo e de grau de cristalinidade em amostras.

É importante ressaltar que o principal interesse no uso da técnica de Raios $X$ neste trabalho é a avaliação qualitativa, com 0 intuito de obter informações sobre a morfologia das nanopartículas poliméricas preparadas, bem como avaliar diferenças morfológicas entre uma partícula polimérica pura e associada com o complexo marcador, a fim de verificar possíveis variações em função da mistura. Portanto, não será aprofundado o estudo e realização de cálculos dos fatores de forma e estrutura.

A análise foi feita utilizando-se o método de pó, no intervalo de 5 a $90^{\circ}$, para os complexos precursores e os aglomerados de nanopartículas poliméricas de PHB, estes obtidos após a liofilização na presença de sacarore como crioprotetor. Para os complexos de terras raras, são apresentados separadamente, os difratogramas dos complexos com ligantes acac (FIG 5.12) e dos complexos com ligantes tta (FIG 5.13).

Os difratogramas de Raios $\mathrm{X}$ dos complexos precursores $\left(\left[\mathrm{TR}(\mathrm{acac})_{3}\left(\mathrm{H}_{2} \mathrm{O}\right)_{3}\right]\right.$ e $\left[\mathrm{TR}(\mathrm{tta})_{3}\left(\mathrm{H}_{2} \mathrm{O}\right)_{2}\right]$ onde $\mathrm{TR}=\mathrm{Eu}^{3+}, \mathrm{Tb}^{3+}, \mathrm{Sm}^{3+}$ e $\left.\mathrm{Gd}^{3+}\right)$ apresentam picos de difração finos e bem definidos, o que caracteriza uma alta cristalinidade ${ }^{[12]}$. A partir dos difratogramas observa-se também que tanto os complexos de $\mathrm{TR}^{+3}$ com ligante tta quanto acac formam séries isomorfas. 


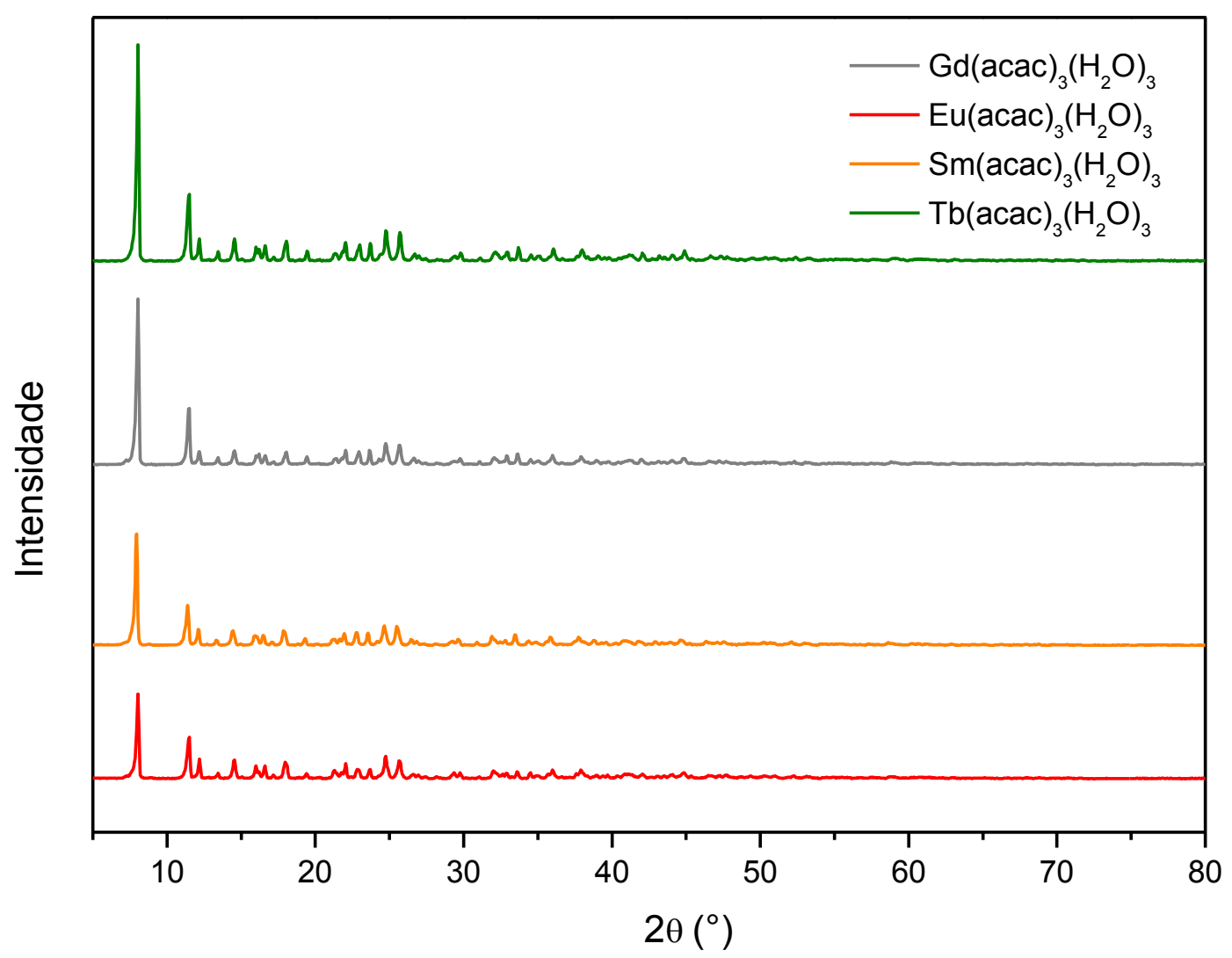

FIG.5.12: Difratogramas de Raios $X$ dos complexos de acac.

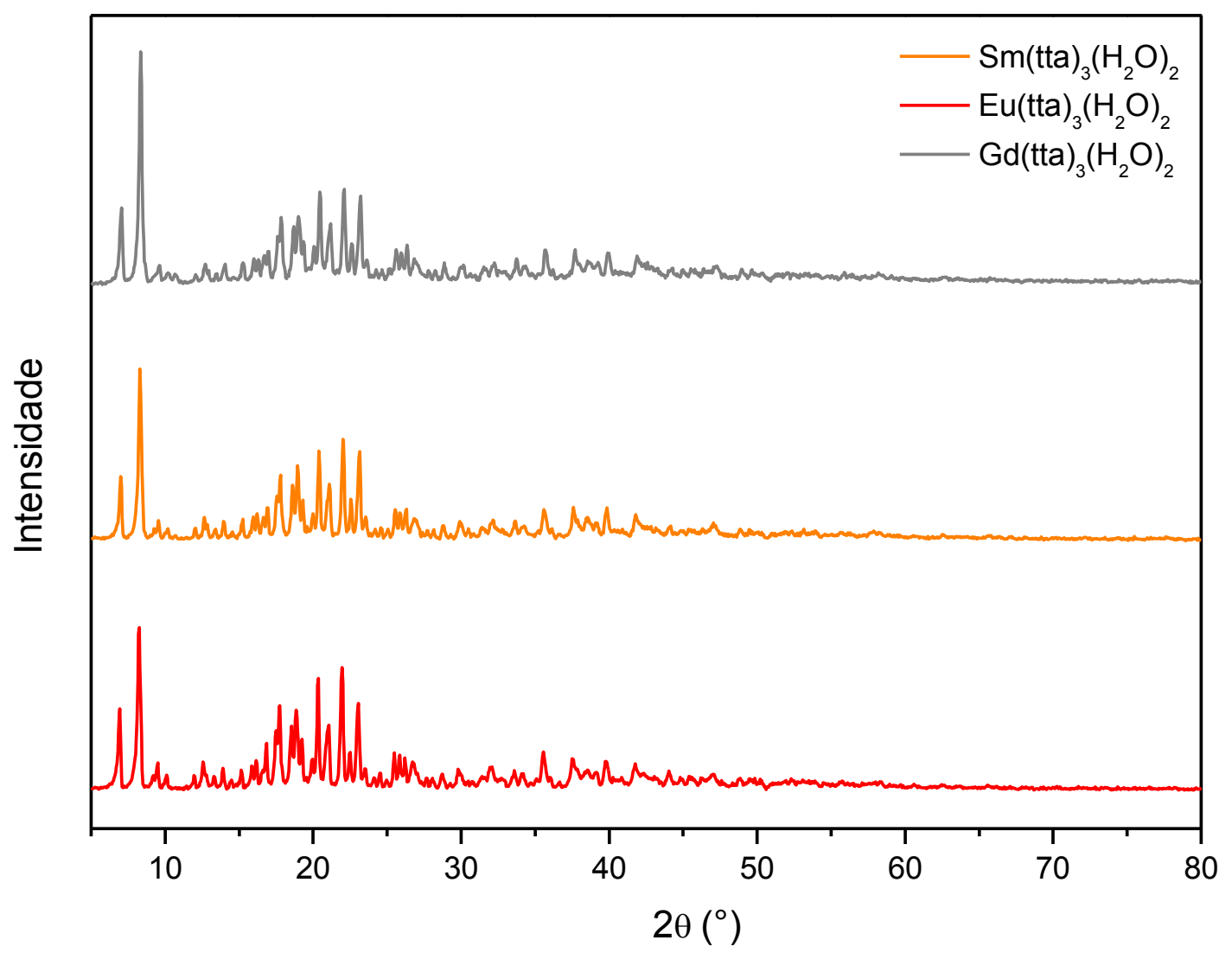

FIG.5.13: Difratogramas de Raios $X$ dos complexos de tta. 
Com relação aos difratogramas de Raios $\mathrm{X}$ obtido a partir dos aglomerados de nanopartículas poliméricas com os complexos de $\beta$ dicetonatos, tta (FIG 5.14) e acac (FIG 5.15) foi observada a presença de bandas relativamente definidas, no entanto, alargadas, o que sugere um sistema polimérico semicristalino ${ }^{[13]}$. Percebe-se também que a posição da maioria dos picos, assim como a intensidade relativa, não possui grande variação, o que indica que a morfologia estrutural do sistema não sofre grande variação com a mudança do ín terra rara. Pode-se observar que os difratogramas dos aglomerados de nanopartículas com os complexos de samário e gadolínio apresentam um halo de amorficidade referente ao polímero, mais acentuado.

É importante enfatizar que nesse trabalho não foi avaliado as características físico-químicas e estruturais em função do teor dos complexos de terras raras, portanto, não é possível indicar com os difratogramas de raios $\mathrm{X}$, o aumento ou decréscimo da cristalinidade no sistema polimérico das nanopartículas.

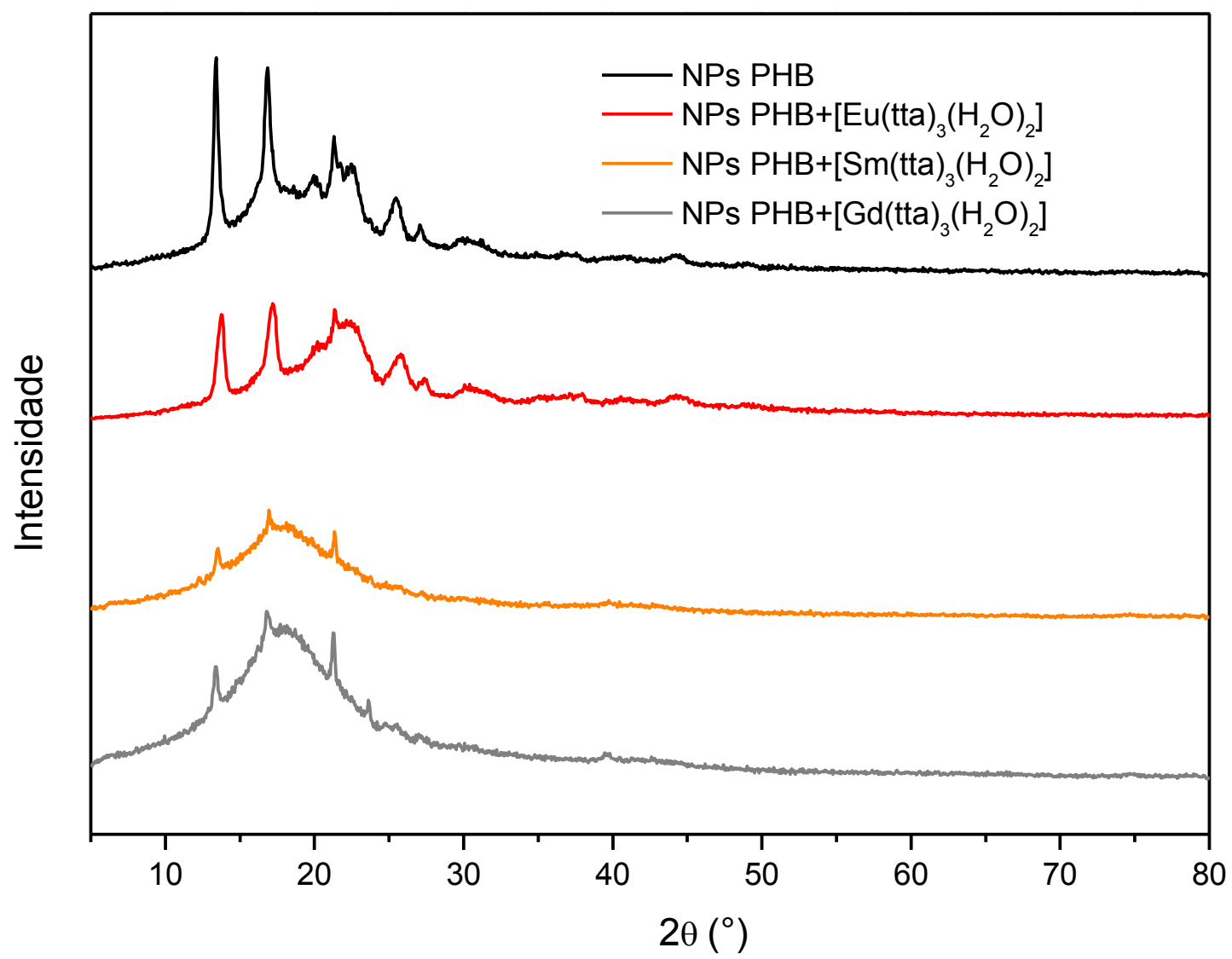

FIG.5.14: Difratogramas de Raios $X$ das nanopartículas de PHB + complexos com ligante tta. 


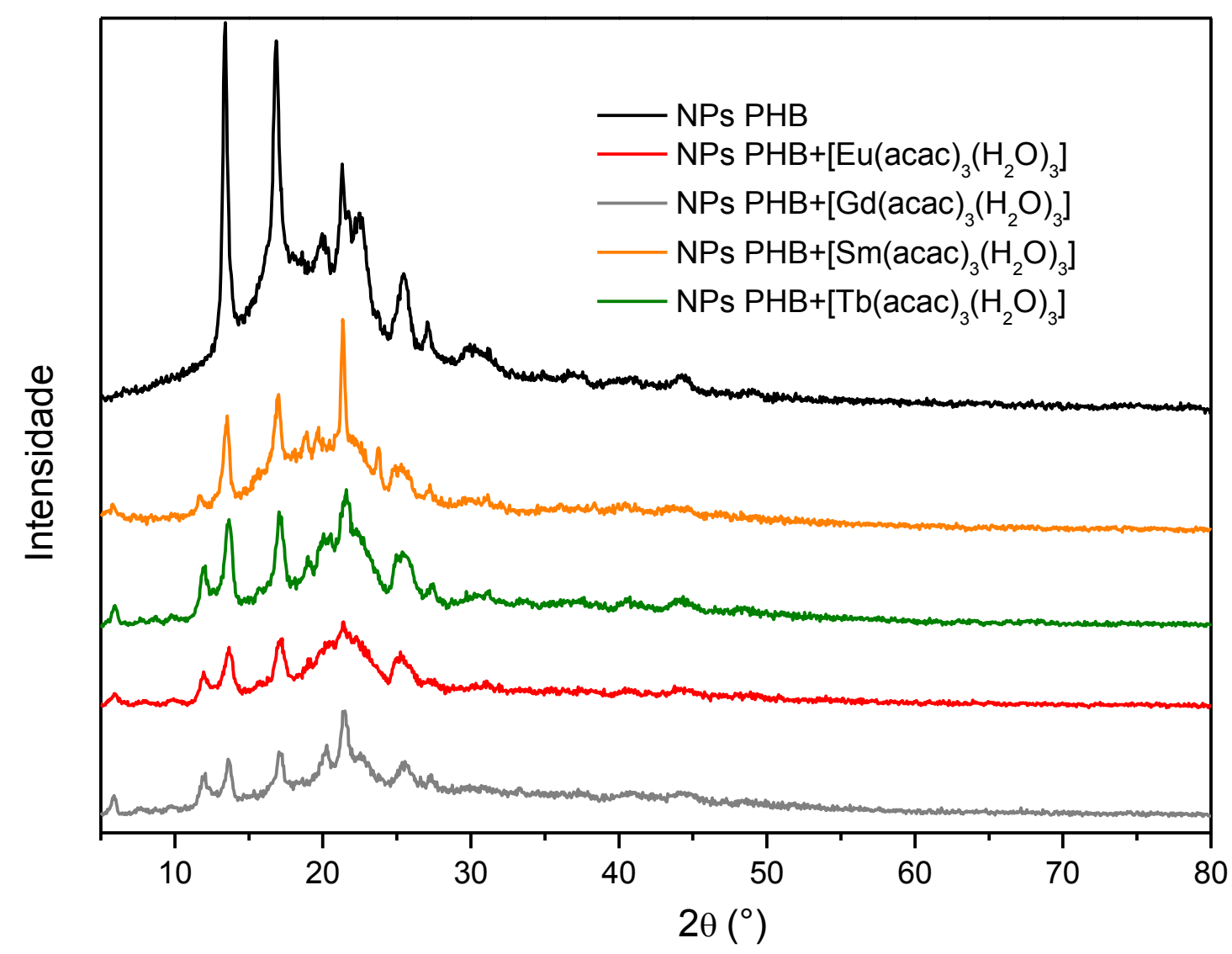

FIG.5.15: Difratogramas de Raios X das nanopartículas de PHB + complexos com ligante acac.

\subsection{Microscopia eletrônica de varredura (MEV) das nanopartículas}

O Microscópio Eletrônico de Varredura (MEV) é um dos instrumentos com alta resolução utilizado para a observação de características microestruturais de materiais no estado sólido, com resoluções de valores na ordem de 2 a $5 \mathrm{~nm}$ para equipamentos comerciais e de $1 \mathrm{~nm}$ para equipamentos mais avançados para uso em pesquisa ${ }^{[14]}$.

São apresentadas na FIG 5.16 as imagens obtidas por microscopia de varredura (MEV) das nanopartículas poliméricas de PHB com os complexos de terras raras. As amostras para visualização foram obtidas com a diluição da emulsão e passagens repetidas por um papel de filtro, a fim de prender as nanopartículas gradualmente evitando a formação de filmes. Após a filtração, o papel de filtro ficou 24 horas em dessecador. 

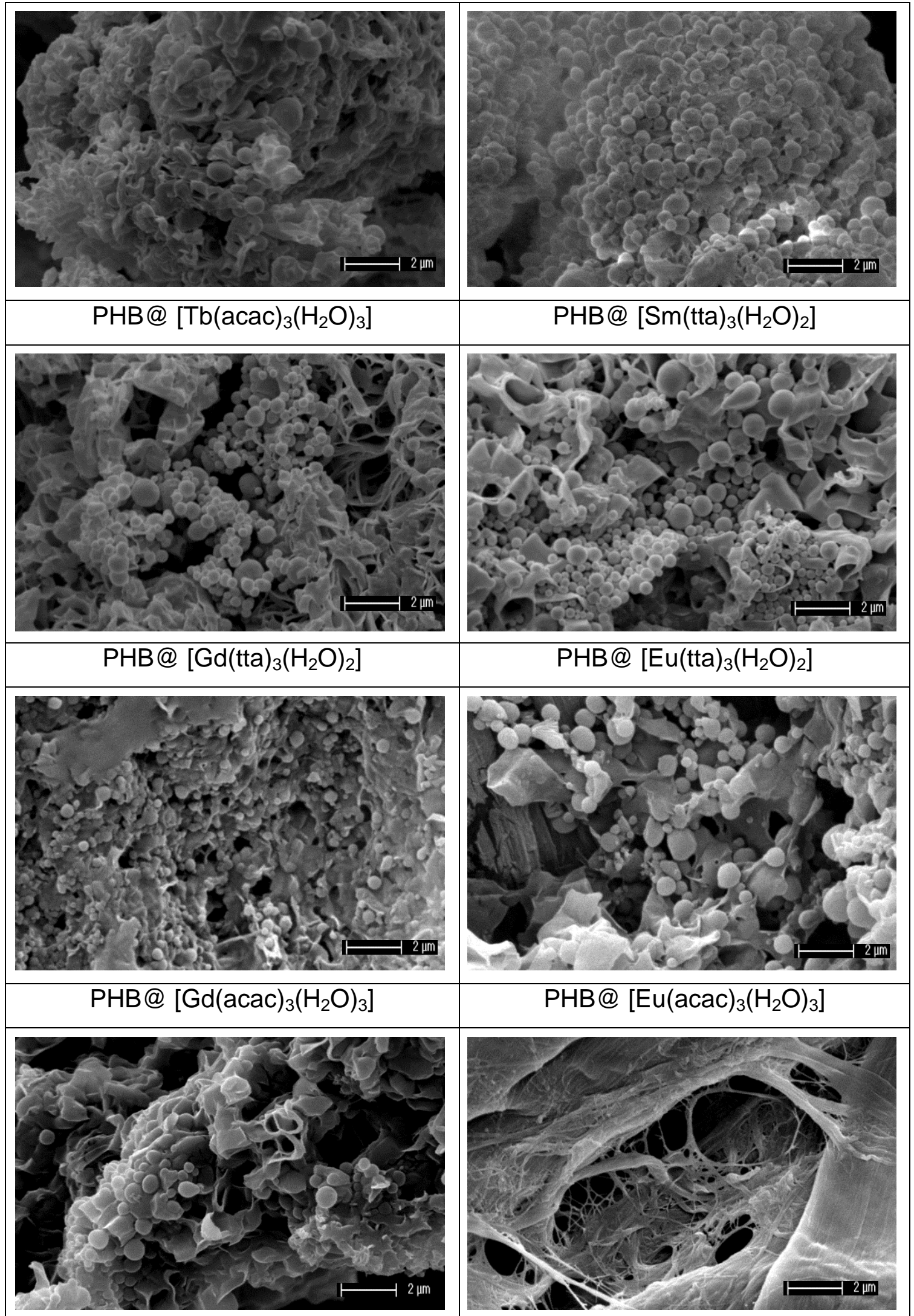

$\mathrm{PHB} @\left[\mathrm{Sm}(\mathrm{acac})_{3}\left(\mathrm{H}_{2} \mathrm{O}\right)_{3}\right]$

Papel de Filtro

FIG.5.16: Micrografias dos papéis de filtro sem e com nanopartículas de PHB com complexos de terras raras. 
São observadas partículas de diversos tamanhos, principalmente partículas com aproximadamente, 100, 200 e 500 nm, assim bem como aglomerados maiores. Uma imagem do papel de filtro foi obtida para certificação que a superfície do papel não tivesse formas arredondadas que pudessem ser confundidas com as nanopartículas poliméricas.

\subsection{Testes de Citotoxicidade e Hemocompatibilidade}

O principal objetivo do teste de citotoxicidade é identificar se o material ou dispositivo tem a capacidade de produzir efeitos letais ou subletais no meio biológico em nível celular e deve ser aplicado a todos os tipos de biomateriais. $O$ teste de citotoxicidade pode ser realizado através da difusão em Agar, ou por eluição ${ }^{[15]}$.

Nos testes de citotoxicidade, cujo procedimento esta descrito no item 4.9 e 4.10 foram avaliados o PHB e o PHB com complexo [ $\mathrm{Eu}(\mathrm{tta})_{3}\left(\mathrm{H}_{2} \mathrm{O}\right)_{2}$ ] frente a um controle negativo (polietileno de alta densidade) e controle positivo (fenol). Na FIG 5.17, são apresentados às curvas obtidas com as diferentes diluições.

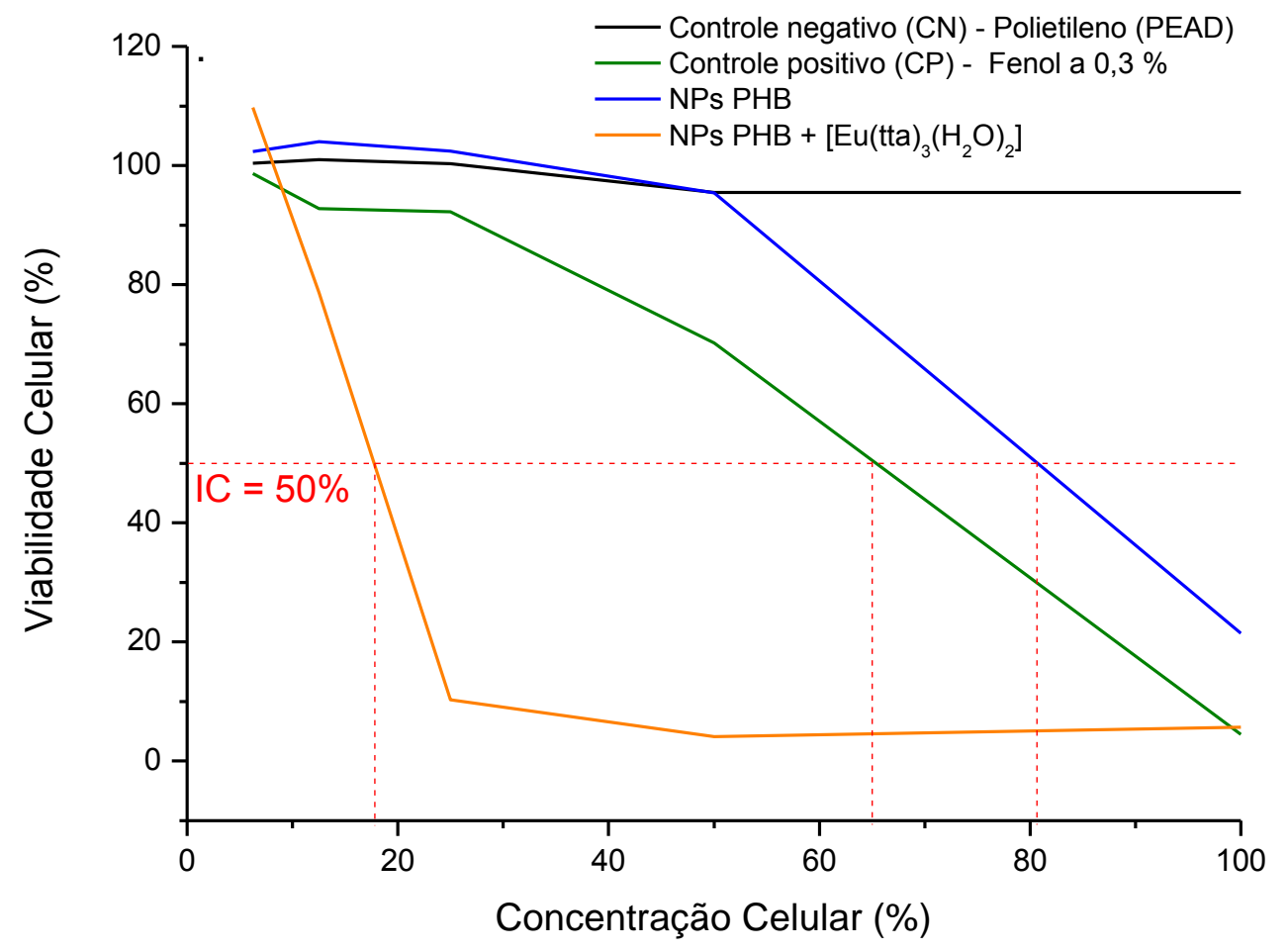

FIG.5.17: Gráfico de Citotoxicidade para as nanopartículas de PHB e PHB com $\left[\mathrm{Eu}(\mathrm{tta})_{3}\left(\mathrm{H}_{2} \mathrm{O}\right)_{2}\right]$. 
De acordo com o gráfico de citotoxicidade, o PHB puro se mostrou pouco citotóxico, uma vez que seu IC50 corresponde a aproximadamente $82 \%$ e o PHB tratado com complexo $\left[\mathrm{Eu}(\mathrm{tta})_{3}\left(\mathrm{H}_{2} \mathrm{O}\right)_{2}\right.$ ], O IC50 (concentração necessária para inibir metade da atividade celular) ficou em torno de $18 \%$ o que indica alta toxicidade. Controle negativo e controle positivo tiveram IC50 100 e $60 \%$ respectivamente.

Uma vez que a proposta desse trabalho é o uso das nanopartículas para teste de diagnóstico, ou seja, sem aplicação in vivo, o teste de citotoxicidade só vem confirmar a inviabilidade do uso desse biomaterial in vivo.

Por outro lado as células sanguíneas são responsáveis pelos processos fisiológicos extremamente importantes à vida de um organismo. As hemácias são responsáveis pelo transporte de gases $\left(\mathrm{O}_{2}\right.$ e $\left.\mathrm{CO}_{2}\right)$ através das hemoglobinas e os leucócitos estão relacionados ao sistema de defesa do organismo, alem das propriedades de coagulação relacionadas às plaquetas. Devido a essa importância é necessário se ter o controle sobre a interação dos materiais biocompatíveis quando em contato direto com o sangue.

Em função do uso dessas nanopartículas em sangue, torna-se interessante uma avaliação do comportamento de algumas estruturas do sangue tal como as plaquetas, frente ao material de PHB-complexo de $\mathrm{TR}^{3+}$. Os testes de hemocompatibilidade foram descritos no item 4.10 e resultaram nas micrografias apresentadas na FIG 5.18.

De acordo com as micrografias registradas no MEV, observa-sea presença de trombos e plaquetas rompidas nos filmes de PHB e PHB dopados com $\left[\mathrm{Eu}(\mathrm{tta})_{3}\left(\mathrm{H}_{2} \mathrm{O}\right)_{2}\right]$ e algumas plaquetas rompidas no PHB dopado com $\left[\mathrm{Tb}(\mathrm{acac})_{3}\left(\mathrm{H}_{2} \mathrm{O}\right)_{3}\right]$, assim como plaquetas inteiras. Dessa forma, pode-se afirmar que os dois primeiros apresentam baixa hemocompatibilidade e 0 terceiro, média hemocompatiblidade. $O$ controle positivo usado foi o vidro e o controle negativo, o latex. 


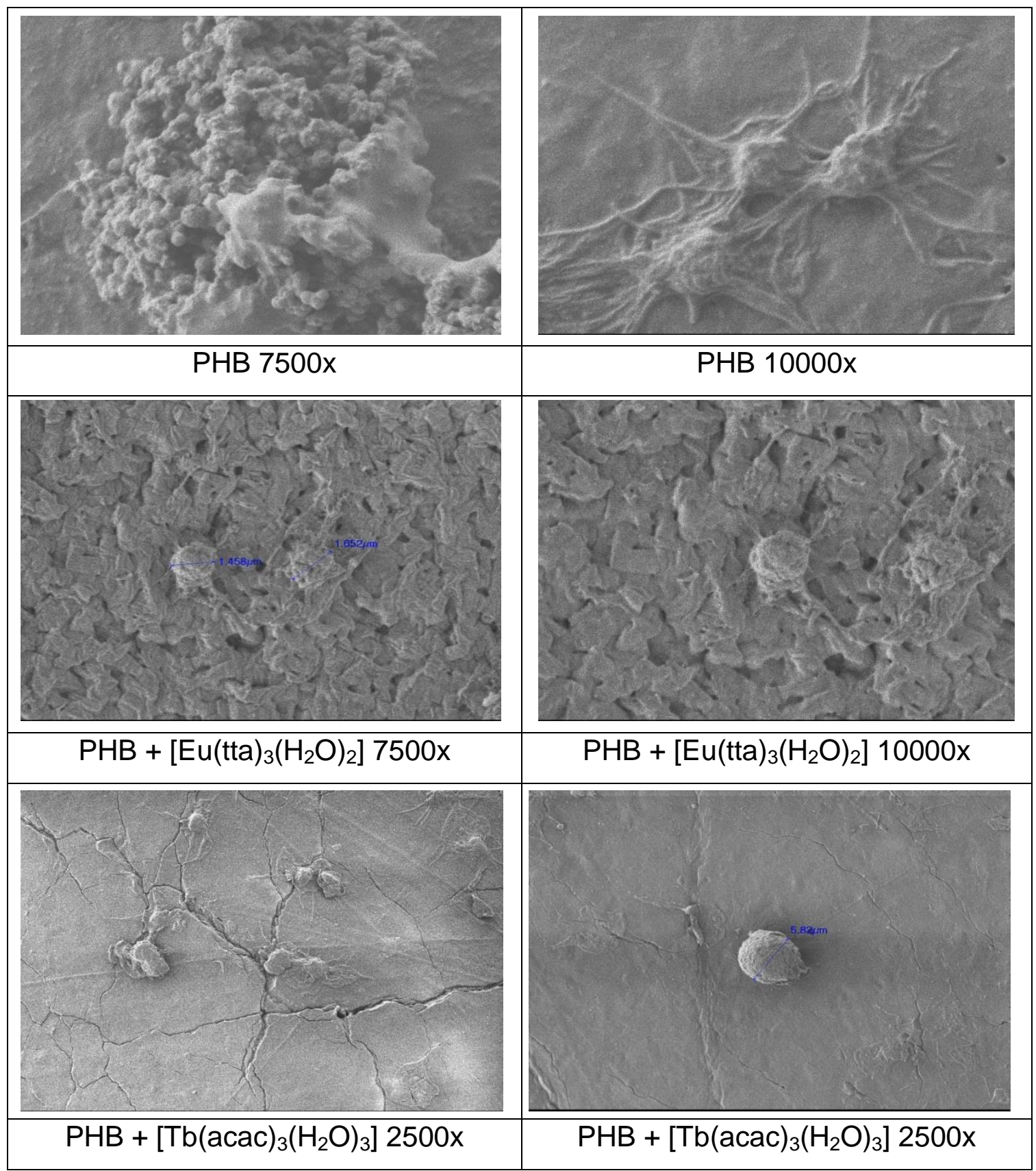

FIG.5.18: Micrografias de filmes de PHB com e sem complexos de terras raras. 


\subsection{Espectroscopia de correlação de fotóns}

A Espectroscopia de Correlação de Fótons (PCS) é uma técnica recente capaz de apresentar um perfil granulométrico para sistemas coloidais de forma satisfatória e sem a destruição da amostra, diferentemente de outras técnicas. A técnica de PCS, conhecida também como espalhamento de luz dinâmico, produz um feixe de luz que atravessa uma cubeta (similar a cubeta usada nas técnicas de espectrofotometria de absorção molecular UV-Visível) contendo a amostra ${ }^{[16]}$.

Soluções contendo nanopartículas apresentam movimentos brownianos em função das colisões com moléculas do fluido. Esse movimento é aleatório e quanto menor a partícula, maior a frequência de ocorrência desses movimentos. Portanto, a luz espalhada por partículas que apresentam movimento browniano também variam com o tempo, o que provoca interferência no sinal que chega ao detector, sendo assim, é possível criar uma relação entre a intensidade de sinal gerada e aquela que chega ao detector em função da quantidade e do tamanho de partículas que atravessam aquele feixe em um determinado tempo ${ }^{[16,17]}$. A técnica de PCS tem sido inclusive, utilizada como técnica de avaliação temporal sobre a agregação de partículas ${ }^{[18]}$.

Para a análise de tamanho de partícula, utilizou-se a técnica de espectroscopia de correlação de fótons, através de um equipamento Nano Sizer.

Todas as amostras apresentaram um comportamento bimodal, com tamanhos de partícula em torno de $10 \mathrm{~nm}$ e $300 \mathrm{~nm}$ para as nanopartículas preparadas com PHB e os complexos de tta conforme gráficos apresentados na FIG 5.19. 


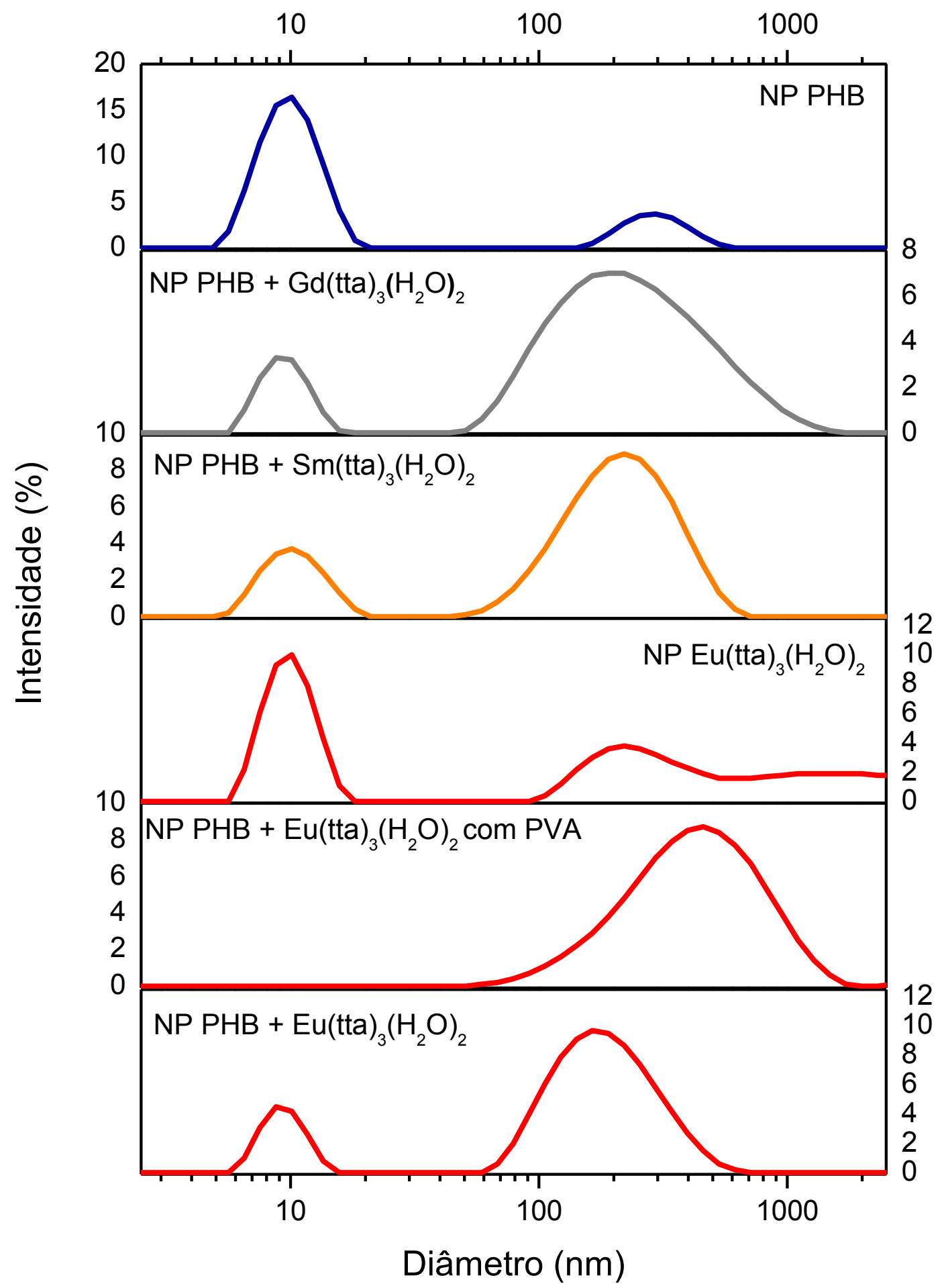

FIG.5.19: Distribuição granulométrica obtida pela técnica de Espectroscopia de Correlação de Fótons (PCS) para as nanopartículas de PHB + complexos $\mathrm{TR}(\mathrm{tta})_{3}\left(\mathrm{H}_{2} \mathrm{O}\right)_{2}$. 
Todas as amostras foram preparadas e lidas após 7 dias. Foram feitas leituras de todas as suspensões preparadas com nanopartículas de PHB misturados aos complexos de tta. Além disso, foram preparadas suspensões com nanopartículas de PHB, outra com o complexo [Eu(tta $)_{3}\left(\mathrm{H}_{2} \mathrm{O}\right)_{2}$ ] como padrão e um terceiro teste, substituindo o Tween 80 pelo PVA como agente de dispersão, conforme relatado na literatura ${ }^{[18,19]}$.

Constata-se uma tendência muito clara para todos os sistemas, com um comportamento bimodal, ou seja, formação de partículas menores, centradas em $10 \mathrm{~nm}$ e partículas maiores ou aglomerados, centrados em 200 a 300 nm, com uma distribuição mais alargada, conforme verificado na FIG.5.19. Algumas observações podem ser notadas, como a troca do dispersante Tween 80 pelo PVA, que provocou uma intensidade maior no sinal para partículas maiores que $250 \mathrm{~nm}$. Além disso, não há registro de partículas centradas em $10 \mathrm{~nm}$, ao contrário do que ocorre em outros sistemas. Tal fato pode ser explicado por uma maior interação do PVA pela superfície da partícula, funcionando como uma segunda capa polimérica e, portanto aumentando o tamanho dessa partícula.

Outro fator verificado, trata dos sistemas contendo apenas o PHB e o complexo $\left[\mathrm{Eu}(\mathrm{tta})_{3}\left(\mathrm{H}_{2} \mathrm{O}\right)_{2}\right]$. Fica claro que nesses sistemas ocorre a tendência inversa de quando os dois materiais são misturados na formulação, ou seja, há uma quantidade maior de partículas menores $(\sim 10 \mathrm{~nm})$ em relação às partículas maiores ou aglomerados de partículas. Essa questão pode ser justificada pelo provável comportamento de formação da partícula, uma vez que uma partícula recoberta por uma capa polimérica possui um tamanho maior do que a própria partícula, de composição única.

Para as nanopartículas de PHB misturado aos complexos derivados do acac, são apresentadas as curvas na FIG 5.20. 


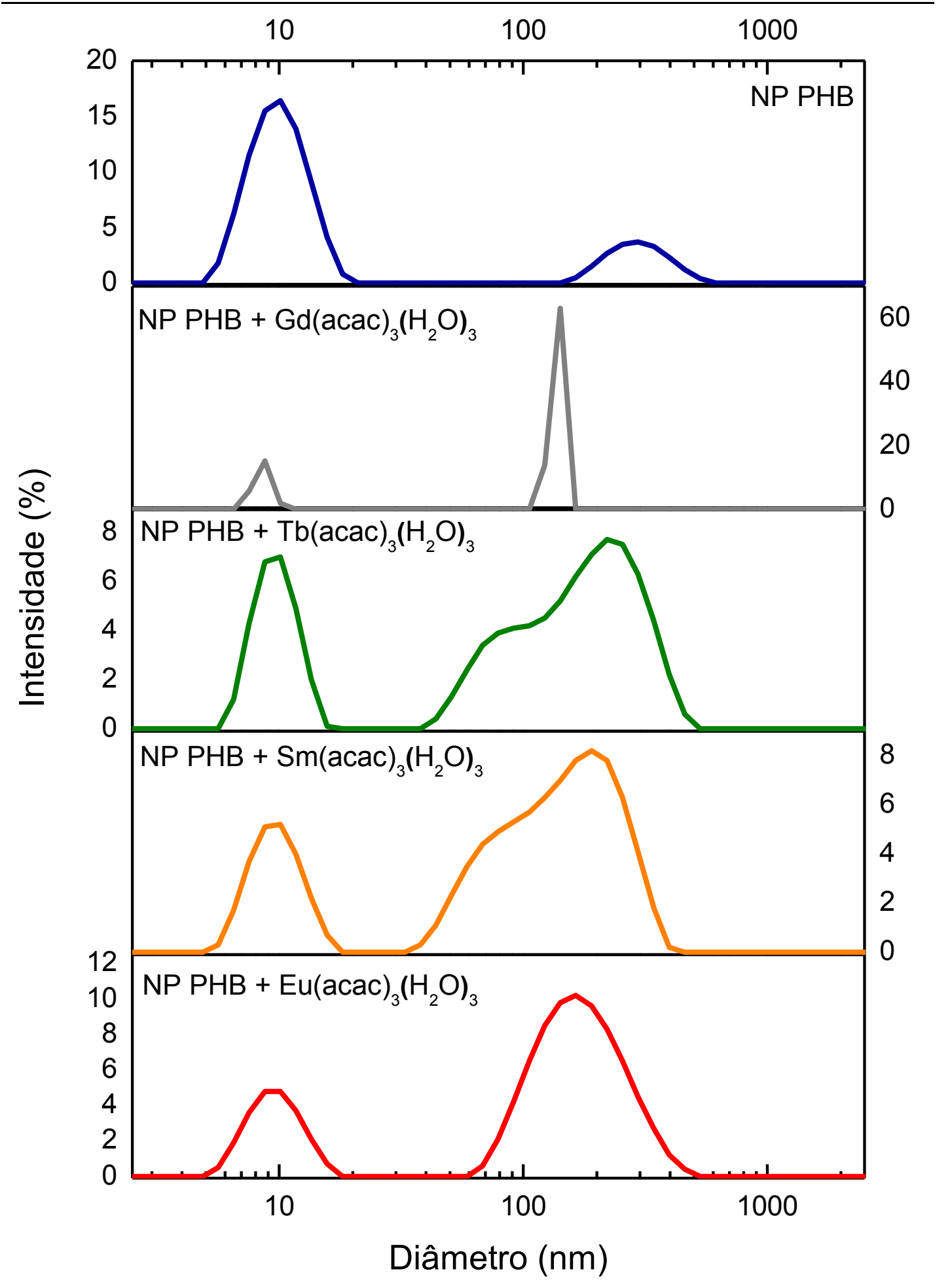

FIG.5.20: Distribuição granulométrica obtida pela técnica de Espectroscopia de Correlação de Fótons (PCS) para as nanopartículas de PHB + complexos $\operatorname{TR}(\operatorname{acac})_{3}\left(\mathrm{H}_{2} \mathrm{O}\right)_{3}$. 
Assim como observado para as nanopartículas de PHB com complexos de tta, nas nanopartículas de PHB com complexos de acac, se verifica a mesma tendência, com um comportamento bimodal, ou seja, formação de partículas menores, centradas em $10 \mathrm{~nm}$ e partículas maiores ou aglomerados, centrados em 200 a 300 nm, com uma distribuição mais alargada, conforme verificado na FIG 5.20.

\subsection{Análise de Potencial Zeta das nanopartículas}

O Potencial Zeta é uma técnica que avalia o potencial de superfície das partículas uma vez que esse é influenciado por alterações na interface com o meio dispersante, seja por dissociação de grupos funcionais na superfície da partícula ou pela presença de espécies iônicas em um meio aquoso de dispersão. Corresponde ao potencial elétrico no plano de cisalhamento, ou seja, no limite de separação entre os contra-íons que conseguem ou não se manter ao redor da partícula em movimento devido a aplicação de um campo elétrico ${ }^{[18]}$.

As nanopartículas em meio aquoso adquirem uma carga elétrica superficial e consequentemente afetam a concentração de contra-íons a sua volta, formando dessa forma, uma camada elétrica dupla. Essa camada possui uma região interna mais fortemente ligada a superfície da partícula e uma região externa, fracamente ligada a nanopartícula cuja estabilidade depende de forças eletrostáticas e temperatura (FIG 5.21) ${ }^{[21]}$.

Quando se aplica um campo elétrico, as nanopartículas e a camada interna irão se mover e arrastar a camada externa até um ponto em que as forças contrárias causam o rompimento das ligações. O potencial zeta pode ser definido como a diferença entre o potencial elétrico da região de rompimento e um ponto no fluido longe da nanopartícula ${ }^{[21]}$. 


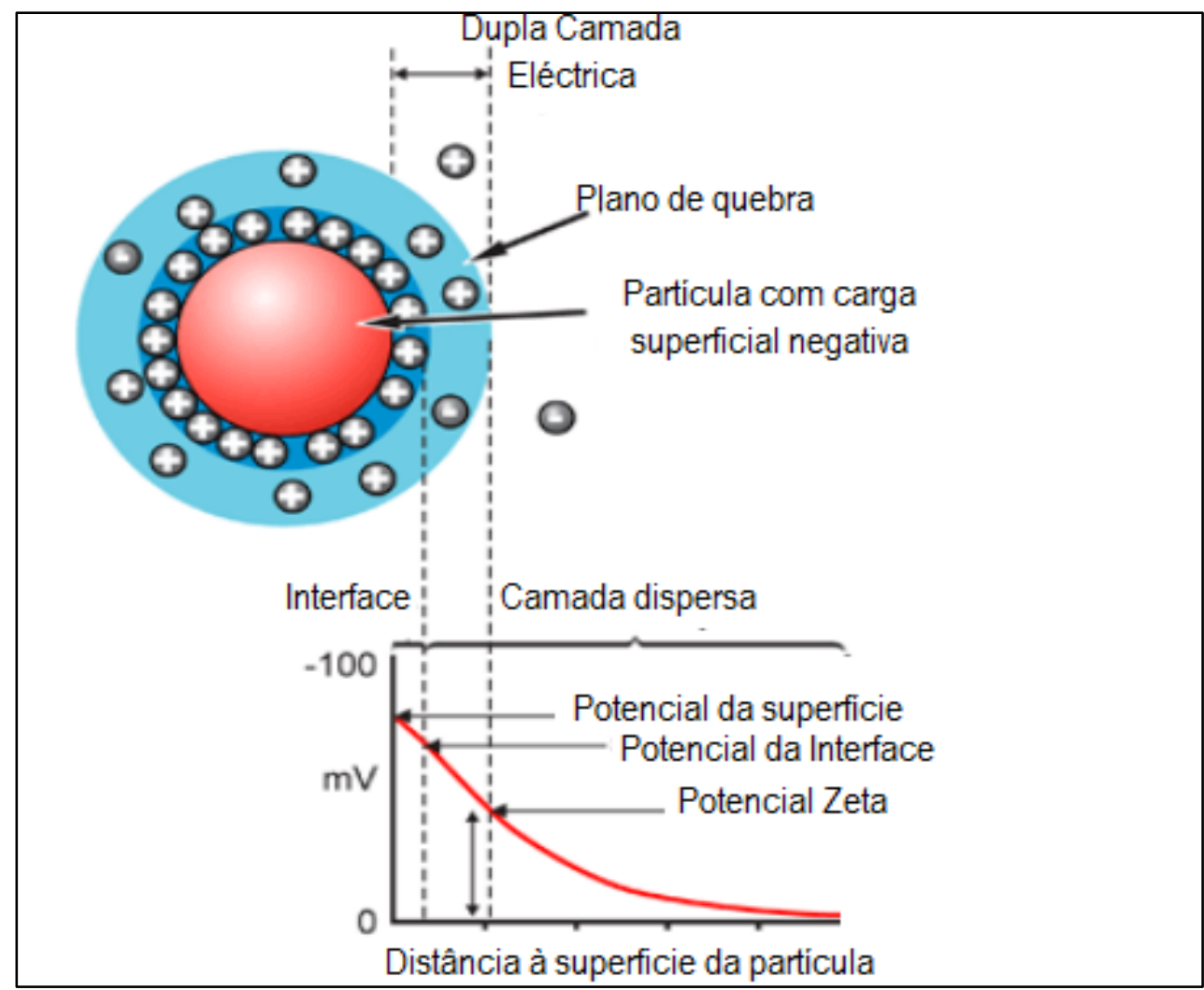

FIG.5.21: Desenho esquemático do Potencial Zeta ${ }^{21}$.

Trata-se de um parâmetro muito importante para colóides ou nanopartículas em suspensão, pois este dado está diretamente relacionado a estabilidade da suspensão assim como a morfologia da superfície da partícula ${ }^{[22]}$.

Existem três técnicas disponíveis para a medida de potencial zeta, que são: a acústica, a eletroacústica e o espalhamento de luz eletroforético (ELS), essa última de maior precisão e sensibilidade que as demais é a técnica utilizada nesse trabalho. O potencial zeta é uma propriedade que está relacionada não só com a própria partícula, mas também, influenciada pelo meio, em função de $\mathrm{pH}$, força iônica e até pelo tipo de íon presente no meio. Desse modo, é importante enfatizar que a leitura mais representativa é aquela feita sem diluições, uma vez que a diluição interfere no ambiente da partícula, alterando o potencial zeta e consequentemente, induzindo a uma avaliação equivocada do resultado ${ }^{[23]}$. 
Os resultados de potencial zeta para as suspensões de nanopartículas de PHB são apresentados na TAB 5.10 e complementam os dados de tamanho de partícula. Observou-se que as nanopartículas com o ligante acac apresentam o maior valor negativo de potencial zeta, com exceção daquele referente às nanopartículas contendo $\mathrm{Eu}^{3+}$, o que indica maior estabilidade do sistema, ou seja, menor tendência de aglomeração.

Outro fator relevante é o potencial zeta da amostra onde 0 dispersante Tween 80 foi substituído pelo PVA. Nesse caso, as partículas apresentaram um potencial próximo de zero, ou seja, com maior tendência de aglomeração, o que justifica a indicação de partículas grandes majoritariamente no sistema.

TAB 5.10: Resultados de potencial zeta das nanopartículas de PHB dopadas com complexos de terras raras e valores de $\mathrm{pH}$ das soluções.

\begin{tabular}{ccc}
\hline NPs & Potencial Zeta $(\mathbf{m V})$ & pH \\
\hline $\mathrm{PHB}+\left[\mathrm{Eu}(\mathrm{tta})_{3}\left(\mathrm{H}_{2} \mathrm{O}\right)_{2}\right]$ & $-5,01$ & 7,4 \\
$\mathrm{PHB}+\left[\mathrm{Eu}(\mathrm{acac})_{3}\left(\mathrm{H}_{2} \mathrm{O}\right)_{3}\right]$ & $-2,59$ & 7,4 \\
{$\left[\mathrm{Eu}(\mathrm{tta})_{3}\left(\mathrm{H}_{2} \mathrm{O}\right)_{2}\right]$} & $-4,24$ & 7,4 \\
$\mathrm{PHB}+\left[\mathrm{Eu}(\mathrm{tta})_{3}\left(\mathrm{H}_{2} \mathrm{O}\right)_{2}\right]+\mathrm{PVA}$ & $-1,02$ & 7,4 \\
$\mathrm{PHB}$ & $-3,06$ & 7,4 \\
$\mathrm{PHB}+\left[\mathrm{Tb}(\mathrm{acac})_{3}\left(\mathrm{H}_{2} \mathrm{O}\right)_{3}\right]$ & $-10,4$ & 7,4 \\
$\mathrm{PHB}+\left[\mathrm{Sm}(\mathrm{tta})_{3}\left(\mathrm{H}_{2} \mathrm{O}\right)_{2}\right]$ & $-9,82$ & 7,4 \\
$\mathrm{PHB}+\left[\mathrm{Sm}(\mathrm{acac})_{3}\left(\mathrm{H}_{2} \mathrm{O}\right)_{3}\right]$ & $-11,8$ & 7,4 \\
$\mathrm{PHB}+\left[\mathrm{Gd}(\mathrm{tta})_{3}\left(\mathrm{H}_{2} \mathrm{O}\right)_{2}\right]$ & $-4,23$ & 7,4 \\
$\mathrm{PHB}+\left[\mathrm{Gd}(\mathrm{acac})_{3}\left(\mathrm{H}_{2} \mathrm{O}\right)_{3}\right]$ & $-5,31$ & 7,4 \\
\hline
\end{tabular}




\subsection{Espectroscopia de luminescência}

\subsubsection{Fotoluminescência dos sistemas contendo íon $\mathrm{Gd}^{3+}$.}

A avaliação e interpretação dos espectros eletrônicos das transições intraconfiguracionais de vários íons de camada semi-preenchidas, de configuração $\mathrm{nf}^{7}$ para $\mathrm{n}=4$ de terras raras $\left(\mathrm{Eu}^{2+}, \mathrm{Gd}^{3+}\right.$ e $\left.\mathrm{Tb}^{4+}\right)$ e $\mathrm{n}=5$ de actinídeos $\left(\mathrm{Am}^{2+}, \mathrm{Cm}^{3+}\right.$ e $\left.\mathrm{Bk}^{4+}\right)$ tem sido de grande ajuda para dados teóricos e experimentais nas últimas três décadas. No que se refere a configuração $\mathrm{f}^{7}$, tem-se 119 multipletos, onde a interação spin-orbital, geram $327{ }^{28+1} L_{\jmath}$ níveis que se desdobram em 3.432 subníveis em função da interação do campo cristalino ${ }^{[10]}$.

O desdobramento do estado fundamental ${ }^{8} \mathrm{~S}_{7 / 2}$ apresenta a seguinte ordem para a série isoeletrônica $\mathrm{f}^{7}$ : aproximadamente $1 \mathrm{~cm}^{-1}\left(\mathrm{Gd}^{3+}\right), 2 \mathrm{~cm}^{-1}$ $\left(\mathrm{Cm}^{3+}\right)$ e $58 \mathrm{~cm}^{-1}\left(\mathrm{Bk}^{4+}\right)$. Essa característica espectroscópica é decorrente da diferença de energia (energy gap) entre o estado fundamental ${ }^{8} \mathrm{~S}_{7 / 2} \mathrm{e}$ o primeiro estado excitado do $\mathrm{Gd}^{3+}\left({ }^{6} \mathrm{P}_{7 / 2}\right), \mathrm{Cm}^{3+}\left({ }^{6} \mathrm{D}_{7 / 2}\right)$ e $\mathrm{Bk}^{4+}\left({ }^{6} \mathrm{D}_{7 / 2}\right)$ com energias de aproximadamente $32.000 \mathrm{~cm}^{-1}\left(\mathrm{Gd}^{3+}\right), 16.800 \mathrm{~cm}^{-1}\left(\mathrm{Cm}^{3+}\right)$ e $16.000 \mathrm{~cm}^{-1}$ $\left(\mathrm{Bk}^{4+}\right)^{[10]}$.

O íon $\mathrm{Gd}^{3+}$ apresenta na subcamada $4 \mathrm{f}^{7}$, O seu primeiro nível excitado, ${ }^{6} \mathrm{P}_{7 / 2}$, com energia aproximada de $32.000 \mathrm{~cm}^{-1}(312 \mathrm{~nm})$ acima do seu nível fundamental, ${ }^{8} \mathrm{~S}_{7 / 2}$. Desse modo, este íon apresenta luminescência apenas na região do ultravioleta atuando como um "branco", uma vez que este é transparente na região espectral entre 32.000 a $100 \mathrm{~cm}^{-1}$, do ultravioleta ao infravermelho. Uma vez que o primeiro estado tripleto $\left(T_{1}\right)$ da maioria dos ligantes orgânicos localizam-se em energia menor em relação ao primeiro nível emissor do $\mathrm{Gd}^{3+}\left({ }^{6} \mathrm{P}_{7 / 2}\right)$ que se concentra em alta energia, podemos obter de forma seletiva e sem interferência, propriedades eletrônicas dos ligantes coordenados ao íon terra rara ${ }^{[10]}$. Vale destacar, que o íon $\mathrm{Gd}^{3+}$ é preferencialmente utilizado para se estudar a fosforescência dos ligantes ao invés dos íons $\mathrm{La}^{3+}, \mathrm{Ce}^{4+}$ e $\mathrm{Lu}^{3+}$ (não possuem transições intraconfiguracionais $4 f-4 f$ por apresentarem configuração $4 f^{0}$ ou $4 f^{14}$ ), por possuir a vantagem de um raio iônico muito semelhante aos dos íons emissores no visível, $\mathrm{Sm}^{3+}, \mathrm{Eu}^{3+}$, 
$\mathrm{Tb}^{3+}$ e $\mathrm{Dy}^{3+}$, tornando-o um bom mimetizador destes íons em uma mesma estequiometria e estrutura. Além disso, o efeito paramagnético do íon $\mathrm{Gd}^{3+}$ que possui a configuração $4 f^{7}$ induz a um aumento no cruzamento intersistema (CIS) do estado singleto $\left(S_{1}\right)$ para o estado tripleto $\left(T_{1}\right)$ (efeito do íon pesado). ${ }^{[24,25]}$ Portanto, os espectros dos complexos de $\mathrm{Gd}^{3+}$ servem para analisar a posição dos níveis de energia dos tripletos dos ligantes que poderão ser utilizados para projetar compostos de $\mathrm{TR}^{3+}$ luminescente. Este dado é extremamente importante na interpretação dos processos de transferência de energia intramolecular dos Ligantes- $\mathrm{TR}^{3+}$.

A fosforescência oriunda dos ligantes nos complexos de $\mathrm{Gd}^{3+}$ é normalmente suprimida à temperatura ambiente $(298 \mathrm{~K}),{ }^{[26]}$ através de processos não radiativos, portanto usualmente esses espectros são obtidos a baixa temperatura $(77 \mathrm{~K})$.

A fosforescência de menor comprimento de onda no espectro obtido a $77 \mathrm{~K}$ corresponde à transição entre o nível vibracional mais baixo do estado $T_{1}$ para o nível vibracional mais baixo do estado $S_{0}$ (transição 0-0 fônon). Devido à semelhança entre os raios dos íons $\mathrm{Eu}^{3+}(r=1,066)$ e $\mathrm{Gd}^{3+}(r=1,053)$, onde os valores de $r$ são os raios para um número de coordenação 8 , deve-se esperar que os níveis de energia dos ligantes nos complexos contendo esses íons com a mesma estequiometria, apresentem estruturas semelhantes. Portanto, os espectros dos complexos de $\mathrm{Gd}^{3+}$ servem para analisar a posição dos níveis de energia dos tripletos dos ligantes que são utilizados para projetar compostos de $\mathrm{TR}^{3+}$ luminescente. Este dado é extremamente importante na interpretação dos processos de transferência de energia intramolecular dos Ligantes-E $\mathbf{u}^{3+}$.

\subsubsection{Complexo precursor $\left[\mathrm{Gd}(\mathrm{tta})_{3}\left(\mathrm{H}_{2} \mathrm{O}\right)_{2}\right]$}

Os espectros de fosforescência dos complexos de $\mathrm{Gd}^{3+}$ apresentam bandas largas resultante das transições centradas nos ligantes.

O complexo $\left[\mathrm{Gd}(\mathrm{tta})_{3}\left(\mathrm{H}_{2} \mathrm{O}\right)_{2}\right]$ foi analisado com a intenção de se obter informações relativas as propriedades fosforescentes dos estados emissores tripletos do ligante tta. A análise foi feita a temperatura de $77 \mathrm{~K} \mathrm{com}$ 
auxílio de nitrogênio líquido em intervalo de 400 a 700 nm, com excitação monitorada nos estados singletos dos ligantes, em torno de aproximadamente em 365 nm (FIG 5.22).

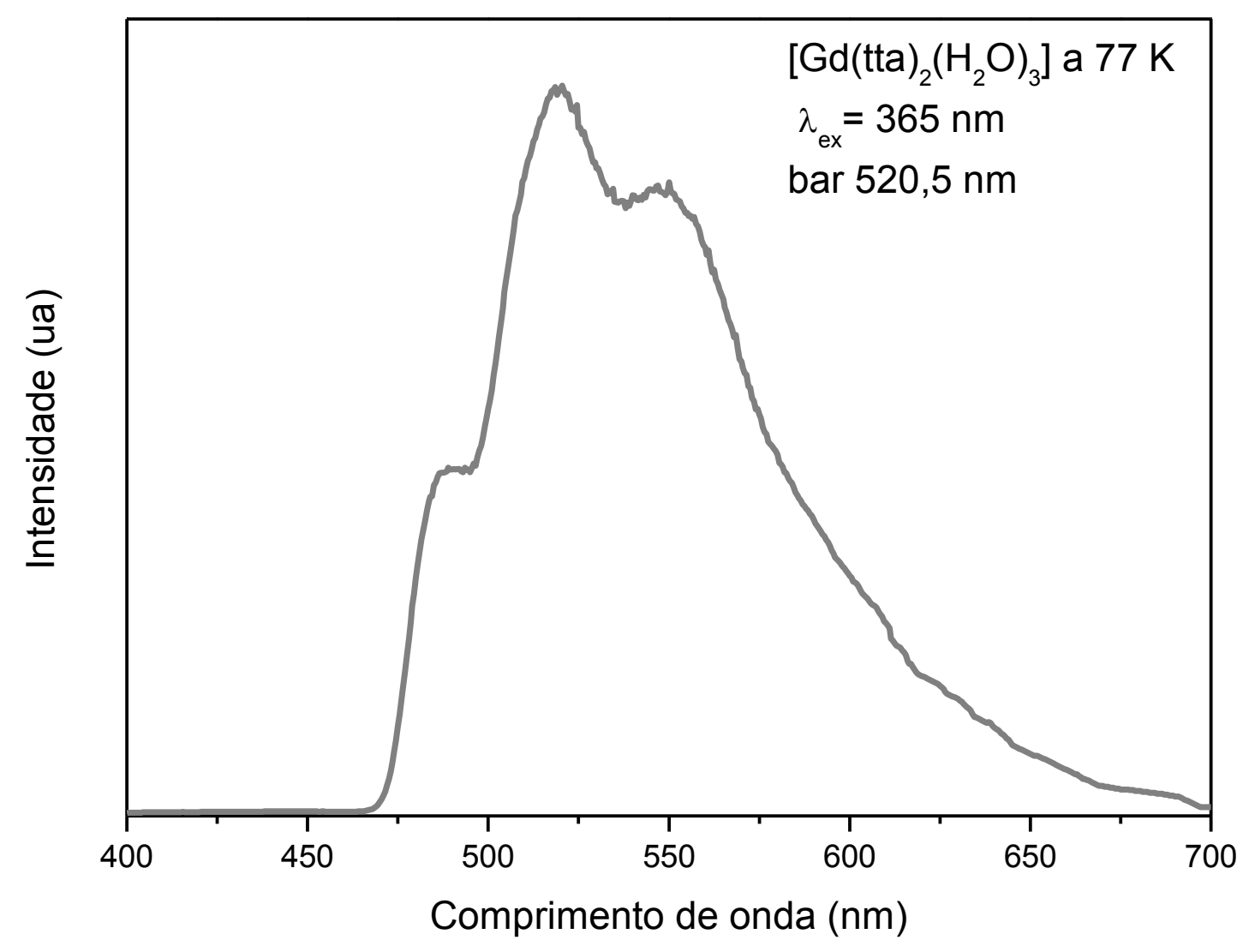

FIG.5.22: Espectro de fosforescência do complexo $\left[\mathrm{Gd}(\mathrm{tta})_{3}\left(\mathrm{H}_{2} \mathrm{O}\right)_{2}\right]$ no intervalo de 400 a 700 nm, monitorado a excitação em 365 nm a $77 \mathrm{~K}$.

Pode-se observar a presença de três bandas entre 460 e 650 nm associada à transição eletrônica do ligante tripleto-singleto $T_{1} \rightarrow S_{0}$ do tta. Estas três bandas sobrepostas com máximos em torno de 488, 520 e 550nm, são correspondentes às emissões características dos três estados tripletos do tta.

Os espectros dos complexos de gadolínio exibem também uma banda de emissão muito fraca em torno de $450 \mathrm{~nm}$ (não visíveis nas figuras) a qual está associada à fluorescência dos estados singletos dos ligantes $\beta$ dicetonatos. Isto indica que a conversão interna e cruzamento intersistema para o estado tripleto de menor energia é muito eficiente nos sistemas estudados. 


\subsubsection{Complexo precursor $\left[\mathrm{Gd}(\mathrm{acac})_{3}\left(\mathrm{H}_{2} \mathrm{O}\right)_{2}\right]$}

O complexo $\left[\mathrm{Gd}(\mathrm{acac})_{3}\left(\mathrm{H}_{2} \mathrm{O}\right)_{3}\right]$ assim como o complexo de tta, foi analisado com o objetivo de se obter informações relativas as propriedades fosforescentes dos estados emissores tripletos do ligante acac. A análise foi feita a temperatura de $77 \mathrm{~K}$ com auxílio de nitrogênio líquido em intervalo de 400 a $700 \mathrm{~nm}$, com a excitação monitorada aproximadamente em $330 \mathrm{~nm}$. É possível observar (FIG 5.23) a presença de três banda largas sobrepostas entre 450 e $650 \mathrm{~nm}$ associada a transição eletrônica do ligante tripleto singleto $T_{1} \rightarrow S_{0}$ do acac.

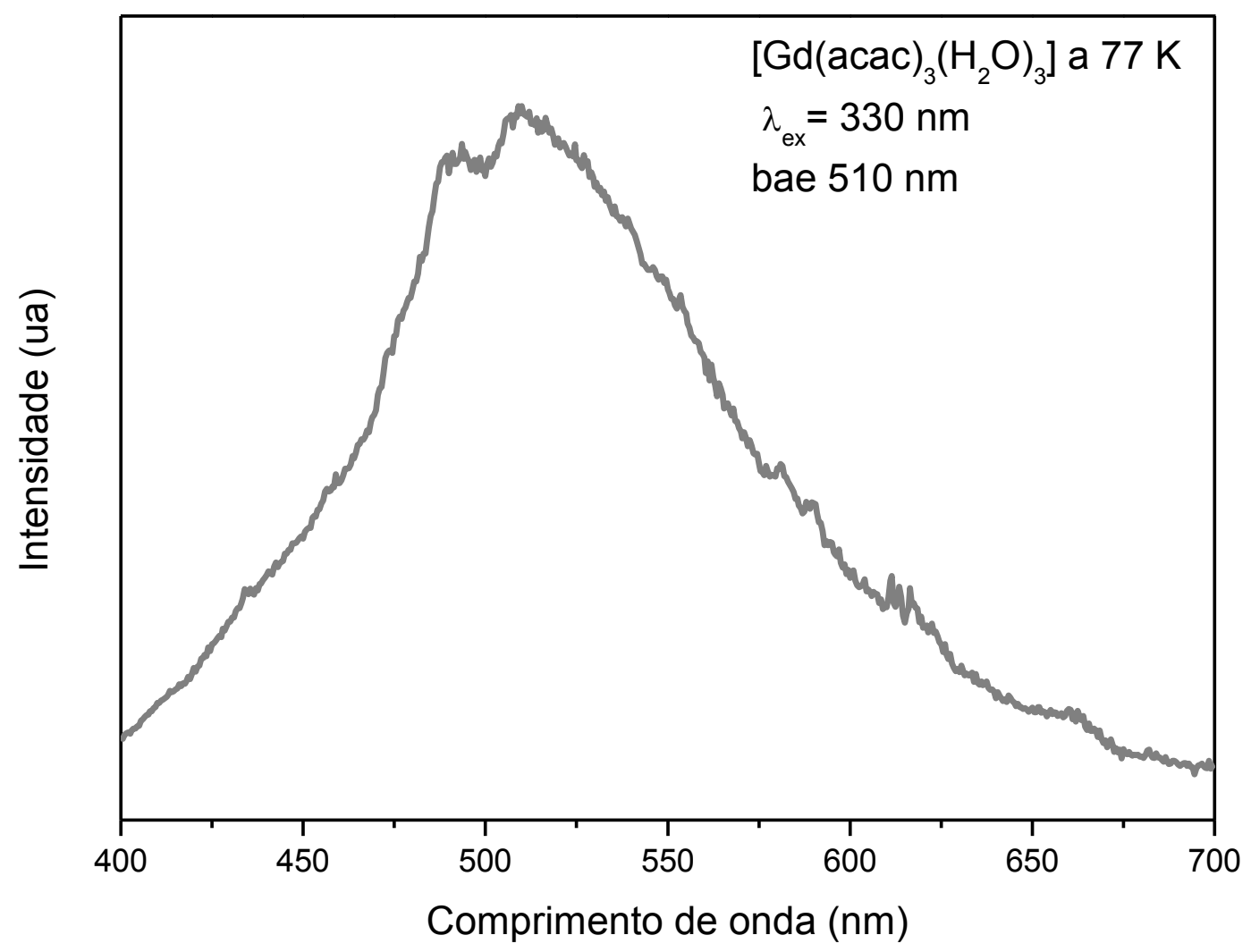

FIG.5.23 Espectro de fosforescência do complexo $\left[\mathrm{Gd}(\mathrm{acac})_{3}\left(\mathrm{H}_{2} \mathrm{O}\right)_{3}\right]$ no intervalo de 400 a $700 \mathrm{~nm}$, monitorado a emissão em $330 \mathrm{~nm}$ a $77 \mathrm{~K}$.

A atribuição do estado tripleto para os complexos com acac e tta, registrado no estado estacionário, apresentou valores de 24509 e 20331 $\mathrm{cm}^{-1}$ respectivamente, indicando que com o aumento da concentração não houve alteração na posição do estado tripleto. 


\subsubsection{Fotoluminescência dos sistemas contendo íon $\mathrm{Eu}^{3+}$.}

Os compostos contendo o íon $\mathrm{Eu}^{3+}$ (configuração [Xe]4f ${ }^{6}$ ) têm sido extensivamente estudados por apresentarem alta luminescência monocromática de cor vermelha. Além disso, a partir de seus espectros de emissão pode-se obter informações sobre o desdobramento do campo ligante, processos de transferência de energia e eficiência quântica do estado emissor. Os espectros exibidos pelos complexos de $\mathrm{Eu}^{3+}$ apresentam, principalmente, bandas oriundas das transições intraconfiguracionais ${ }^{5} \mathrm{D}_{0} \rightarrow{ }^{7} \mathrm{~F}_{\mathrm{J}}$ (onde $\mathrm{J}=0,1,2$, $3,4,5$ e 6), sendo que as transições ${ }^{5} D_{0} \rightarrow{ }^{7} F_{5}$ e ${ }^{5} D_{0} \rightarrow{ }^{7} F_{6}$ apresentam intensidade muito baixa e dificilmente são observadas nos espectros dos compostos de coordenação. Como pode ser observado, o principal nível emissor ${ }^{5} \mathrm{D}_{0}$ é não degenerado e não se desdobra em qualquer simetria em torno do íon metálico ${ }^{[27,28,29]}$, ao contrário por exemplo, do estado emissor do $\mathrm{Tb}^{3+}\left({ }^{5} \mathrm{D}_{4}\right)$ que tem uma degenerescência igual a nove. Portanto, o número máximo de bandas resultantes de uma transição ${ }^{5} D_{0} \rightarrow{ }^{7} F_{J}$ é dado pela regra de $(2 \mathrm{~J}+1)$-componentes. O número de bandas associado a cada transição depende da simetria pontual ao redor do íon $\mathrm{TR}^{3+}$ e pode ser facilmente determinada usando a teoria de grupos ${ }^{[28,29,30]}$.

Quando um espectro apresenta número de picos maior do que da regra $(2 \mathrm{~J}+1)$-componentes, isso evidencia ou a presença de mais de um sítio de simetria para o íon metálico ou que o composto está impuro, por exemplo em sistemas dinucleares sem centro de inversão, ou mistura de isômeros, ou ainda o aparecimento de transições vibrônicas devido à interação dos níveis eletrônicos e estados de densidade fônons. Este último fenômeno resulta na presença de "bandas satélites" e é observado principalmente nas transições ${ }^{5} \mathrm{D}_{0} \rightarrow{ }^{7} \mathrm{~F}_{2}$, considerando que o nível ${ }^{7} \mathrm{~F}_{2}$ encontra-se na região espectral correspondente as freqüências de estiramentos $v(\mathrm{C}=\mathrm{O}), v(\mathrm{C}=\mathrm{C})$ e $v(\mathrm{~N}=\mathrm{O})$ presentes nos ligantes orgânicos.

As transições ${ }^{5} \mathrm{D}_{0} \rightarrow{ }^{7} \mathrm{~F}_{0,3,5}$ são proibidas pelas regras de seleção de dipolo-elétrico forçado e dipolo-magnético. No entanto, a primeira regra pode ser relaxada pelo campo ligante conduzindo aos efeitos de misturas dos J's e, consequentemente, apesar de pequeno, existe um momento de transição 
diferente de zero. A intensidade da transição ${ }^{5} \mathrm{D}_{0} \rightarrow{ }^{7} \mathrm{~F}_{0}$ tem sido caracterizada como sendo, principalmente, devido à mistura do estado ${ }^{7} \mathrm{~F}_{2}$ dentro do estado ${ }^{7} F_{0}$, e essa mistura é expressa em termos do parâmetro $R_{02}$, definido como a razão entre as intensidades das bandas oriundas das transições ${ }^{5} \mathrm{D}_{0} \rightarrow{ }^{7} \mathrm{~F}_{0} \mathrm{e}$ ${ }^{5} \mathrm{D}_{0} \rightarrow{ }^{7} \mathrm{~F}_{2}$. Por outro lado, a transição ${ }^{5} \mathrm{D}_{0} \rightarrow{ }^{7} \mathrm{~F}_{1}$ é permitida somente por dipolomagnético e sua intensidade é praticamente insensível ao ambiente químico nas vizinhanças do íon $\mathrm{Eu}^{3+}$, por conseguinte, essa transição tem sido tomada como uma referência interna ${ }^{[28,29]}$.

As transições ${ }^{5} \mathrm{D}_{0} \rightarrow{ }^{7} \mathrm{~F}_{2,4}$ são permitidas por dipolo-elétrico forçado, sendo que a transição ${ }^{5} \mathrm{D}_{0} \rightarrow{ }^{7} \mathrm{~F}_{2}(\sim 612 \mathrm{~nm})$, hipersensível ao ambiente químico do íon central, é geralmente dominante em compostos não-centrossimétricos. Estas transições fornecem informações se grupo o pontual em torno do íon $\mathrm{Eu}^{3+}$ apresenta centro de inversão, considerando que em compostos centrossimétricos as transições ${ }^{5} \mathrm{D}_{0} \rightarrow{ }^{7} \mathrm{~F}_{2,4}$ são estritamente proibidas por mecanismo de dipolo elétrico.

Uma vez que, as bandas de emissão do íon $\mathrm{Eu}^{3+}$ na região do visível são de fácil interpretação, devido a estrutura dos seus níveis de energia, este íon tem sido utilizado como sonda espectroscópica na obtenção de valiosas informações em sistemas bioinorgânicos, tais como: i) a determinação do número de ambientes químicos ao redor do íon $\mathrm{Eu}^{3+}$ através do número de bandas relativo à transição ${ }^{5} \mathrm{D}_{0} \rightarrow{ }^{7} \mathrm{~F}_{0}$; ii) Constante de ligação dos íons biomolécula-Eu ${ }^{3+}$, determinada por curvas de titulação e iii) distância doadorreceptor $(R)$, normalmente assumindo o mecanismo de acoplamento dipolodipolo fraco ${ }^{[28,29]}$. 


\subsubsection{Complexo precursor $\left.\mathrm{Eu}(\mathrm{tta})_{3}\left(\mathrm{H}_{2} \mathrm{O}\right)_{2}\right]$}

Os estudos fotoluminescentes do $\beta$-dicetonado de európio (tta), neste trabalho, foi feito com base nos espectros de excitação e emissão registrados a temperatura ambiente $(\sim 298 \mathrm{~K})$ e a do nitrogênio líquido (77 K). Os espectros de excitação foram registrados no intervalo de 240 a $590 \mathrm{~nm}$, com emissão monitorada na transição hipersensível ${ }^{5} D_{0} \rightarrow{ }^{7} F_{2}(\sim 611 \mathrm{~nm})$. Por outro lado, os espectros de emissão foram obtidos com excitação no íon $\mathrm{TR}^{3+}$ $(\sim 394 \mathrm{~nm})$ e/ou via banda do ligante $(\sim 350 \mathrm{~nm})$ no intervalo de 420 a $720 \mathrm{~nm}$, correspondente às transições intraconfiguracionais ${ }^{5} D_{0} \rightarrow{ }^{7} \mathrm{~F}_{0-4}$. É importante salientar, que não houve diferenças significativas entre os espectros registrados a 298 e $77 \mathrm{~K}$. No entanto, os espectros registrados a $77 \mathrm{~K}$ são melhor resolvidos (apresentam um número maior de bandas resolvidas), devido ao menor acoplamento vibrônico, o que facilita a interpretação dos dados espectroscópicos. Os espectros de emissão dos complexos de $\mathrm{Eu}^{3+}$ registrados a $77 \mathrm{~K}$ estão apresentados nas figuras inseridas.

A FIG. 5.24 mostra o espectro de excitação do complexo de TTA hidratado. Na região de 250 a $450 \mathrm{~nm}$, o espectro apresenta uma banda larga com máximo em torno de $350 \mathrm{~nm}$ associada à transição permitida $\mathrm{S} \rightarrow \mathrm{S}_{0}$ pertencente aos ligantes TTA. As bandas finas oriundas das transições intraconfiguracionais- $4 f^{6}{ }^{7} \mathrm{~F}_{0} \rightarrow{ }^{5} \mathrm{~L}_{7}$ e ${ }^{5} \mathrm{~L}_{6}$ apresentam-se sobrepostas com as bandas largas dos ligantes. Deve-se informar que, as bandas finas com menores intensidades observadas em torno de 464, 532 e $578 \mathrm{~nm}$, as quais foram atribuídas às transições ${ }^{7} F_{0} \rightarrow{ }^{5} D_{2},{ }^{5} D_{1} e{ }^{5} D_{0}$ do íon $E^{3+}$.

É observado que os espectros de excitação dos complexos apresentam bandas de maior intensidade na região de absorção dos ligantes (dicetonatos) comparados com aquelas das transições ${ }^{7} \mathrm{~F}_{0} \rightarrow{ }^{5} \mathrm{D}_{\jmath}$ do íon $\mathrm{Eu}^{3+}$, evidenciando o grande potencial do ligante TTA em atuar como "antena" no processo de transferência de energia Ligante-Eu ${ }^{3+}$. 


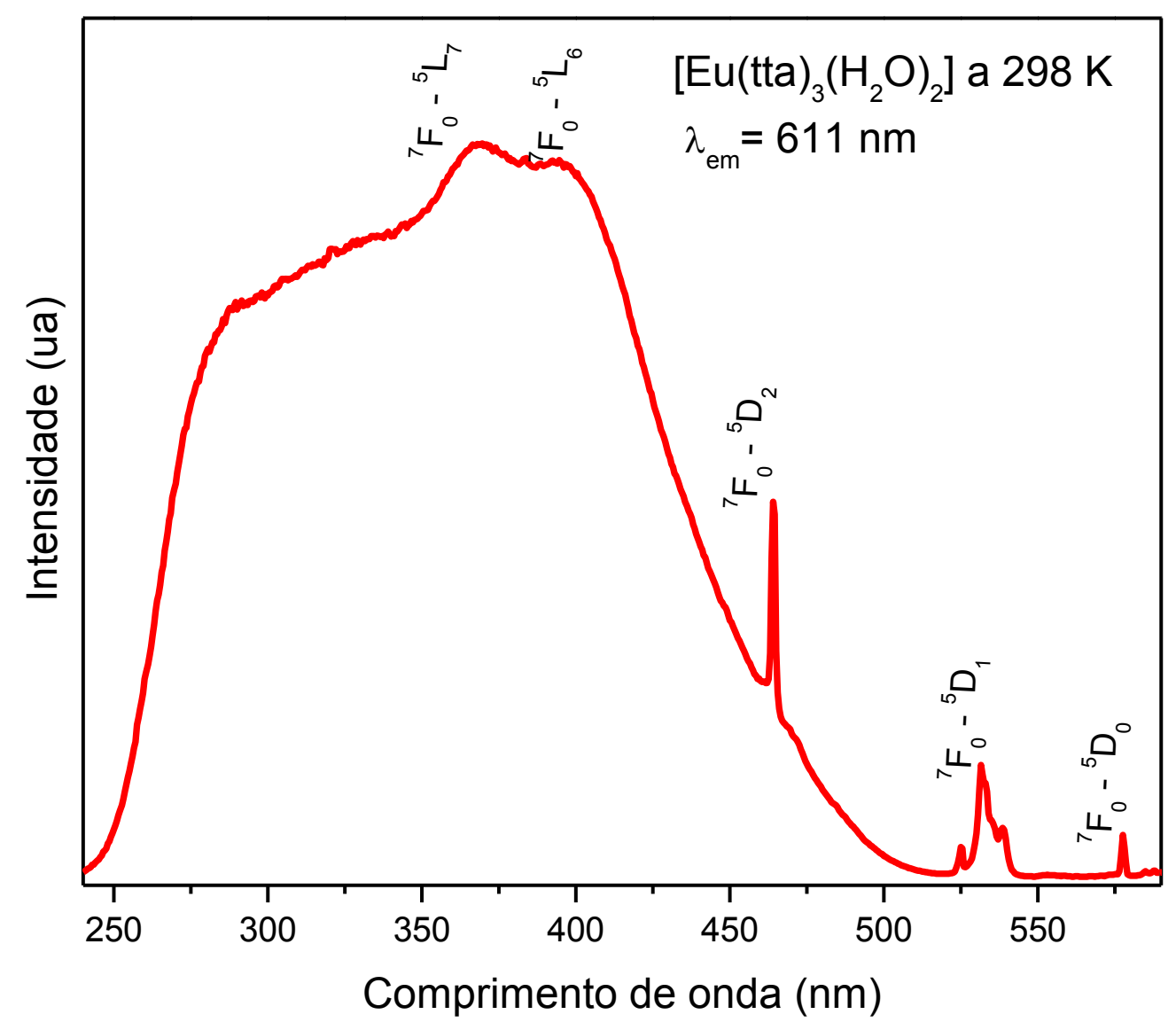

FIG.5.24: Espectro de excitação do complexo $\left[\mathrm{Eu}(\mathrm{tta})_{3}\left(\mathrm{H}_{2} \mathrm{O}\right)_{2}\right]$ no intervalo de 250 a 590 nm, monitorado a emissão em $611 \mathrm{~nm}$ a $298 \mathrm{~K}$.

Os espectros de emissão do complexo de $\left[\mathrm{Eu}(\mathrm{tta})_{3}\left(\mathrm{H}_{2} \mathrm{O}\right)_{2}\right]$ ilustrado nas FIG. 5.25, foi registrado no intervalo de 420 a 720 nm, a 298 e $77 \mathrm{~K}$, com excitação na transição ${ }^{7} \mathrm{~F}_{0} \rightarrow{ }^{5} \mathrm{~L}_{6}(\sim 394 \mathrm{~nm})$. Estes espectros exibem bandas finas atribuídas às transições ${ }^{5} D_{0} \rightarrow{ }^{7} F_{J}$ (onde $J=0,1,2,3,4$ ), sendo a transição hipersensível ${ }^{5} D_{0} \rightarrow{ }^{7} F_{2}$ a mais proeminente. A Figura (inserida) também apresentam bandas finas na região espectral de 500 a $570 \mathrm{~nm}$ oriundas das transições ${ }^{5} D_{1} \rightarrow{ }^{7} F_{0}$ (532 nm), ${ }^{5} D_{1} \rightarrow{ }^{7} F_{1}$ (539nm) $e^{5} D_{1} \rightarrow{ }^{7} F_{2}$ (558 $\mathrm{nm}$ ), no entanto, essas bandas apresentam intensidades muito baixas, sendo somente observadas com ampliação da escala espectral.

É importante salientar que, o espectro de emissão do complexo de $\mathrm{Eu}^{3+}$ hidratado não apresentou uma banda larga proveniente da fosforescência do TTA no intervalo espectral de 420-600 nm. Esse resultado sugere que os processos de transferência de energia do estado tripleto desse ligante para os níveis excitados do európio são muito eficientes. 
A presença da banda correspondente a transição ${ }^{5} \mathrm{D}_{0} \rightarrow{ }^{7} \mathrm{~F}_{0}$ no espectro de emissão do complexo de TTA como um único pico $(\sim 579 \mathrm{~nm})$, indica a existência de somente um único sítio de simetria em torno do ambiente químico do ín $\mathrm{Eu}^{3+}$. Além disso, de acordo com a regra de seleção por simetria, essa transição só é permitida quando o $\mathrm{Eu}^{3+}$ está classificado em um dos grupos pontuais $C_{n v}, C_{n}$ ou $C_{s}{ }^{[31]}$. Adicionalmente, pode-se observar que as bandas correspondentes à transição ${ }^{5} \mathrm{D}_{0} \rightarrow{ }^{7} \mathrm{~F}_{2}$ estão desdobradas em no mínimo quatro componentes, indicando que os possíveis grupos pontuais estão limitados aqueles de baixa simetria, $\mathrm{C}_{2 \mathrm{v}}, \mathrm{C}_{2}, \mathrm{C}_{1}$ ou $\mathrm{C}_{\mathrm{s}}$.

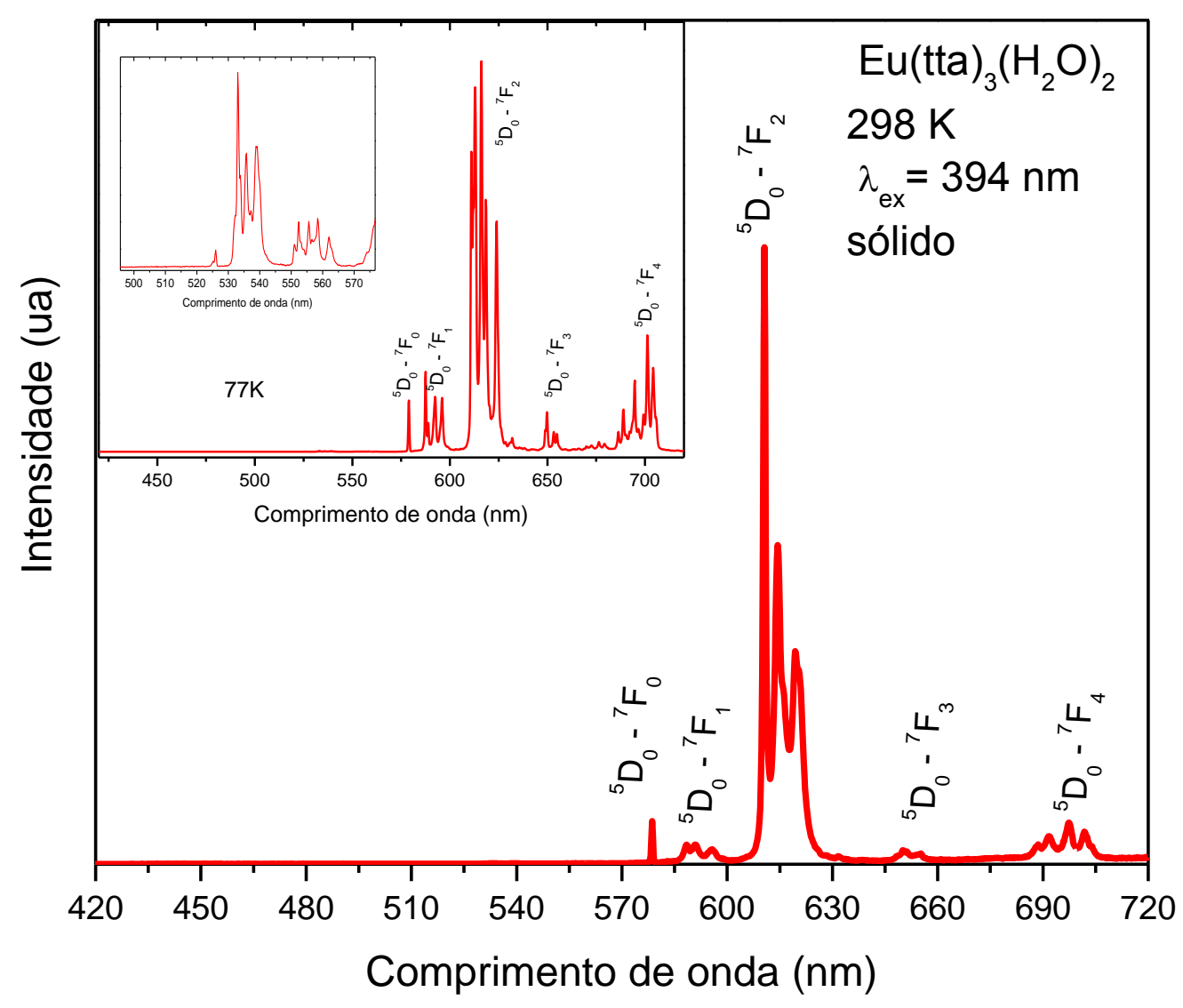

FIG.5.25: Espectro de emissão do complexo $\left[\mathrm{Eu}(\mathrm{tta})_{3}\left(\mathrm{H}_{2} \mathrm{O}\right)_{2}\right]$ no intervalo de 420 a $720 \mathrm{~nm}$, monitorado a excitação em $394 \mathrm{~nm}$ a $298 \mathrm{~K}$. A Figura inserida apresenta 0 espectro de emissão a $77 \mathrm{~K}$ com aumento na região entre 500 e $580 \mathrm{~nm}$. 


\subsubsection{Nanopartículas de PHB com o complexo [Eu(tta) $\left.)_{3}\left(\mathrm{H}_{2} \mathrm{O}\right)_{2}\right]$}

As nanopartículas de PHB incorporando o complexo $\left[\mathrm{Eu}(\mathrm{tta})_{3}\left(\mathrm{H}_{2} \mathrm{O}\right)_{2}\right]$ foram analisadas em suspensão aquosa a temperatura ambiente $(298 \mathrm{~K})$ e os espectros de excitação foram registrados em um intervalo de 250 a $590 \mathrm{~nm}$, com a emissão monitorada na transição ${ }^{5} \mathrm{D}_{0} \rightarrow{ }^{7} \mathrm{~F}_{2}, \sim 611 \mathrm{~nm}$.

A FIG. 5.26 mostra o espectro de excitação das nanopartículas em suspensão aquosa, da solução bulk e da suspensão filtrada em uma membrana filtrante com porosidade de $450 \mathrm{~nm}$. Quando estes espectros são comparados às partículas do complexo no estado sólido, observa-se que na região de 250 a $400 \mathrm{~nm}$, o espectro apresenta uma banda larga e sobreposta as transições $4 \mathrm{f}-4 \mathrm{f}$ com máximo em torno de $340 \mathrm{~nm}$ para as partículas poliméricas com deslocamento do pico máximo para a região do azul, em função da contribuição do polímero e do ligante tta e outro máximo em 372 nm para a partícula, que pode ser associado à transição permitida $S \rightarrow S_{0}$ referente ao ligante tta. Percebe-se também que em função da alta intensidade desta banda, as transições intraconfiguracionais $4 \mathrm{f}$ do íon $\mathrm{Eu}^{3+}$ são totalmente imperceptíveis.

Também é importante frisar que os espectros de excitação destas partículas de PHB em líquido são muito similares aos espectros reportados por

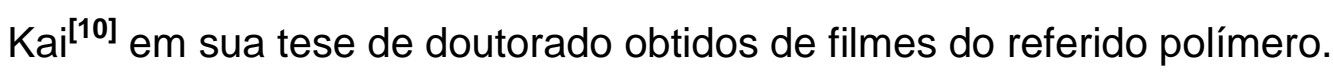

Outro dado relevante é o comportamento de intensidade da banda no espectro de excitação da suspensão bulk e da suspensão após filtração em membrana de porosidade de $450 \mathrm{~nm}$. Percebe-se que a suspensão filtrada, ou seja, com partículas menores que $450 \mathrm{~nm}$ apresentam maior intensidade de excitação do que a suspensão com a presença de partículas maiores. Esse é um dado relevante, considerando que a suspensão filtrada possui uma quantidade menor de partículas e mesmo assim, apresentou uma excitação mais alta, conforme FIG 5.26. 


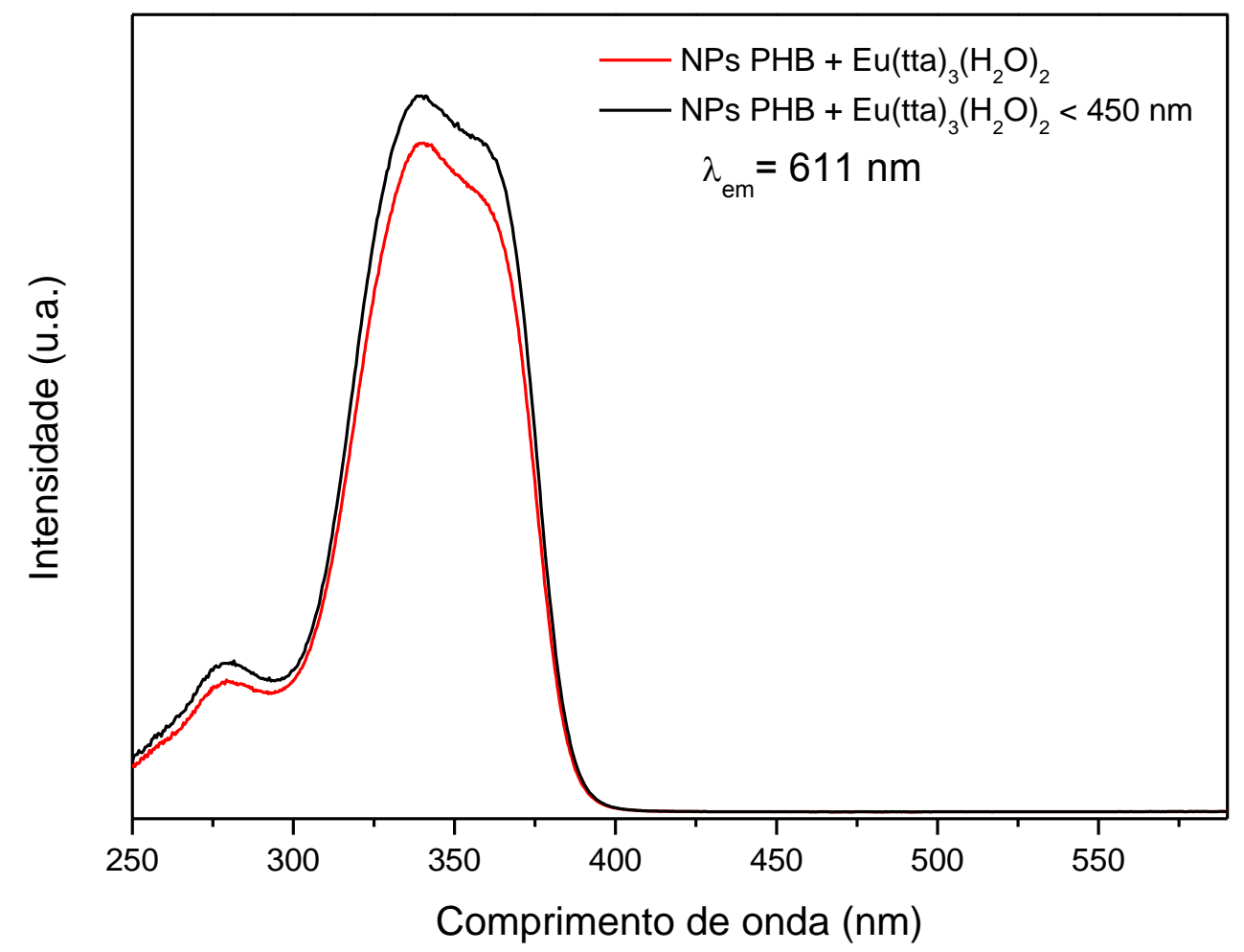

FIG.5.26: Espectro de excitação da suspensão de nanopartículas de PHB incorporando o complexo $\left[\mathrm{Eu}(\mathrm{tta})_{3}\left(\mathrm{H}_{2} \mathrm{O}\right)_{2}\right]$.

Pode-se dizer que mesmo com uma suspensão com quantidade menor de partículas, a intensidade de excitação foi maior, uma vez que a quantidade de partículas pequenas presentes e sem sobreposição de partículas maiores, aumenta consideravelmente a superfície de contato para interação com a luz. Da integração dos espectros de excitação determinou-se um deslocamento para o azul do baricentro das partículas com tamanhos menores do que $450 \mathrm{~nm}$. (Bulk=340,5nm e partículas $<450 \mathrm{~nm}=338,5 \mathrm{~nm}$ ).

$\mathrm{Na}$ FIG. 5.27 apresentam-se os espectros de excitação das emulsões de nanopartículas de PHB em bulk e do complexo de európio, diversificando o agente emulsificador. Observa-se claramente que em mesmas condições experimentais as partículas de PHB incorporando o complexo, quando dispersas em diferentes agentes emulsificantes, neste trabalho, o PVA e o Tween 80, sofrem supressão nos espectros de excitação.

A baixa intensidade do sinal quando se tem nanopartículas poliméricas na presença do PVA, possivelmente é ocasionada pela adsorção desse polímero na superfície da partícula. Esse dado pode ser confirmado na 
avaliação do tamanho de partícula, maiores para o sistema com PVA se comparado aos demais que usam Tween 80.

Observa-se também que a partícula desprotegida da camada polimérica, PHB, forma uma espécie diferente com o tween 80 como é observado no espectro de excitação, com um perfil discordante das partículas de PHB e do complexo de $\left[\mathrm{Eu}(\mathrm{tta})_{3}\left(\mathrm{H}_{2} \mathrm{O}\right)_{2}\right]$ no estado sólido.

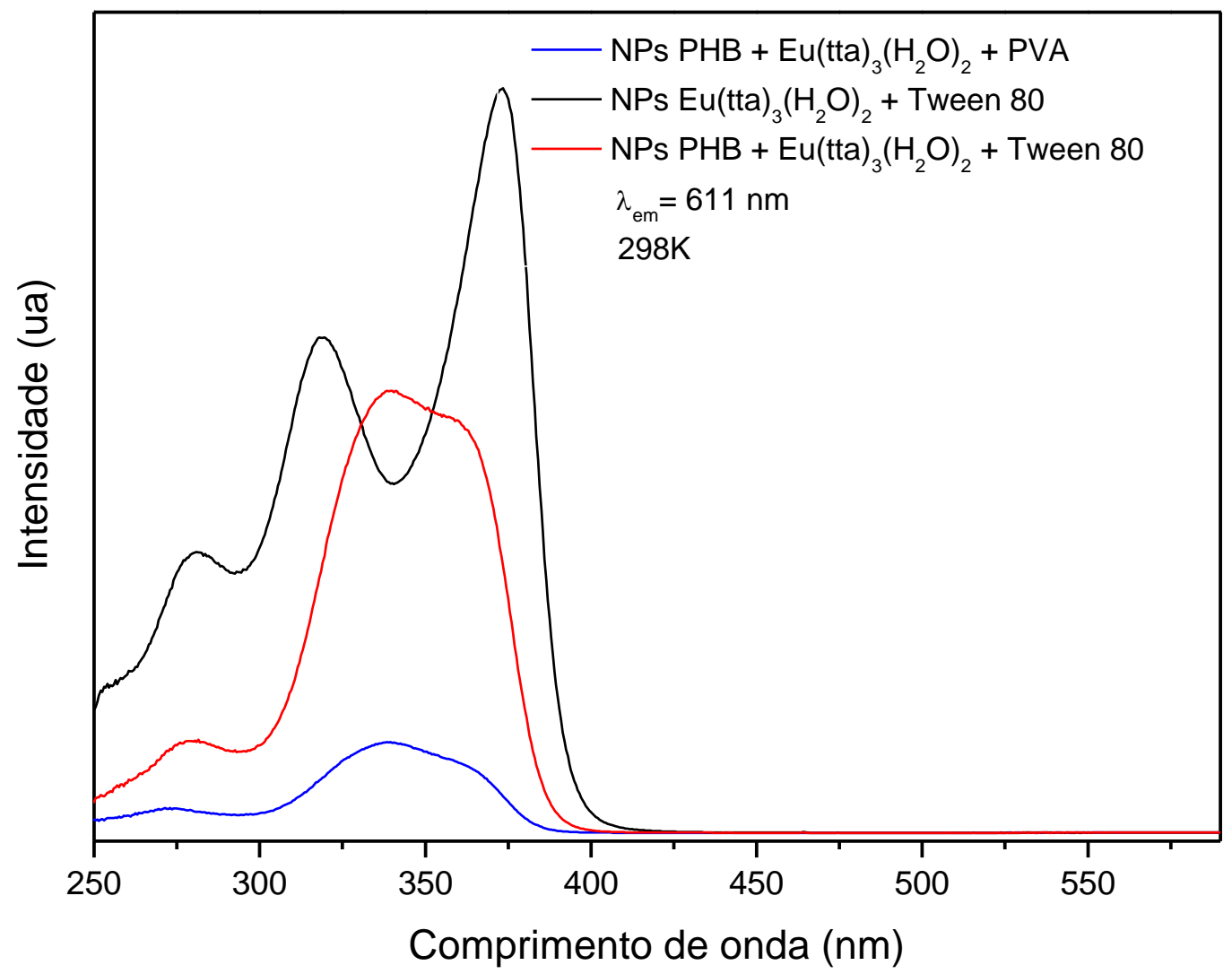

FIG.5.27: Espectro de excitação da suspensão de nanopartículas de PHB incorporando o complexo $\left[\mathrm{Eu}(\mathrm{tta})_{3}\left(\mathrm{H}_{2} \mathrm{O}\right)_{2}\right]$.

Já os espectros de emissão das nanopartículas de PHB incorporando o complexo $\left[\mathrm{Eu}(\mathrm{tta})_{3}\left(\mathrm{H}_{2} \mathrm{O}\right)_{2}\right.$ são apresentados na FIG.5.28 e foram obtidos no intervalo de 420 a $720 \mathrm{~nm}$ utilizando o monitoramento da excitação via banda de máxima absorção do sistema polimérico- ligante em 340 nm. O espectro mostra perfil característico dos espectros de emissão do íon európio em complexo com ligante tta sendo observado o alargamento das transições $4 \mathrm{f}-4 \mathrm{f}$ pertencente aos níveis característicos de energia ${ }^{5} \mathrm{D}_{0} \rightarrow{ }^{7} \mathrm{~F}_{\mathrm{J}}(\mathrm{J}=$ 0 -4) do íon európio, quando comparadas com aquelas do complexo precursor sendo a transição hipersensível ${ }^{5} \mathrm{D}_{0} \rightarrow{ }^{7} \mathrm{~F}_{2}$ a mais intensa. Este comportamento 
espectroscópico é devido ao efeito da distribuição de diferentes sítios de simetria ocupados pelo íon $\mathrm{Eu}^{3+}$ no polímero, produzindo um alargamento não homogêneo das bandas de emissão ${ }^{[29]}$. Na FIG. 5.28 (inserida) também podese observar bandas finas na região espectral de 500 a $570 \mathrm{~nm}$ oriundas das transições ${ }^{5} D_{1} \rightarrow{ }^{7} F_{0}(535 \mathrm{~nm}),{ }^{5} D_{1} \rightarrow{ }^{7} F_{1}$ (538 nm) $e^{5} D_{1} \rightarrow{ }^{7} F_{2}$ (560 nm). No entanto, essas bandas apresentam intensidade muito baixas, sendo somente observadas com ampliação da escala espectral.Também é observado nos espectros de emissão das nanopartículas poliméricas (FIG 5.28) um aumento discreto nas intensidades das transições luminescentes ${ }^{5} D_{0} \rightarrow{ }^{7} F_{J} \quad(J=1,2$ e 4$)$ para as nanopartículas menores do que $450 \mathrm{~nm}$.

É importante ressaltar que, os espectros de emissão das nanopartículas de PHB incorporando o complexo de $\mathrm{Eu}^{3+}$ não apresenta banda larga oriunda da fosforescência do TTA no intervalo espectral de 420-600 nm. Esse resultado indica que os processos de transferência de energia do estado tripleto desse ligante para os níveis excitados do európio continuam sendo eficientes mesmo sendo espectro registrado em solução aquosa.

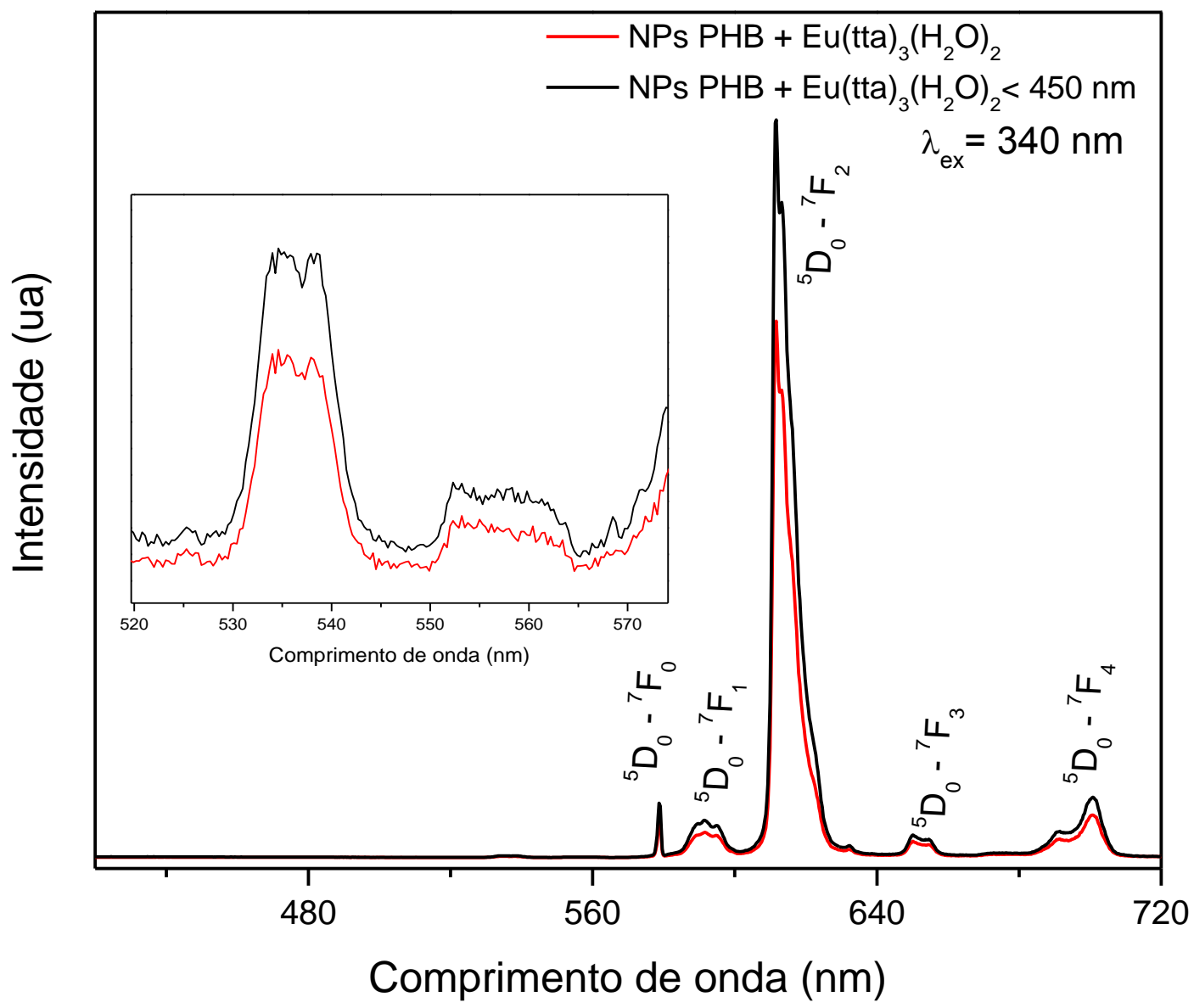

FIG.5.28: Espectro de emissão da suspensão de nanopartículas incorporando o complexo [ $\mathrm{Eu}(\mathrm{tta})_{3}\left(\mathrm{H}_{2} \mathrm{O}\right)_{2}$ ]. A Figura inserida apresenta 0 espectro de emissão com aumento na região entre 520 e 580 nm. 
Na FIG 5.29 apresenta os perfis dos espectros de emissão das nanopartículas de PHB incorporando o complexo $\left[\mathrm{Eu}(\mathrm{tta})_{3}\left(\mathrm{H}_{2} \mathrm{O}\right)_{2}\right]$ em meio aquoso utilizando Tween 80 e PVA com agentes emulsificantes e das nanopartículas do complexo $\left[\mathrm{Eu}(\mathrm{tta})_{3}\left(\mathrm{H}_{2} \mathrm{O}\right)_{2}\right]$ em Tween 80 com excitação monitorada em 340nm e 372nm (máximo dos espectros de excitação). Estes espectros quando comparados ao espectro de emissão do complexo no estado sólido mostra grandes mudanças no perfil. Observa-se novamente 0 alargamento das bandas atribuídas às transições $4 \mathrm{f}-4 \mathrm{f}$ pertencente aos níveis característicos de energia ${ }^{5} D_{0} \rightarrow{ }^{7} F_{J}(J=0-4)$ do íon európio, quando comparadas com aquelas do complexo precursor. Como já observado nos espectros de excitação, a intensidade das bandas na região de 560 a 720 nm do espectro de emissão evidenciam supressão de luminescência quando utiliza-se o PVA como agente de emulsão, atribuído ao aumento da partícula proveniente de uma possível adsorção do PVA a superfície da mesma. A partir destes resultados descartou-se a utilização de PVA para emulsificação e estabilização dos sistemas estudados.

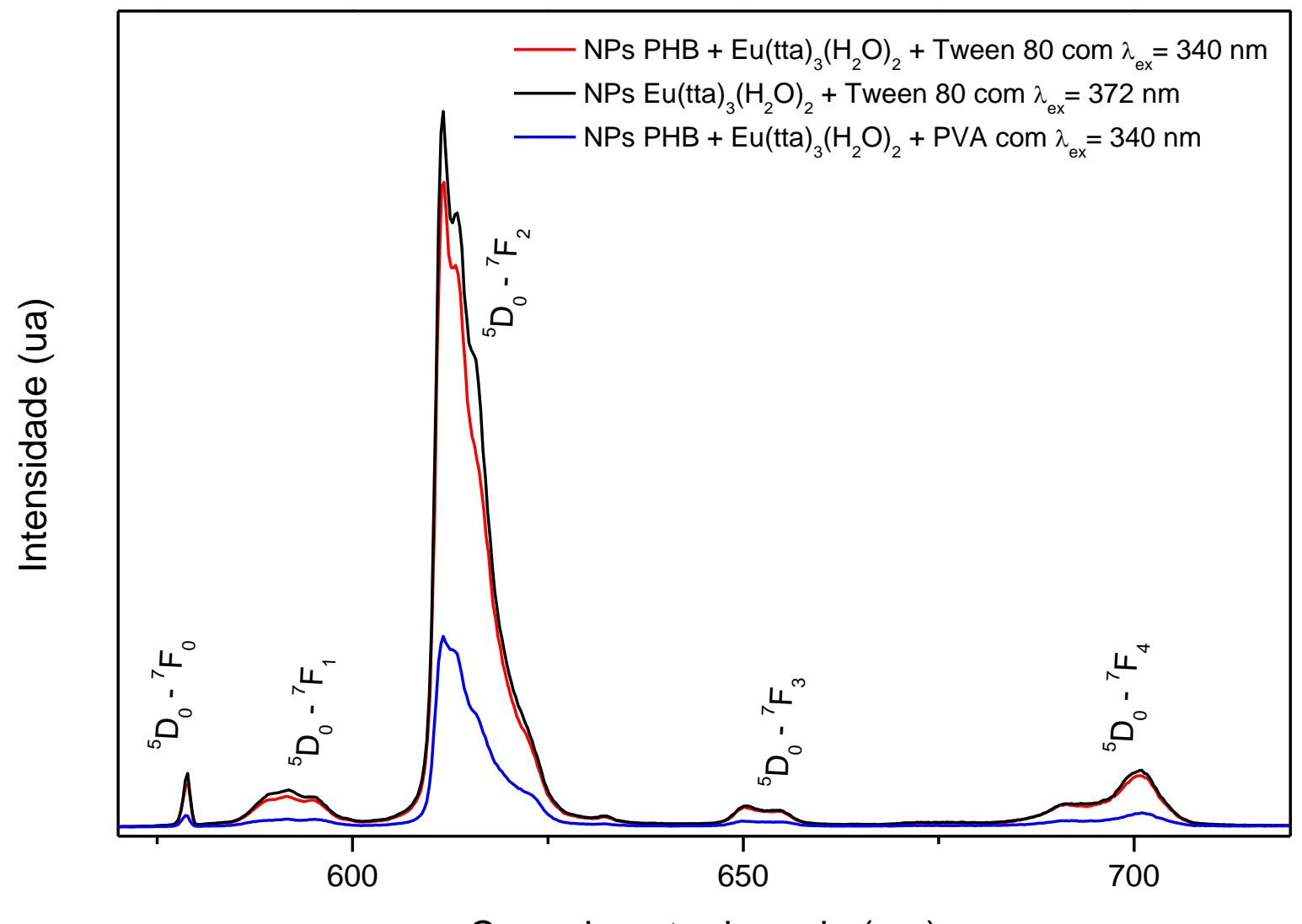

Comprimento de onda $(\mathrm{nm})$

FIG.5.29: Espectro de emissão da suspensão de nanopartículas incorporando o complexo $\left[\mathrm{Eu}(\mathrm{tta})_{3}\left(\mathrm{H}_{2} \mathrm{O}\right)_{2}\right.$ Avaliação do efeito do agente de emulsão na intensidade do espectro. 


\subsubsection{Complexo precursor $\left.\mathrm{Eu}(\mathrm{acac})_{3}\left(\mathrm{H}_{2} \mathrm{O}\right)_{3}\right]$}

A FIG. 5.30 mostra o espectro de excitação do complexo $\left[\mathrm{Eu}(\mathrm{acac})_{3}\left(\mathrm{H}_{2} \mathrm{O}\right)_{3}\right]$ registrado na região de 250 a $590 \mathrm{~nm}$, monitorado na transição ${ }^{5} \mathrm{D}_{0} \rightarrow{ }^{7} \mathrm{~F}_{2}$ em $611 \mathrm{~nm}$, à temperatura ambiente $(298 \mathrm{~K})$. O espectro apresenta uma banda de absorção larga na região de 250 a $350 \mathrm{~nm}$ associada à transição $\mathrm{S}_{1} \rightarrow \mathrm{S}_{0}$ do complexo de acac de $\mathrm{Eu}^{3+}$ que exibe menor intensidade do que esta transição no complexo contendo o ligante tta. Além disso, as bandas finas características e oriundas das transições $4 f^{6}-4 f^{6}$ foram atribuídas aos níveis de energia: ${ }^{7} \mathrm{~F}_{0} \rightarrow{ }^{5} \mathrm{D}_{4}(\sim 360 \mathrm{~nm}),{ }^{7} \mathrm{~F}_{0} \rightarrow{ }^{5} \mathrm{~L}_{6}(\sim 393 \mathrm{~nm}),{ }^{7} \mathrm{~F}_{0} \rightarrow{ }^{5} \mathrm{D}_{2}(\sim 465$ $\mathrm{nm}),{ }^{7} \mathrm{~F}_{0} \rightarrow{ }^{5} \mathrm{D}_{1}(\sim 534 \mathrm{~nm})$ e ${ }^{7} \mathrm{~F}_{0} \rightarrow{ }^{5} \mathrm{D}_{0}(\sim 578 \mathrm{~nm})$ têm maior intensidade de absorção que o ligante acetilacetonato. Para este complexo, $\left[\mathrm{Eu}(\mathrm{acac})_{3}\left(\mathrm{H}_{2} \mathrm{O}\right)_{3}\right]$, foram observadas bandas de maior intensidade de absorção para as transições ${ }^{7} \mathrm{~F}_{0} \rightarrow{ }^{5} \mathrm{D}_{\mathrm{J}}$ do íon európio trivalente, ao invés do que as bandas referentes a parte orgânica, sugerindo que o ligante acac não pode atuar como um eficiente sensibilizador de luminescência. Este fato está relacionado com o gap de energia entre o estado tripleto do acac e o primeiro nível emissor $\left(T_{1} \rightarrow{ }^{5} D_{0}\right)$ do íon $\mathrm{Eu}^{3+}$ que favorece o processo não radiativo.

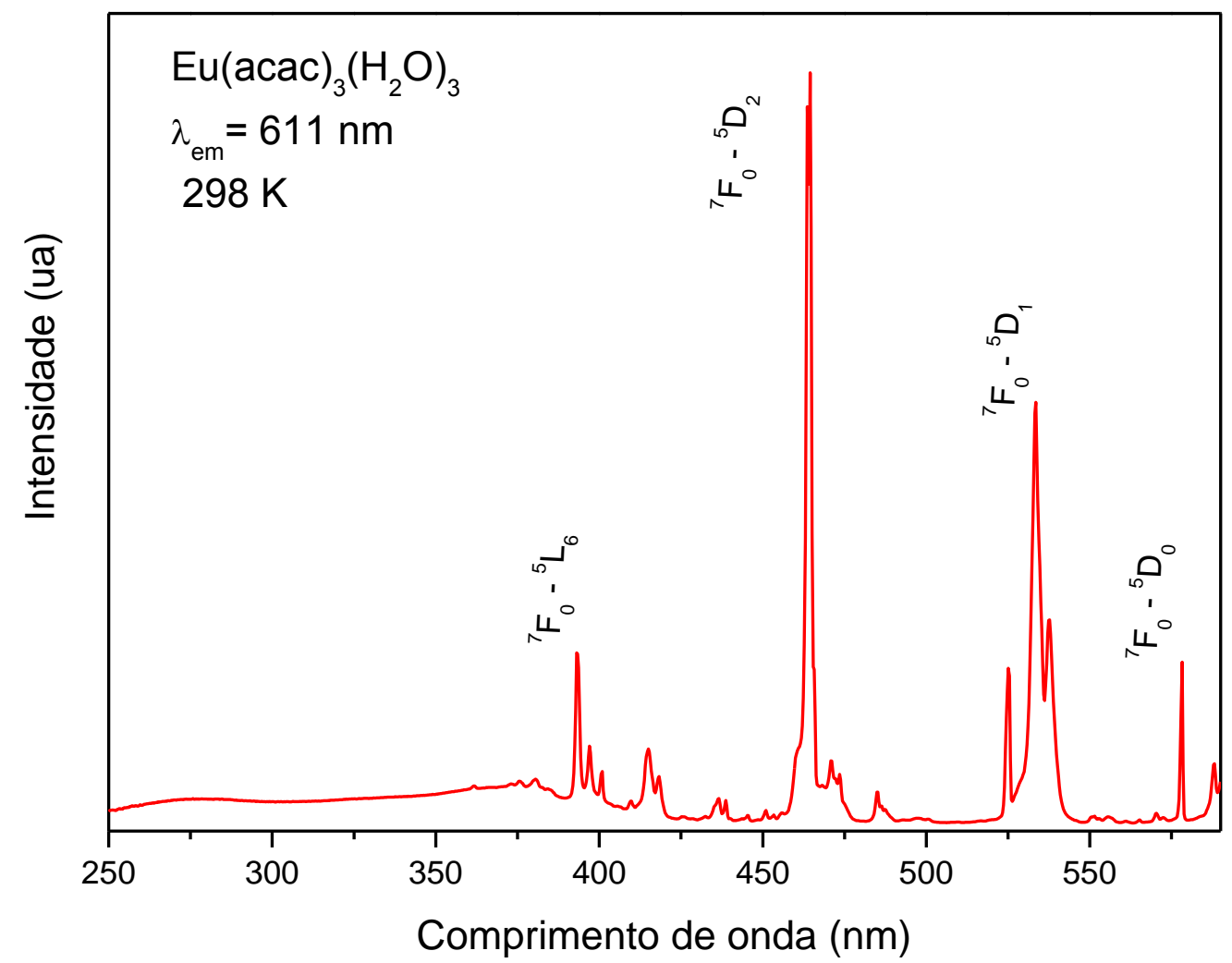

FIG. 5.30: Espectro de excitação do complexo $\left[\mathrm{Eu}(\mathrm{acac})_{3}\left(\mathrm{H}_{2} \mathrm{O}\right)_{3}\right]$ no intervalo de 250 a $590 \mathrm{~nm}$, monitorando a emissão em $611 \mathrm{~nm}$ a $298 \mathrm{~K}$ 
Os espectros de emissão do complexo $\left[\mathrm{Eu}(\mathrm{acac})_{3}\left(\mathrm{H}_{2} \mathrm{O}\right)_{3}\right]$ foram registrados a temperatura ambiente $(298 \mathrm{~K})$ e a $77 \mathrm{~K}$ (FIG.) no intervalo de 570 a $720 \mathrm{~nm}$, com a excitação monitorada na transição ${ }^{7} \mathrm{~F}_{0} \rightarrow{ }^{5} \mathrm{D}_{2}$, aproximadamente em $465 \mathrm{~nm}$. Observa-se que o espectro de emissão do complexo $\left[\mathrm{Eu}(\mathrm{acac})_{3}\left(\mathrm{H}_{2} \mathrm{O}\right)_{2}\right]$ apresenta bandas finas relacionadas as transições ${ }^{5} \mathrm{D}_{0} \rightarrow{ }^{7} \mathrm{~F}_{\mathrm{J}}$, (onde $J=0,1,2$, 3 e 4) com a transição ${ }^{5} D_{0} \rightarrow{ }^{7} F_{2}$ sendo ade maior intensidade.

Os dados fotoluminescentes do complexo hidratado $\left[\mathrm{Eu}(\mathrm{acac})_{3}\left(\mathrm{H}_{2} \mathrm{O}\right)_{3}\right]$ serão utilizados com o intuito de comparar as propriedades espectroscópicas deste composto com aqueles dos sistemas de nanopartículas poliméricas de PHB incorporando este complexo.

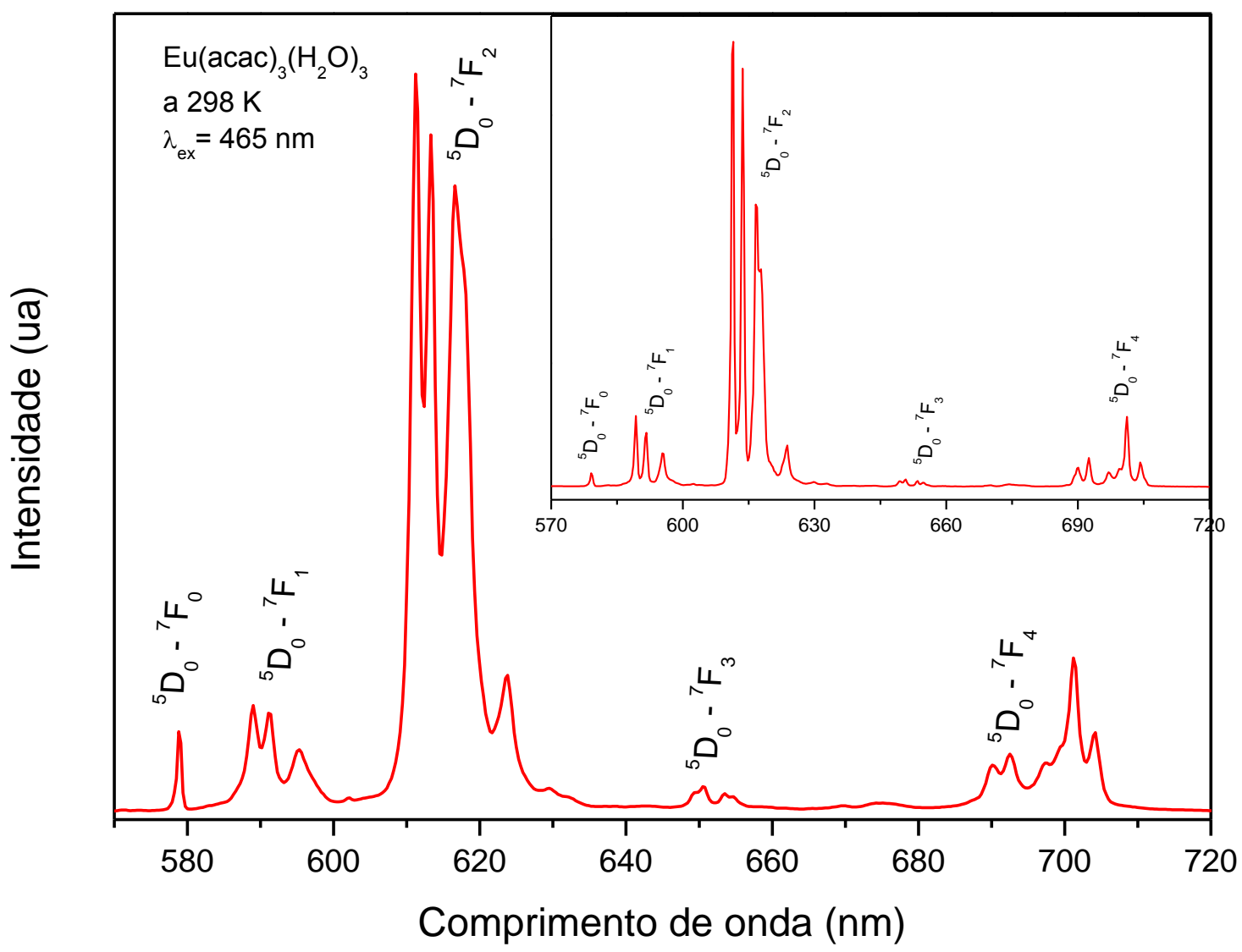

FIG.5.31: Espectro de emissão do complexo $\left[\mathrm{Eu}(\mathrm{acac})_{3}\left(\mathrm{H}_{2} \mathrm{O}\right)_{3}\right]$ no intervalo de 570 a $720 \mathrm{~nm}$, monitorado a excitação em $465 \mathrm{~nm}$ a $298 \mathrm{~K}$. A figura inserida apresenta o espectro de emissão a $77 \mathrm{~K}$. 


\subsubsection{Nanopartículas de PHB com o complexo [Eu(acac $\left.)_{3}\left(\mathrm{H}_{2} \mathrm{O}\right)_{3}\right]$.}

Os espectros de excitação das nanopartículas de PHB incorporando o complexo [ $\left.\mathrm{Eu}(\mathrm{acac})_{3}\left(\mathrm{H}_{2} \mathrm{O}\right)_{3}\right]$ em suspensão aquosa, foram registrados a temperatura ambiente $(298 \mathrm{~K})$ na faixa espectral de 250 a $590 \mathrm{~nm}$, com a emissão monitorada na transição ${ }^{5} \mathrm{D}_{0} \rightarrow{ }^{7} \mathrm{~F}_{2}$, aproximadamente em $611 \mathrm{~nm}$.

A FIG 5.32 mostra o espectro de excitação das nanopartículas de PHB incorporando o complexo $\left[\mathrm{Eu}(\mathrm{acac})_{3}\left(\mathrm{H}_{2} \mathrm{O}\right)_{3}\right]$ em suspensão aquosa, bulk, e da solução filtrada em membrana filtrante com porosidade de $450 \mathrm{~nm}$. Observa-se que na região de 250 a 400nm, o espectro apresenta uma banda larga sobrepondo as transições $4 \mathrm{f}-4 \mathrm{f}$ com máximo em torno de $340 \mathrm{~nm}$ para as partículas poliméricas, atribuídas a absorção do polímero e do ligante acac. Verifica-se também que as transições intraconfiguracionais $4 f$ do ín $\mathrm{Eu}^{3+}$ não foram observadas.

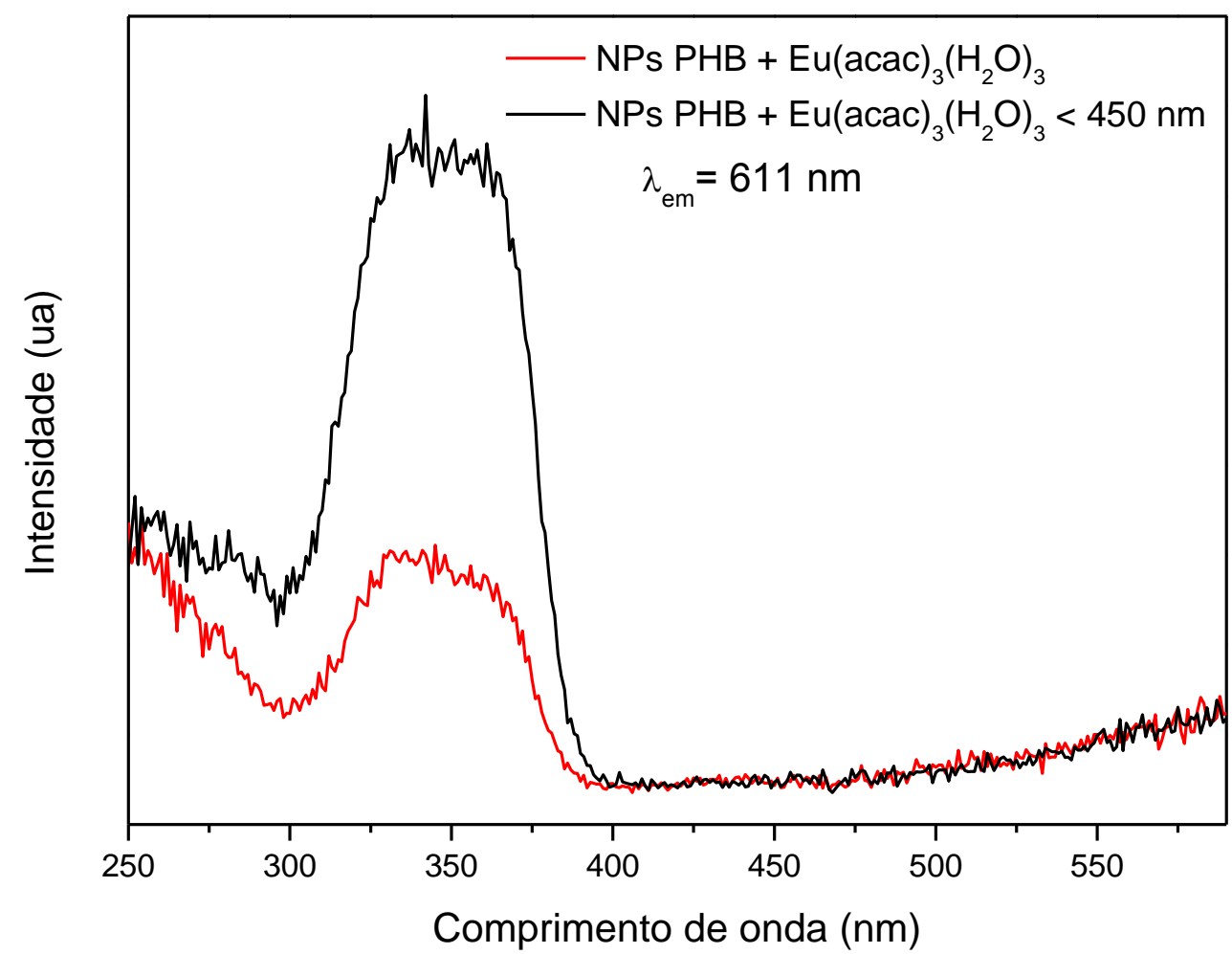

FIG. 5.32: Espectro de excitação da suspensão de nanopartículas contendo $\left[\mathrm{Eu}(\mathrm{acac})_{3}\left(\mathrm{H}_{2} \mathrm{O}\right)_{3}\right]$.

Este é um comportamento análogo a emissão da suspensão de nanopartículas de PHB incorporando o complexo $\left[\mathrm{Eu}(\mathrm{tta})_{3}\left(\mathrm{H}_{2} \mathrm{O}\right)_{2}\right]$ do complexo 
com ligante tta no que se refere ao tamanho de partícula. Novamente, a suspensão filtrada, ou seja, com partículas menores que $450 \mathrm{~nm}$, apresentam maior intensidade da banda de excitação do ligante do que a suspensão bulk. Esta relação e da ordem de 2,6 e o baricentro da suspensão com partículas menores que $450 \mathrm{~nm}$ é deslocado para região espectral do azul em dois nm.

Já os espectros de emissão são apresentados na FIG 5.33 e foram registrados no intervalo de 570 a 720 nm monitorando a excitação no máximo da banda de excitação do sistema polimérico com o complexo do íon $\mathrm{Eu}^{3+}, \mathrm{em}$ aproximadamente $340 \mathrm{~nm}$. Estes espectros de emissão mostram as transições ${ }^{5} D_{0} \rightarrow{ }^{7} F_{J}$ alargadas quando comparadas ao complexo precursor. Isso se justifica por um efeito de distribuição de diferentes pontos de simetria ocupados pelo íon no polímero, gerando bandas mais alargadas. Este é o mesmo efeito verificado com as nanopartículas poliméricas contendo o complexo com ligante tta.

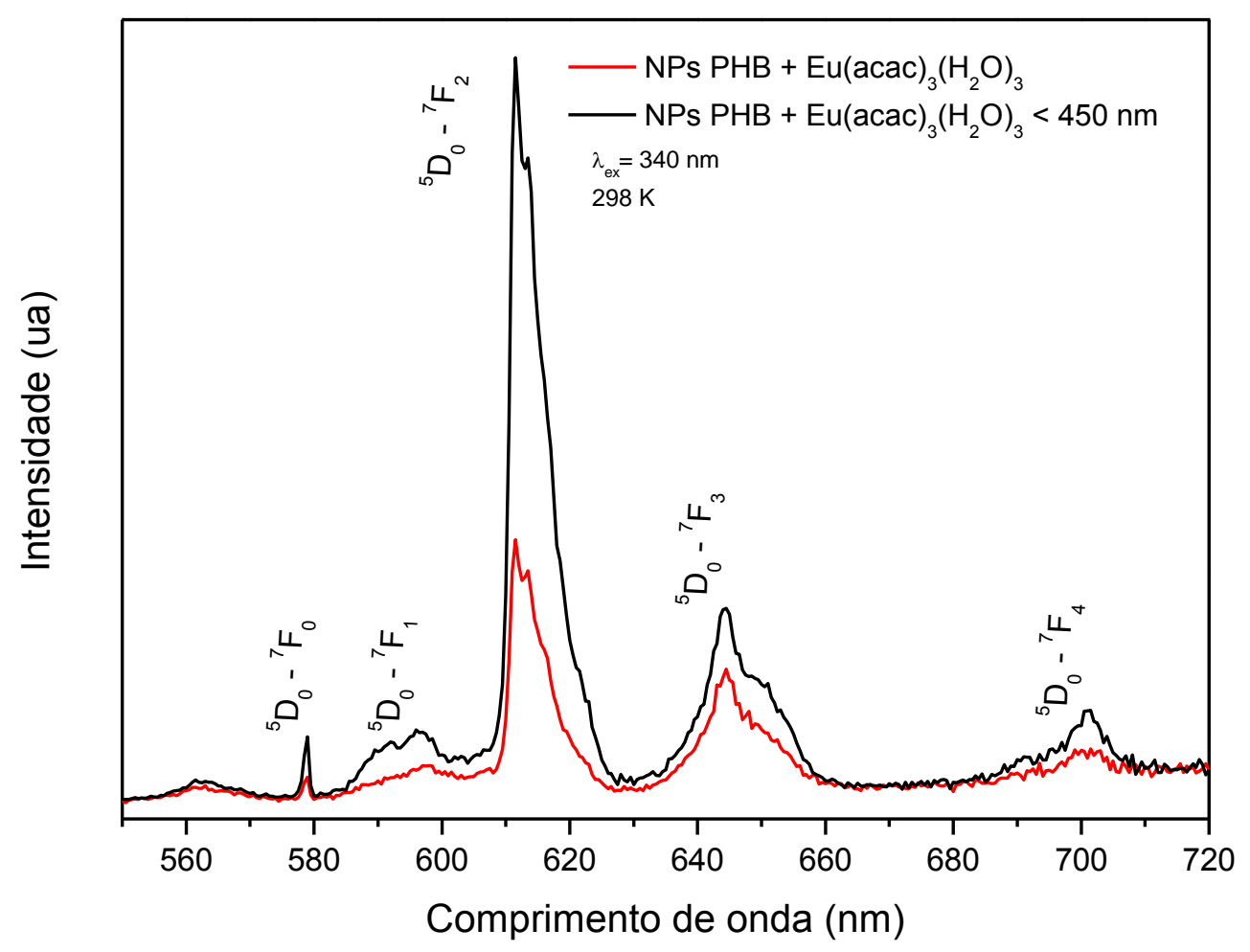

FIG. 5.33: Espectro de emissão da suspensão de nanopartículas contendo $\left[\mathrm{Eu}(\mathrm{acac})_{3}\left(\mathrm{H}_{2} \mathrm{O}\right)_{3}\right]$. Avaliação do efeito de tamanho de partícula. 
Uma singularidade a ser considerado nestes espectros é que as transições proibidas por dipolo elétrico ${ }^{5} \mathrm{D}_{0} \rightarrow{ }^{7} \mathrm{~F}_{0,3,5}$ estão presentes no espectro $\left({ }^{5} D_{0} \rightarrow{ }^{7} F_{0,3}\right)$ pela relaxação da regra de seleção devido ao campo ligante, que produz misturas de J's. Vale salientar que a transição ${ }^{5} D_{0} \rightarrow{ }^{7} F_{3}$ para este sistema apresenta uma intensidade incomum para materiais contendo íons európio.

\subsubsection{Fotoluminescência dos sistemas contendo íon $\mathbf{T b}^{3+}$.}

O íon $\mathrm{Tb}^{3+}$ possui configuração eletrônica $4 f^{8}$ além dos níveis de Stark invertidos em relação ao íon $\mathrm{Eu}^{3+}$. O estado fundamental é o ${ }^{7} \mathrm{~F}_{6}$ e seu primeiro estado emissor é $\circ{ }^{5} D_{4}$. Praticamente todas as suas transições se encontram na região do visível, com exceção da transição ${ }^{5} D_{3} \rightarrow{ }^{7} F_{6}$ situada na região do UV próximo. O processo de sensibilização dos materiais contendo o íon $\mathrm{Tb}^{3+}$ é muito semelhante aqueles do íon $\mathrm{Eu}^{3+}$, com a diferença que neste, todas as transições são muito intensas. É importante enfatizar que é necessário por parte do ligante, um estado tripleto em região de maior energia ou em ressonância com o primeiro nível de emissão ${ }^{5} \mathrm{D}_{4}$ do íon térbio para que ocorra o processo de transferência de energia ${ }^{[28,29]}$.

\subsubsection{Complexo precursor $\left[\mathrm{Tb}(\mathrm{acac})_{3}\left(\mathrm{H}_{2} \mathrm{O}\right)_{3}\right]$}

$\mathrm{O}$ espectro de excitação do complexo $\left[\mathrm{Tb}(\mathrm{acac})_{3}\left(\mathrm{H}_{2} \mathrm{O}\right)_{3}\right]$ foi registrado a temperatura ambiente $(298 \mathrm{~K}$ ) em intervalo de 250 a $520 \mathrm{~nm}$, com a emissão monitorada na transição hipersensível do íon $\mathrm{Tb}^{3+}$ em $548 \mathrm{~nm}$. Pode-se observar a presença de duas bandas finas características das transições intraconfiguracionais $4 f^{8}-4 f^{8}$ atribuídasas transições ${ }^{7} F_{5} \rightarrow{ }^{5} G_{6}$ (378 $n m)$ e ${ }^{7} F_{0} \rightarrow{ }^{5} D_{4}(487 n m)$ além da presença de uma banda larga e centrada em $330 \mathrm{~nm}$ associada à transição permitida $S_{1} \rightarrow S_{0}$ do ligante acac (FIG 5.34). 


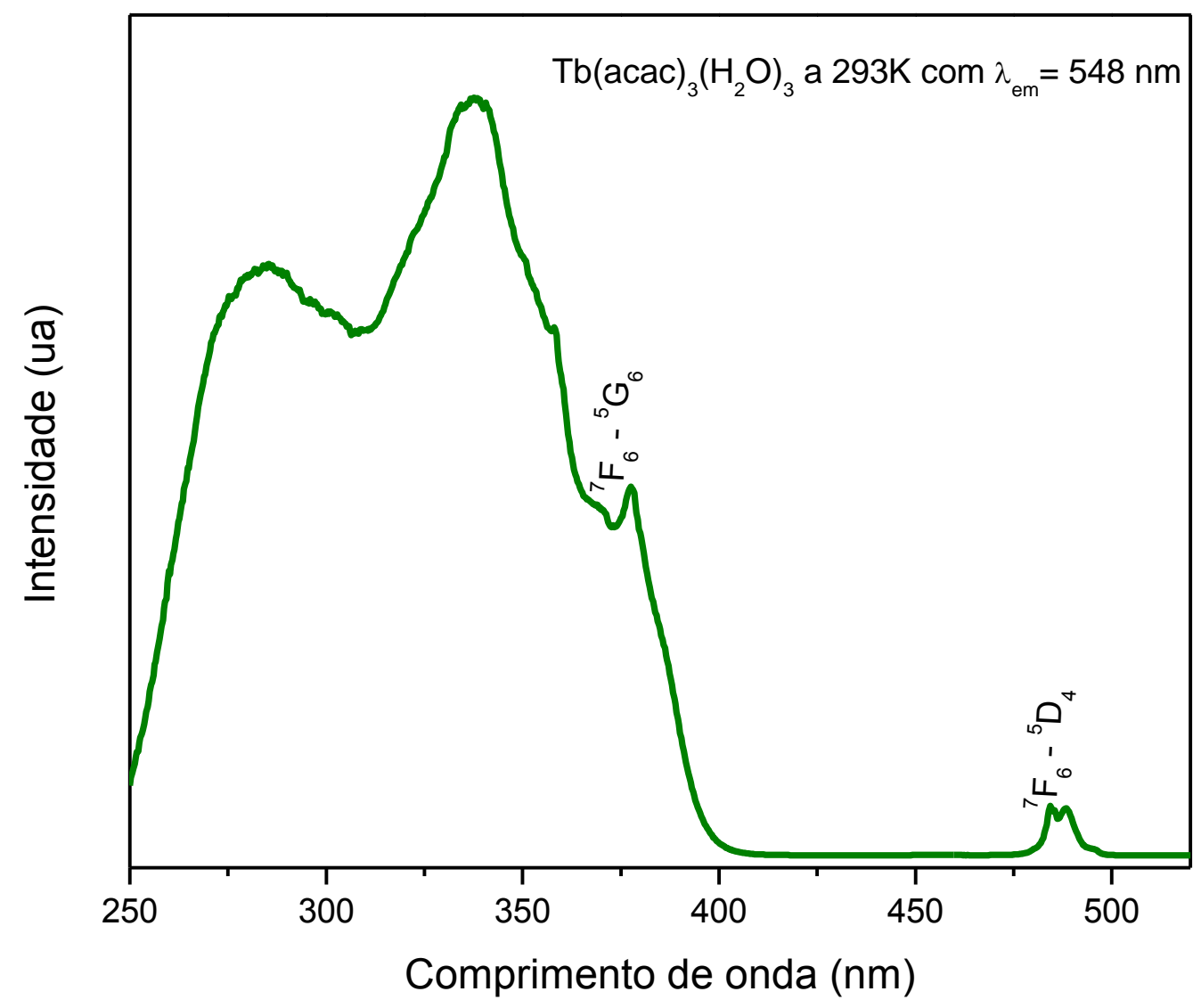

FIG. 5.34: Espectro de excitação do complexo $\left[\mathrm{Tb}(\mathrm{acac})_{3}\left(\mathrm{H}_{2} \mathrm{O}\right)_{3}\right]$ no intervalo de 250 a $590 \mathrm{~nm}$, monitorado a emissão em $548 \mathrm{~nm}$ a $298 \mathrm{~K}$.

Os espectros de emissão do complexo $\left[\mathrm{Tb}(\mathrm{acac})_{3}\left(\mathrm{H}_{2} \mathrm{O}\right)_{3}\right]$ foram registrados a temperatura ambiente $(298 \mathrm{~K})$ e do nitrogênio líquido ,77 K (FIG 5.35) na faixa espectral de 470 a $700 \mathrm{~nm}$, e com a excitação monitorada em $338 \mathrm{~nm}$. Observa-se que o espectro de emissão do complexo [ $\left.\mathrm{Tb}(\mathrm{acac})_{3}\left(\mathrm{H}_{2} \mathrm{O}\right)_{2}\right]$ apresenta bandas finas relacionadas as transições ${ }^{5} \mathrm{D}_{4} \rightarrow{ }^{7} \mathrm{~F}_{\mathrm{J}}$, (onde $\mathrm{J}=0-6$ ), sendo a ${ }^{5} \mathrm{D}_{4} \rightarrow{ }^{7} \mathrm{~F}_{6}$ em $\sim 490 \mathrm{~nm},{ }^{5} \mathrm{D}_{4} \rightarrow{ }^{7} \mathrm{~F}_{5}$ em $\sim 548 \mathrm{~nm},{ }^{5} \mathrm{D}_{4} \rightarrow{ }^{7} \mathrm{~F}_{4} \mathrm{em} \sim 587 \mathrm{~nm},{ }^{5} \mathrm{D}_{4}$ $\rightarrow{ }^{7} \mathrm{~F}_{3}$ em $\sim 620 \mathrm{~nm},{ }^{5} \mathrm{D}_{4} \rightarrow{ }^{7} \mathrm{~F}_{2}$ em $\sim 650 \mathrm{~nm} \mathrm{e}{ }^{5} \mathrm{D}_{4} \rightarrow{ }^{7} \mathrm{~F}_{1}$ em $\sim 670 \mathrm{~nm}$ com a transição de maior intensidade sendo $a^{5} D_{4} \rightarrow{ }^{7} F_{5}$.

No espectro não foi observado transições relativas a fosforescência do ligante indicando que o processo de transferência de energia intramolecular no complexo $\left[\mathrm{Tb}(\mathrm{acac})_{3}\left(\mathrm{H}_{2} \mathrm{O}\right)_{3}\right]$ do ligante acac para o íon $\mathrm{Tb}^{3+}$ é eficiente. 


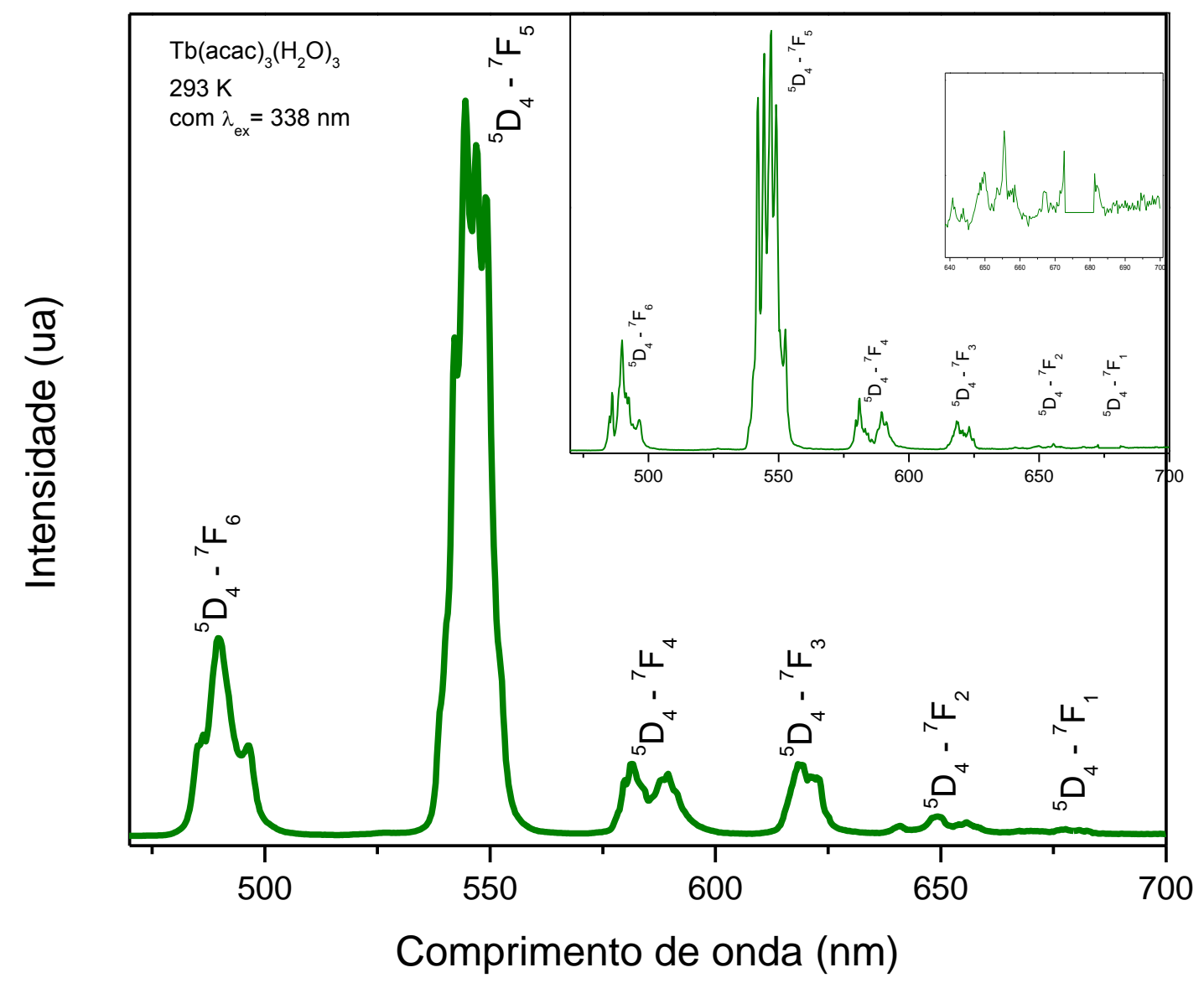

FIG. 5.35: Espectro de emissão do complexo $\left[\mathrm{Tb}(\mathrm{acac})_{3}\left(\mathrm{H}_{2} \mathrm{O}\right)_{3}\right]$ no intervalo de 470 a 700 nm, monitorado a excitação em 338 nm a 298 K. A Figura inserida apresenta o espectro de emissão a $77 \mathrm{~K}$.

A transição de maior intensidade espectral é a ${ }^{5} D_{4} \rightarrow{ }^{7} F_{5}$, predominante no espectro de emissão, centrada em $548 \mathrm{~nm}$, portanto, é de se esperar uma emissão monocromática de cor verde para compostos de térbio sob radiação UV.

\subsubsection{Nanopartículas de PHB com o complexo[Tb(acac $\left.)_{3}\left(\mathrm{H}_{2} \mathrm{O}\right)_{3}\right]$}

As nanopartículas de PHB incorporando 0 complexo $\left[\mathrm{Tb}(\mathrm{acac})_{3}\left(\mathrm{H}_{2} \mathrm{O}\right)_{3}\right]$ foram analisados em suspensão aquosa e em suspensão aquosa filtrada em membrana filtrante com porosidade de $450 \mathrm{~nm}$ a temperatura ambiente (298 K). Os espectros de excitação foram registrados em 
um intervalo de 250 a $520 \mathrm{~nm}$, com a emissão monitorada na transição hipersensível, ${ }^{5} \mathrm{D}_{4} \rightarrow{ }^{7} \mathrm{~F}_{5}$, em $\sim 548 \mathrm{~nm}$.

Além disso, o complexo de térbio hidratado (FIG 5.36) exibe bandas finas oriundas das transições intraconfiguracionais ${ }^{7} \mathrm{~F}_{5} \rightarrow{ }^{5} \mathrm{G}_{6}(377 \mathrm{~nm})$ e ${ }^{7} \mathrm{~F}_{5} \rightarrow{ }^{5} \mathrm{D}_{4}$ (486nm). que não aparecem nos espectros das nanopartículas poliméricas FIG 5.36 ou seja, são totalmente suprimidas para as nanopartículas poliméricas de PHB. Na região de 250 a $325 \mathrm{~nm}$, os espectros apresentam uma banda larga com máximo em torno de $294 \mathrm{~nm}$ associada à transição permitida $\mathrm{S} \rightarrow \mathrm{S}_{0}$ pertencente ao ligante acetilacetonato.

Quando se correlaciona estes dados com os da literatura ${ }^{[10]}$ observase que as nanopartículas de PHB tem seu máximo no espectro de excitação, deslocado para região do azul do espectro (294nm), quando comparado com os dados de Kai ${ }^{[10]}$ (326nm em 15\% de dopagem).

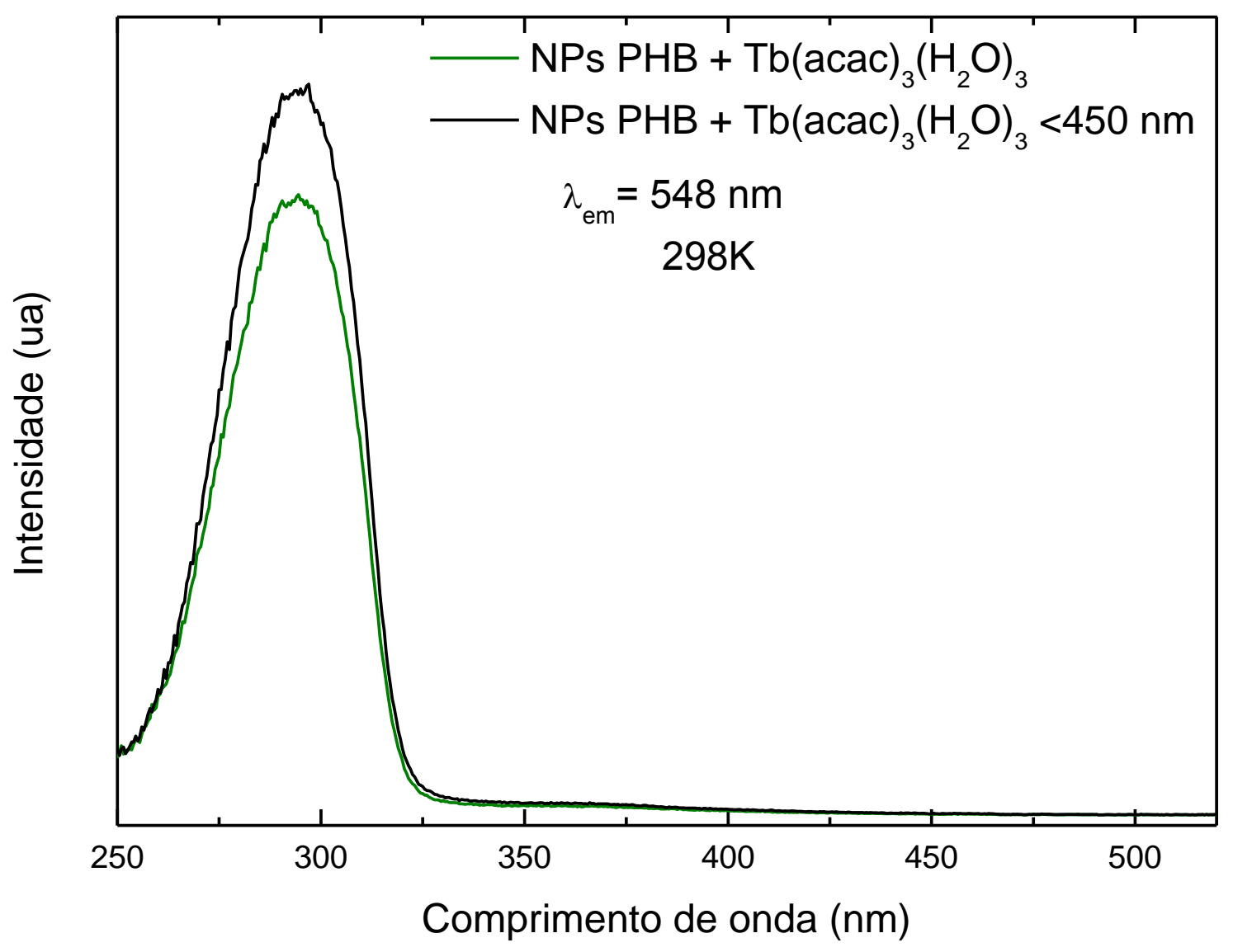

FIG. 5.36: Espectro de excitação da suspensão de nanopartículas contendo $\left[\mathrm{Tb}(\mathrm{acac})_{3}\left(\mathrm{H}_{2} \mathrm{O}\right)_{3}\right]$. Avaliação do efeito de tamanho de partícula. 
Os espectros de emissão foram obtidos no intervalo de 450 a 700nm monitorando a excitação em $295 \mathrm{~nm}$, transição permitida, $\mathrm{S} \rightarrow \mathrm{S}_{0}$ do ligante acetilacetonato, conforme mostrado na FIG 5.37.

Os espectros exibem bandas oriundas das ${ }^{5} \mathrm{D}_{4} \rightarrow{ }^{7} \mathrm{~F}_{\mathrm{J}}(\mathrm{J}=0-6)$ do íon metálico atribuídas as transições ${ }^{5} \mathrm{D}_{4} \rightarrow{ }^{7} \mathrm{~F}_{6}(489 \mathrm{~nm}),{ }^{5} \mathrm{D}_{4} \rightarrow{ }^{7} \mathrm{~F}_{5}(544 \mathrm{~nm})$, ${ }^{5} D_{4} \rightarrow{ }^{7} F_{4}(582 \mathrm{~nm}),{ }^{5} D_{4} \rightarrow{ }^{7} F_{3}(621 \mathrm{~nm}),{ }^{5} D_{4} \rightarrow{ }^{7} F_{2}(653 \mathrm{~nm}) e^{5} D_{4} \rightarrow{ }^{7} F_{1}(670 \mathrm{~nm})$. A transição hipersensível ${ }^{5} \mathrm{D}_{4} \rightarrow{ }^{7} \mathrm{~F}_{5}$ é predominante nos espectros de emissão, apresentando uma grande diferença de energia entre o nível emissor ${ }^{5} D_{4}$ e o nível final ${ }^{7} \mathrm{~F}_{5}$ ao redor de $15.000 \mathrm{~cm}^{-1}$. Portanto, compostos de $\mathrm{Tb}^{3+}$ geralmente exibem uma emissão monocromática da cor verde sob irradiação UV.

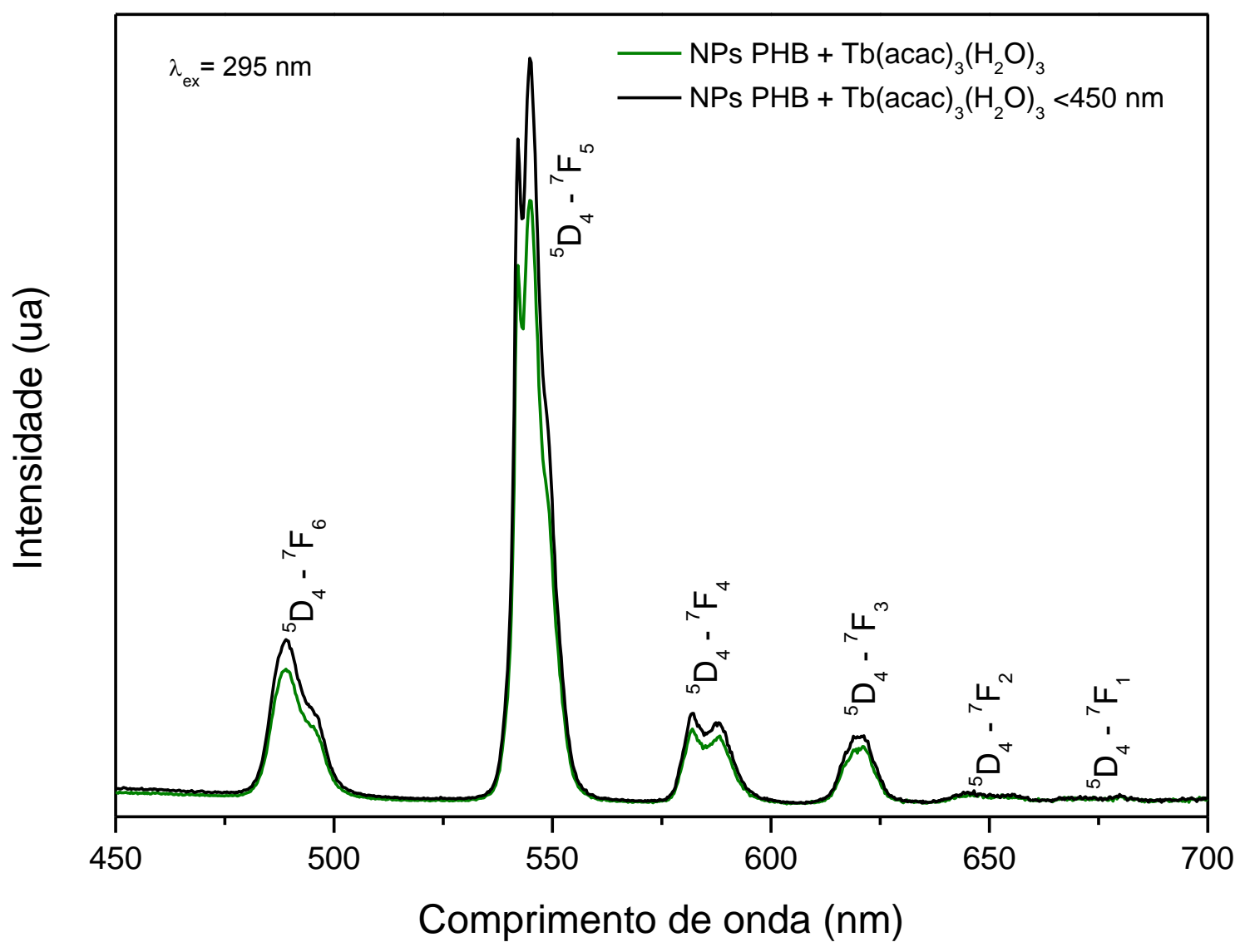

FIG. 5.37: Espectro de emissão da suspensão de nanopartículas contendo $\left[\mathrm{Tb}(\mathrm{acac})_{3}\left(\mathrm{H}_{2} \mathrm{O}\right)_{3}\right]$. Avaliação do efeito de tamanho de partícula. 
Verificou-se que este sistema polimérico apresenta bandas alargadas atribuídas às transições ${ }^{5} \mathrm{D}_{4} \rightarrow{ }^{7} \mathrm{~F}_{J}$ do íon térbio, quando comparadas àquelas do complexo precursor $\left[\mathrm{Tb}(\mathrm{acac})_{3}\left(\mathrm{H}_{2} \mathrm{O}\right)_{3}\right]^{[31]}$. Este comportamento espectroscópico é devido ao efeito da distribuição de diferentes sítios de simetria ocupados pelo íon $\mathrm{Tb}^{3+}$ no polímero, produzindo um alargamento não homogêneo das bandas de emissão ${ }^{[10]}$. Também é observado nos espectros de emissão das nanopartículas poliméricas dopadas (FIG 5.37) um discreto aumento na intensidade luminescente em função do tamanho da nanopartícula, quando o sistema é excitado diretamente no ligante

\subsubsection{Fotoluminescência dos sistemas contendo íon $\mathrm{Sm}^{3+}$.}

O íon $\mathrm{Sm}^{3+}\left([\mathrm{Xe}] 4 \mathrm{f}^{5}\right)$ tem configuração com número de elétrons ímpar, e de acordo com a regra de Kramer, os seus estados são no mínimo duplamente degenerados em qualquer perturbação do campo ligante $e^{[28,32,33]}$. Consequentemente, um estado oriundo do número quântico $\mathrm{J}$-semi-inteiro se desdobrará em no máximo ( $\mathrm{J}+1 / 2)$-componentes Stark. A degenerescência de Kramer é somente removida por meio de uma interação adicional que quebre a invariância tempo-reverso do Hamiltoniano do íon com configuração impar, tal como, as interações magnéticas entre os átomos nos compostos ${ }^{[28,34]}$.

Os compostos de $\mathrm{Sm}^{3+}$ são conhecidos por exibirem emissão alaranjada sob radiação ultravioleta. Seus espectros de emissão apresentam, principalmente, bandas finas oriundas das transições intraconfiguracionais ${ }^{4} G_{5 / 2} \rightarrow{ }^{6} H_{J}$ (onde $J=5 / 2,7 / 2$, 9/2 e 11/2) localizadas na região do visível. A transição ${ }^{4} \mathrm{G}_{5 / 2} \rightarrow{ }^{6} \mathrm{H}_{5 / 2}(\sim 560 \mathrm{~nm})$ e ${ }^{4} \mathrm{G}_{5 / 2} \rightarrow{ }^{6} \mathrm{H}_{7 / 2}(\sim 600 \mathrm{~nm})$ apresentam alto caráter de dipolo magnético e são, geralmente, dominadas por este mecanismo. Por outro lado, a transição hipersensível ${ }^{4} \mathrm{G}_{5 / 2} \rightarrow{ }^{6} \mathrm{H}_{9 / 2}(\sim 645 \mathrm{~nm})(\Delta \mathrm{J}=2)$ é dominada pelo mecanismo de dipolo-elétrico e é, geralmente, a transição mais intensa nos espectros de emissão dos compostos de $\mathrm{Sm}^{3+}$. Com base nesses resultados, a transição ${ }^{4} \mathrm{G}_{5 / 2} \rightarrow{ }^{6} \mathrm{H}_{5 / 2}$ tem sido tomada como referência na determinação do parâmetro $\eta_{S m}$ que é definido como a razão entre as intensidades integradas das transições ${ }^{4} \mathrm{G}_{5 / 2} \rightarrow{ }^{6} \mathrm{H}_{9 / 2}$ e ${ }^{4} \mathrm{G}_{5 / 2} \rightarrow{ }^{6} \mathrm{H}_{5 / 2}$ nos complexos 
de $\mathrm{Sm}^{3+[28,35]}$. Além disso, fez-se uma análise comparativa da influência dos ligantes orgânicos sobre o ambiente químico do íon central que se reflete nas propriedades espectroscópicas dos complexos. Esses estudos são realizados com base nos espectros de luminescência (excitação e emissão), tempo de vida do estado emissor ${ }^{4} G_{5 / 2}$ e nos valores do parâmetro de intensidade experimental, $\eta_{S m}$ (Equação 5.1)

$$
\eta_{\mathrm{Sm}}=\frac{\mathrm{S}\left({ }^{4} \mathrm{G}_{5 / 2} \rightarrow{ }^{6} \mathrm{H}_{9 / 2}\right)}{\mathrm{S}\left({ }^{4} \mathrm{G}_{5 / 2} \rightarrow{ }^{6} \mathrm{H}_{5 / 2}\right)}
$$

\subsubsection{Complexo precursor $\left[\mathrm{Sm}(\mathrm{tta})_{3}\left(\mathrm{H}_{2} \mathrm{O}\right)_{2}\right]$}

Os espectros de excitação do complexo $\left[\mathrm{Sm}(\mathrm{tta})_{3}\left(\mathrm{H}_{2} \mathrm{O}\right)_{2}\right]$ foram registrados a temperatura ambiente $(298 \mathrm{~K})$ e $77 \mathrm{~K}$ em intervalo de $240 \mathrm{a}$ 630nm, com a emissão monitorada na transição ${ }^{4} \mathrm{G}_{5 / 2} \rightarrow{ }^{6} \mathrm{H}_{9 / 2}$, aproximadamente em 644 nm (FIG 5.38). Pode-se observar a presença de uma banda entre 260 e $450 \mathrm{~nm}$ associada à transição permitida $S_{1} \rightarrow S_{0}$ do ligante tta. Essa banda se sobrepõe as bandas finas das transições intraconfiguracionais $4 \mathrm{f}-4 \mathrm{f}$ envolvendo o estado fundamental ${ }^{6} \mathrm{H}_{5 / 2}$ e os estados excitados ${ }^{4} \mathrm{H}_{11 / 2}(390 \mathrm{~nm})$, ${ }^{4} \mathrm{M}_{19 / 2}(418 n m),{ }^{4} \mathrm{I}_{15 / 2}(442 n m),{ }^{4} \mathrm{~F}_{3 / 2}(452 \mathrm{~nm}),{ }^{4} \mathrm{I}_{11 / 2}(478 \mathrm{~nm})$ e ${ }^{4} G_{7 / 2}(499 \mathrm{~nm})$. 


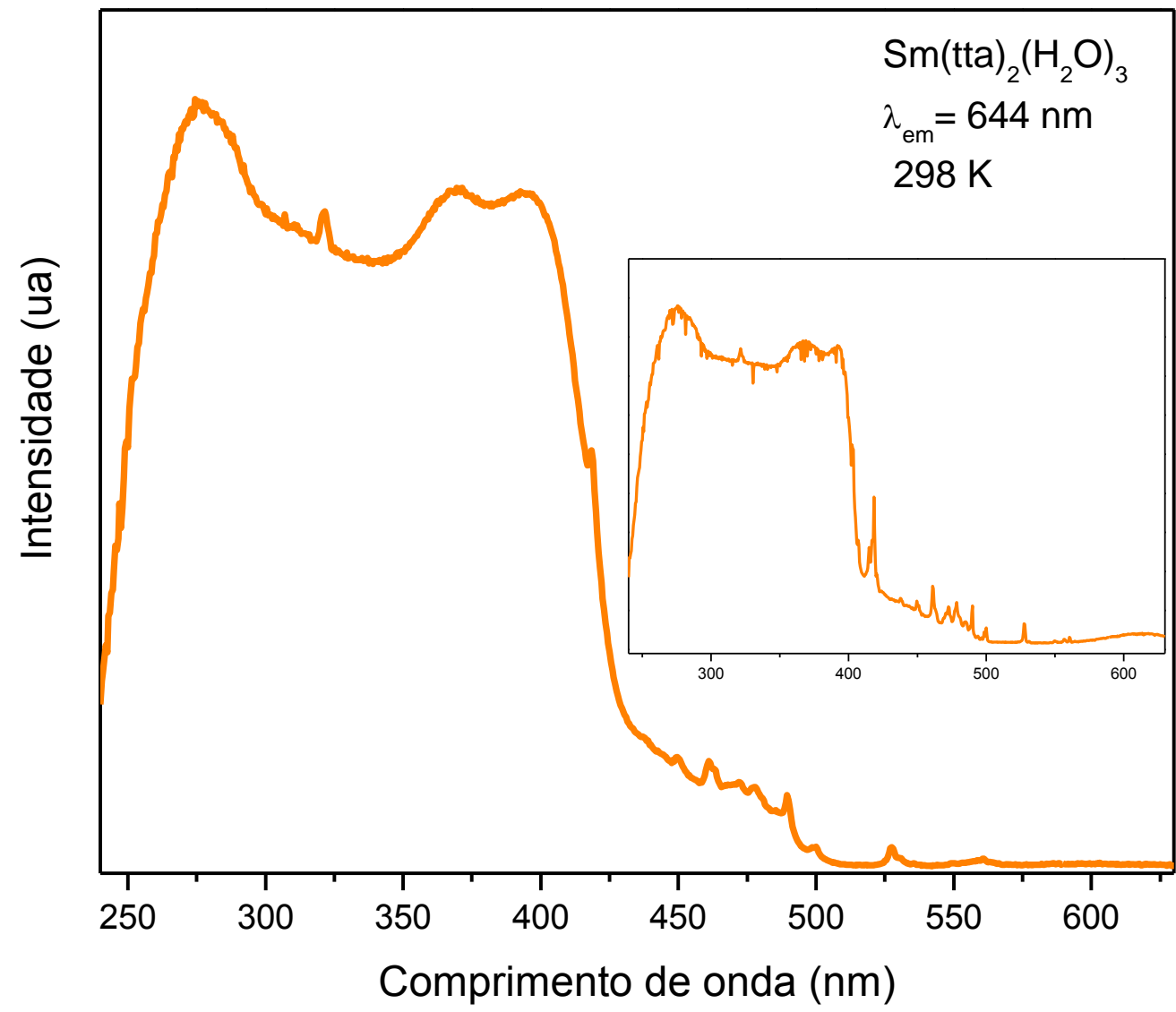

FIG. 5.38: Espectro de excitação do complexo $\left[\mathrm{Sm}(\mathrm{tta})_{3}\left(\mathrm{H}_{2} \mathrm{O}\right)_{2}\right]$ no intervalo de 240 a $630 \mathrm{~nm}$, monitorado a emissão em $644 \mathrm{~nm}$ a $298 \mathrm{~K}$. A figura inserida apresenta o espectro de excitação a $77 \mathrm{~K}$.

Os espectros de emissão do complexo [Sm(tta) $\left.)_{3}\left(\mathrm{H}_{2} \mathrm{O}\right)_{2}\right]$ foram obtidos a temperatura ambiente $(298 \mathrm{~K}$ ) e a $77 \mathrm{~K}$ (FIG 5.39) no intervalo espectral de 400 a $700 \mathrm{~nm}$, com a excitação monitorada em 390nm . Observase que o espectro de emissão do complexo $\left[\mathrm{Sm}(\mathrm{tta})_{3}\left(\mathrm{H}_{2} \mathrm{O}\right)_{2}\right]$ exibem bandas relacionadas as transições ${ }^{4} G_{5 / 2} \rightarrow{ }^{6} H_{J}$, (onde $J=5 / 2,7 / 2,9 / 2$ e 11/2), sendo a ${ }^{4} \mathrm{G}_{5 / 2} \rightarrow{ }^{6} \mathrm{H}_{9 / 2}$ amais intensa, o que indica uma transferência de energia intramolecular eficiente do estado $T$ do ligante tta para o nível emissor ${ }^{4} G_{5 / 2}$ do ín $\mathrm{Sm}^{3+}$. A ausência de bandas largas oriundas da fosforescência dos ligantes evidencia a eficiência na transferência de energia Ligante- $\mathrm{Sm}^{3+}$, indicando que o ligante TTA também é bom sensibilizador de luminescência para o íon $\mathrm{Sm}^{3+}$. $\mathrm{O}$ espectro de emissão a $77 \mathrm{~K}$ mostra ainda que as bandas atribuídas às transições ${ }^{4} G_{5 / 2} \rightarrow{ }^{6} H_{J}$ estão desdobradas no número máximo de $(J+1 / 2)$ componentes indicando que o íon $\mathrm{Sm}^{3+}$ ocupa um ambiente químico de baixa simetria. 


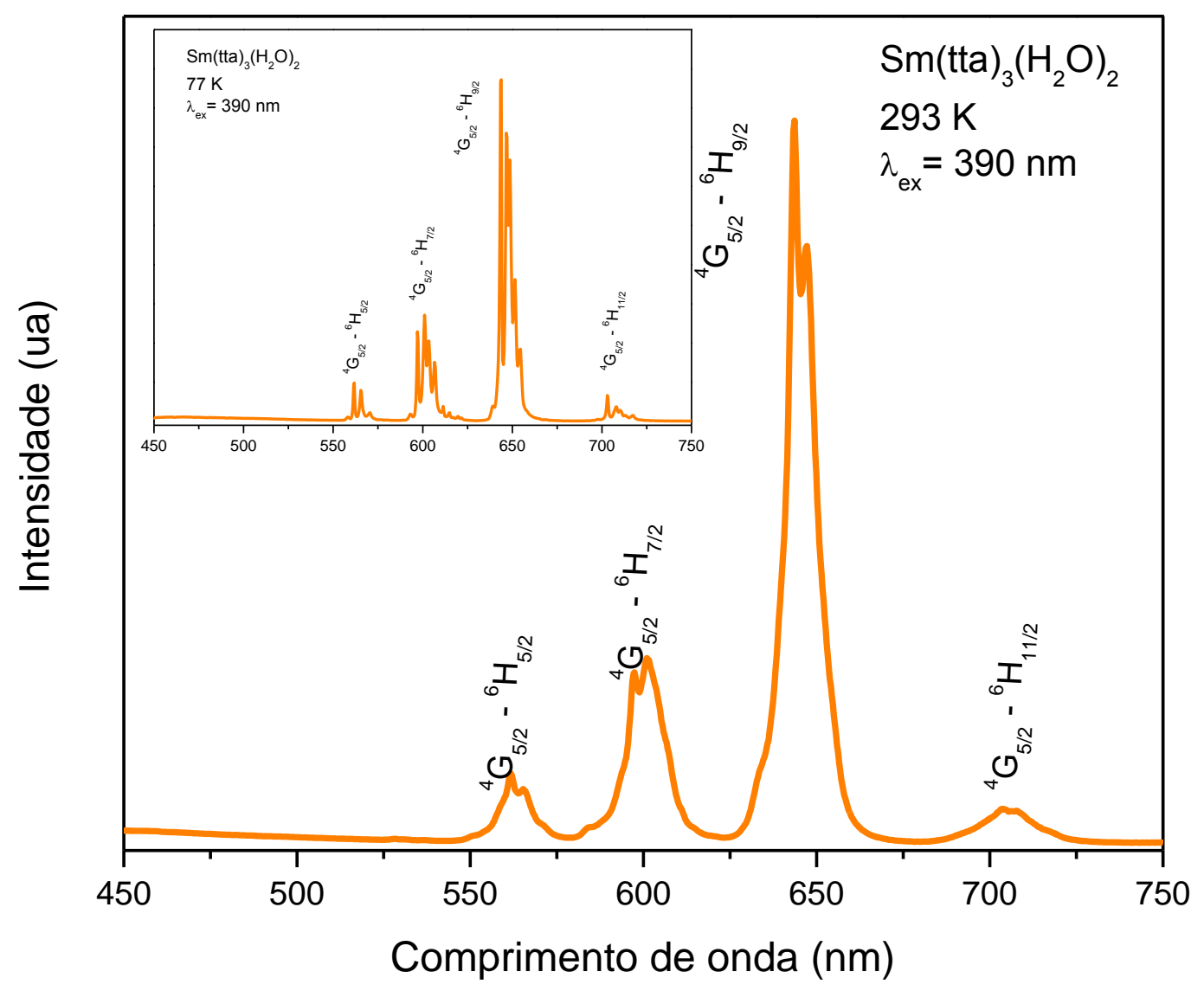

FIG. 5.39: Espectro de emissão do complexo [ $\left.\mathrm{Sm}(\mathrm{tta})_{3}\left(\mathrm{H}_{2} \mathrm{O}\right)_{2}\right]$ no intervalo de 450 a $750 \mathrm{~nm}$, monitorado a excitação em $390 \mathrm{~nm}$ a $298 \mathrm{~K}$. A figura inserida apresenta o espectro de emissão a $77 \mathrm{~K}$.

\subsubsection{Nanopartículas de PHB com o complexo $\left[\mathrm{Sm}(\mathrm{tta})_{3}\left(\mathrm{H}_{2} \mathrm{O}\right)_{2}\right]$}

Os espectros de excitação das nanopartículas de PHB dopadas com [Sm $\left.(\mathrm{tta})_{3}\left(\mathrm{H}_{2} \mathrm{O}\right)_{2}\right]$ foram registrados em suspensão aquosa a temperatura ambiente $(298 \mathrm{~K})$. Os espectros de excitação foram registrados no intervalo de 240 a $580 \mathrm{~nm}$, com a emissão monitorada na transição ${ }^{4} \mathrm{G}_{5 / 2} \rightarrow{ }^{6} \mathrm{H}_{9 / 2}$, aproximadamente em $644 \mathrm{~nm}$, verificado como máximo de absorção no espectro de emissão do sistema nanoparticulado.

A FIG 5.40 mostra o espectro de excitação das nanopartículas em suspensão aquosa bulk e da suspensão filtrada em membrana filtrante com porosidade de $450 \mathrm{~nm}$. Observa-se que na região $350 \mathrm{~nm}$, o espectro apresenta uma banda que pode ser associada à transição permitida $S_{1} \rightarrow S_{0}$ do 
ligante tta. No entanto, não se observa absorção na região onde se esperava por uma banda larga sobreposta as bandas finas oriundas de transições $4 f-4 f$ que envolve $\mathrm{o}$ estado fundamental ${ }^{6} \mathrm{H}_{5 / 2}{ }^{[10]}$. $\mathrm{O}$ efeito do tamanho da partícula apresentou-se de forma muito discreta nesses espectros.

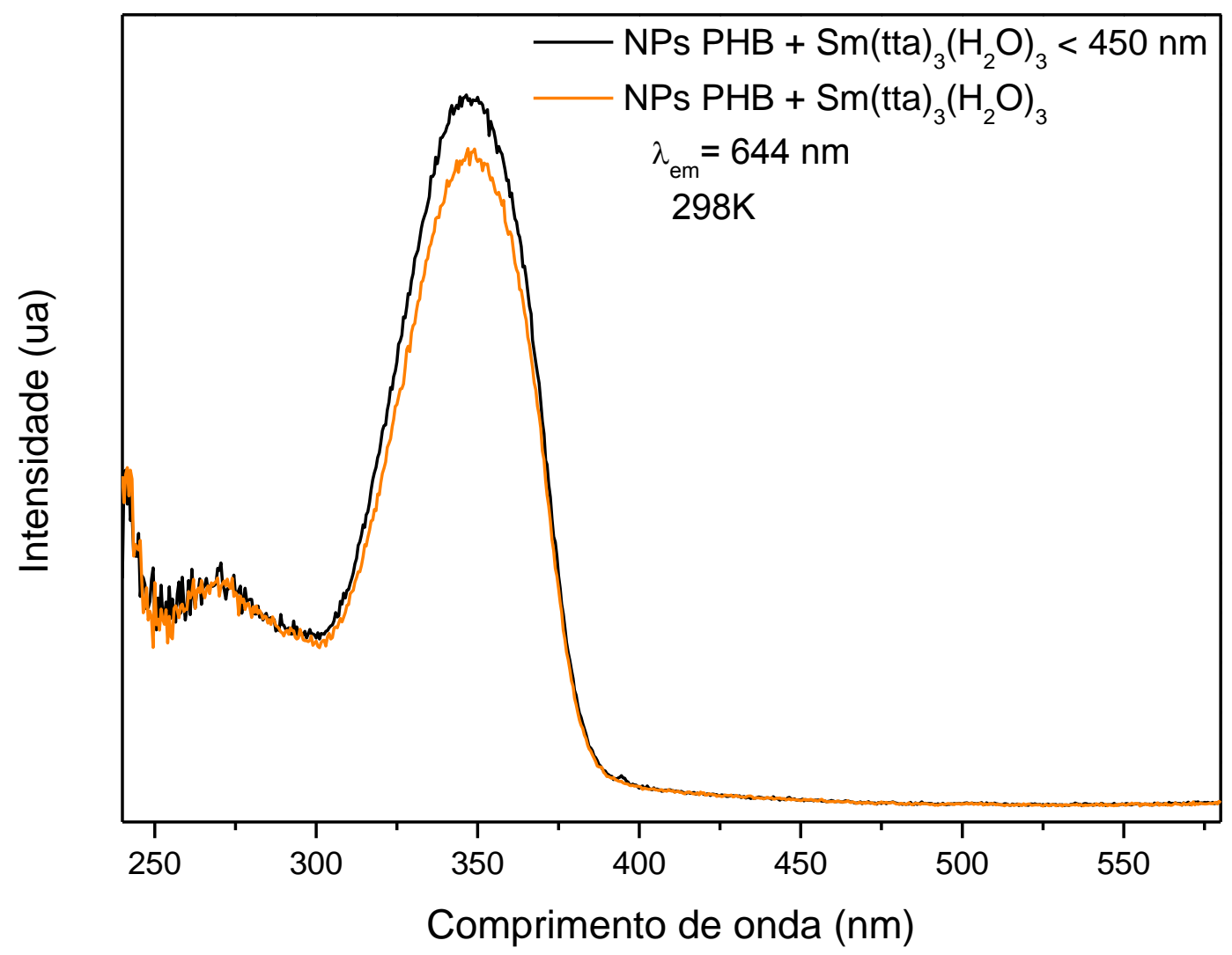

FIG. 5.40: Espectro de excitação da suspensão de nanopartículas contendo $\left[\mathrm{Sm}(\mathrm{tta})_{3}\left(\mathrm{H}_{2} \mathrm{O}\right)_{2}\right]$. Avaliação do efeito de tamanho de partícula.

Já os espectros de emissão foram obtidos no intervalo de 450 a 675 $\mathrm{nm}$ utilizando o monitoramento da excitação em $350 \mathrm{~nm}$, que corresponde à banda de absorção da parte orgânica do complexo. No espectro de emissão (FIG 5.41) apresentam-se as transições relativas ao íon $\mathrm{Sm}^{3+}$ das nanopartículas em suspensão aquosa, bulk, e da suspensão filtrada em membrana com porosidade de $450 \mathrm{~nm}$. Observam-se também as mesmas transições ${ }^{4} \mathrm{G}_{5 / 2} \rightarrow{ }^{6} \mathrm{H}_{\mathrm{J}}$ do íons $\mathrm{Sm}^{3+}$ com o mesmo alargamento das bandas presentes nos espectros dos sistemas com $\mathrm{Eu}^{3+} \mathrm{e} \mathrm{Tb}^{3+}$. Isso pode ser atribuído a um efeito de distribuição de diferentes pontos de simetria ocupados pelo íon no polímero, gerando bandas mais largas, e efeito do solvente, a água, questão 
também discutida nos espectros das nanopartículas contendo os complexos de $\mathrm{Eu}^{3+} \mathrm{e} \mathrm{Tb}^{3+}$.

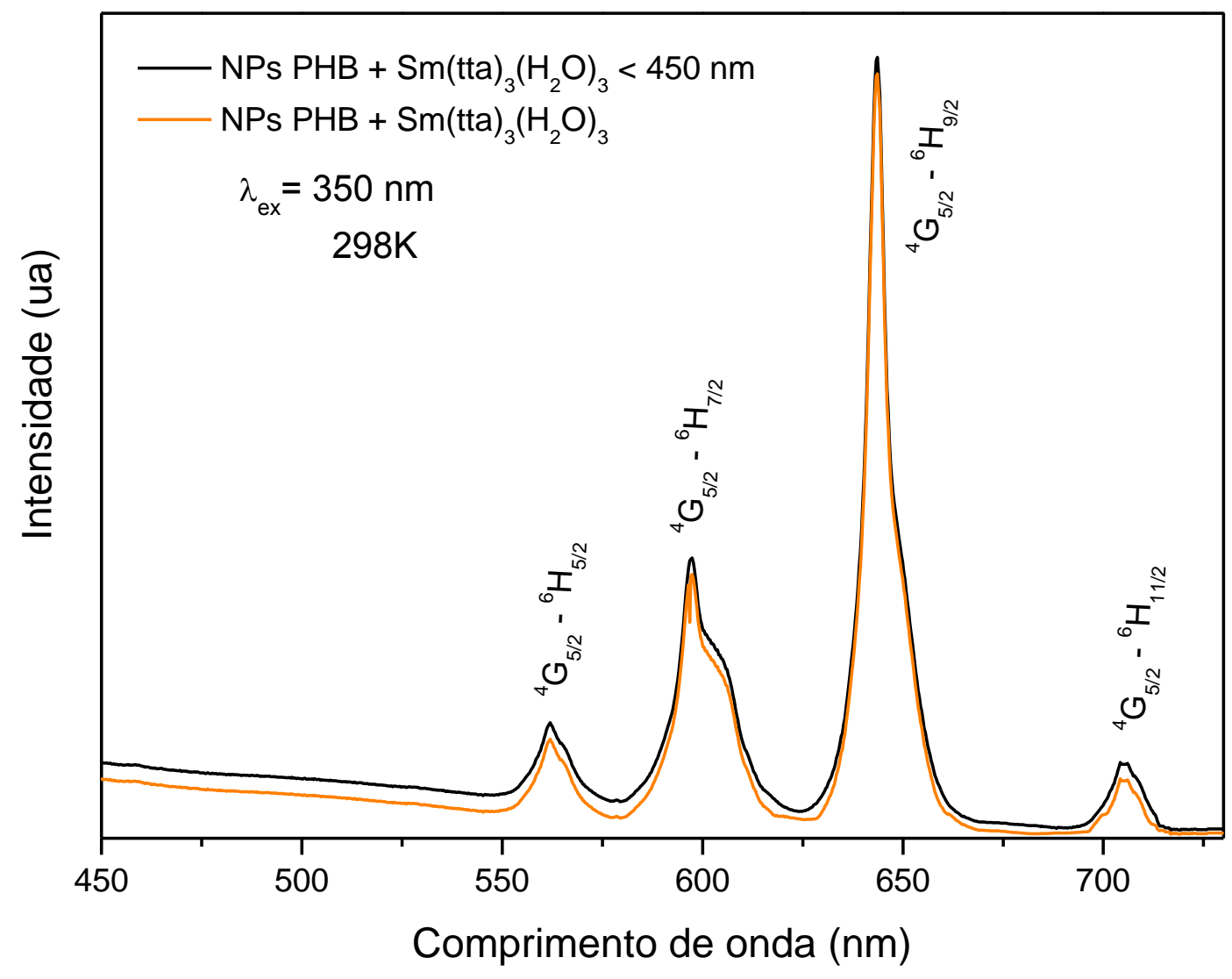

FIG. 5.41: Espectro de emissão da suspensão de nanopartículas incorporando 0 [Sm(tta $\left.)_{3}\left(\mathrm{H}_{2} \mathrm{O}\right)_{2}\right]$. Avaliação do efeito de tamanho de partícula.

\subsubsection{Complexo precursor $\left[\mathrm{Sm}(\mathrm{acac})_{3}\left(\mathrm{H}_{2} \mathrm{O}\right)_{3}\right]$}

O complexo [Sm $\left.(\mathrm{acac})_{3}\left(\mathrm{H}_{2} \mathrm{O}\right)_{2}\right]$ foi analisado a temperatura ambiente (298 K) e $77 \mathrm{~K}$ em intervalo de 250 a 580nm, com a emissão monitorada na transição ${ }^{4} \mathrm{G}_{5 / 2} \rightarrow{ }^{6} \mathrm{H}_{9 / 2}$, aproximadamente em $645 \mathrm{~nm}$ (FIG 5.42). Pode-se observar a presença de uma banda entre 250 e $400 \mathrm{~nm}$ associada à transição permitida $S_{1} \rightarrow S_{0}$ do ligante acac. Essa banda está sobreposta a algumas bandas finas das transições intraconfiguracionais $4 \mathrm{f}-4 \mathrm{f}$ são relacionada ao estado fundamental ${ }^{6} \mathrm{H}_{5 / 2}$ e aos estados excitados do $\mathrm{Sm}^{3+},{ }^{4} \mathrm{H}_{9 / 2}(\sim 345),{ }^{4} \mathrm{~F}_{9 / 2}$ ( 362), ${ }^{4} \mathrm{~L}_{17 / 2}$ ( 375.4), ${ }^{4} \mathrm{~F}_{7 / 2}$ ( 403), ${ }^{4} \mathrm{M}_{19 / 2}(\sim 417),{ }^{4} \mathrm{I}_{15 / 2}$ ( 449), ${ }^{4} \mathrm{I}_{13 / 2}$ ( 463), ${ }^{4} \mathrm{I}_{11 / 2}(\sim 479),{ }^{4} \mathrm{G}_{7 / 2}(\sim 500,8),{ }^{4} \mathrm{~F}_{3 / 2}(2)(\sim 527) \mathrm{e}{ }^{4} \mathrm{G}_{5 / 2}(\sim 562)$. 


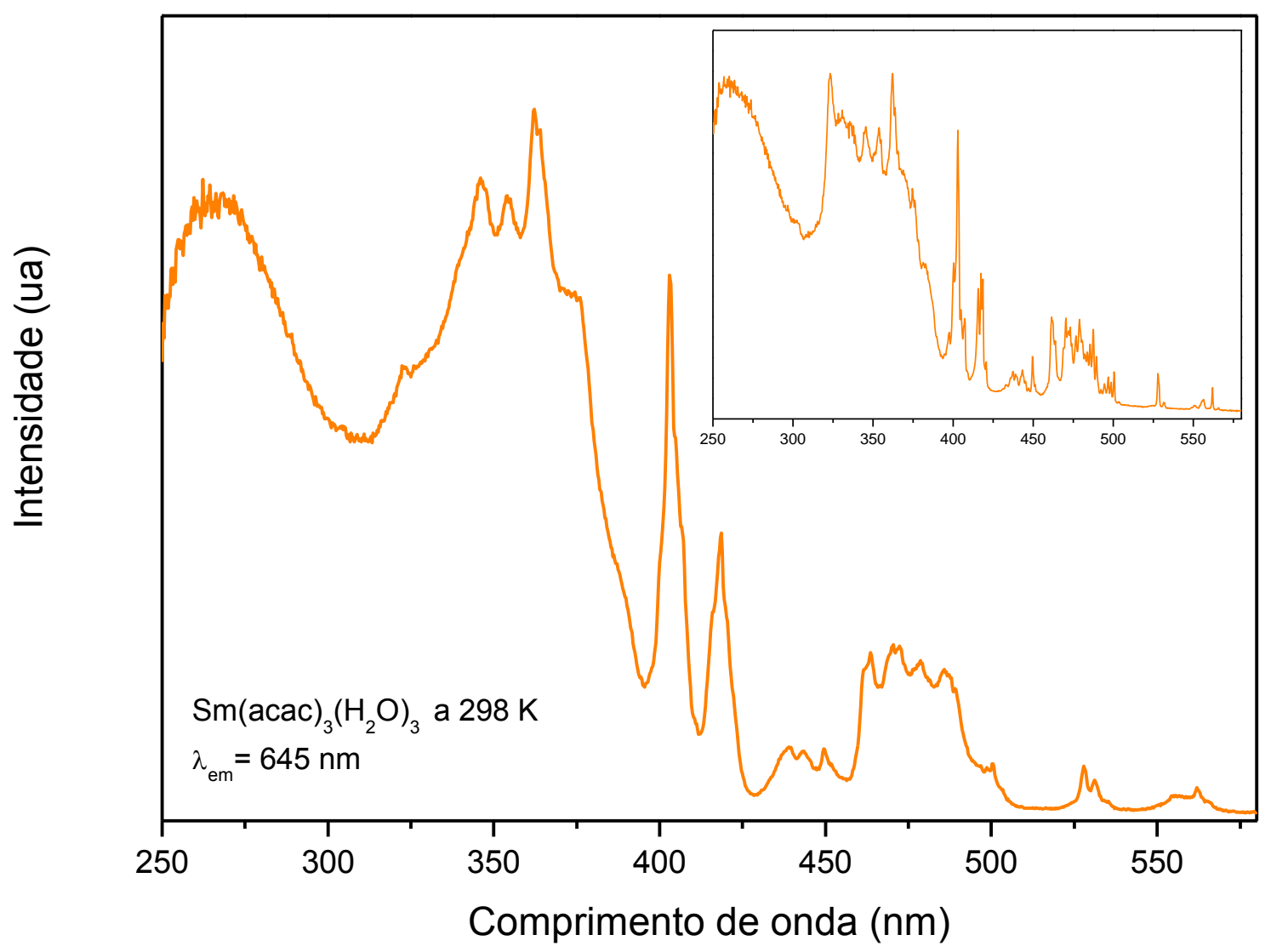

FIG. 5.42: Espectro de excitação do complexo [Sm(acac $)_{3}\left(\mathrm{H}_{2} \mathrm{O}\right)_{3}$ ] no intervalo de 250 a $580 \mathrm{~nm}$, monitorado a excitação em $645 \mathrm{~nm}$ a $298 \mathrm{~K}$. A figura inserida apresenta o espectro de excitação a $77 \mathrm{~K}$.

Os espectros de emissão do complexo [Sm(acac $\left.)_{3}\left(\mathrm{H}_{2} \mathrm{O}\right)_{3}\right]$ foram registrados a temperatura ambiente $(298 \mathrm{~K})$ e a $77 \mathrm{~K}$ (FIG 5.43) em intervalo de 450 a $700 \mathrm{~nm}$, com a excitação monitorada em 362 nm referente ao ligante acac e $403{ }^{6} \mathrm{H}_{5 / 2} \rightarrow{ }^{4} \mathrm{~F}_{7 / 2}$ referente a banda do íon $\mathrm{Sm}^{3+}$ que apresentou alta absorção no espectro de excitação. Observa-se que o espectro de emissão do complexo $\left[\mathrm{Sm}(\mathrm{acac})_{3}\left(\mathrm{H}_{2} \mathrm{O}\right)_{3}\right]$ exibe bandas mais estreitas relacionadas as transições ${ }^{4} \mathrm{G}_{5 / 2} \rightarrow{ }^{6} \mathrm{H}_{\mathrm{J}}$, (onde $\mathrm{J}=5 / 2,7 / 2,9 / 2$ ), sendo a ${ }^{4} \mathrm{G}_{5 / 2} \rightarrow{ }^{6} \mathrm{H}_{9 / 2}$ mais intensa, o que indica uma transferência de energia intramolecular eficiente do estado $T$ do ligante acac para o nível emissor ${ }^{4} \mathrm{G}_{5 / 2}$ do íon $\mathrm{Sm}^{3+}$. No espectro de 
luminescência a 77K foi observado uma banda discreta de fosforescência do ligante.

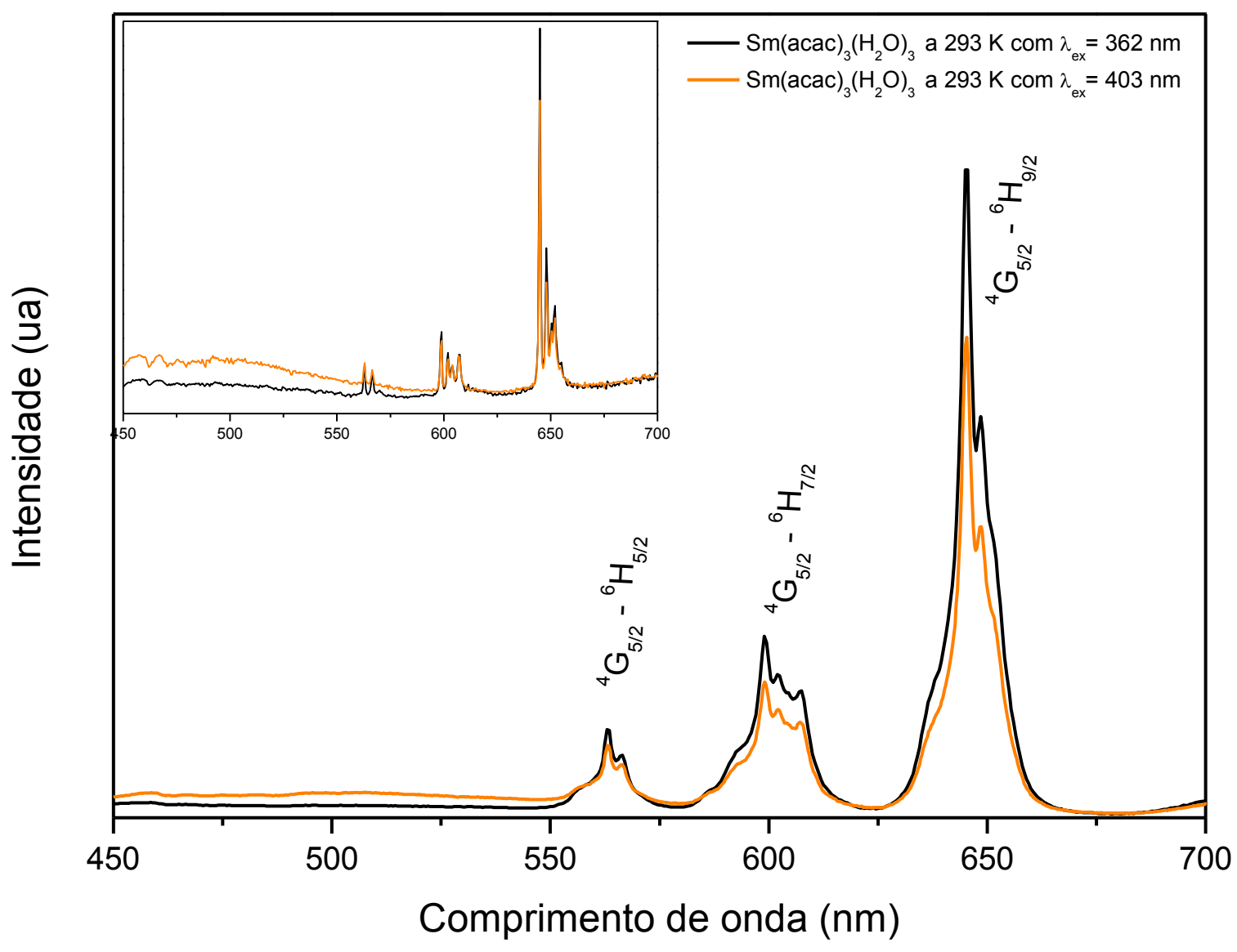

FIG. 5.43: Espectro de emissão do complexo $\left[\mathrm{Sm}(\mathrm{acac})_{3}\left(\mathrm{H}_{2} \mathrm{O}\right)_{3}\right]$ no intervalo de 450 a $700 \mathrm{~nm}$, monitorado a excitação em 363 e $403 \mathrm{~nm}$ a $298 \mathrm{~K}$. A figura inserida apresenta os espectros de emissão a $77 \mathrm{~K}$.

\subsubsection{Nanopartículas de PHB com o complexo[Sm(acac $\left.)_{3}\left(\mathrm{H}_{2} \mathrm{O}\right)_{2}\right]$}

Os espectros de excitação das nanopartículas de PHB dopadas com $\left[\mathrm{Sm}(\mathrm{acac})_{3}\left(\mathrm{H}_{2} \mathrm{O}\right)_{3}\right]$ foram registrados em suspensão aquosa a temperatura ambiente $(298 \mathrm{~K})$. Os espectros de excitação foram registrados no intervalo espectral de 250 a $500 \mathrm{~nm}$, com a emissão monitorada na transição ${ }^{4} \mathrm{G}_{5 / 2} \rightarrow{ }^{6} \mathrm{H}_{9 / 2}$, aproximadamente em $643 \mathrm{~nm}$. 
A FIG 5.44 mostra o espectro de excitação das nanopartículas em suspensão aquosa, material bulk e da suspensão filtrada em membrana filtrante com porosidade de $450 \mathrm{~nm}$. Observa-se que na região $300 \mathrm{~nm}$, o espectro apresenta uma banda com baixa intensidade que pode ser associada à transição permitida $S_{1} \rightarrow S_{0}$ do ligante acac. Não se observa absorção das bandas finas oriundas de transições $4 f-4 f$ que envolve o estado fundamental do samário trivalente ${ }^{6} \mathrm{H}_{5 / 2}$.

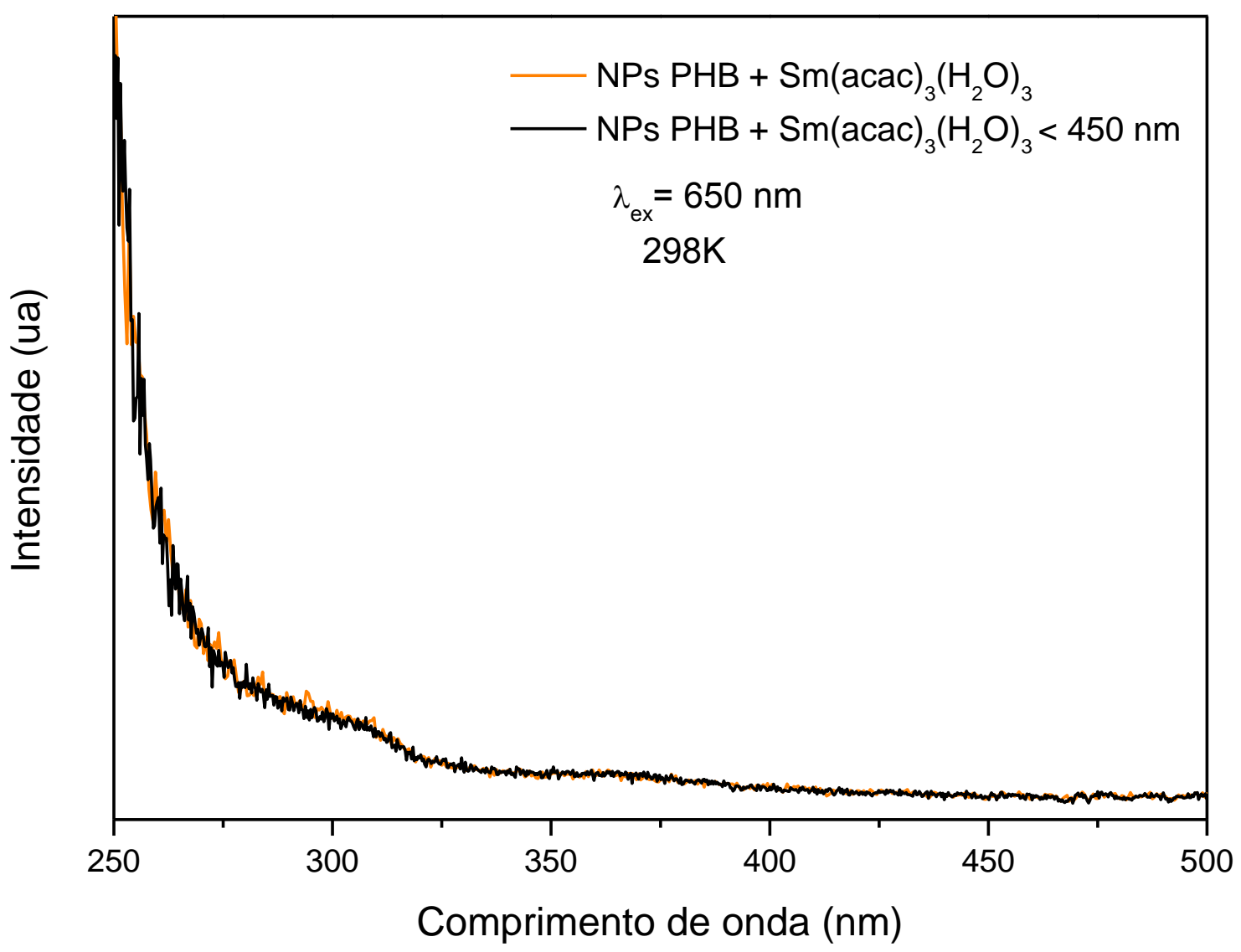

FIG. 5.44: Espectro de excitação da suspensão de nanopartículas contendo $\left[\mathrm{Sm}(\mathrm{acac})_{3}\left(\mathrm{H}_{2} \mathrm{O}\right)_{3}\right]$. Avaliação do efeito de tamanho de partícula.

Já os espectros de emissão foram obtidos no intervalo de 500 a 700 $\mathrm{nm}$ utilizando o monitoramento da excitação em $306 \mathrm{~nm}$, que corresponde à banda de absorção da parte orgânica. No caso do espectro de emissão (FIG 5.45) observam-se as mesmas transições ${ }^{4} \mathrm{G}_{5 / 2} \rightarrow{ }^{6} \mathrm{H}_{\lrcorner}$do íon $\mathrm{Sm}^{3+}$ com 0 mesmo alargamento das bandas presentes também nos espectros dos sistemas com $\mathrm{Eu}^{3+} \mathrm{e} \mathrm{Tb}^{3+}$. Como relatado em vários sub itens anteriores, este fato pode ser relacionado com o efeito de distribuição de diferentes pontos de 
simetria ocupados pelo íon no polímero, gerando bandas mais largas e com o efeito do solvente, questões também discutidas nos espectros das nanopartículas contendo os complexos de $\mathrm{Eu}^{3+} \mathrm{e} \mathrm{Tb}^{3+}$. No entanto, a intensidade de luminescência foi extremamente baixa em relação às outras nanopartículas, o que evidencia que esse complexo nessas condições, não possui eficiência no processo de transferência de energia ligante- metal não sendo indicado como um bom marcador.

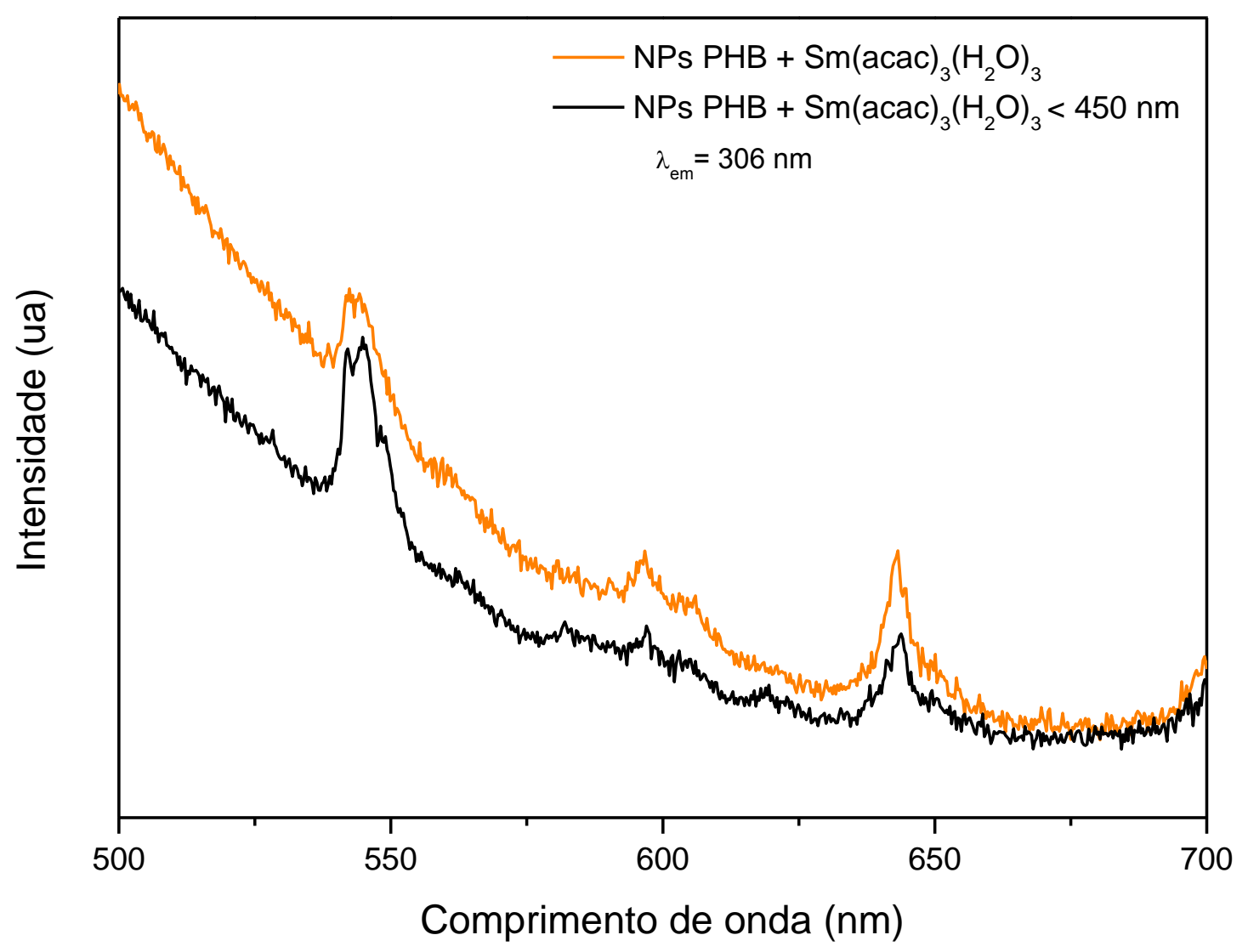

FIG. 5.45: Espectro de emissão da suspensão de nanopartículas contendo $\left[\mathrm{Sm}(\mathrm{acac})_{3}\left(\mathrm{H}_{2} \mathrm{O}\right)_{3}\right]$. Avaliação do efeito de tamanho de partícula.

Com o intuito de se fazer um estudo comparativo entre o comportamento hipersensível dos íons $\mathrm{Sm}^{3+}$ e do $\mathrm{Eu}^{3+}$ foram determinados os parâmetros $\eta_{S m} \eta_{E u}$ dos complexos de $\mathrm{Eu}^{3+} \mathrm{e} \mathrm{Sm}^{3+}$ que vem dado pela dados pela equação 5.2: 


$$
\eta_{\mathrm{Eu}}=\frac{\mathrm{S}\left({ }^{5} \mathrm{D}_{0} \rightarrow{ }^{7} \mathrm{~F}_{2}\right)}{\mathrm{S}\left({ }^{5} \mathrm{D}_{0} \rightarrow{ }^{7} \mathrm{~F}_{1}\right)}
$$

Pode-se observar que os maiores valores de $\eta_{\text {Sm }}$ foram obtidos para os complexos de tta e suas nanopartículas de tta com PHB, evidenciando um ambiente químico mais polarizável nas vizinhanças do íon $\mathrm{Sm}^{3+} \mathrm{e} \mathrm{Eu}^{3+[32]}$ (TAB 5.11).

TAB 5.11: Parâmetros de intensidade $\eta_{\mathrm{Sm}}$ experimentais dos compostos de $\mathrm{Sm}^{3+}$ e $\eta_{\mathrm{sm}}$ dos complexos de $\mathrm{Eu}^{3+}$.

\begin{tabular}{ccc}
\hline Nanopartículas ou Complexo & $\eta_{\text {sm }}$ & $\eta_{\text {Еи }}$ \\
\hline$\left[\operatorname{TR}(\mathrm{TTA})_{3}\left(\mathrm{H}_{2} \mathrm{O}\right)_{2}\right]$ & 10,2 & 22,6 \\
PHB@[TR $\left.(\mathrm{TTA})_{3}\left(\mathrm{H}_{2} \mathrm{O}\right)_{2}\right]$ bulk & 4.54 & 13,5 \\
PHB@[TR $\left.(\mathrm{TTA})_{3}\left(\mathrm{H}_{2} \mathrm{O}\right)_{2}\right]<450 \mathrm{~nm}$ & 6,1 & 14,2 \\
{$\left[\mathrm{TR}(\mathrm{acac})_{3}\left(\mathrm{H}_{2} \mathrm{O}\right)_{3}\right]$} & 7,1 & 13,4 \\
$\mathrm{PHB} @\left[\mathrm{TR}(\mathrm{acac})_{3}\left(\mathrm{H}_{2} \mathrm{O}\right)_{3}\right]$ bulk & 0,31 & 4,4 \\
PHB@[TR $\left.(\mathrm{acac})_{3}\left(\mathrm{H}_{2} \mathrm{O}\right)_{3}\right]<450 \mathrm{~nm}$ & 0,34 & 5,8 \\
\hline
\end{tabular}

\subsection{Tempo de vida do nível excitado}

Define-se tempo de vida de luminescência como o tempo médio no qual o sistema permanece em estado excitado. Considerando um sistema com dois níveis, onde ocorre uma transição espontânea a partir de um nível emissor $E_{i}$, com população $N_{i}$, para um nível excitado $E_{j}$, onde a variação na população de $\mathrm{N}_{\mathrm{i}}, \mathrm{dN}_{\mathrm{i}}$, durante um período de tempo dt é dado por ${ }^{[36]}$ : 


$$
N_{j} \mathrm{~A}_{i j}=\frac{\mathrm{dN}_{i}}{\mathrm{dt}}
$$

Onde $A_{i j}$ é a taxa de decaimento total envolvendo as contribuições radioativas e não radioativas que contribuem para o processo de despopulação do estado emissor, $E_{j}$. Considerando a expressão 5.3 para $N_{i}$ variando de $N_{i}(0)$ em $\mathrm{t}=0$ a $\mathrm{N}_{\mathrm{i}}$, no tempo $\mathrm{t}$, integrando tem-se:

$$
N_{i}(\mathrm{t})=\mathrm{N}_{i}(0) e^{-A_{i j} t}
$$

Após um tempo $\tau_{\mathrm{i}}=$ Onde $1 / \mathrm{A}_{\mathrm{ij}}$, a densidade populacional $\mathrm{N}_{\mathrm{i}}$ tem diminuído para $1 / \mathrm{e}$ do valor inicial a $\mathrm{t}=0$. Assim, $\mathrm{t}=\tau_{\mathrm{i}}$ é definido como o tempo para a população de um nível emissor decair a 1/e do seu valor inicial, conhecido também como tempo de vida emissor. Em função da proporcionalidade entre intensidade $\left(\mathrm{I}_{\mathrm{i}}\right)$ de emissão e a densidade populacional $\mathrm{N}_{\mathrm{i}}$, obtém-se ${ }^{[37]}$ :

$$
I_{i}(\mathrm{t})=\mathrm{I}_{i}(0) e^{\frac{1}{\tau_{i}} t}
$$

Utilizando a equação 5.5 , os valores de $\tau_{i}$ podem ser obtidos experimentalmente através de ajustes na curva de decaimento de luminescência experimentais em uma curva exponencial.

Normalmente, se observa um tempo de vida do nível emissor ${ }^{5} D_{0}$ do íon $\mathrm{Eu}^{3+}$ menor do que o nível emissor ${ }^{5} \mathrm{D}_{4}$ do térbio trivalente ${ }^{[38]}$, uma vez que a diferença entre os níveis emissor e fundamental do $\mathrm{Eu}^{3+}\left({ }^{5} \mathrm{D}_{0} \rightarrow{ }^{7} \mathrm{~F}_{0}\right)$ é menor em relação ao $\mathrm{Tb}^{3+}\left({ }^{5} \mathrm{D}_{4} \rightarrow{ }^{7} \mathrm{~F}_{0}\right)$. Mais uma vez é importante notar a influência de moléculas de água coordenadas ao íon terra rara no que se refere ao tempo de 
vida, já que a presença dessas promove uma despopulação do nível emissor por acoplamento vibrônico, diminuindo o tempo de emissão.

Na FIG 5.46 estão demonstradas as curvas de decaimento para os complexos precursores. Para os complexos de samário, não foi possível obter uma leitura confiável, apesar de todas tentativas de adequação do equipamento para essa leitura, dessa forma, não serão apresentados dados de meia-vida para os complexos de samário.

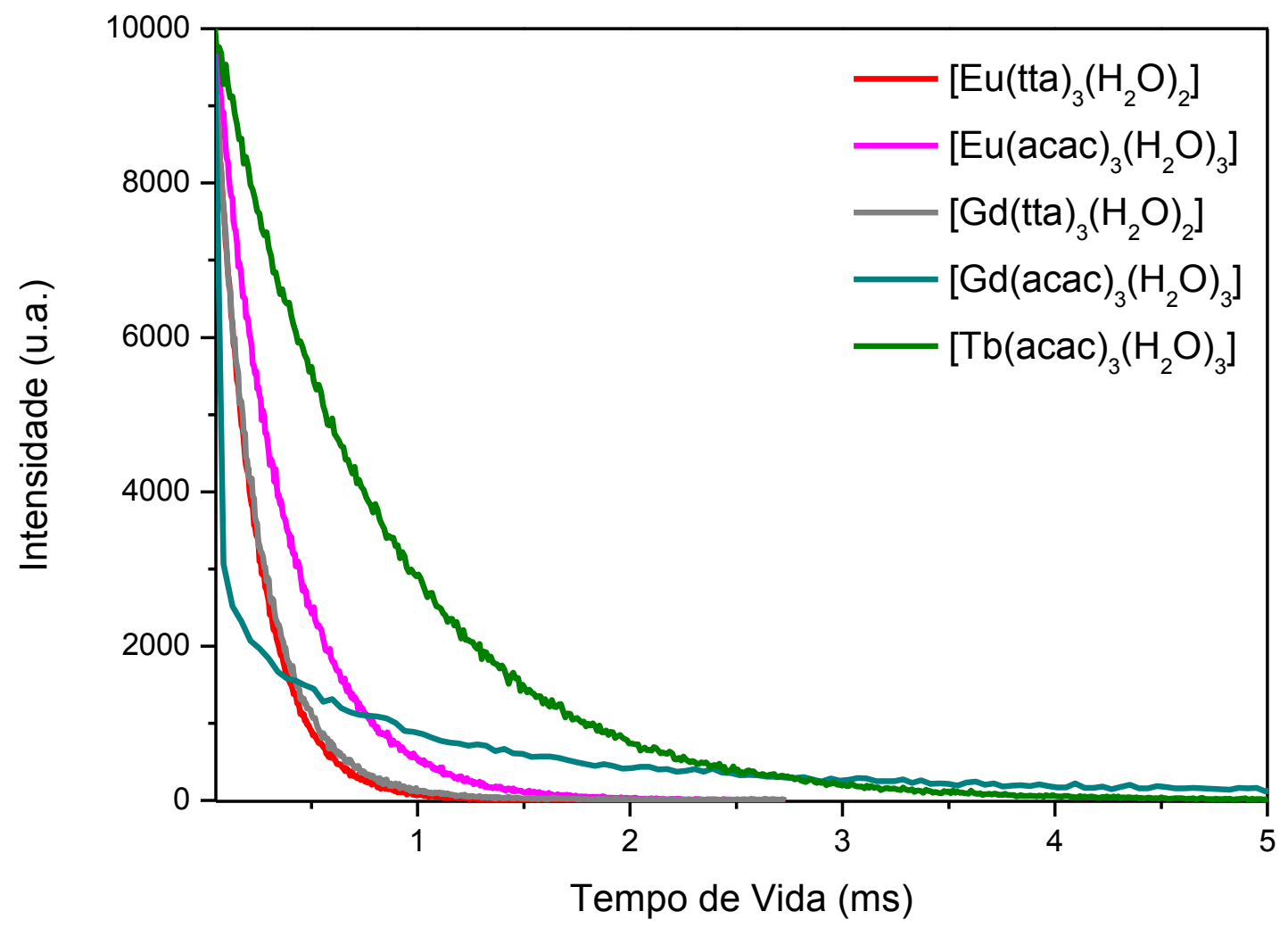

FIG. 5.46: Curvas de decaimento da luminescência do estado emissor dos complexos precursores ${ }^{5} \mathrm{D}_{0}$ do ion $\mathrm{Eu}^{3+},{ }^{3} \mathrm{D}_{4}$ do ionTb ${ }^{3+} \mathrm{eT}$ do $\mathrm{Gd}^{3+}$.

Os valores de tempos de vida dos estados emissores $\tau_{1}$ dos ligantes e dos íons $\mathrm{Eu}^{3+}$ e $\mathrm{Tb}^{3+}$ são apresentados na TAB 5.12. Como já esperado o íon $\mathrm{Eu}^{3+}$ possui menor tempo de vida em relação ao $\mathrm{Tb}^{3+}$, em função da estrutura dos níveis de energia. Entre os ligantes, o acac apresenta a energia do nível emissor mais alto, ao contrário do ligante tta. 
TAB 5.12: Tempos de vida dos níveis emissores do $\mathrm{Eu}^{3+}, \mathrm{Tb}^{3+}$ e do estado tripleto dos ligantes tta e acac nos complexos de $\mathrm{Gd}^{3+}$.

\begin{tabular}{cc}
\hline Complexos Precursores & $\boldsymbol{\tau}_{\mathbf{i}}(\mathbf{m s})$ \\
\hline$\left[\mathrm{Eu}(\mathrm{tta})_{3}\left(\mathrm{H}_{2} \mathrm{O}\right)_{2}\right]\left({ }^{5} \mathrm{D}_{0}\right)$ & 0,260 \\
{$\left[\mathrm{Eu}(\mathrm{acac})_{3}\left(\mathrm{H}_{2} \mathrm{O}\right)_{3}\right]\left({ }^{5} \mathrm{D}_{0}\right)$} & 0,327 \\
{$\left[\mathrm{~Tb}(\mathrm{acac})_{3}\left(\mathrm{H}_{2} \mathrm{O}\right)_{3}\right]\left({ }^{5} \mathrm{D}_{4}\right)$} & 0,762 \\
{$\left[\mathrm{Gd}(\mathrm{tta})_{3}\left(\mathrm{H}_{2} \mathrm{O}\right)_{2}\right](\mathrm{T})$} & 1,520 \\
{$\left[\mathrm{Gd}(\mathrm{acac})_{3}\left(\mathrm{H}_{2} \mathrm{O}\right)_{3}\right](\mathrm{T})$} & 1,189 \\
\hline
\end{tabular}

Com relação às suspensões contendo nanopartículas de PHB com os complexos de terras raras, as curvas de tempo de vida são ilustradas na FIG 5.47.

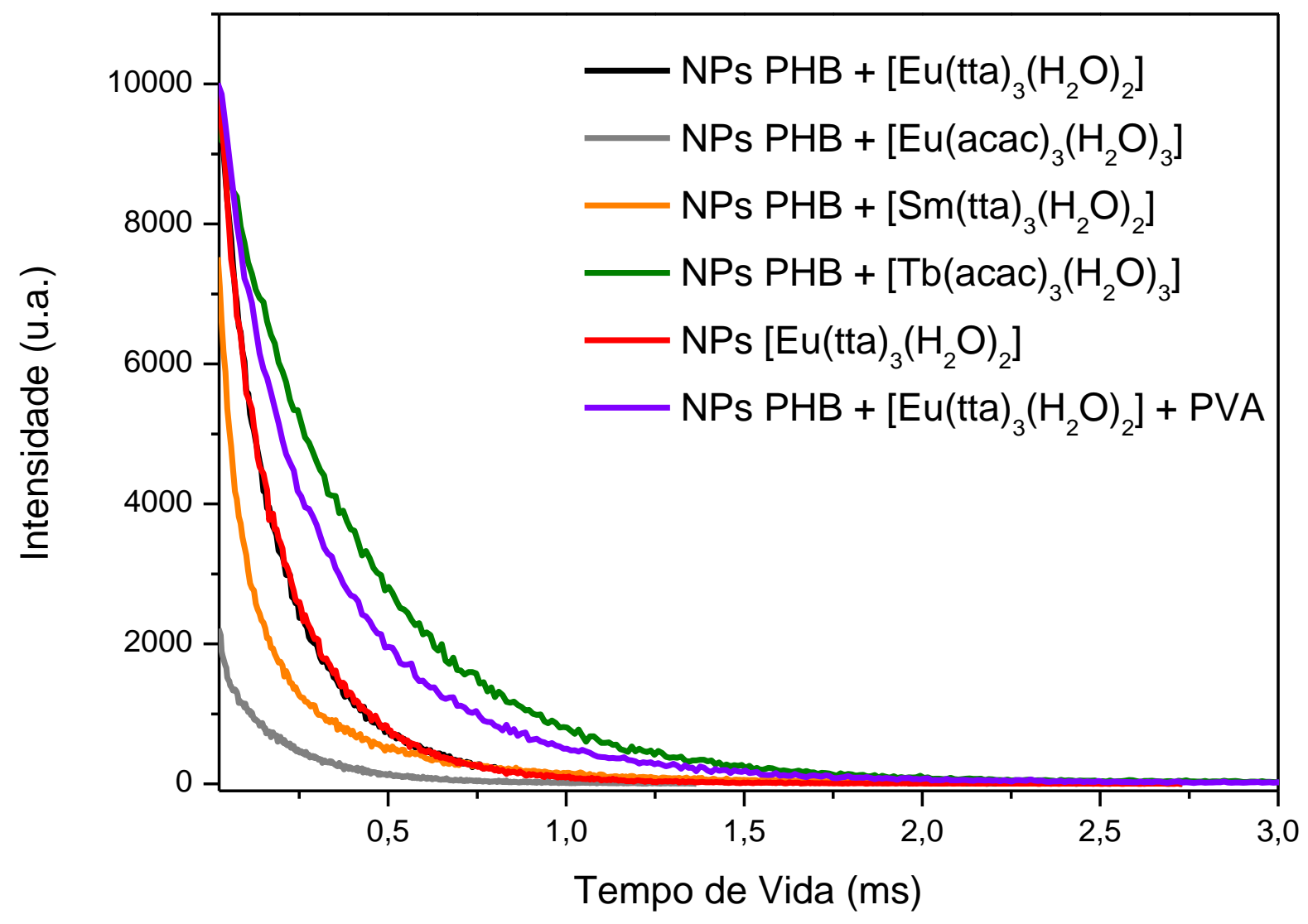

FIG.5.47: Curvas de decaimento da luminescência do estado emissor dos complexos precursores ${ }^{5} \mathrm{D}_{0}$ do ion $\mathrm{Eu}^{3+},{ }^{5} \mathrm{D}_{4}$ do ionTb ${ }^{3+} \mathrm{e}^{6} \mathrm{H}_{9 / 2}$ do $\mathrm{Sm}^{3+}$. 
Os valores de tempos de vida dos estados emissores $\tau_{j}$ das nanopartículas de PHB misturado aos complexos de $\mathrm{Eu}^{3+}, \mathrm{Tb}^{3+}$ e $\mathrm{Sm}^{3+}$ são apresentados na TAB 5.13. Não foi possível obter uma curva para as nanopartículas poliméricas com os complexos de $\mathrm{Gd}^{3+}$ e com o complexo $\left[\mathrm{Sm}(\mathrm{acac})_{3}\left(\mathrm{H}_{2} \mathrm{O}\right)_{3}\right]$.

TAB 5.13: Tempos de vida dos níveis emissores do $\mathrm{Eu}^{3+}, \mathrm{Tb}^{3+}$ e $\mathrm{Sm}^{3+}$.

\begin{tabular}{cc}
\hline Nanopartículas em suspensão & $\boldsymbol{\tau}_{\mathbf{i}}(\mathbf{m s})$ \\
\hline PHB @ [Eu(tta $\left.)_{3}\left(\mathrm{H}_{2} \mathrm{O}\right)_{2}\right]\left({ }^{5} \mathrm{D}_{0}\right)$ & 0,176 \\
{$\left[\mathrm{Eu}(\mathrm{tta})_{3}\left(\mathrm{H}_{2} \mathrm{O}\right)_{2}\right]\left({ }^{5} \mathrm{D}_{0}\right)$} & 0,260 \\
$\mathrm{PHB} @\left[\mathrm{Eu}(\mathrm{tta})_{3}\left(\mathrm{H}_{2} \mathrm{O}\right)_{2}\right]+\mathrm{PVA}\left({ }^{5} \mathrm{D}_{0}\right)$ & 0,317 \\
PHB @ [Eu(acac $\left.)_{3}\left(\mathrm{H}_{2} \mathrm{O}\right)_{3}\right]\left({ }^{5} \mathrm{D}_{0}\right)$ & 0,153 \\
PHB @ [Sm $\left.(\mathrm{tta})_{3}\left(\mathrm{H}_{2} \mathrm{O}\right)_{2}\right]\left({ }^{6} \mathrm{H}_{9 / 2}\right)$ & 0,154 \\
{$\left[\mathrm{~Tb}(\mathrm{acac})_{3}\left(\mathrm{H}_{2} \mathrm{O}\right)_{3}\right]\left({ }^{5} \mathrm{D}_{4}\right)$} & 0,762 \\
PHB @ [Tb(acac $\left.)_{3}\left(\mathrm{H}_{2} \mathrm{O}\right)_{3}\right]\left({ }^{5} \mathrm{D}_{4}\right)$ & 0,393
\end{tabular}

Percebe-se que o íon $\mathrm{Eu}^{3+}$ possui menor tempo de vida em relação ao $\mathrm{Tb}^{3+}$, como já visto com os próprios complexos precursores no estado sólido. Os tempos de vida de emissão das nanopartículas diminuem em todos os casos em relação aos complexos precursores, devido ao meio se tratar de uma solução aquosa onde os níveis vibronicos da molécula de água suprimem o fenômeno de luminescência (emissão). Além disso, pode haver interferência da cobertura polimérica de PHB. Também é possível notar o aumento do tempo de vida no sistema contendo PVA como dispersante, o que evidencia uma possível contribuição do PVA na emissão desse sistema. 


\subsection{Nanopartículas funcionalizadas}

As nanopartículas estudadas nesse trabalho apresentam propriedades fotoluminescentes adequadas para serem usadas como marcadores luminescentes, exceção feita as partículas de PHB@[Sm $\left.(\mathrm{acac})_{3}\left(\mathrm{H}_{2} \mathrm{O}\right)_{3}\right]$. Para que estas nanopartículas funcionem como um marcador biológico muitas vezes faz-se necessário ligar-se a estas nanopartículas um espaçador que será a entidade que fará a ligação entre o luminóforo e a espécie biológica como, por exemplo, o glutaraldeído ou liga-la diretamente a parte biológica. Neste trabalho foram feitos dois testes para avaliar a viabilidade de conjugação direta (BSA) ou usando um espaçador, no caso, o glutaraldeído.

Para as nanopartículas que passaram pelo teste de funcionalização, foram feitas análises de tamanho de partícula para verificar alguma modificação na distribuição, principalmente no que se refere ao aumento de tamanho ou aglomoreração de partículas.

\subsubsection{Comportamento das nanopartículas funcionalizadas e conjugadas em função do tamanho das partículas}

$\mathrm{Na}$ FIG 5.48 são apresentados os gráficos obtidos para as nanopartículas de PHB + [Eu(tta $\left.)_{3}\left(\mathrm{H}_{2} \mathrm{O}\right)_{2}\right]$ Tween 80 quando conjugadas com a Albumina do soro bovino (BSA) em meio tamponado $(\mathrm{pH} 7,4)$ a $4^{\circ} \mathrm{C}$ por 48 horas e a $4^{\circ} \mathrm{C}$. 


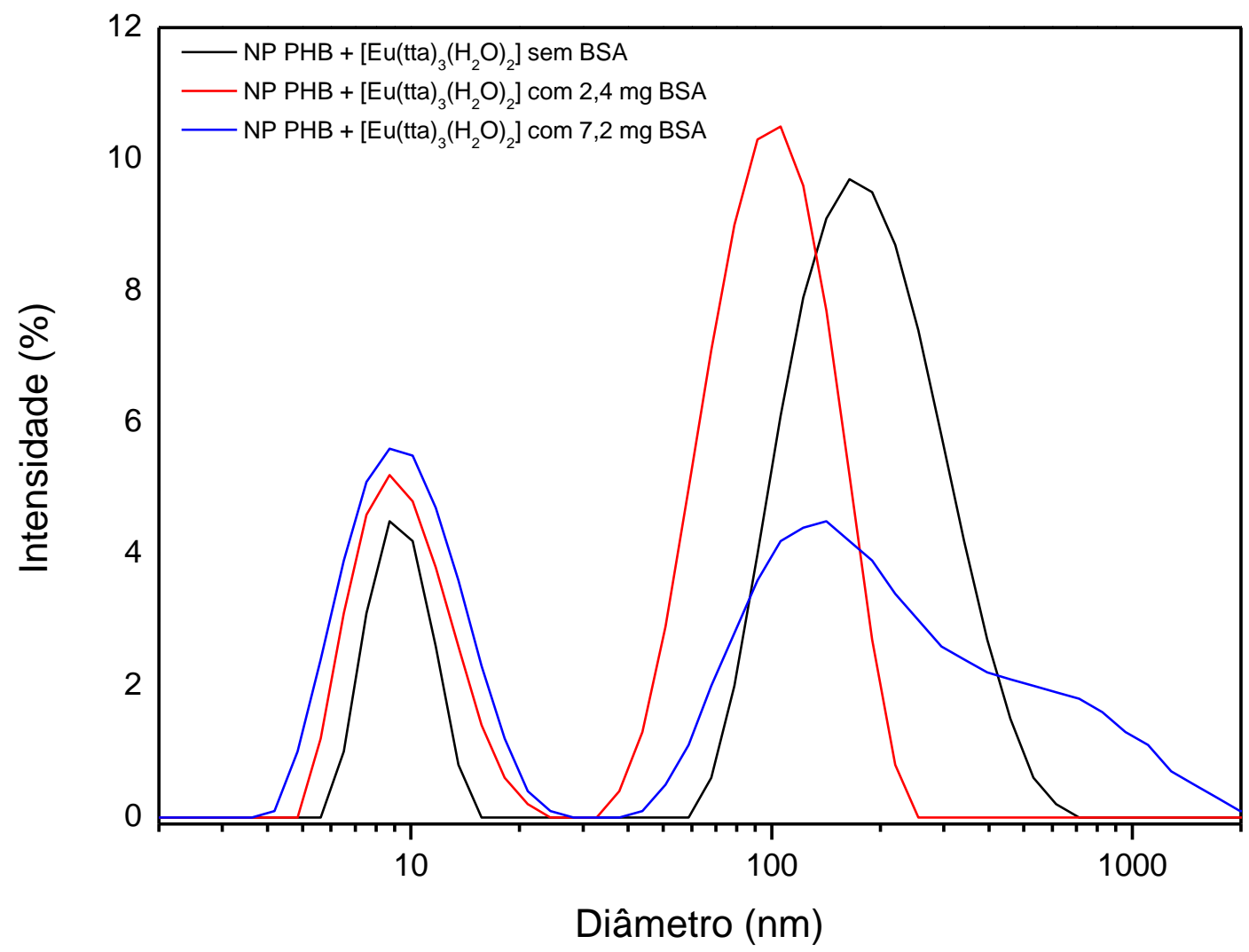

FIG. 5.48: Distribuição granulométrica obtida pela técnica de Espectroscopia de Correlação de Fótons (PCS) para as nanopartículas de PHB + complexo $\mathrm{Eu}(\mathrm{tta})_{3}\left(\mathrm{H}_{2} \mathrm{O}\right)_{2}$ conjugadas com BSA.

É possível observar que o aumento da concentração de BSA no sistema, promove um deslocamento de intensidade centralizado em $100 \mathrm{~nm}$, e a população de partículas em $10 \mathrm{~nm}$ aumenta de forma tímida, o que pode indicar um processo de desagregação de aglomerados à medida que a superfície dessas partículas passou a interagir com a proteína, modificando a carga da superfície e aumentando a energia de repulsão entre elas. Outro detalhe importante é o aparecimento de partículas acima de $1000 \mathrm{~nm}$, reflexo provável de uma aglomeração acelerada pela presença de proteínas na superfície da partícula, tornando a partícula maior e mais pesada, o que justifica o aparecimento de precipitado na solução analisada quatro dias após as medidas. Além disso, o pH da solução foi mantido em 7,4, um pouco acima ponto isoelétrico ( $\mathrm{PI}$ ) da BSA, de 4,9, portanto, com leve tendência de aglomeração ${ }^{[39]}$. Nesse $\mathrm{pH}$, a BSA apresenta carga negativa, pois o $\mathrm{pH}$ do sistema é maior que o PI. 
Na FIG 5.49 são apresentados os gráficos de tamanho de partícula obtidos para as nanopartículas de PHB $+\left[\mathrm{Eu}(\mathrm{tta})_{3}\left(\mathrm{H}_{2} \mathrm{O}\right)_{2}\right]$ quando funcionalizadas com glutaraldeído em meio tamponado por 48 horas e a $4^{\circ} \mathrm{C}$.

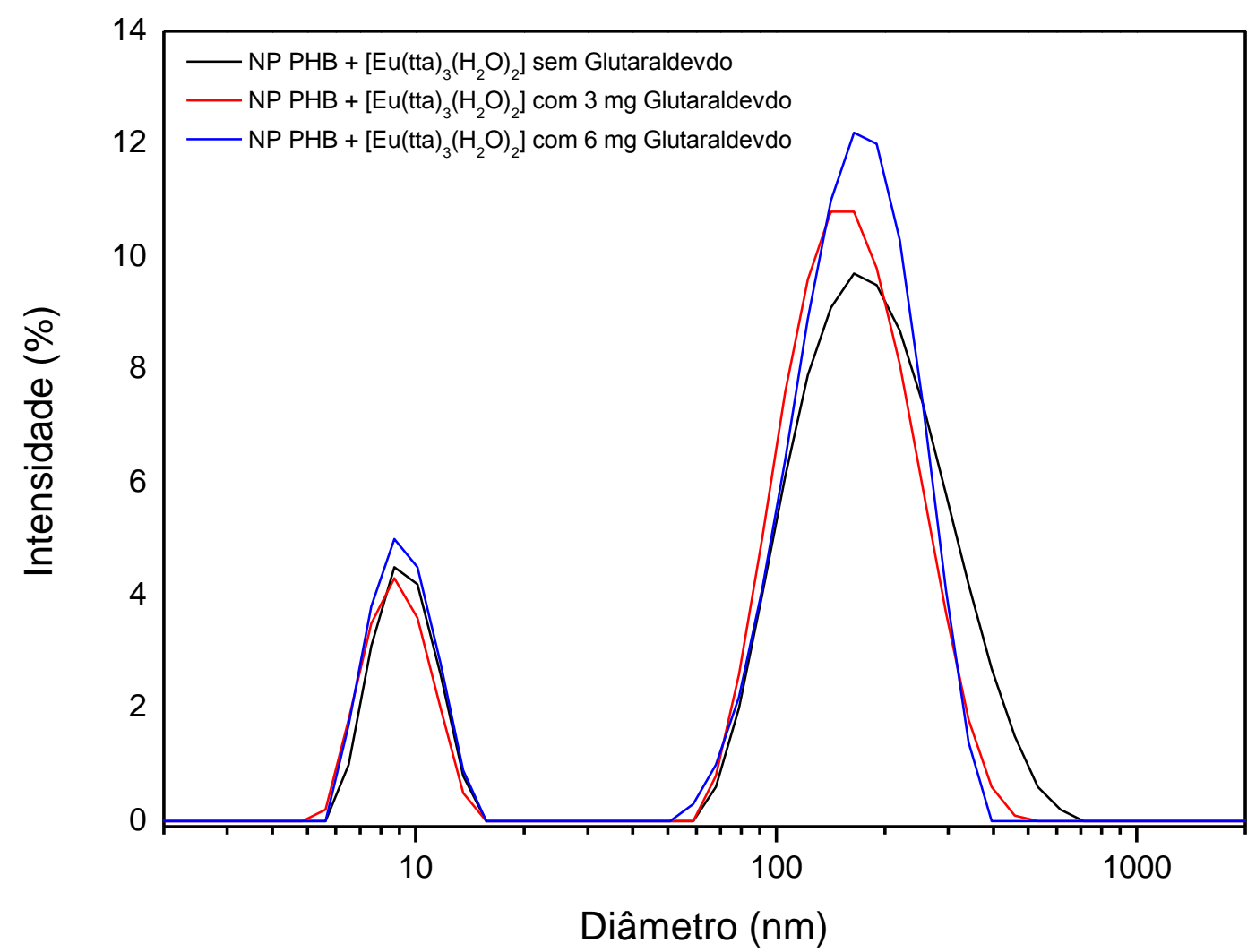

FIG. 5.49: Distribuição granulométrica obtida pela técnica de Espectroscopia de Correlação de Fótons (PCS) para as nanopartículas de PHB + complexo $\mathrm{Eu}(\mathrm{tta})_{3}\left(\mathrm{H}_{2} \mathrm{O}\right)_{2}$ funcionalizadas com Glutaraldeído.

A mesma tendência observada quando as nanopartículas estão conjugadas a BSA, verifica-se com o glutaraldeído. Percebe-se um deslocamento de intensidade centralizado em $200 \mathrm{~nm}$, e uma leve diminuição da dispersão de tamanhos, observado por uma diminuição na largura dos picos das curvas na presença de glutaraldeído. Além disso, a população de partículas em $10 \mathrm{~nm}$ aumenta de forma tímida, o que pode indicar um processo de desagregação de aglomerados à medida que a superfície dessas partículas passou a interagir com o glutaraldeído, modificando a carga da superfície e aumentando a energia de repulsão. Esse fenômeno também é observado com as partículas maiores. Trata-se de um processo similar ao ocorrido com a BSA, com a diferença que não se nota partículas maiores quando se aumenta a concentração de glutaraldeído. 
Na FIG 5.50 são apresentadas os gráficos de tamanho de partícula obtidos para as nanopartículas de $\mathrm{PHB}+\left[\mathrm{Tb}(\mathrm{acac})_{3}\left(\mathrm{H}_{2} \mathrm{O}\right)_{3}\right]$ quando conjugadas a Albumina do soro bovino (BSA) em meio tamponado por 48 horas e a $4^{\circ} \mathrm{C}$.

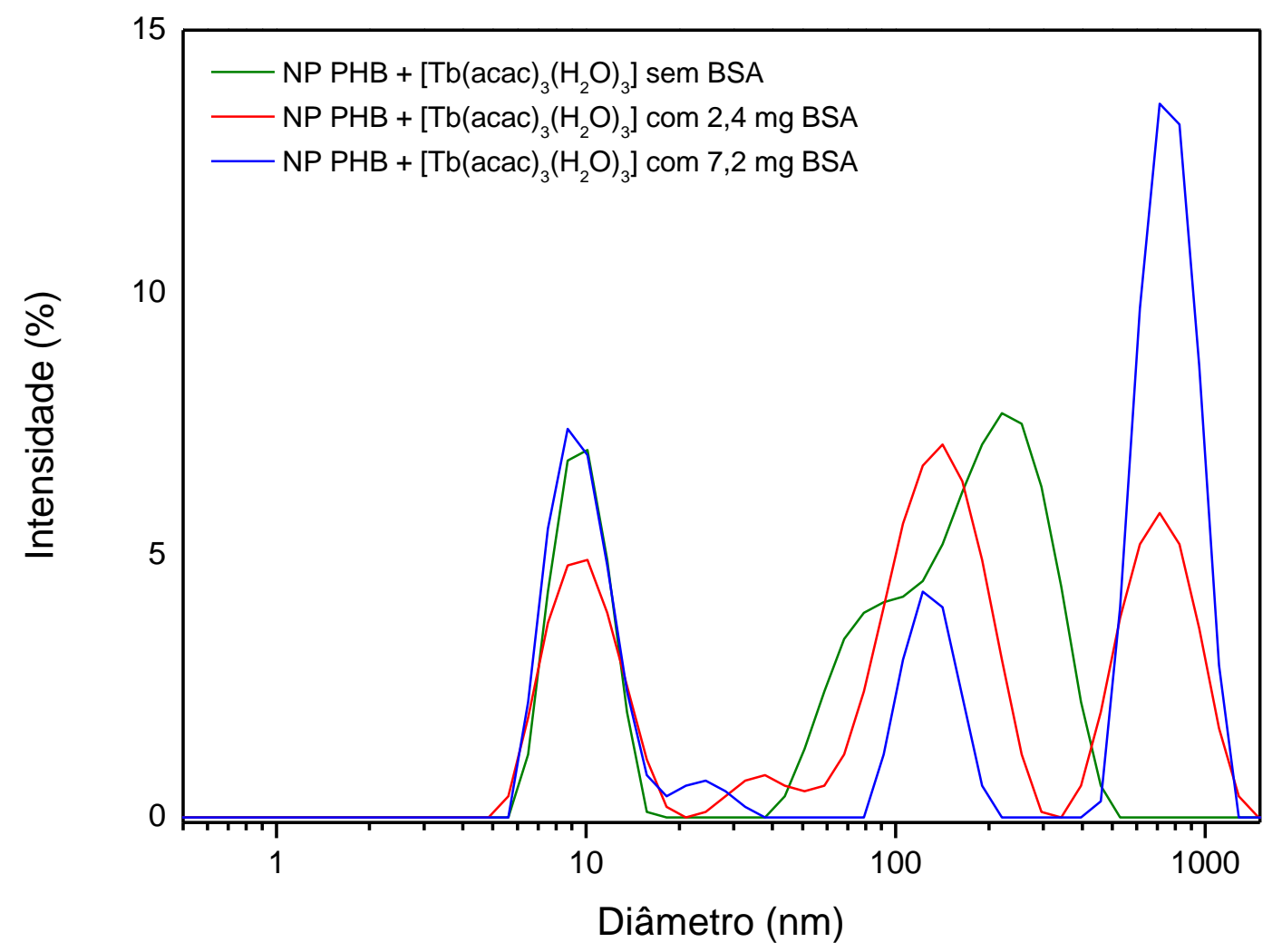

FIG. 5.50: Distribuição granulométrica obtida pela técnica de Espectroscopia de Correlação de Fótons (PCS) para as nanopartículas de PHB + complexo $\mathrm{Tb}(\mathrm{acac})_{3}\left(\mathrm{H}_{2} \mathrm{O}\right)_{3}$ conjugadas com BSA.

Pode-se notar um deslocamento de intensidade centralizado em 250 $\mathrm{nm}$ para $100 \mathrm{~nm}$ aproximadamente, e uma leve diminuição da dispersão de tamanhos, observado por um afinamento das curvas na presença da BSA. Além disso, a população de partículas em $10 \mathrm{~nm}$ aumenta de forma tímida apenas para a concentração mais alta de BSA, o que pode indicar um processo de desagregação de aglomerados à medida que a superfície dessas partículas passou a interagir com a BSA, modificando a carga da superfície e aumentando a energia de repulsão. Outro detalhe importante, assim como ocorreu com as nanopartículas com complexo tta, é o aparecimento de partículas em $1000 \mathrm{~nm}$, reflexo provável de uma aglomeração acelerada pela 
presença de proteínas a superfície da partícula, tornando a partícula maior e mais pesada, o que justifica o aparecimento de precipitado quatro dias depois.

Na FIG 5.51 são apresentados os gráficos de tamanho de partícula obtidos para as nanopartículas de PHB $+\left[\mathrm{Tb}(\mathrm{acac})_{3}\left(\mathrm{H}_{2} \mathrm{O}\right)_{3}\right]$ quando funcionalizadas com glutaraldeído em meio tamponado por 48 horas e a $4^{\circ} \mathrm{C}$.

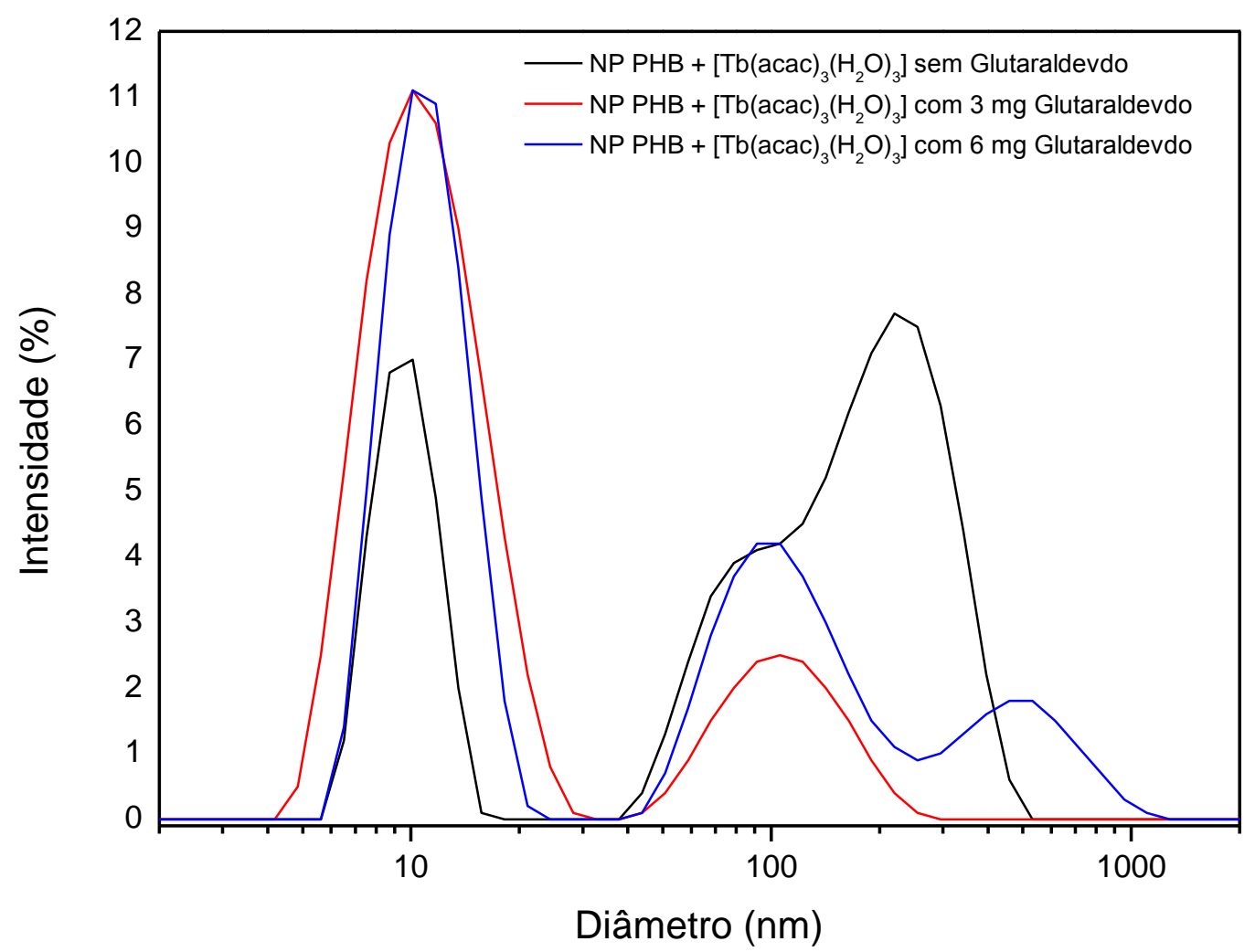

FIG. 5.51: Distribuição granulométrica obtida pela técnica de Espectroscopia de Correlação de Fótons (PCS) para as nanopartículas de PHB + complexo $\mathrm{Tb}(\mathrm{acac})_{3}\left(\mathrm{H}_{2} \mathrm{O}\right)_{3}$ funcionalizadas com Glutaraldeído.

Novamente se nota um deslocamento de intensidade centralizado em $250 \mathrm{~nm}$ para $100 \mathrm{~nm}$, e uma leve diminuição da dispersão de tamanhos, observado por um afinamento das curvas na presença de glutaraldeído. Uma diminuição de intensidade nessa região também é bem nítida. Além disso, a população de partículas em $10 \mathrm{~nm}$ aumenta de forma mais acentuada, o que pode indicar um processo de desagregação de aglomerados conforme já discutido. É possível verificar também que na concentração máxima de glutaraldeído, partículas maiores são observadas, tal fenômeno pode ser 
explicado pela propriedade do glutaraldeído polimerizar ${ }^{[40]}$, processo que pode ter acelerado com o aumento da concentração do mesmo.

\subsubsection{Comportamento das nanopartículas funcionalizadas e conjugadas em função do Potencial Zeta}

As nanopartículas conjugadas com BSA e glutaraldeído também foram avaliadas em função do Potencial Zeta. Dessa forma, são apresentadas nas FIG 5.52 e FIG 5.53 o comportamento das nanopartículas de PHB@ [Eu(tta $\left.)_{3}\left(\mathrm{H}_{2} \mathrm{O}\right)_{2}\right]$ e PHB@[Tb(acac $\left.)_{3}\left(\mathrm{H}_{2} \mathrm{O}\right)_{3}\right]$ ligadas a BSA e ao Glutaraldeído respectivamente.

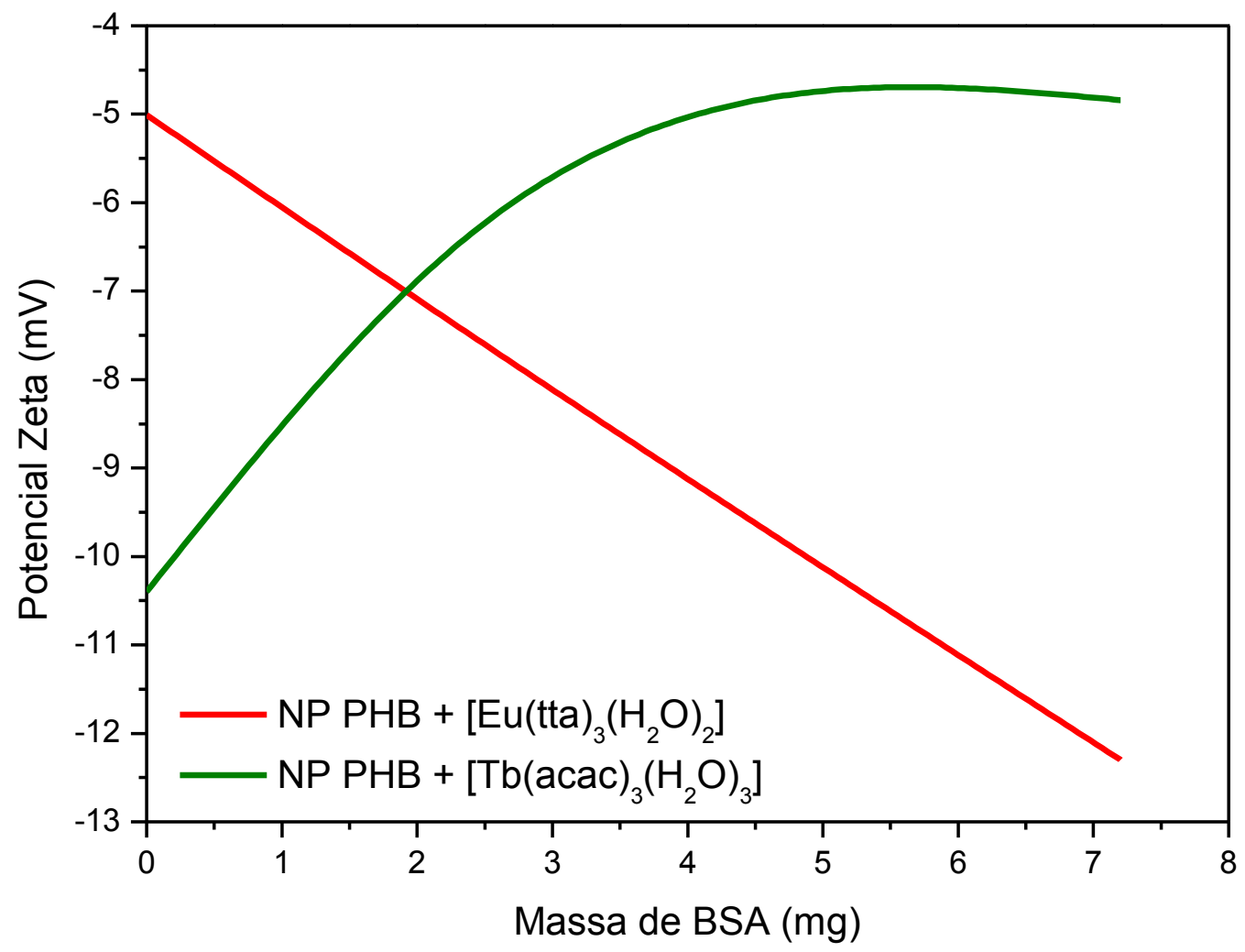

FIG. 5.52: Comportamento de Potencial Zeta das Nanopartículas frente a variação de concentração de BSA. 


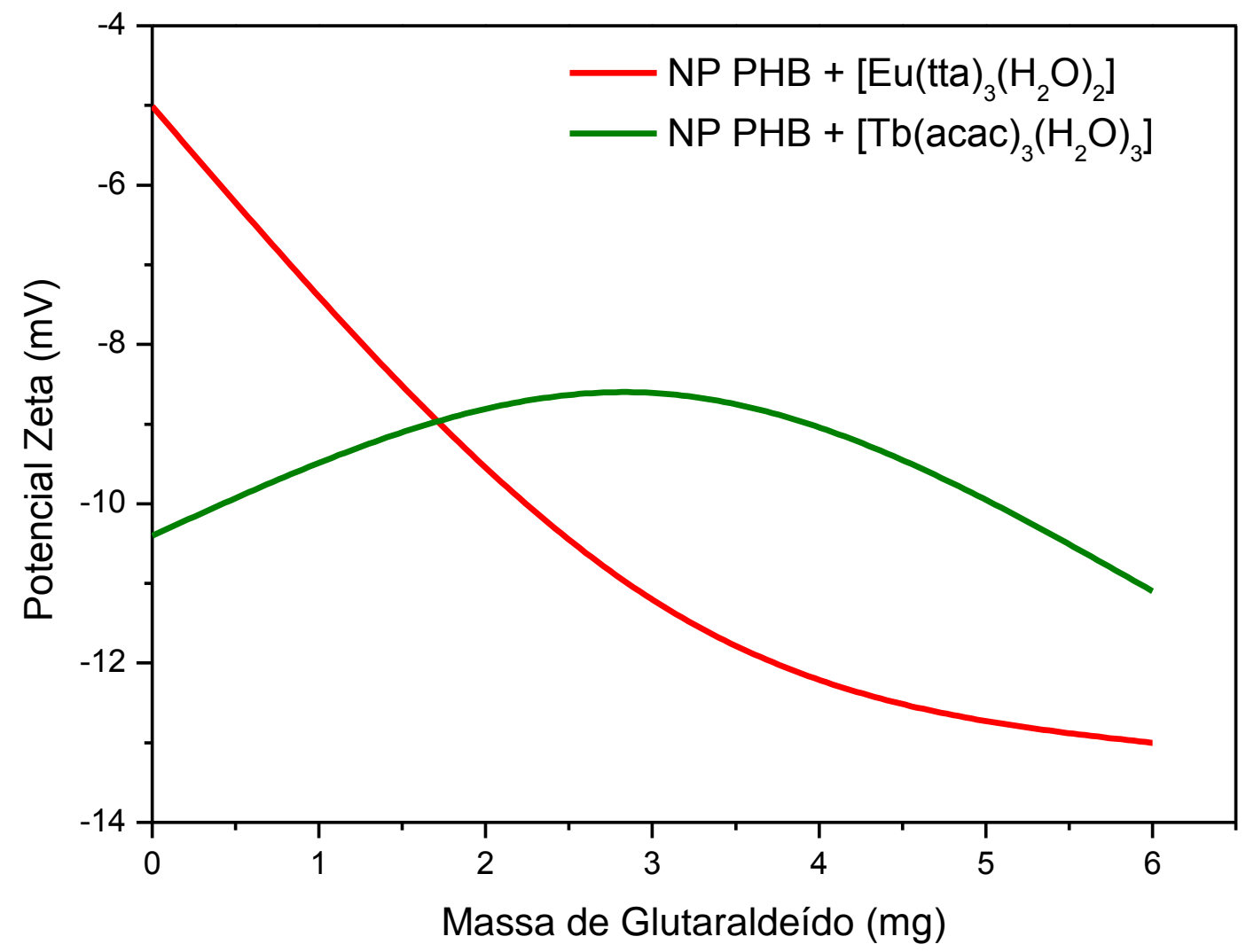

FIG. 5.53: Comportamento de Potencial Zeta das Nanopartículas frente a variação de concentração de glutaraldeído.

Os dados de potencial zeta corroborando com os dados de tamanho de partícula confirmam a modificação da carga da superfície das nanopartículas ao se ligarem tanto a BSA quanto o Glutaraldeído. A tendência ainda não é clara, pois seriam necessários mais testes para essa avaliação, no entanto, é perceptível um aumento negativo do potencial zeta das nanopartículas de PHB com o complexo $\left[\mathrm{Eu}(\mathrm{tta})_{3}\left(\mathrm{H}_{2} \mathrm{O}\right)_{2}\right]$ tanto no sistema com BSA quanto com Glutaraldeído.

No caso das nanopartículas de PHB com o complexo [Tb(acac $\left.)_{3}\left(\mathrm{H}_{2} \mathrm{O}\right)_{3}\right]$, ocorre o inverso, ou seja, a partícula sem nenhum dos ativos já possui potencial zeta negativo e alto, a medida que se adicionam o ativo, esse potencial zeta negativo diminui e estabiliza.

Um estudo mais aprofundado se faz necessário para uma avaliação mais efetiva sobre o comportamento dessas nanopartículas ao serem mantidas em contato com moléculas capazes de adsorver em sua superfície. De qualquer modo, se observa uma clara variação de potencial zeta nessas condições, o que indica uma provável adsorção. 
5.9.3 Comportamento das nanopartículas de PHB contendo [Eu(tta) $\left.)_{3}\left(\mathrm{H}_{2} \mathrm{O}\right)_{2}\right]$ funcionalizadas e conjugadas em função do Espectro de Absorção no UV-Vísivel

Nas FIGS 5.54 e 5.55 estão registrados os espectros de absorção das nanopartículas, do agente de funcionalização, o glutaraldeído e da proteína BSA. Os espectros mostram modificações nos sistemas estudados como podese observar, para interação BSA - nanopartícula, o máximo de absorção para a BSA $(278 \mathrm{~nm})$ se desloca para o vermelho (282nm), efeito batocrômico, e esta banda é desdobrada para o material conjugado. Além destes fatos a intensidade do espectro da nanopartícula conjugada ao BSA é maior do que nas duas espécies separadas ${ }^{[41]}$.

Para a funcionalização das partículas com o glutaraldeído observa-se um comportamento semelhante onde se tem o deslocamento da banda de absorção do glutaraldeído em direção à região do vermelho e intensificação destas bandas. Estes resultados corroboram com os encontrados no potencial ZETA e tamanho de partículas e indicam a conjugação e funcionalização das partículas estudadas.

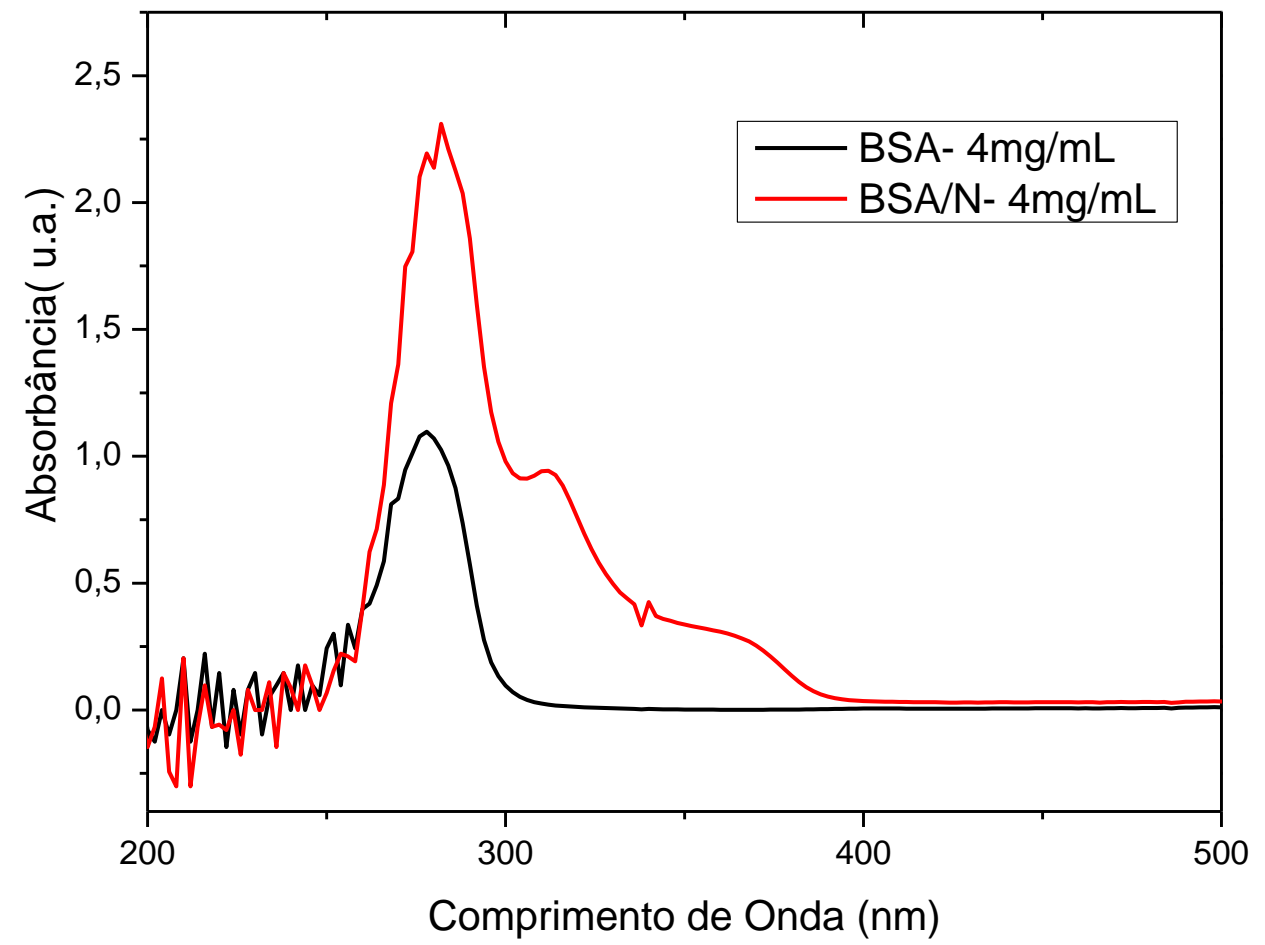

FIG. 5.54: Espectro de absorção na região do UV-vis da BSA e das nanopartículas funcionalizadas com BSA. 


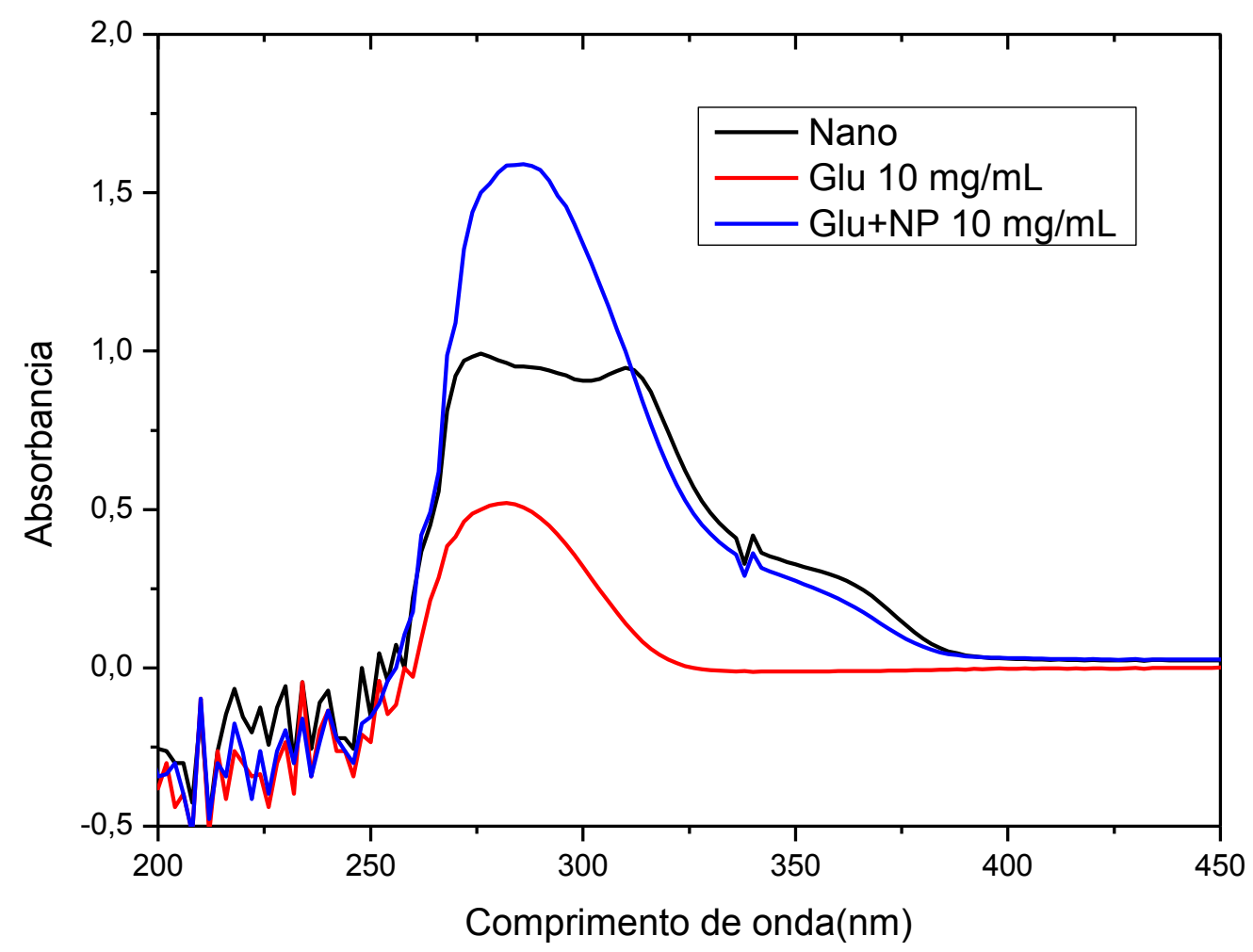

FIG. 5.55: Espectro de absorção na região do UV-vis da nanopartícula, do glutaraldeído e da nanopartícula funcionalizada com glutaraldeído. 


\section{REFERÊNCIAS BIBLIOGRÁFICAS}

[1] TAYYARI, S.; MILANI-NEJAD, F. Vibrational Assignment of Acetylacetone. Spectrochimica Acta A, v. 56(14), p. 2679-2691, 2000.

[2] PINCHAS, S.; SILVER, B. L.; LAULICHT, I. Infrared absorption spectra of the $18^{\circ}$-labeled Acetylacetonates of $\mathrm{Cr}(\mathrm{III})$ and $\mathrm{Mn}(\mathrm{III})$. Jounal of Chemical Physics.v. 46(4), p. 1506-1010, 1967.

[3] PURUSHOTHAM, D.; RAMACHANDRA, V. R.; RAGAVAVA, S. V. R. Studies on Rare Earth 11,3-diketonatos. Analytica Chimica Acta, v. 33, p. 182-197, 1965.

[4] WENDLAND, W. W.Thermal Analysis. $3^{\circ}$ ed. New York. Wiley, 1986.

[5] BROWN, M. E. Introduction to thermal analysis techniques and applications. London. Company and Hall, 1988.

[6] HAINES, P. J. Thermal methods of analysis principles, applications and problems. Glasgow. Blackie Academic and Professional, 1995.

[7] CHARSLEY, E. O.; WARRINGTON, S. B. Thermal analysis techniques and applications. Cambridge. Hart Noll Ltda, 1992.

[8] FREIRE, R. M. L. Estudo da estabilidade térmica de adoçantes naturais e artificiais. 2010 - Dissertação (Mestrado) - Universidade Federal do Rio Grande do Norte, João Pessoa.

[9] TEOTONIO, E. E. S. Síntese e investigação das propriedades fotoluminescentes de dispositivos moleculares conversores de luz (DMCL) de complexos dicetonatos de terras raras com ligantes amidas. 2004 - Tese (Doutorado) - Universidade de São Paulo, São Paulo.

[10] KAl, J. Desenvolvimento de sistemas luminescentes à base de polímeros PHB e PMMA dopados com complexos terras raras. 2009 Tese (Doutorado) - Universidade de São Paulo, São Paulo.

[11] SHOEMAKER, D.; GARLAND, C.; NIBLER, J. Experiments in Physical Chemistry. 6. ed. New York: McGraw Hill Co., 1996. p. 472. 
[12] SOUZA, E. R. Síntese de complexos benzenotricarboxilatos de terras raras e estudo de suas propriedades fotoluminescentes. 2008 Dissertação (Mestrado) - Universidade de São Paulo, São Paulo.

[13] AZÁROFF, L. V. Elements of X-rayCrystallography. Internation Student Edition.ed. New York: McGraw Hill Co., 1998.

[14] NAGATANI, T.; SAITO, S.; SATO, M.; YAMADA, M. Development of an ultra high resolution scanning electron microscope by means of a field emission source and in-lens system. Scanning Microscopy, v. 1, n. 3, p. 901-909, 1987.

[15] PEREIRA, K. R. Avaliação da biocompatibilidade "in vivo" e "in vitro" de ligas metálicas de titânio para aplicação odontológica. . 2008 Dissertação (Mestrado) - Universidade de São Paulo, São Paulo.

[16] FILELLA, M.; ZHANG, J.; NEWMAN, M. E.; BUFFLE, J. Analytical applications of photon correlation spectroscopy for size distribution measurements of natural colloidal suspensions: capabilities and limitations. Colloids and Surfaces - A: Physicochemical and Engineering Aspects120, p. 27-46, 1995.

[17] WILLEMSE, A. W.; MARIJNISSEN, J. C. M; ROOS,, R.; VAN WUYCKHUYSE, A.; SCARLETT, B. Photon Correlation Spectroscopy for analysis of flow concentration submicrometer samples. Journal of 'Aerosol Science - Pergamon, v. 27, p. 535 - 536, 1996.

[18] SCHAFFAZICK, S. R.; GUTERRES, S. S.; FREITAS, L. L.; POHLMANN, A. R. Caracterização e estabilidade físico-química de sistemas poliméricos nanoparticulados para administração de fármacos. Química Nova,v. 26, n. 5, p.726-737. 2003.

[19] POHLMANN, A. R.; POLETTO, F. S.; FIEL, L. A.; DONIDA, B.; RÉ, M. I.; GUTERRES, S. S. Controlling the size of poly(hydroxybutyrate-cohydroxyvalerate) nanoparticles prepared by emulsification-diffusion technique using ethanol as surface agent. Colloids and Surfaces A: Physicochemical and Engineering Aspects, v. 324, p. 105-112, 2008.

[20] NEUFELD, R. J.; REIS, C. P.; RIBEIRO, A. J.; VEIGA, F. Nanoencapsulation I. Methods for preparation of drug-loaded polymeric nanoparticles. Nanomedicine: Nanotechnology, Biology, and Medicine, v. 2, p. 8-21, 2005. 
[21] PEREIRA, J. C. Estudo do comportamento de nanopartículas de dióxido de titânio em diferentes suspensões. 2010 - Dissertação (Mestrado) Universidade Nova de Lisboa, Lisboa.

[22] $X U, R$. Progress in nanoparticles characterization: Sizing and zeta potential measurement. Particuology, v. 6, p. 112-115, 2007.

[23] TANTRA, R.; SCHULZE, P.; QUINCEY, P. Effect of nanoparticle concentration on zeta-potential measurement results and reproducibility. Particuology, v. 8, p. 279-285, 2010.

[24] TOBITA, S.; ARAKAWA, M.; TANAKA, I., Electronic relaxation processes of rare earth chelates of benzoyltrifluoroacetone. Journal of Physical Chemistry,v.88, n.13, p.2697-2702, 1984

[25] SATO, S.; WADA, M., Relation between Intramolecular Energy Transfer Efficiencies and Triplet State Energies in Rare Earth -diketone Chelate.Bulletin of Chemical Society of Japan.v.43, n.7, p.1955-1962, 1970.

[26] de SA, G. F.; MALTA, O. L.; DONEGA, C. D.; SIMAS, A. M.; LONGO, R. L.; SANTA-CRUZ, P. A.; DA SILVA, E. F., Spectroscopic properties and design of highly luminescent lanthanide coordination complexes.Coordination Chemistry Reviews,v.196, p.165-195, 2000

[27] MALTA, O.L.; BRITO, H.F.;MENEZES, J.F.S.; GONÇALVES E SILVA, F.R.; ALVES JR, S.;FARIAS JR,F.S.; ANDRADE, A.V.M.; Spectroscopic properties of a new light-converting device $\mathrm{Eu}$ (thenoyltrifluoroacetonate) ${ }_{3}$ 2(dibenzylsulfoxide). a theoretical analysis based on structural data obtained from a sparkle model. Journal of Luminescence, v.75, p.255, 1997.

[28] BÜNZLI, J.-C.G. AND CHOPPIN, G.R."Lanthanide Probes in Life, Chemical and Earth Sciences - Theory and Practice",Elsevier, Amsterdam, 1989.

[29] RICHARDSON, F.S.Terbium(III) and europium(III) ions as luminescent probes and stains for biomolecular systems.Chemical Reviews,v.82, p.541-552, 1982.

[30] COTTON, F.A; "Chemical Application of Group Theory", WileyIntercience, New York, 1971. 
[31] MALTA, O. L.; CARLOS, L. D. Intensities of $4 \mathrm{f}-4 \mathrm{f}$ transitions in glass materials. Quimica Nova, v. 26, p. 889-895, 2003.

[32] JANDL, S.; MARTEL, J. F.; VIANA, B.; VIVIEN, D. Crystal-field study of $\mathrm{Sm}^{3+}$ ions in $\mathrm{Sm}_{2} \mathrm{O}_{3}, \mathrm{Sm}^{3+}: \mathrm{Gd}_{2} \mathrm{O}_{3}$ and $\mathrm{Sm}^{3+}: \mathrm{Y}_{2} \mathrm{O}_{3}$. Journal of Physics and Chemistry of Solids, v. 61, p. 1455-1463, 2000.

[33] MAY, P. S.; METCALF, D. H.; RICHARDSON, F. S.; CARTER, R. C.; MILLER, C. E.; PALMER, R. A. Measurement and analysis of excitedstate decay kinetics and chiroptical activity in the transitions of $\mathrm{Sm}^{3+}$ in trigonal $\mathrm{Na}_{3}\left[\mathrm{Sm}\left(\mathrm{C}_{4} \mathrm{H}_{4} \mathrm{O}_{5}\right)_{3}\right] \cdot 2 \mathrm{NaClO}_{4} \cdot 6 \mathrm{H}_{2} \mathrm{O}$. Journal of Luminescence, v. 51, p. 249-268, 1992.

[34] GRIFFITH, J. S. The theory of transition-metal ions.Londres: Cambridge at the University Press, 1961.

[35] BRITO, H.F.; MALTA, O.L.; FELINTO, M.C.F.C.; TEOTONIO, E.E.S.; MENEZES, J.F.S.; SILVA, C.F.B.; TOMIYAMA, C.S.; CARVALHO, C.A.A. Luminescence investigation of the $\mathrm{Sm}(\mathrm{III})$-b-diketonates with sulfoxidesphosphine oxides and amides ligands.Journal of Alloys Compounds,v.344, p.293-297, 2002.

[36] MALTA, O. L.; MENEZES, J. F. S.; GONÇALVES E SILVA, F. R.; ALVES, S.; FARIAS, F. S. JR.; ANDRADE, A. V. M. Spectroscopic properties of a new light-converting device $\mathrm{Eu}$ (thenoyltrifluoroacetonate) 3 2(dibenzylsulfoxide). A theoretical analysis based on structural data obtained from a sparkle model. Journal of Luminescence, v. 75, p. 255-268, 1997.

[37] TEOTONIO, E. E. S.; BRITO, H. F.; FELINTO, M. C. F. C.; KODAIRA, C. A.; MALTA, O. L.Luminescence investigations on $\mathrm{Eu}$ (III) thenoyltrifluoroacetonate complexes with amide ligands. Journal of Coordination Chemistry, v.56, p.913-921, 2003.

[38] RACK, P. D.; NAMAN, A.; HOLLOWAY, P. H.; SUN, S-S.; TUENGE, R. T. Materials used in electroluminescent displays. MRS Bulletin, v.21, p. 49-58, 1996.

[39] JUN, J. Y.; NGUYEN, H. H.; PAIK, S-Y-R.; CHUN, H. S.; KANG, B-C.; $\mathrm{KO}$, S. Preparation of size-controlled bovine serum albumin (BSA) nanoparticles by a modified desolvation method. Food Chemistry, v. 127, p. 1892-1898, 2011. 
[40] KIKUCHI, M. J.; MATSUMOTO, H. N.; YAMADA, T.; KOYAMA, Y.; TAKAKUDA, K.; TANAKA, J.Glutaraldehyde cross-linked hydroxyapatite/collagen self-organized nanocomposites. Biomaterials, v. 25 , p. $63-69,2004$.

[41] TOMIYAMA C, S. Utilização de supermoléculas de Beta-Dicetonatos de Európio e Samário como agentes de fluoroimunoensaio para detecção do antígeno específico da próstata (PSA) 2007 - Dissertação (Mestrado) - Universidade de São Paulo, São Paulo. 


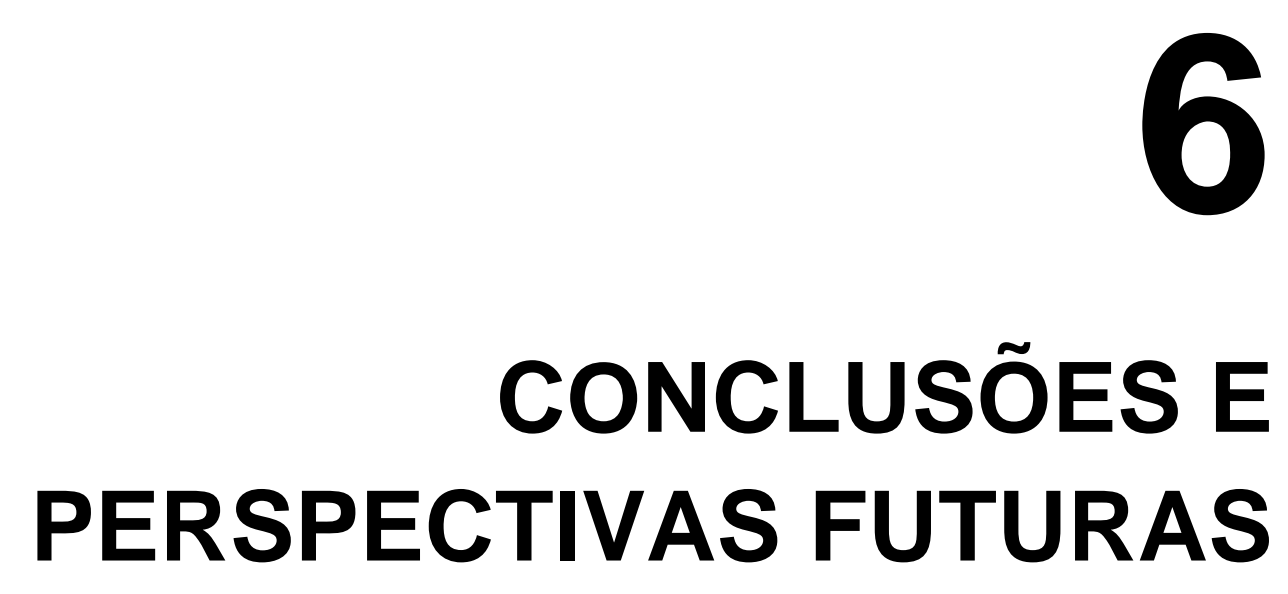




\title{
6 CONCLUSÕES E PERSPECTIVAS FUTURAS
}

\subsection{Conclusões}

\begin{abstract}
A síntese dos complexos de $\left[\mathrm{TR}(\mathrm{tta})_{3}\left(\mathrm{H}_{2} \mathrm{O}\right)_{2}\right]$ onde $\left(\mathrm{TR}=\mathrm{Eu}^{3+}, \mathrm{Sm}^{3+} \mathrm{e}\right.$ $\left.\mathrm{Gd}^{3+}\right)$ e $\left[\mathrm{TR}(\mathrm{acac})_{3}\left(\mathrm{H}_{2} \mathrm{O}\right)_{3}\right]\left(\mathrm{TR}=\mathrm{Eu}^{3+}, \mathrm{Sm}^{3+}, \mathrm{Tb}^{3+}\right.$ e $\left.\mathrm{Gd}^{3+}\right)$ assim como 0 processo de produção das nanopartículas de PHB contendo esses complexos apresentou resultados coerentes e satisfatórios em relação aos procedimentos, propriedades físico-químicas e luminescência.
\end{abstract}

$\mathrm{Na}$ determinação das relações estequiométricas para todos os complexos, as técnicas de volumetria de complexação mediante uso de EDTA para quantificação do teor de terras raras assim como as análises elementares de carbono e hidrogênio confirmaram a estrutura já amplamente proposta para esses complexos na literatura.

Os difratogramas de Raios $X$ também confirmaram a cristalinidade dos complexos e mostraram que as nanopartículas poliméricas misturada aos complexos de terras raras não apresentaram diferença substancial em relação ao polímero semi-cristalino PHB. O que indica que por ser uma técnica de avaliação morfológica e, portanto, de superfície, as nanopartículas possuem uma capa polimérica sem evidências de associação polímero-complexo.

Para complementar as observações feitas nos resultados de Raios $X$, os espectros de absorção na região do infravermelho demonstram claramente a presença predominante do polímero na superfície da partícula, uma vez que não fica evidenciada a presença dos estiramentos característicos dos complexos nos espectros das nanopartículas. 
Com relação às curvas termogravimétricas, foi confirmado o grau de hidratação dos complexos precursores. As curvas de TG/DTG também deixaram mais clara a característica proposta por esse trabalho para a estrutura das nanopartículas. Na decomposição térmica do polímero PHB e do ligante tta e acac, observam-se dois eventos, sendo o primeiro mais acentuado, a decomposição do PHB e o segundo evento, mais gradual e na sequencia do primeiro. Dessa forma, é possível concluir que houve decomposição inicial da capa polimérica e sequencialmente do complexo no interior da partícula.

$\mathrm{Na}$ avaliação do tamanho das nanopartículas pela técnica de espectroscopia de correlação de fótons, fica evidenciado um comportamento bimodal, com tamanhos centrados em aproximadamente $10 \mathrm{~nm}$ e $250 \mathrm{~nm}$ e um alto índice de polidispersão, demonstrado pelo alargamento das bandas nos espectros. A microscopia eletrônica de varredura também confirma essa tendência observada, além de demonstrar que as partículas apresentam formas bem arredondadas.

O potencial zeta demonstrou uma tendência de carga de superfície sempre negativa, com os maiores valores negativos para as nanopartículas de PHB misturado aos complexos de ligante acac. Essa informação é relevante, demonstrando um sistema não tão estável e suscetível a aglomerações.

$\mathrm{Na}$ avaliação sobre a eficiência do processo de funcionalização, tanto a técnica de espectroscopia de correlação de fótons quanto o potencial zeta foram utilizados para demonstrar a capacidade ou não e adsorção ou ligação da BSA e do Glutaraldeído a superfície das nanopartículas. Ainda não são dados satisfatórios, no entanto, são claros ao demonstrar variação de tamanho de partícula e mudança da carga superficial dessas nanopartículas nos sistemas contendo a proteína e o Glutaraldeído.

Todos os complexos precursores foram avaliados com relação as suas propriedades luminescentes e se confirmou todos os dados relatados até o momento. Portanto, a principal avaliação das propriedades luminescentes centrou-se nas nanopartículas. Verificou-se que nas suspensões contendo partículas menores que $450 \mathrm{~nm}$ e em uma quantidade menor, os sistemas apresentaram uma intensidade de sinal maior. Esse fator é importantíssimo, 
pois indica que sistemas com partículas menores, apresentam maior eficiência de emissão luminescente, pelo aumento de superfície de contato com o feixe de excitação e para a emissão.

De um modo geral, as nanopartículas de PHB com complexos de $\mathrm{Sm}^{3+}$ não apresentaram bons resultados luminescentes no sistema estudado. Já as nanopartículas de PHB com complexos de $\mathrm{Eu}^{3+} \mathrm{e} \mathrm{Tb}^{3+}$ responderam de forma satisfatória e conclusiva, indicando que o estudo a partir desses dois sistemas e nas condições propostas, possuem maiores chances de sucesso.

\subsection{Perspectivas Futuras}

Aprofundar estudos:

- Possibilidade de uso de outros agentes dispersantes e espaçadores;

- Executar mais testes com relação ao aumento de luminescência com partículas de menor tamanho;

- Determinar a relação de massa nas partículas entre polímero e complexo;

- Estudar outros complexos capazes de aumentar a luminescência em um sistema nanoparticulado;

- Verificar outros polímeros para o preparo de nanopartículas;

- Definir o sistema mais eficiente, sensível e específico;

- Verificar os antígenos mais interessantes do ponto de vista de especificidade.

Pretende-se desenvolver um kit de diagnóstico para a doença de Chagas testá-lo e validá-lo. 